\title{
A Compendium of Computer Codes for the Safety Analysis of Fast Breeder Reactors
}

\section{October 1977}

\section{U.S. Department of Energy}

Division of Reactor Research \&

Development

\begin{tabular}{|c|}
\hline $\begin{array}{l}\text { This report was prepared as an account of work } \\
\text { sponsored by the United States Government Nerther the } \\
\text { United States nor the Unted States Depariment of } \\
\text { Energy nor any of their employees, nor any of their } \\
\text { contractors, subcontractors, or their employees, makes } \\
\text { any warranty, express or Impled, or assumes any legal } \\
\text { lubility or responsibility for the accuracy, completeness } \\
\text { or usefulness of any information, apparatus, product o } \\
\text { process diclosed, or represents that its use would no } \\
\text { infringe provately owned nghts }\end{array}$ \\
\hline
\end{tabular}

infringe provately owned nghts 


\section{DISCLAIMER}

This report was prepared as an account of work sponsored by an agency of the United States Government. Neither the United States Government nor any agency Thereof, nor any of their employees, makes any warranty, express or implied, or assumes any legal liability or responsibility for the accuracy, completeness, or usefulness of any information, apparatus, product, or process disclosed, or represents that its use would not infringe privately owned rights. Reference herein to any specific commercial product, process, or service by trade name, trademark, manufacturer, or otherwise does not necessarily constitute or imply its endorsement, recommendation, or favoring by the United States Government or any agency thereof. The views and opinions of authors expressed herein do not necessarily state or reflect those of the United States Government or any agency thereof. 


\section{DISCLAIMER}

Portions of this document may be illegible in electronic image products. Images are produced from the best available original document. 


\section{FOREWORD}

A high level of mathematical sophistication is required in the safety analysis of breeder reactors to adequately meet the demands for realism and confidence in a11 areas of accident consequence evaluation. The numerical solution procedures associated with these anslyses are generally complex and time consuming so as to necessitate their programming into computer codes. These computer codes have become extremely powerful tools for safety analyses, combining unique advantages in accuracy, speed and cost.

The number, diversity and complexity of breeder reactor safety codes in the U.S. has grown rapidly in recent years. It is estimated that over 100 such codes exist in various stages of development throughout the country. It is inevitable that such a large assortment of codes will require rigorous cataloguing and abstracting to aid individuals in identifying what is available. It is the purpose of this compendium to provide such a service through the compilation of code summaries which describe and clarify the status of domestic safety codes.

The objective of this compendium is to provide the reader with a guide which briefly describes many of the computer coles used for liquid metal fast breeder reactor safety analyses, since it is for this system that most of the codes have been developed. The compendium is designed to address the following frequently asked questions from individuals in licensing and research and development activities:

1. What does the code do?

2. To what safety problems has it been applied?

3. What are the code's limitations?

4. What is being done to remove these limitations?

5. How does the code compare with experimental observations and other code predictions?

6. What reference documents are available?

The compendium is divided into several sections. Those new to safety analyses and unfamiliar with the "in-house" syntax and jargon are urged to familiarize themselves with the 1 ist of acronyms immediately following the table of contents. Many of the computer codes have novel and euphonious sounding names (folk lore has it that perhaps half of a code development effort is devoted to determining the proper code name) and a listing of code name origins follow the acronyms. A sample summary outline of computer code information is included, and finally the 
computer codes are placed in categories which are related to specific modeling areas for which they were developed. A description of the individual codes then follows.

This compendium represents a revision and expansion of an earlier document, ERDA-31, "A Compendium of Computer Codes for the Safety Analysis of LMFBR's", published in 1975. In order that this document provide the most complete, accurate and current information, a continuous process of review and upating is required. It is anticipated that a revised compendium will be made available on a timely basis. That this compendium properly reflect the needs of the breeder reactor safety community for general computer code information, comments and suggestions on the contents or on ways to improve the existing format are welcomed and encouraged. All correspondence should be addressed to:

\section{Harry Alter}

Chief, Safety Analysis Branch

Division of Reactor Development

and Demonstration

U.S. Department of Energy

Washington, D.C. 20545 
ACRONYMS $\ldots \ldots \ldots \ldots \ldots \ldots \ldots \ldots \ldots \ldots \ldots \ldots \ldots \ldots \ldots \ldots \ldots \ldots \ldots \ldots \ldots \ldots$

ORIGIN OF COMPUTER CODE NAMES $\ldots \ldots \ldots \ldots \ldots \ldots \ldots \ldots \ldots \ldots \ldots \ldots \ldots$

COMPUTER CODE SUMMARY OUTLINE $\ldots \ldots \ldots \ldots \ldots \ldots \ldots \ldots \ldots \ldots \ldots \ldots \ldots \ldots$

COMPUTER CODE CATEGORIES ......................... 12

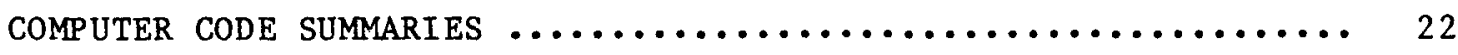




\section{ACRONYMS}

\begin{tabular}{|c|c|}
\hline ACC & A-Argonne Code Center \\
\hline AI & A-tomics International \\
\hline ANC & Áerojet N- Nuclear Corporation \\
\hline ANL & Árgonne Nationa1 Laboratory \\
\hline ANL/AP & ANL/Applied Physics Division \\
\hline $\mathrm{ANL} / \mathrm{CT}$ & ANL/Components Technology Division \\
\hline ANL/MS & ANL/Material Sciences Divisions \\
\hline ANL/RAS & ANL/Reactor Analysis and Safety Division \\
\hline ANL-RDP & ANL-Reactor Development Program \\
\hline ARAC & Átmospheric Release Advisory Capability \\
\hline ARL & NOAA--Air Resources Laboratories \\
\hline BCL & Battelle Columbus Laboratories \\
\hline BNL & B rookhaven Nationa 1 Laboratory \\
\hline BNWL & Battelle North West Laboratory \\
\hline CCFA & C-ommon $\underline{\text { Cause F}}$ Filure Analysis \\
\hline CDA & Core Disruptive Accident \\
\hline $\mathrm{CDC}$ & Control Data Corporation \\
\hline CE & C-ombustion Engineering \\
\hline CL IRA & Closed Loop In-Vessel Reactor Assembly \\
\hline CLS & Closed Loop System \\
\hline CRBRP & $\underline{\mathrm{C}}$ linch $\underline{\mathrm{R}}$ iver $\underline{B}$ reeder $\underline{R}$ eactor $\underline{\text { Plant }}$ \\
\hline CSMP & C̄ontinuous System Modeling Program \\
\hline DEH & Direct Electrical Heating Experiment \\
\hline DHRS & Direct Heat Removal Service \\
\hline DHX & Dump ㅌeat EXgchanger \\
\hline EBR-II & Experimental Brreeder Reactor-II \\
\hline EG\&G & Edgerton, Germushausen and Greer Incorporated \\
\hline ENDF & Evaluated Nuclear Data File \\
\hline EOS & Equation of $\underline{\text { State }}$ \\
\hline ERDA & Energy $\underline{\text { Research }} \overline{\text { and }}$ Development $\underline{\text { Administration }}$ \\
\hline ETR & Engineering Test Reactor \\
\hline FBR & Fast $\underline{B} r e e d e r$ Reactor \\
\hline FCI & Fuel-Coolant Thermal Interaction \\
\hline FCTT & Fuel-chladding Transient Test \\
\hline FFT F & Fast Flux Test Facility \\
\hline FSAR & Final Safety Analysis Report \\
\hline FTR & Fast Test $\underline{\text { Reactor in FFTF }}$ \\
\hline GCFR & Gas C-ooled Fast Reactor \\
\hline GE-FBRD & General Electric-Fast Breeder Reactor Division \\
\hline GIT & Georgia Institute of Technology \\
\hline $\mathrm{HCDA}$ & Hypothetical Core Disruptive Accident \\
\hline HEDL & Hanford Engineering Development Laboratory \\
\hline HIE & Hanford Internal Exposure System \\
\hline
\end{tabular}


ICRP

IHTS

IHX

INEL

LASL

LBL

LLL

LLTR

LMF BR

LOA

LOB

LOF

LOPI

LWR

MIT

NASA

NOAA

ORNL

PAHR

PHTS

PLBR

PPS

PSAR

RDD

RL

RSIC

SAR

SHRS

SLSF

SNR

SRI

THORS

TOP

TREAT

TUC

TVA

UCLA

USGS

W-ARD

ZPR

1-D

2-D

3-D

International Commission on Radiological Protection Intermediate Heat Transport System Intermediate $\overline{\text { Heat }}$ EXchanger

Idaho Nationā Engiñeering Laboratory Los Alamos Scientific Laboratory

Lawrence Berkeley Laboratory

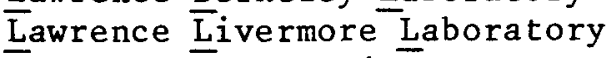

Large Leak Test Rig

Liquid Metal Fast Breeder Reactor

Line of Assurance

Loss of Fuel Pin Sodium Bond Accident

Loss of Flow Accident

Loss Of Piping Integrity

Light Water Reactor

Massachusetts Institute of Technology

National Aeronautics and Space Administration

National Oceanic and Atmospheric Administration

Oak Ridge National Laboratory

Post Accident Heat Removal

Primary Heat Transport System

Prototype Large Breeder Reactor

Plant Protection System

Preliminary Safety Analysis Report

Reactor Development and Demonstration Division of ERDA

$\bar{R}$ ichLand, Washington Operations Office of ERDA

Radiation Shielding Information Center

Safety Ana $\bar{l} y$ sis Report

Shutdown Heat Removal System

Sodium Loop Safety Facility

Sodium Cooled Nuclear Reactor

Stanford Researrch Institute

Thermal-Hyydraulic Out-of-Pile Reactor Safety Facility

$\bar{T}$ ransient OverPowe $\bar{r}$ Accident

Transient REActor Test Facility

Transient UnderCooling Accident

Tennessee $\bar{V}$ a1 ley Authority

University of California at Los Angeles

United States Geological Survey

Westinghouse--Ādvanced Reactor Division

Zero Power Reactor

One-Dimens iona 1

Two-Dimensional

Three-Dimensional 
ACRA

ADPIC

AIPECS

AIRDOS

AQUAMOD

BEHAVE (SST)

CACECO

CLASP

COASTDWN

COBRA

COMCAN

COMRADEX

CORTAC

COTEC

DACRIN

DEMO

DIF3DS

DSTRESS

DUGUID \& REEVES

EPIC

EXREM

FEFPSLUG

FEFPSTY

FETRA/SERATRA

FPIN

FRAS

FSTATE

FUMO

FURFAN

FX2

FX2-POOL

GRAS S

GROWS

HAA
Atmospheric Code for Reactor Accidents

Attmospheric Dispersion Analys is Using the

Particle-In-Cell Numerical Technique

Átomics Internationa1 Probabilistic Evaluation of

$\overline{\mathrm{C}}$ ladding Stress

Radionuclide AIR-borne Release DOSe to Man

AQUAtic MODe1

In-Pile $\overline{B E H A V}(E)$ ior of Fuel Pins, Steady State and Transient

CAvity, CE11s, COntainment

Closed Loop Analytical Simulation Program

$\bar{F}$ low COASTDoWNN in the SLSF Loop

Coolant Boiling Rod Arrays

COmmon Cause ANalysis

COntainment and Meteorology on Environmental

RADiation EXposure

COre Restraint Transient Analysis Code

Coolant TEmperature Calculation

Dose to Specific Organs from Acute or Chronic

Radionuclide INhalation

DEMOnstration Plant (CRBRP) Analyses

DIFfusion Theory in 2 and 3 Dimensions for SAS

Fuel Deformation STRESSes

Method Developed by J.0. DUGUID and M. REEVES

for Calculating Dissolved Material Transport in

Groundwater

Eulerian Particle-In-Cell Fuel/Coolant Modeling

EXternal Radiation Doses (REM) from Environmental

Radionuclide Release

Fuel Element Failure Propagation Loop SLUG Expulsion

Fuel Element Failure Propagation Loop STeady State

Analysis

Finite Element TRAnsport/SEdiment RAdionuclide TRAnsport Fuel PIN

$\bar{F}$ ission Gas Release And Swelling

Fuel STATE

FUel MOtion Model

FUe1 Rod Failure ANalysis

Not kñown

Neutronic (FX2), Thermodynamic and Hydrodynamic

Analysis of a Boiling Fuel/steel POOL

Gas Release And Swelling Subroutine

GROWth(S) of a Molten Pool

Heterogeneous Aerosol Agglomeration 
HAARM

HAMOC

HEDPIN

HE RME S

HOPE

HORSE

HOTP IM

IANUS

ICECO

ICEPEL

INDOS

INREM

ISOSHLD

LA-COBRA

LAFM

LONAC

LIFE

MARGE / SLUMP

MELT

ME SODIF

MICE

MOCARS

MOTION

NABOND

NAHAMME R

NALAP

NATRAN

NATRANS IENT

NICER

ORRIBLE

ORSLAP

PAD

PECS

PECTCLAD

PECTPIN

PFRAS

PIFITE

PLOFA

PLOOP

PLUTO
HAA-Revised Model

Hammer Analysis Method of Characteristics

HEDL PI $\overline{\mathrm{N}}$ Power Code

Hanford Engineering Regional Model for Environmental

Study

Hypothetical Over Power Excursion

$\overrightarrow{G r a s s}$ Modified Into HORSE

Hydrodynamics of Two-phase Internal Motion

Integrated Analys is of NUclear Systems

Implicit Continuous Eulerian Containment Code

ICECO Piping and ELbow Analysis

INternal Radiation DOSe to Man

INternal Radiation Dose (REM) To Target Organs of Man ISOtope SHieLDing Calculations

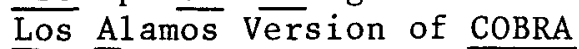

Los Âlamos Fuel Model

Analysis of Systems Dynamics Under LOw Forced Flow Or NAtura1 Convection

AnaLysis of In-Pile Fuel Elements

MARGE/Fue 1 SLUMPing

Multi-Channel Evaluation of LMFBR Transients

MESOscale DIFfusion

Multi-Field Implicit Continuous Eulerian Code

Monte CARlo Simulation Code

Analysis of Head MOTION Due to HCDA Loads

Sodium (NA) BONDing

Sodium ( $\overline{N A}$ ) Fluid-HAMMER Analys is

Sodium ( $\overline{\mathrm{NA}})$ Version of RELAP

Sodium ( $\overline{\mathrm{NA}}$ ) TRANsient Analys is

Sodium ( $\overline{\text { NA }}$ ) TRANSIENT Analys is

Not known

Oak Ridge Reactor Inlet BLockagE Code

Oak Ridge Sodium Loop Analys is Program

PAjarito Dynamics Code

Probabilistic Evaluation of Cladding Stress

Plastic, Elastic, Creep and Thermal Behavior Model

of Fuel Pin CLADding Materials

Plastic, Elastic, Creep and Thermal Behavior Model of Fuel PINs

Parametric Fission-Gas Release And Swelling

PIpe FIlling With Temperature Efffects

$\bar{A}$ Program for Fuel Motion Analysis in Loss of Flow Accidents

Analysis of Cold Pool LMFBR Primary LOOP Transients

Prediction of MoLten FUel Behavior Under TOP

Conditions 


\begin{tabular}{|c|c|}
\hline POPS & $\begin{array}{l}\text { Probabilistic Evaluation of Transient Over Power } \\
\text { Cladding Stress }\end{array}$ \\
\hline POROUS & Behavior of Fission Gas in POROUS Fuel \\
\hline PORPLUG & PORous PLUG Heat Generating Blockage \\
\hline PROSA & PROBbabilistic Sensitivity and Approximation Code \\
\hline PUDEQ & $\begin{array}{l}\text { Computation of PlUtonium Dose EQuivalent to Body } \\
\text { Organs }\end{array}$ \\
\hline RAS & Reliability Analysis System \\
\hline REXCAT & REXCO Coupled With SADCAT \\
\hline REXCO & Reactor EXcursion COntainment Analysis \\
\hline REZONE & REZON(E) ing of a Lagrangian Grid \\
\hline RIBD & Reactor Inventory of Beta Decay Isotopes \\
\hline SACO & $\underline{\text { Safety }}$ Analysis Code \\
\hline SADCAT & Śtructural Analysis of 3-D Core Assembly Transient \\
\hline SAS & Safety Analysis System \\
\hline SIEX & Fuel SIntering Routine--EXtended \\
\hline SIEXB & SIEX-Boron Carbide \\
\hline SIMMER & $\begin{array}{l}\text { Sn Implicit Multifield Multicomponent Eulerian } \\
\text { Recriticality Code }\end{array}$ \\
\hline SIMPLE & $\begin{array}{l}\text { S̄ubassembly Interchannel Mixing Program for FLow } \\
\text { Effects }\end{array}$ \\
\hline SODIPROP & SODIum PROPerties \\
\hline SOFIRE & $\overline{\text { Analy sis of SOdium FIREs }}$ \\
\hline SOMIX & Sodium MIXing With $\overline{\text { Oxygen }}$ \\
\hline SPOOL-FIRE & Sodium POOL-FIRE \\
\hline SPQR & 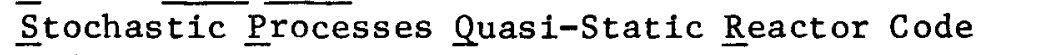 \\
\hline SPRAY & $\overline{\text { Sodium SPRA } \bar{Y}}$ Fires \\
\hline SSC & Super System Code \\
\hline STRAW & S-tructura1 Transient Response of Assembly Wrappers \\
\hline SUBDOSA & $\begin{array}{l}\text { SUBmersion } \bar{D} \text { oSe for Accidental Releases of } \\
\text { Radioactive Materials }\end{array}$ \\
\hline SUPER ENERGY & $\begin{array}{l}\text { A Transient (SUPER) Version of the ENERGY Model } \\
\text { (energy mixing) }\end{array}$ \\
\hline SUPORAN & SUPPORt ANalysis \\
\hline SUPWAN & SUperior Pressure Wave ANalysis Code \\
\hline TEMP & $\begin{array}{l}\text { A Computer Code to Calculate Fuel Pin TEMPerature } \\
\text { During a Transient }\end{array}$ \\
\hline TERMOD & $\begin{array}{l}\text { Radionuclide Environmental Transport Through } \\
\text { TERrestial Food Chains MODel }\end{array}$ \\
\hline THT & 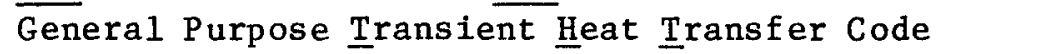 \\
\hline THYME & Thermal HYdraulī̄ Mode1 for Expēriments \\
\hline TOFF & Transient $\underline{\text { Overpower }}$ Fuel Element Failure \\
\hline TOPLE & Trransient Ōver Power Loop Experiment \\
\hline TRANSIENT & TRANSITion $\bar{P}$ Phase Analysis \\
\hline TRANSWRAP & TRANsient Sodium Water Reaction Analysis Program \\
\hline TRAPP & Transient Response to Applied Pressure Pulses \\
\hline
\end{tabular}


TRITON

TUBE

UNCLE

VENUS

WATRE

XPAND
TRI-Dimensional Thermal-Hydraulic Overall Core Numerical Analysis

Pressure Pulses in TUBEs

Uranium Nitride or Carbide LIFE Evaluation VENUS Superseded the MARS Code WATer RElease Code EXPAN (D) sion of Unclad Fuel 


\section{CODE SUMMARY OUTLINE INFORMATION}

\section{Purpose}

A brief statement concerning the nature of the physical problem solved and/or the code objective.

\section{Status}

A. Development: Name of development organization and name of current developmental version.

B. Availability: Names of various versions of the code and their documentation or availability status and the locations or organizations which have run the code. The availability status of a code is classified as one or more of the following:

Developmental: Code is still in its early development or in the process of debugging and has not been made to run successfully on a computer outside of development facility, but may be partially operational at the development site.

Operational: Code is being run successfully on a computer at or outside of the development facility. This implies the code is debugged and ready for use by people other than developer. An operational code is generally accompanied by a user's manual and some document ation.

Released: A released code implies a fully documented code available through the ANL Code Center.

Proprietary: Code is not available for use outside of development facility, except through contractual arrangements with the developer.

C. Utilization: Current use of code and specific safety problems for which it has been or is being applied.

Problems Solved

A listing of the various phenomena or physical problems solved to identify the scope of problems for which the code is applicable. 
Models

A verbal description of the mathematical models, basic physics approximations and numerical solution methodology contained in the code.

Limitations

A listing of the restrictions on the range of applicability of the code or on the complexity of the phenomena or physical problems solved and of the restrictions implied by computer storage allocation (e.g., maximum number of mesh points) or inherent code approximations.

Future Efforts

Efforts in progress or planned to reduce limitations.

Computer Operation

1. A 1 ist of computers upon which the code has been made operational.

2. Logistics: A description of core memory requirements and special peripherals, mode of operation (interactive or batch), programming language and compiler requirements, special systems routines, and special plotting software.

3. Typical Problem Running Time: Computer running times on a problem for which the code was written to solve. A brief description of the problem is given (geometry, real time, number of nodes, etc.). The section of the code requiring the major consumption of time is given.

4. Code Validation: A list of references which report comparison of the code to experiments and other codes. Also contains a statement on planned experimental comparison.

Interface/Overlap

Other codes with which the described code interfaces to provide or receive data/similar or equivalent codes.

$\underline{\text { References }}$

A listing of references for documentation of or information relating to various versions of the code. 
CODE CATEGORIES

Table 1 has been prepared to present to the user information concerning the functions for which each code has been developed. These functional areas have been broken into categories. The category number is shown on top of the table. Categories corresponding to each of these numbers are given on the right hand side of the table. Since many of the codes have functions applicable to more than one category, the code's primary category is marked with a $\mathrm{P}$ while secondary categories are marked with an S. Table 1 also lists the contractor responsible for development of the code and the line-of-assurance for which the code is applicable. The Breeder Reactor Safety Office has structured its research and development program into four "lines of assurance." They are:

LOA 1: Prevent CDA's

LOA 2: Limit Core Damage

LOA 3: Control CDA Progression

LOA 4: At tenuate Radiological Consequences

LOA 1 concerns the inherent and engineered features of the plant design which prevent accidents which could lead to fuel melting. LOA 2 provides core protection features which terminate core damage prior to whole-core disruption following the initiation of an HCDA. LOA 3 provides assurance that whole-core disruption is controlled such that radioactive core debris remains inside the primary containment. LOA 4 provides additional confidence that the public health and safety is assured by demonstrating that inherent or engineered features exist which can attenuate the radioactive releases from primary containment. Codes marked with an asterisk are not described in this compendium. They are no longer being improved by their developers, or they have seen very limited use for safety analyses. These codes, however, are described in ERDA-31 (1), the first version of the compendium.

A. Steady State Fuel Pin Characterization

Before a hypothetical core disruptive accident can be analyzed, the characterization of the fuel prior to the accident is required. The LIFE and SIEX codes are capable of providing the information on fuel restructuring which has occurred under operating conditions prior to the accident, while whole core HCDA analysis codes, such as SAS, have their own steady-state characterization routines. These codes must be capable of providing information, such as fuel swelling, clad swelling, fission gas releases, etc. which are required for accurate analysis of the accident. 


\section{B. Whole Core Analysis}

These codes model the response of the entire core to an HCDA. Depending on the state of the core during the accident, the analysis can be broken into four phases: initiating phase, transition phase, core disassembly phase, reactor vessel and structure response phase.

1. Initiating Phase Analysis

Codes in this category are concerned with the phenomena occurring from accident inception until either:

a) there is a benign neutronic shutdown with intact core geometry and very little core damage;

b) there is a gradual meltdown of the core;

c) there is gross core disassembly due to the massive pressures generated by vaporized core materials.

Codes which analyze the initating phase can treat the individual phenomena, such as fuel pin behavior (BEHAVE, LAFM), fission gas behavior (FRAS), and fuel and clad motion (PLUTO), separately or they can combine the individual phenomena into an integrated whole core analysis (SAS, MELT).

2. Transition Phase Analysis

If the negative reactivity feedback during the initiating phase is not sufficient to terminate the accident but sufficient to preclude a prompt-critical power excursion, it is probable that the core would gradually melt and begin to boil. Codes such as TRANSIT and FUMO attempt to model the phenomena occurring during this transition phase.

3. Core Disassembly Analysis

Should there be a prompt-critical power excursion during the course of an accident, a level of energetics sufficient to challenge the energy absorption capability of primary containment can be postulated. A prompt-critical power excursion may theoretically occur during:

a) the initiating phase because of reactivity insertions from sodium voiding and/or autocatalytic fuel pin failures; 
b) the transition phase due to molten fuel pool compaction and subsequent recriticality.

Codes in this category calculate the energetics resulting from such prompt-critical bursts. Examples of disassembly phase analytical tools are VENUS and SIMMER.

4. Reactor Vessel Structural Response

These codes determine whether the energy absorption capability of primary containment is breached. The pressures generated due to either a prompt-critical power excursion or a thermal interaction between fuel and coolant are used to determine the mechanical loading on the structural members of the primary vessel. Codes in this category include REXCO and ICECO.

\section{Neutronics}

At the heart of the analysis of an HCDA is the modeling of the neutronics.

The proper coupling between the neutronic calculations and the mass, momentum and heat balance equations is essential for an adequate description of the accident sequence. Most whole core accident analysis codes have their own neutronic capability built into the code.

\section{Subassembly Analysis}

Codes have been developed to analyze the response of a single subassembly to accident conditions. These are useful in analyzing safety experiments on a single subassembly. They are also capable of more detailed thermal-hydraulic modeling than the whole-core analysis codes. This is important since incoherent effects, such as sodium boiling and fuel pin failure, can be better assessed with these codes than with the whole core accident codes. Examples of such codes are COBRA which models subassembly thermal-hydraulics, STRAW which determines the subassembly structural response to a transient, and PORPLUG which can be used to analyze flow blockages.

D. Heat Transport System Analysis

For a complete analysis of an HCDA, it is not enough to know just what happens to the core. Pressure pulses from such accidents could be transmitted through the primary piping loops to challenge their structural integrity. Normal and off-normal design transients which 
could occur during plant lifetime must also be analyzed to show that the heat transport system is capable of removing the heat generated during such transients. ICEPEL and IANUS can perform such analyses.

E. Post Accident Heat Removal (PAHR)

After neutronic shutdown of the HCDA, there must be a long term capability to cool the decay heat from any molten debris which may be formed. Analysis of post accident heat removal has been performed using the "general principles approach" rather than using large, sophisticated computational packages. Not many computer codes exist in this area. However, a substantial amount of technology has been generated to analyze PAHR phenomena. References 2, 3 , and 4 give a good description of the computational methods used for PAHR analysis.

F. $\quad$ Sodium Fires

In the unlikely event that a leak should develop from a sodium pipe, the reactions of the sodium with the surrounding equipment cell atmosphere and the materials of the cell must be assessed. This is required for proper design of the containment cells. SPOOL-FIRE and SOMIX are intended for such analysis. For a more extensive discussion of this technology area see References 5 and 6 .

G. Aerosol Behavior

After the reactor vessel structural response has been assessed, it is necessary to determine how much radioactive material is released through the vessel and into the containment building in order to define the radiological source term. Most of the radioactive material generated is in the form of aerosols. The amount of radioactive material that could eventually be released to the environment depends on the behavior of these aerosols. Codes such as HAA-3 are capable of modeling aerosol behavior. A more extensive discussion of aerosol models and technology can be found in References 6 and 7 .

H. Environmental Release Analysis

These codes assess the radioactive dose to man due to release of materials from containment to the environment. There have been many codes developed for the analysis of environmental release of radioactive material. An excellent and more extensive review and discussion of these codes is given in Reference 8 . Examples of such codes are ACRA and COMRADEX. 
I. Probabilistic Analysis

Since there are many uncertainties in a mechanistic analysis of an HCDA, methods for assessing the effects of these uncertainties' on accident consequences are being developed. Probability distributions are developed for the uncertain parameters. These distributions are fed into a probabilistic assessment code, such as PROSA. This probabilistic assessment code is coupled to a fast running accident analysis code, such as SACO, to determine the distribution of accident consequences. A methodology for the probabilistic assessment of an HCDA is discussed in Reference 9.

Codes also included in this category are intended to determine the probability of occurrence of an HCDA in support of LOA 1 . These codes make use of reliability data on components and control systems in a fault tree analysis to determine the probability of accident occurrences. Codes like RAS and COMCAN are used in such analyses.

J. Codes for Analytical Support of Safety Experiments

Due to the limitations of an experimental facility, some experiments intended to simulate actual accident conditions may introduce effects non-prototypic of the expected behavior of an actual reactor. Codes in this category are important in the assessment of such non-prototypic effects. Others aid in the experimental equipment design and choice of experimental conditions. Codes in this category include COASTDWN and SIMPLE.

K. Miscellaneous Codes

Codes not applicable to any of the previous categories are placed here. Examples of such codes are SODIPROP which determines sodium physical properties and REZONE which rezones a distorted Lagrangian fluid grid.

\section{References}

1. ERDA-31, "A Compendium of Computer Codes for the Safety Analysis of LMFBR's," Safety Analysis Branch, Division of Reactor Research and Development, June 1975.

2. L. Baker, et a1., "Postaccident Heat Removal Technology," ANL/RAS 74-12, July 1974 .

3. L. Baker, et a1., "Postaccident Heat Removal In Fast Reactors," ANL/RAS 75-44, November 1975. 
4. L. Baker, et al., "Postaccident Heat Removal Technology," ANL/RAS 77-2, January 1977.

5. B. U. B. Sarma, R. C. Thompson, R. K. Stitt, "Review of Sodium Fire Analytical Models," GEAP-14053, June 1975.

6. ERDA-56, "Status of Safety Technology for Radiological Consequence Assessment of Postulated Accidents in Liquid Metal Fast Breeder Reactors," July 1975.

7. T. C. Huang and R. K. Stitt, "Review and Evaluation of Current Aerosol Models for LMFBR Safety Analysis," GEAP-14054, June 1975.

8. F. O. Hoffman, et al., "A Compilation of Documented Computer Codes Applicable to Environmental Assessment of Radioactivity Releases," ORNL/TM-5830, Apri1 1977.

9. K. O. Ott, "Risk-Assesment Methodology for Fast Breeder Reactors," ANL-76-39, April 1976. 


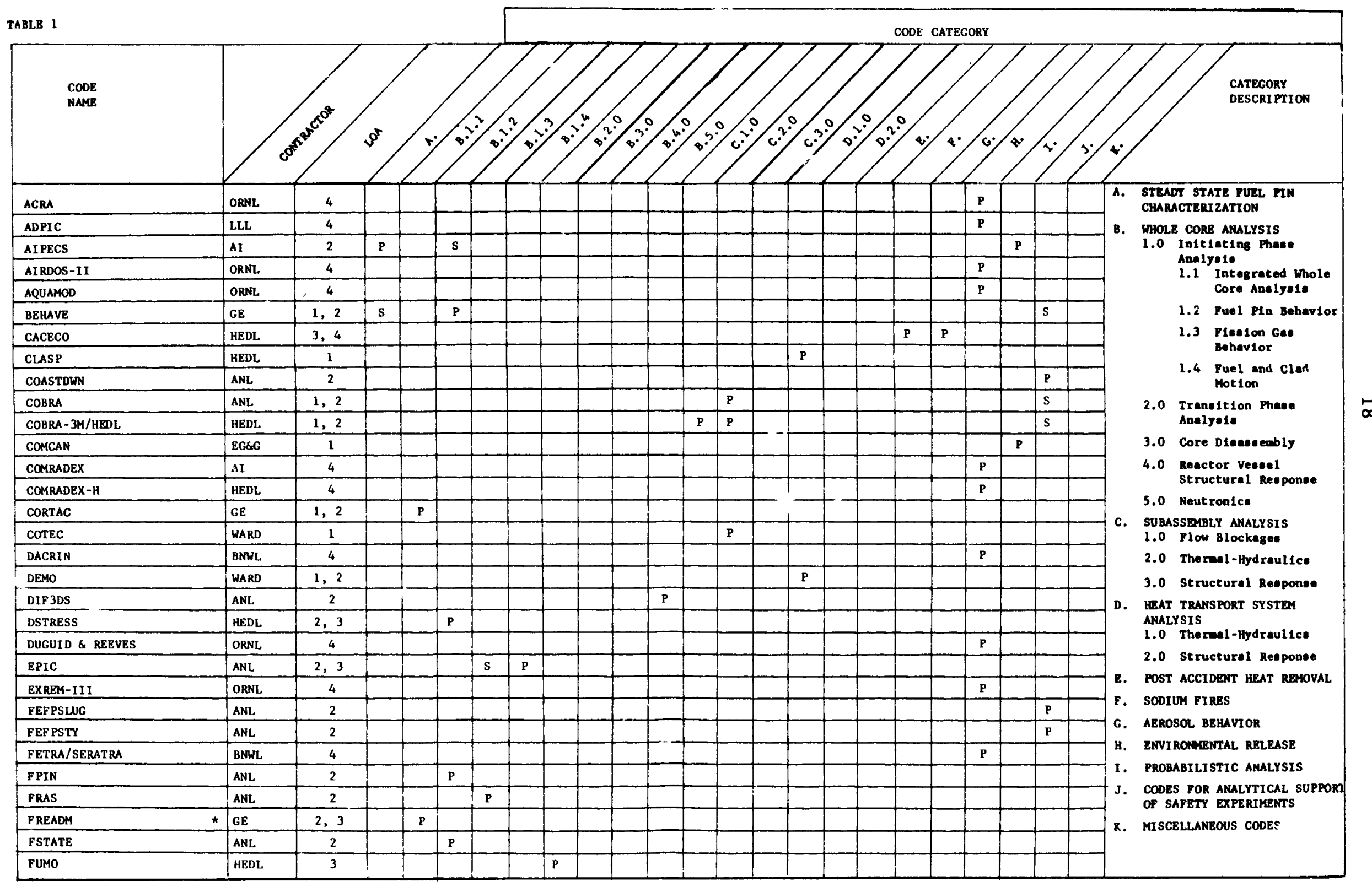




\section{-}

TABLE ! - Continued

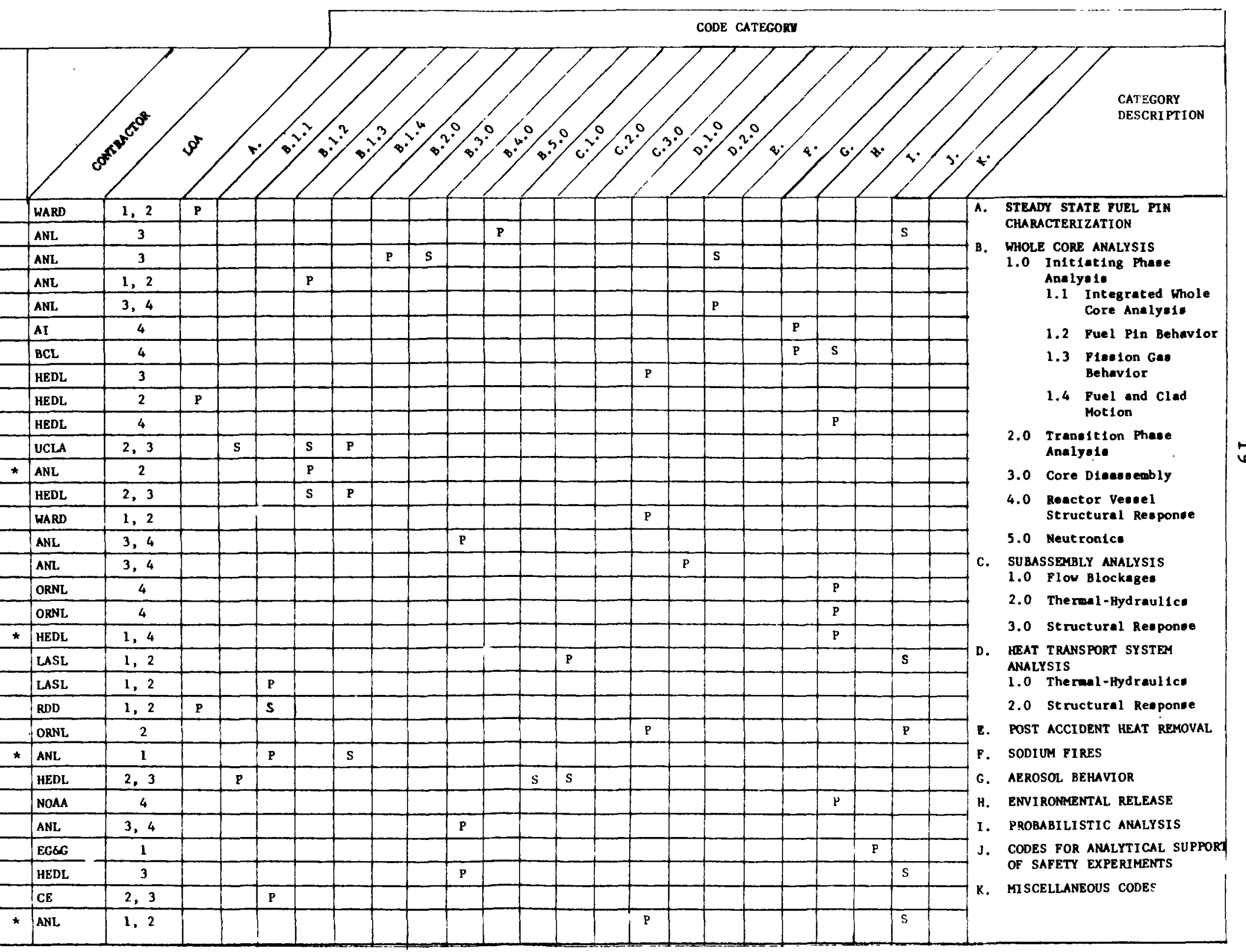




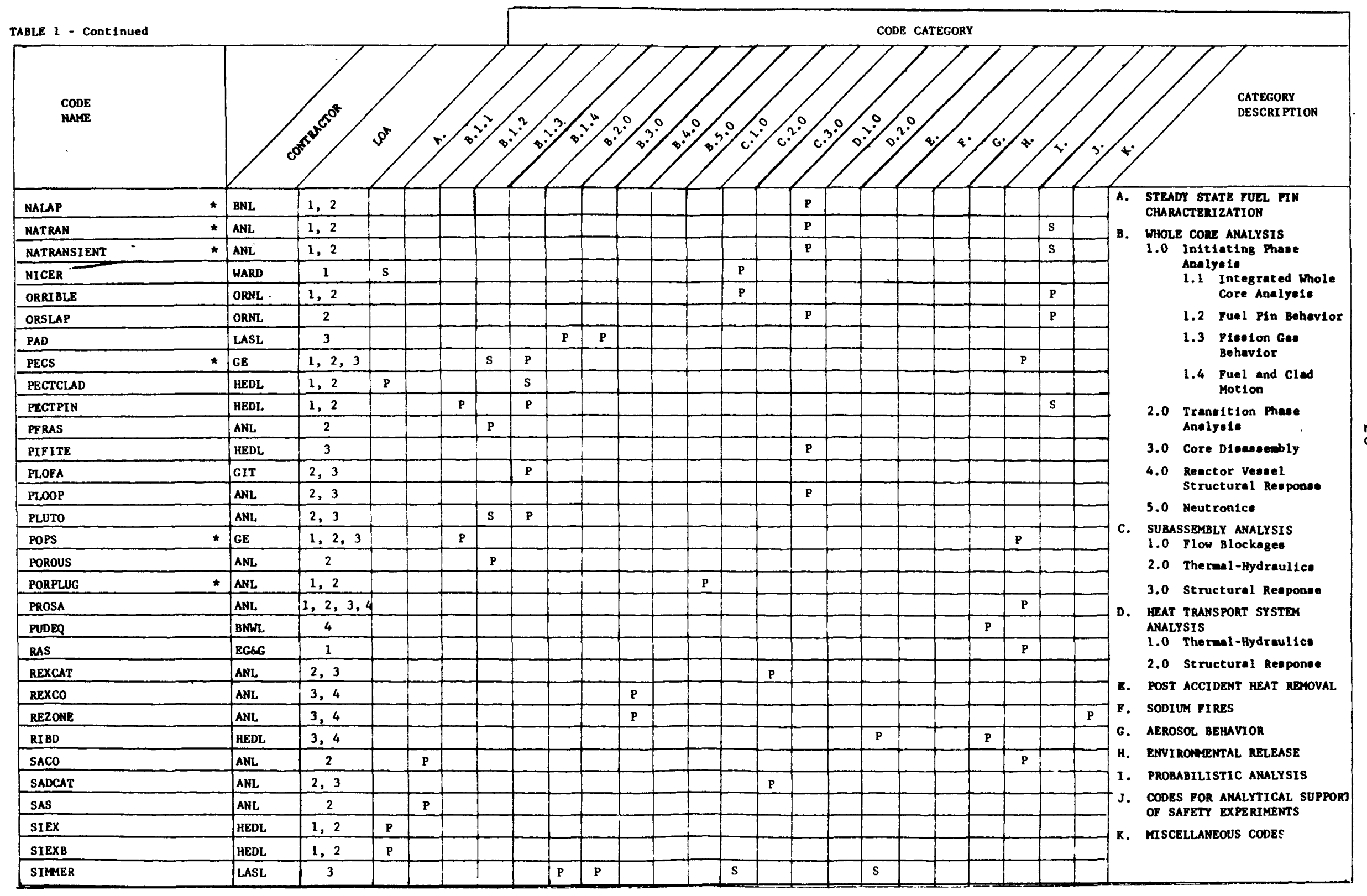




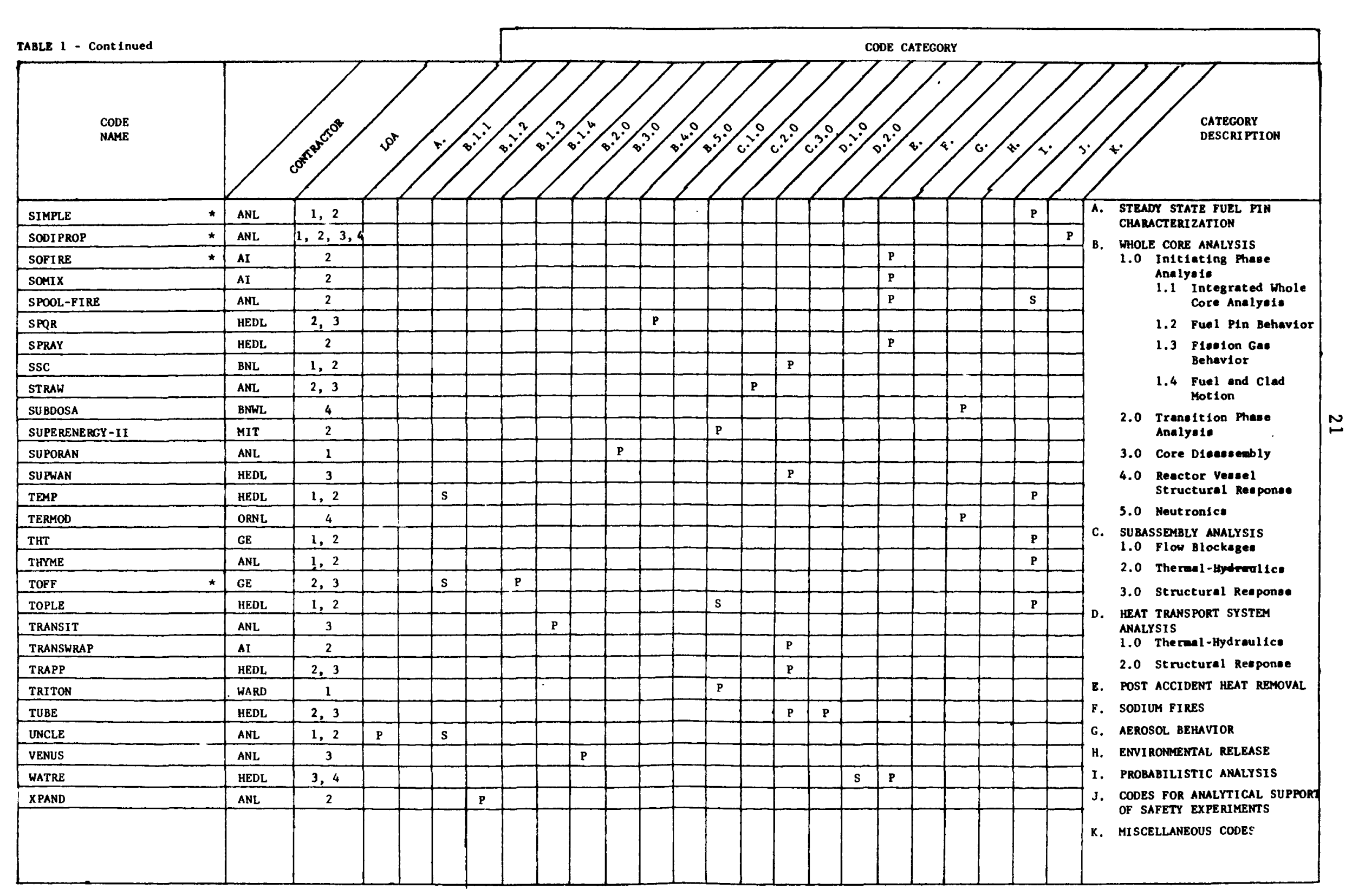


ACRA

\section{Purpose}

Calculates inhalation dose and external gamma dose from release of radionuclides to the atmosphere.

\section{$\underline{\text { Status }}$}

A. Development: Developed at Oak Ridge National Laboratory. ACRAII is current version.

B. Availability: ACRA-I was documented in 1973 (Ref. 1). ACRA-II was described in 1974 (Ref. 2), and it is available from the Radiation Shielding Information Center, ORNL. ACRA-II runs on a IBM $360 / 91$ at ORNL.

C. Utilization: ACRA-II has not yet been applied to any specific radiological assessment projects.

\section{Problems Solved}

ACRA-II calculates the dispersion of a cloud of radionuclides released to the atmosphere by a reactor accident. At downwind distances from the release, it then calculates:

1. The internal dose from inhalation of the radionuclides,

2. The external gamma dose due to the passing cloud,

3. The total ground contamination due to plume depletion during travel.

Up to 100 receptor locations, 20 time intervals, and 300 radioisotopes can be handled in one run of the program.

Mode1s

\section{Source Description}

The type of nuclides being emitted and the rate of emission are specified as input data which remain constant over any prescribed period of time. An option is provided to automatically sum contributions from different emission periods if desired. 


\section{Atmospheric Dispersion}

Dispersion of the plume in the atmosphere is based on a threedimensional normal distribution (Ref. 3 ). The model includes corrections for radioactive decay in transit, dry deposition, and washout by rain. It may also include the presence of an atmospheric lid if desired by the user. Ground contamination calculated as a result of deposition from the plume is corrected for environmental loss, such as leaching.

\section{Externa1 Dose}

The external gamma dose is determined by integrating over a finite cloud for a prescribed time period. Linear absorption and buildup in air are considered.

4. Internal Dose

The dose to up to 12 different organs as a result of inhalation of the radionuclides in the cloud can be calculated. It is obtained by multiplying the amount of radioactivity inhaled by an appropriate dose conversion factor. The former is the product of the air concentration at the point under consideration and the inhalation rate.

\section{$\underline{\text { Limitations }}$}

1. ACRA-II does not calculate doses due to radionuclides deposited on the ground.

2. Depletion of the plume by dry deposition extends uniformly in the vertical over the cloud.

3. The rate of plume depletion by washout is assumed to be the same for all nuclides.

4. Only linear decay sequences can be handled directly by the program.

5. Beta particles are not included in the external dose calculations.

6. Perfect reflection of the cloud at the ground and no penetration of the upper lid is assumed.

7. No allowance is made for differences in physical and chemical forms of the radionuclides being emitted, or their transformation within the plume during travel. 


\section{Future Efforts}

No further developmental work on this code is planned at present.

Interface/Overlap

-/AIRDOS, COMRADEX

\section{$\underline{\text { References }}$}

1. T. W. Stallman and F.B.K. Kam, "ACRA - A Computer Program for the Estimation of Radiation Doses Caused by a Hypothetical Reactor Accident," ORNL-TM-4082, Oak Ridge National Laboratory, Apri1 1973.

2. RSIC Computer Code Collection, "ACRA-II, Kernal Integration Code Estimation of Radiation Doses Caused by a Hypothetical Reactor Accident," CCC-213, Radiation Shielding Information Center, Oak Ridge National Laboratory, July 1974.

3. F. T. Binford, J. Barish, and F.B.K. Kam, "Estimation of Radiation Doses Following a Reactor Accident," ORNL-4086, Oak Ridge National Laboratory, February 1968. 
$\mathrm{ADPIC}$

\section{Purpose}

A numerical, three-dimensional, Cartesian, particle-diffusion code for calculating the time-dependent distribution of air pollutants resulting from reactor releases.

\section{$\underline{\text { Status }}$}

A. Development: Developed and under improvement at Lawrence Livermore Laboratory, California.

B. Availability: Operational at LLL on a CDC 7600. The models and numerical methods used in the code have been described (Ref. 1).

C. Utilization: Has been used to study plume depletion following postulated accidental releases of plutonium dioxide (Ref. 2) and is being incorporated into the Atmospheric Release Advisory Capability (ARAC) program (Ref. 3).

\section{Problems Solved}

ADPIC calculates the time-dependent distribution of air pollutants under a variety of conditions including strongly distorted advection wind fields, calm conditions, space variable surface roughness, wet and dry deposition, radioactive decay, and space- and time-variable diffusion parameters. The code determines:

1. The pollutant concentration as a function of time and space.

2. The cumulative deposition of pollutant on the surface.

Prompt gamma-ray (cloudshine) from the pollutants may also be included.

\section{Models}

The code solves the three-dimension advection-diffusion equation in its flux-conservative form (pseudo-velocity technique) for a mass-consistent advection field by finite difference approximations in Cartesian coordinates. The method is based on the particle-in-cell technique with the pollutant concentration represented statistically by imbedded Lagrangian marker particles in an Eurlerian grid (Ref. 4). 
1. The mass-consistent wind advection field used in ADPIC is based on adjusted interpolated wind-field data generated by another code, MATHEW (Ref. 5).

2. Input particle distributions, either of constant density or Gaussian, are generated by a random number generator. They may be generated anywhere within the grid mesh or on an inflow boundary.

3. An inversion layer and variations in topography within the grid system can be specified as input data.

4. Dry deposition and below cloud washout of pollutants can be included.

Dry deposition can be specified as a function of topography.

Two versions of the code are available depending upon the type of grid system used. The moving, expanding grid version is especially suited for the long-range (out to $1000 \mathrm{~km}$ ) study of surface, single puff releases. The fixed grid version is suitable for the study of instantaneous or continuous releases on or near the surface over a range of scales, from close-in ( 5 to $10 \mathrm{~km}$ ) to mid-range $(10$ to $200 \mathrm{~km}$ ).

\section{Limitations}

1. Calculation of plume depletion by rainout is not included.

2. Isotropy of atmospheric turbulence is assumed.

3. It is assumed that the horizontal components of the diffusivity coefficients are the same.

4. Similarity theory was used as the framework upon which to base the form of the diffusivity coefficients.

5. Large amounts of wind data as a function of space and time are necessary to specify the mass-consistent advection field accurately.

6. Most of the usable large core memory of a CDC 7600 is necessary to run $A D P I C$ for a regional scale study.

Future Efforts

Comparison of model predictions with fleld data is continuing.

Interface/Overlap

MATHEW/- 


\section{References}

1. R. Lange, "ADPIC, A Three-Dimensional Computer Code for the Study of Pollutant Dispersal and Deposition under Complex Conditions," UCRL-51462, Lawrence Livernore Laboratory, October 18, 1973.

2. P. H. Gudiksen, K. R. Peterson, R. Lange, and J. B. Knox, "Plume Depletion Following Postulated Atmospheric Plutonium Dioxide Releases," Health Physics, Vo1. 31, p. 127, August 1976.

3. J. B. Knox and R. C. Orphan, ed., "Program Report - FY 1975, Atmospheric and Geophysical Sciences Division, Physics Department," UCRL-51444-75, Lawrence Livermore Laboratory, October 8, 1975.

4. R. C. Sklarew, A. J. Fabrik, and J. E. Prager, "A Particle-in-Cell Meth id for Numerical Solution of the Atmospheric Diffusion Equation, and Application to Air Pollution Problems," Rept. 3SR-844, Systems, Science and Software, LaJolla, California, 1971.

5. C. A. Sherman, "MATHEW: A Mass Adjusted Three-Dimensional Windfield Model," Ph.D. Thesis, University of California at Davis, Department of Applied Science, May 1975. 


\section{AIPECS}

\section{Purpose}

To provide a method of statistically analyzing fuel-pin cladding structural performance and failure which is computationally more flexible and more economical than analysis by the Monte Carlo method.

\section{$\underline{\text { Status }}$}

A. Development: Developed at Atomics International. Is currently being calibrated to measured cladding strain data.

B. Availability: AIPECS is operational on the CDC -7600 at Lawrence Berkeley Laboratory. Its checkout and comparison to the GE Monte Carlo Code PECS-II, as well as supporting numerical algorithms, are described in References 1 and 2 .

C. Utilization: It has been used to predict the sensitivity of cladding performance variables (strain, corrosion depth, etc.), as well as time-to-failure, to proposed cladding materials correlations' parameters.

\section{Problems Solved}

AIPECS solves the problem of predicting the statistics of fuel-pin cladding performance. It does so in the following way:

Given: (a) The expected values of the constant parameters of the cladding's geometry, thermal-mechanical correlations, its fission gas release correlation, and the time-to-rupture correlation of the cladding material.

(b) The parameters $s^{\circ}$ uncertainties (standard deviations) and linear correlation coefficients.

(c) The fuel-pin's operating history (power level, midwall temperature, etc.) as functions of time.

Find: (a) The expected values, uncertainties, and linear correlation coefficients of the performance variables and cumulative damage functional.

(b) From the time-dependent expected values, uncertainties, and linear correlations, reconstruct the time profiles 
of the one-dimensional probability distribution functions ( $p d f^{\prime} s$ ) of the cladding state variables and cumulative damage functional. Optionally, reconstruct the joint (multidimensional) pdf of the set, taking into account the statistical correlations between its members.

$\underline{\text { Models }}$

The performance model used by AIPECS is identical to the model used in PECS-II (see Reference 3). It differs from PECS-II (and other versions of PECS) in two essential ways:

1. It does not make use of the Monte Carlo method, but rather uses an analytical method based on calculating the first moments and second central moments of the joint pdf of the set of cladding performance variables and cumulative damage functional.

2. It utilizes the error-controlling variable-step second-order time integration algorithms documented in Reference 2. Their use assures holding errors due to finite step integration with respect to time to a level which is negligible compared with the standard deviations of statistical fluctuations in the solution variables.

AIPECS starts with the assumption that, at every instant of time, the amplitudes or random fluctuations of the state variables and of the cumulative damage functional are sufficiently small to permit their representation as linear functions of the parmaeters" fluctuations about their mean values. It also uses the theorem that the expected value of any such first-order function of the parameter vector (the set of performance parameters) is the function itself, evaluated at the mean value of the parameter vector. It applies this theorem to calculate the expected values of the cladding state variables and of their first partial derivatives with respect to the parameters as functions of time. (See Reference 4). Since any choice of damage functional depends on the performance parameters implicitly through the state variables, its first-order Taylor expansion about the mean of the parameter vector can always be constructed from the calculated means of the state vector (set of state variables) and its derivatives, with the aid of the chain rule for differentiation. In general, the sum of the first-order terms in the Taylor expansion of a function of the random fluctuation from its own mean; the function's fluctuation has the form of a weighted sum of the parameters' fluctuations from their means. Hence squaring this sum and taking the expected value of the result yields an expression for the variance of the function in question, which variance is a weighted sum of the elements of the known covariance matrix of the parameter vector. 
Hence, at each instant of time, AIPECS actually maps the mean value of the parameter vector and its covariance matrix into the means and variances of each state variable and of the damage functional.

The dispersion in the values of the cladding performance variables which results from statistical uncertainties in the correlation parameters can be calculated either by Monte Carlo methods (See Reference 3) or by a non-Monte Carlo mathematical probability method (See Reference 4).

\section{Limitations}

The limitations on both geometrical detail and ability to faithfully represent the physical reality of fuel-pin cladding behavior are identical to those given for the PECS Codes.

In addition during the course of performing studies with the AIPECS Code, it became evident that the statistical characterization of the scatter in the data, from which correlations are extracted, needs to be given much more serious consideration than it has been given heretofore. Consequently, quantitatively reproducible estimates of data dispersion, which reflects the degree of precision with which materials properties are known, are not available. The reason for this lack seems to be the lack of both knowledge of and software with which to perform nonlinear multivariate regression analysis.

To meet the specific need to find a proper statistical characterization of the $\mathrm{UO}_{2}$ gas release correlation for the AIPECs, a software package has been developed which implements regression analysis in a manner used to analyze space vehicle tracking and telemetry data by NASA engineers and scientists. Reference 5 presents the analysis of the gas release data and serves to illustrate methods which are applicable to analysis of experimental measurements in general.

\section{Future Efforts}

Plans for improvement of AIPECS include:

1. Implementing it for automatic least-squares calibration to experimental data from EBR-II.

2. Accumulating the least-squares estimates of the expected values, uncertainties, and linear correlation coefficients of the performance parameters extracted from the experimental data in a permanent data bank for subsequent use in error analyses of proposed LMFBR fue1-pin designs. 


\section{$\underline{\text { References }}$}

1. B. D. O'Reilly and C. A. Vok, "Comparison of Monte Carlo and First-0rder Statistical Analysis Methods Applied to the PECS Gas-Pressure Fuel-Pin Cladding Performance Model, " N707T1240029 $(8 / 76)$.

2. B. D. $0^{\prime}$ Reilly, "Time-Integration Algorlthms for the LIFE FuelPin Performance Mode1," TI-707-240-025 (6/75).

3. M. I. Temme and D. B. Atcheson, "PECS-II; A Computer Program for Probabilistic Evaluation of Fuel Rod Failure Caused by Fission Gas-Pressure," GEAP-13993 (6/74).

4. B. D. O'Reilly, "A Mathematical Probability Method for Predicting Fue1-Pin Reliability," TI-707-240-023 (2/75).

5. B. D. 0'Reilly and C. A. Vok, "A Revised Fission Gas Release Correlation for the PECS Gas-Pressure Cladding Performance Model," N907TI124003 (11/76). 
AIRDOS-II

\section{Purpose}

To estimate the maximum individual dose to man or the population dose resulting from airborne release of radionuclides from nuclear facilities.

\section{$\underline{\text { Status }}$}

A. Development: The code was developed at Oak Ridge National Laboratory (ORNL). Current version is AIRDOSII.

B. Availability: Operational at ORNL on IBM $360-75$ and IBM 360-91.

C. Utilization: The code has been applied to environmental impact analysis for all types of nuclear facilities and power plants, cost/benefit studies, investigations of alternative fuels, fuel cycles, and plant sites, and predictions of pollutant concentration from fossil fuel combustion.

\section{Problems Solved}

Annual-average meterological data are used to estimate annual-average air concentrations and ground-deposition rates of radionuclides released from a nuclear facility at various specified distances and directions from the release point. The concentration in af $r$ at ground level are used to estimate annual doses to man through inhalation and immersion. Rates of deposition on ground surfaces are used to estimate annual doses through exposure to contaminated surfaces, ingestion of food produced on contaminated land, and immersion in contaminated water as by swimming. Doses to total body and ten reference organs are estimated using dose conversion factors supplied as input data. At the option of the user, either the maximum individual dose and location received or the population dose within a specified area are calculated.

Mode1s

Plume rise above the plant stack or roof vent can be estimated either through use of equations for buoyant plumes or through use of an equation for momentum-based plumes. A modified Gaussion plume model is used to estimate atmospheric dispersion at specified locations downward from the release point. Simple, standard models are used to estimate the rate of deposition on ground surfaces through dry and wet processes. Depletion 
of the plume through dry deposition involves a numerical integration step which is performed in a subroutine based on Simpson's rule. Radioactive decay is taken into account in the code. An upper limit to vertical dispersion (a 11d) is imposed by the user of the code.

Either plume centerline or $22.5^{\circ}$ sector-averaged values can be calculated. For the sector-averaged calculations, plumes overlapping adjacent sectors are compressed within their own $22.5^{3}$ sectors. The circular configuration about the plant allows concentrations to be estimated in 16 compass directions and up to 20 distances away from the plant. An optional feature of the code, however, allows calculations at the centers of each of 400 grid squares in a 20 by 20 grid with the plant at the center. The grid size is selected by the user, as many as 36 radionuclides released from one to six plant stacks or roof vents can be handled in a single computer run.

Concentrations in air at ground level are multiplied by dose conversion factors supplied as input to estimate inhalation annual dose commitment (for 50 years), which is treated in the code as equivalent to annual dose, and the annual afr immersion dose. The rate of deposition on ground surface is used to estimate surface exposure by use of dose conversion factors for gamma radiation supplied as input. A buildup time (often 50 years in assessments) is supplied as input to calculate surface concentration. Equilibrium on ground surfaces is reached in a much shorter time for most radionuclides because of radioactive decay and environmental losses. Doses through water immerston are calculated similarly. Depth of water is supplied as input to allow calculations of the radionuclide concentrations in water. Deposition rates on ground surfaces are also used with the terrestrial model of Booth, Kaye, and Rohwer (ORNL) to estimate 50-year dose commitments from ingestion of vegetables, beef, and milk.

\section{Limitations}

The atmospheric dispersion calculations of the code are limited similarly to the Gaussian plume eqation $1 . e$. , to distances within a few thousand meters for maximum individual dose estimates. Because of averaging-out of wind direction changes, population dose estimates within 50 miles should be reasonably good unless the population distribution far from the release point is extremely non-uniform. The present version of the code calculates plume depletion from dry deposition as though it occurs from throughout the entire vertical depth of the plume rather than at its bottom, which is closer to the real case. Penetration of low lids by plumes near the stack is not treated, and deposition velocity is not handled as a function of wind speed in the present version. Most of the other code limitations for atmospheric dispersion result from uncertainties in the various parameters used as input data. 
The dose calculations are made for people standing 24 hours a day at their home locations. Dose reductions resulting from the protection afforded by bulldings where people spend most of their time are not included at present.

\section{Future Effort}

Efforts are planned to develop a deposition and depletion model to treat dry deposition as occurring at the bottom of the plume. The code will be modified to estimate lid penetration and to vary deposition velocity with the wind speed. A model recently developed at ORNL ( $C$. C. Kocher, Health and Safety Research Division) calculates dose reduction factors results based on this model from indoor living. A subroutine to be optionally called by the user will be incorporated in AIRDOS-II.

\section{Computer Operation}

1. Operational on the IBM $360-75$ and IBM $360-91$.

2. Logistics: Batch operation, FORTRAN-IV language, $270 \mathrm{~K}$ of core required.

3. Typical. Problem Running Time (IBM 360-91): Running time usually ranges from less than 1 min for maximum individual dose calculations where a small number of grid locations are specified to as much as 5 min for population dose calculations where 160 or more grid locations are required. Some runs may require 20 minutes or longer if multiple release points are involved or if the square grid option of the code is used.

4. Code Validation: The following report discusses several comparisons of measured values in the environment and code predictions: R. E. Moore, ORNL-TM-4687 (January 1975). Comparisons of air monitoring data in Roane County, Tennessee with code predictions of pollutant concentrations resulting from fossil fuel combustion are being sought in a current study to validate the atmospheric dispersion portion of the code.

\section{Interface/Overlap}

AIRDOS-II recelves input data generated by INREM and EXREM to make dose calculations. Output data from AIRDOS-II are used as input data for AREAS, an area-source code used for dispersed sources of nonradioactive pollutants. 


\section{$\underline{\text { References }}$}

R. E. Moore, The AIRDOS-II Computer Code for Estimating Radiation Dose to Man from Airborne Radionuclides in Areas Surrounding Nuclear Facilities, ORNL-5245 (Apri1 1977). 
AQUAMOD

\section{Purpose}

Calculates the bioaccumulation of radioactive or nonradioactive polutants in various compartments of an aquatic ecosystem as a result of accidental or routine releases.

\section{$\underline{\text { Status }}$}

A. Development: Developed at Oak Ridge National Laboratory, Oak Ridge, Tennessee.

B. Availability: The current version of AQUAMOD is presently being developed for operation on an IBM $360 / 91$ computer. The code is presently not available to the public.

C. Utilization: An earlier version was used to study the dynamics of cesium-137 bioaccumulation in an oligotrophic (Ref. 1) and a eutrophic (Ref. 2) lake. The current version will be used to provide bioaccumulation information needed in environmental assessment work and to do dose rate to man calculations.

Problems Solved

AQUAMOD presently calculates:

1. The time dependent specific activity in each compartment of the aquatic ecosystem model.

2. The relationship with time of the bioaccumulation factor for zooplankton-eating $\mathrm{fish}$, detritus-feeding fish, and piscivorous fish.

The computer output includes printer plots of the above-mentioned quantities.

\section{Models}

AQUAMOD is based on a linear ecosystems mode1. The pollutant is input to the receiving water, either as a constant input or as a diffusing, traveling pulse. A sediment model distributes the pollutant to interstitial water, bottom sediment and top sediment. In addition the pollutant is distributed by a foodchain uptake model which includes 
compartments representing detritus, phytoplankton, zooplankton, benthic feeding organisms, zooplankton-eating $f i s h$, detritus-feeding $f$ ish and piscivorous fish. Certain pathways permit the direct uptake by organisms of the pollutant from water. This latter feature distinguishes the ecosystem model from a strict foodchain model.

\section{Limitations}

The current version of AQUAMOD requires the use of the IBM Continuous System Modeling Program (CSMP III). AQUAMOD also requires the avallability of data for the various transfer coefficients. A serious deficiency is the lack of an appropriate hydraulic transport model to describe the physical transport of the pollutant from the point of release to the point of initial contamination of the system. A very simplistic model is currently used to represent hydraulic transport. The specific activity concept is not meaningful for nonradioactive pollutants which have no natural background prior to an accidental or chronic release. The transfer coefficients are considered to be time and temperature independent.

\section{Future Efforts}

The development of an appropriate hydraulic transport model.

\section{References}

1. H. A. Vanderploeg, R. S. Booth, and F. H. Clark, "A SpecificActivity and Concentration Model Applied to Cesium Movement in an Oligotrophic Lake," in Proceedings of Symposium on Mineral Cycling in Southeastern Ecosystems, Augusta, Georgia, May 1-3, 1974.

2. H. A. Vanderploeg, R. S. Booth, and F. H. Clark, "A Specific Activity and Concentration Model Applied to Cesium-137 Movement in a Eutrophic Lake," in Colbert E. Cushing, Jr. (ed.), The Ecological Society of America Special Publication No. 1, Radioecology and Energy Resources, Proceedings of the Fourth National Symposium on Radioecology, Oregon State University, Corvallis, Oregon, May 12-14, 1975. 


\section{BEHAVE}

\section{Purpose}

Analysis of thermal-mechanical performance of fuel pins under steadystate and TOP conditions up to, and including, clad fallure.

\section{$\underline{\text { Status }}$}

A. Development: Developed and under improvement at GE-FBRD. Current development version is BEHAVE-SST.

B. Availability: The versions of BEHAVE and their availability are:

BEHAVE-2: Released in 1973 (Ref. 1). Runs on the Honeywe11-6000 only.

BEHAVE-3: Operational on the Honeywe11-6000 at GE-FBRD. Documented in Reference 2 . Will not be released in favor of BEHAVE-SST.

BEHAVE-SST: Operational at GE-FBRD on the Honeywe116000 compuer and at LBL on the CDC-7600. Documented in Reference 3. To be released to ACC during 1977.

C. Utilization: BEHAVE-SST has been used by GE-FBRD and HEDL to design and interpret TREAT overpower experiments, and to confirm MELT-III predictions of fuel rod failure time and location during FTR TOP. Fourteen TREAT TOP experiments have been analyzed to provide base technology support for TOP failure predictions.

\section{Problems Solved}

BEHAVE-SST predicts steady-state and transient fuel and cladding temperature distributions in two-dimensions $(\mathrm{R}-\mathrm{Z})$. Steady state cladding stress and deformation fields are calculated in $\mathrm{R}-\mathrm{Z}$ geometry using the generalized plane strain approximation. Steady state fuel restructuring, fuel swelling, fission gas production, and fission gas release are predicted. Transient cladding loading due to differential thermal expansion, fuel-cladding friction (or slippage), pressurization of the molten fuel zone by fuel melting expansion, and Gas Bottle pressure caused by fission gas are modeled. Cladding failure is predicted using a Life Fraction Damage function. 
BEHAVE-2 predicts steady state behavior only. BEHAVE-SST contains all BEHAVE-2 steady state models. BEHAVE-3 is superceded by BEHAVE-SST for steady state and transient analyses.

Mode1s

BEHAVE-SST :

1. Geometry

Single fuel rod modeled in two dimensions (circumferential variations neglected). Rod may be divided into five axial sections. Clad is represented by a maximum of 10 radial rings. Fuel is divided into structural (outer), transport (inner), and non-transport (middle) radial zones; each zone may contain a maximum of 10 rings radially. No transport zone exists for transient calculations. Dished fuel pellets are described by user specification of a radially distributed gap volume at the top and bottom of each axial fuel section. The gas plenum is represented simply as a volume available for fission gas, and fuel rod hardware in the plenum region is modeled by imposing a boundary condition limiting the amount of axial fuel expansion. Cladding thickness changes caused by corrosion are neglected. The fuel-clad gap is calculated for thermal calculations; for structural calculations it is assumed that cracked fuel will be pushed outward against the clad. Radial and transverse fuel cracks are represented by boundary conditions on stress and strain and a uniformly distributed volume fraction. The crack distribution is developed within the code based on the stress distribution in the fuel. Molten fuel moves axially within the activie fuel column during transients. As an option, molten fuel can be allowed to move into the axial blanket.

\section{Stress and Strain Mode1}

Elastic-viscous-plastic analysis of cladding is performed during steady state. Viscous effects are neglected for transient calculations. Model includes viscous, plastic and hot-pressing analyses of fuel. Stress and strain solutions are obtained in two dimensions (radial and axial) by finite-element analysis. Compressible molten fuel is simulated by a constant pressure boundary condition applied at the central void surface of the fuel. Imcompressible molten fuel is assumed when the central void is entirely filled with fuel and the porosity of this fuel is less than $0.1 \%$. Under the latter conditions, displacement of fuel in the central region is transmitted to surrounding fuel and cladding. Fuel porosity is removed by hot oressing and diffusion during transients, hot pressing occurs only 
in molten fuel. Axial shear forces are transmitted between fuela nd cladding according to the relative fuel-clad velocity. A rigid restraint can be imposed on axial fuel motion after a user specified amount of fuel movement; rigid axial restraint also occurs when high fuel-clad contact forces are present.

Cladding analysis includes thermoelastic loading. Local stress effects are neglected. Cladding failure predictions are included within the program for transient analyses only.

3. Fission Gas Release

For transient calculations, all gas is released at the fuel solids temperature unless the user specifies the fraction to be released at some lower (user-specified) temperature.

For steady state calculations, the equiaxed and columnar grain regions are defined as regions which are hotter than empirically determined temperatures. Each axial section retains a portion of its fission gas, and the fraction retained is represented by an empirical equation which is a function of burnup and linear power. The user specifies the fraction of gas produced in the columnar region that is retained in that region. Retained gas is distributed unformly in the unrestructured and columnar regions and linearly across the equiaxed region.

An option is available in BEHAVE-SST (the "gas bottle" option) which allows one to assume that the gas released in the inviscid region is isolated from the gas plenum pressure. This creates high gas pressure in the inviscid region, which can cause a high displacement rate or a high-pressure boundary condition to be applied to the structural fuel region.

4. Fuel Swelling

During steady state operation, the fuel matrix material, which is the portion of fuel volume exclusive of crack volume and the volume of large pores, swells at an inexorable rate with burnup. The value of this swelling rate is a constant which was used for code validation. However, the fuel as a whole contains compressible crack and porosity volume, so net contraction of fuel in some time intervals is calculated. Fuel swelling due to expansion of trapped fission gas is not modeled. The swelling of the matrix material per unit burnup is assumed to be the same everywhere in the fuel. No fuel swelling is modeled during transient operation. 
5. Fuel Structure and Thermal Model

Fuel structure is determined during steady state operation by a combination of swelling, sintering, cracking, elastic and plastic creep, hot pressing, and melting.

The thermal and mechanical models are coupled through the fuel structure. Fuel is divided into structural, transport, and inviscid radial zones by definition of time-dependent structural transition temperatures. Porosity in the transport and inviscid zones is calculated by the code; porosity is reduced by diffusion processes in the transport region and by hot pressing in the inviscid, nontransport region. Further thermal-mechanical coupling is introduced by the calculated crack distribution in the thermal portion of the model. Cracking of fuel and consequent release of fission gas also affects the thermal model through the fuel-clad gap conductance, which is dependent on the composition of gas in the fuel-clad gap.

The thermal model employs a phenomenological fuel-clad gap conductance model and an empirical relationship for fuel thermal conductivity. Thermal conductivity is a function of temperature and fuel density (i.e., porosity). BEHAVE calculates fue1-clad gap size based on thermal expansion. When an inviscid region forms, the gap is assumed to close by high-temperature fuel swelling. The gap is assumed to be closed for structural analysis. Plutonium and oxygen redistribution within the fuel is neglected. Axial fuel motion is neglected in the thermal analysis. The temperature solution is obtained using the axial and radial fuel distributions that exist at the beginning of each time step.

Transient thermal conditions may be obtained from detailed twodimensional temperature calculations performed by the THTD code or by any other code. These results are supplied to BEHAVE on tape or by punched cards, and include detailed fuel temperatures and molten fuel distributions. The internal BEHAVE thermal model is also available as a user option. None of the options involve internal iteration between fuel location and thermal conditions (normal usage involves THT updates by the user).

\section{Fuel Motion}

After molten fuel volume is sufficient to fill the central void of an axial section and removal of porosity by hot-pressing has occurred, excess fuel is moved to the nearest axial section with available space. BEHAVE-SST assumes that the top of the fuel column remains solid so that fuel cannot move beyond this point. 
A fuel-motion option may be specified, however, allowing fuel to flow into the axial blanket and gas plenum regions. This motion is restrained by plenum gas pressure, but not by fuel-clad friction or the welght of blanket pellets.

\section{Fuel Thermal Expansion}

Fuel thermal expansion is described by an empirical correlation which is a function of fuel stoichiometry and fuel plutonium fraction. Oxygen bulldup with burnup is included in the code, but radial oxygen and plutonium redistribution is not.

\section{Cladding Failure}

Cladding fallure is predicted using a Life Fraction type of cumulative damage function. This is based on an empirical Larson-Miller Parameter correlation to Fuel Cladding Transient Test (FCTT) data.

\section{Limitations}

1. Maximum of 5 axial sections, 10 radial cladding rings, 20 radial fuel rings (for transients), 30 radial fuel rings for steady state analyses.

2. Cladding mechanical properties are for irradiated $20 \% \mathrm{CW}$ Type-316 stainless steel. Annealed Type-316 properties are available but model is less detailed. Cladding model does not include transient time-temperature effects.

3. Single-rod code. No treatment of interactions between fuel rods.

4. No treatment of fission-gas-induced fuel swelling during steady state or transient.

5. No strain-based cladding failure model.

6. No model of fuel expulsion or other events after cladding faiure.

7. Cumlative damage function does not contain fluence, ramp rate, strain rate, or irradiation temperature dependences.

8. No loading due to fuel vapor pressure.

9. Local (i.e., circumferential) thermal and mechanical effects are neglected.

10. No radial or axial oxygen redistribution model. 
11. No cladding wastage model.

12. Thermal models do not iterate to find a thermal solution which is consistent with fuel motion. Gap conductance subroutine estimates fuel and cladding thermal expansion and iterates on fuel surface temperature as an approximation to thermal effect on fuel radial deformation.

13. Some thermal and mechanical properties are constant with temperature.

14. Transient heat transfer model does not handle coolant bolling.

15. Equation of motion for molten fuel motion into the axial blanket does not contain frictional effects.

16. No radial or axial plutonfum redistribution mode1.

\section{Future Efforts}

1. Refinement of cladding mechanical properties models is in progress.

2. Refinement of cladding cumulative damage model is planned.

3. Development of failure strain and strain fraction cumulative damage models is planned.

4. Continued validation of code by analysis of TREAT overpower experiments and modification of models as suggested by these analyses.

5. Add fuel vapor pressure loading.

6. Add cladding wastage models.

7. Refine thermal properties.

8. Refine fuel creep and plasticity models (properties).

\section{Computer Operation}

1. BEHAVE-SST is operational on the Honeywel1-6000 and CDC-7600 computers.

2. BEHAVE-SST is a batch program written in FORTRAN-IV. It is overlaid extensively on both the $\mathrm{H}-6000$ and $\mathrm{CDC}-7600$ computers. Memory requirements are $150 \mathrm{~K}$ Small Core Memory on the LBL CDC-7600 (MNF complier). The program requires $70 \mathrm{~K}$ on the $\mathrm{H}-6000$. Disc storage is required when temperatures are not calculated internally. 
3. Typical Problem Running Time: On the CDC-7600 computer: With maximum node structure used, a steady state plus 1-second transient case with temperatures calculated internally required $48 \mathrm{CP}$ seconds. When temperatures for a 15-second transient case are supplied on cards at 13 transient times, the case required $287 \mathrm{CP}$ seconds. When temperatures for a 3-second transient are supplied on cards at 30 transient times, the case required $375 \mathrm{CP}$ seconds on the CDC -7600 computer. The temperature calculation requires approximately $50 \%$ of total running time when temperatures are input on cards.

On the H-6000 computer: With maximum node structure used, a 15second transient with temperatures supplied on the tape by the THTD code required 1800 seconds of $\mathrm{H}-6000 \mathrm{CP}$ processing time. Temperature input required approximately half the total time.

4. Code Validation: Cladding failure time and location predictions have been obtained using the BEHAVE-SST program for three unirradiated and 11 irradiated TREAT overpower experiments. BEHAVE-SST models have been refined to obtain agreement between predicted and measured cladding failure times in these experiments. These analyses are planned to continue in order to extend the range of code validation to different combinations of burnup, fluence, steady state power, and transient ramp rate.

The TREAT experiments analyzed, and references for each analysis are as follows:

\begin{tabular}{ll} 
Experiment & References \\
\cline { 2 - 3 } PNL 2-1 & $4,8,9$ \\
PNL 2-11 & $4,8,9$ \\
HOP 3-3C & $4,5,7,8,9$ \\
C4H & $4,7,9$ \\
HUT 5-5B & $12,13,14$ \\
HUT 3-5B & 14,15 \\
C4G & $4,8,9$ \\
HOP 3-2A & 4,10 \\
HOP 3-2B & 4,10 \\
HUT 5-5A & $4,11,13,14$ \\
HUT 3-5A & 15 \\
C4A & $4,6,9$ \\
C4B & $4,5,6,9$ \\
R9 & 11,13
\end{tabular}




\section{Interface/0verlap}

Interface: BEHAVE-SST obtains temperatures from THTD via tape on the $\mathrm{H}-6000$ computer. On the CDC-7600 computer, the program is designed to accept temperatures from any code on punched cards. Primary interfacing codes supplying temperatures have been SAS-2A, MELT-IIIA, and THTD.

Overlap: Other major codes with objectives similar to those of BEHAVE-SST are LIFE-T, PECT, DILATE/DSTRESS, and DEFORM-III.

\section{$\underline{\text { References }}$}

1. GEAP-13788, "BEHAVE-2, Oxide Fuel Performance Code in Two Spatial Dimensions and Time," S. Oldberg, February 1972.

2. GEAP-14021, "Steady State and Transient Fuel Mechanics: The BEHAVE-3 Code," S. O1dberg and R. G. Stuart, August 1974.

3. GEFR-00001, "User's Manual for the BEHAVE-SST (Steady State and Transient), Fuel Rod Mechanics Program,"R. R. Sherry and D. B. Atcheson, February 1977 .

4. CONF-761001, "Cladding Failure in TREAT Overpower Experiments: A Mechanistic Interpretation and Its Implications for LMFBR Safety Analysis," D. B. Atcheson, R. R. Sherry, and K. J. Shimane, ANS International Meeting on Fast Reactor Safety and Related Physics, October 1976.

5. GEAP-13923-9, "Safety Engineering," Ninth Quarterly Report for August-0ctober 1974, GE-FBRD, November 1974 .

6. GEAP-13923-10, "Safety Engineering," Tenth Quarterly Report for November-December 1974 and January 1975, GE-FBRD, February 1975.

7. GEAP-13923-11, "Safety Engineering," Eleventh Quarterly Report for February-Apr11 1975, GE-FBRD, June 1975.

8. GEAP-13923-12, "Safety Engineering," Twelfth Quarterly Report for May-July 1975, GE-FBRD, August 1975.

9. GEAP-13923-13, "Safety Engineering," Thirteenth Quarterly Report for August-October 1975, GE-FBRD, November 1975.

10. GEAP-13923-15, "Safety Engineering," Fifteenth Quarterly Report for February-Apri1 1976, GE-FBRD, May 1976. 
11. GEAP-13923-16, "Safety Engineering," Sixteenth Quarter1y Report for May-July 1976, GE-FBRD, August 1976.

12. GEAP-13923-17, "Safety Engineering," Seventeenth Quarterly Report for August-0ctober 1976, GE-FBRD, November 1976.

13. GEFR-13923-18, "Fuel Rod Mechanics and Failure Analysis," Eighteenth Quarterly Report for November-December 1976 and January 1977, GE-FBRD, February 1977.

14. GEFR-13923-19, "Fue1 Rod Mechanics and Failure Analysis," Nineteenth Quarterly Report for February-April 1977, GE-FBRD, May 1977.

15. GEFR-13923-20, "Fuel Rod Mechanics and Failure Analysis," Twentieth Quarterly Report for May-July 1977, GE-FBRD, (to be published). 
CACECO

\section{Purpose}

To predict the thermodynamic responses of primary and secondary containment to a variety of accidents in an LMFBR facility.

\section{Status}

A. Development: Developed and under improvement at HEDL. Present version, called CACECO, is released for post accident heat removal studies.

B. Availability: Maintained operational at HEDL, at Brookhaven National Laboratory, and at Lawrence Berkeley Laboratory. Released to several ERDA contractors. Released to others through the ANL Code Center.

C. Utilization: Has been used by HEDL for FFTF FSAR analysis and for study of FFTF containment margins. Used by HEDL, GE, and WARD for CRBR PSAR analysis and for subsequent studies.

\section{Problems Solved}

Predicts the pressure and temperature responses as a function of time for 1 to 4 interconnected containment spaces (cells), at least one of which is involved in an accident. The code user defines the accident in terms of the following: (a) sodium leakage as spray and spill, (b) air injection, (c) decay heat release, and (d) space cooler operation. The code analyzes the conditions in the reactor vessel, in the reactor cavity, in pipeways and cells, and in the containment building, according to input data supplied by the user. The code treats each vessel, cavity, pipeway, cell and building as an analysis cell. The code can analyze the conditions in one cell, two cells, three cells, or four cells according to the needs of the accident scenario. The code calculates cell responses from mass and energy balances that include the following effects to accommodate the complex phenomena of accident scenarios for LMFBR facilities.

\section{A. Energy Effects}

1. Fission product decay heating of the atmosphere and pool of any ce11.

2. Atmosphere cooling by a space cooler in any cell. 
3. Heat transfer to the roof, walls, floor, and equipment of any cell and the temperature distribution within these structures.

\section{B. Mass and Energy Effects}

1. Sodium spray into the atmosphere of any cell and sodium spill into the sodium pool of any cell.

2. Nitrogen-oxygen gas injection into the atmosphere of any cell.

3. Atmosphere leakage and vent flows between cells and between any cell and the outside air.

4. Liquid sodium over-flow from one cell to another.

5. Water vapor release upon heating the concrete of the roof, walls, and floor of any cell; the water vapor going into the atmosphere or sodium pool of the cell or another cell.

6. Carbon dioxide release upon heating the limestone concrete of the roof, walls, and floor of any cell; the carbon dioxide going into the atmosphere or sodium pool of the cell or another cell.

7. Chemical reactions as follows:
a. Liquid sodium with concrete.
b. Liquid sodium with carbon dioxide and water vapor to form carbon, sodium oxide, and hydrogen.
c. Sodium oxide with water vapor to form sodium hydroxide.
d. Sodium vapor with carbon dioxide, oxygen, and water vapor to form carbon, sodium oxide, and hydrogen.
e. Hydrogen with oxygen to reform water vapor.
f. Sodium with hydrogen to form sodium hydride.

8. Sodium vapor or water vapor condensation out of any cell atmosphere into a sodium or water pool, respectively.

9. Boil-off of any sodium or water pool of any cell into the atmosphere. 
The code allows special treatment for concrete structures in the following respects:

1. carbon dioxide and water vapor release as concrete is heated,

2. concrete heat capacity effect of calcination and dehydration as a function of temperature,

3. concrete thermal conductivity as a function of temperature, and

4. sodium and concrete chemical reaction.

\section{Models}

A. Facility Modeling

The facility is modeled with $1,2,3$, or 4 analysis cells which may be interconnected by the following:

1. one or more atmosphere leakage and vent flow paths

2. one sodium pool over-flow path

3. one or more heat structures that represent connecting walls or a connecting floor-roof combination

B. Ce11 Analysis

Each cell has an atmosphere and may have a sodium pool or a water pool. The roof, walls, floor, and equipment are represented by heat structures.

1. The atmosphere is assumed to be we11-mixed and characterized by a uniform composition, temperature, and pressure. The atmosphere may have carbon dioxide, hydrogen, nitrogen, oxygen, and either sodium vapor or water vapor. The atmosphere temperature is equal to the pool temperature and is saturated with pool materia'. (if the pool exists).

2. The sodium or water pool, if either exists within a certain cel1, is well-mixed and characterized by a uniform temperature which is equal to the atmosphere temperature.

3. Liquid and solid reaction products of carbon, sodium hydride, sodium hydroxide, and sodium oxide result from chemical reactions in the atmosphere and sodium pool. These products 
are we11-mixed and characterized by a uniform temperature which is equal to the atmosphere temperature.

\section{Heat Structures}

1. Each heat structure is described by the one-dimensional, multi-region, transient heat conduction equation in planar, cylindrical, or spherical geometry. There can be 24 heat structures including the four that represent the sodium pool of each cell. Each heat structure can have up to 20 regions of different materials and different spacings for the temperature nodes, and up to 25 temperature nodes. The materials have constant thermal conductivity and volumetric heat capacity.

2. Heat transfer to and from each heat structure include convection and radiation from both surfaces. The coefficients for convection heat transfer are input data which may be constant or may depend upon time, average film temperature, temperature difference, surface, ox bulk temperature. The total exchange areas for radiation heat transfer are input data which are based on the usual assumptions of grey surfaces having constant values of area, geometrical view factor, and emissivity. The atmosphere between heat structures may range from opaque to transparent for this thermal radiation.

\section{Atmosphere Leakage and Vent Flows}

1. Atmosphere leakage and vent flow rates are based upon pressure differences and will not account for natural convection flows between vertical cells when the lower cell is hotter than the upper cell. Leakage rate is based on a defining equation which has the leakrate proportional to a coefficient (input data) and to the square root of the pressure difference. Vent rates are based on the standard nozzle equations for compressible gas flow.

2. A cell may be purged with air in order to limit its hydrogen concentration to 4 percent.

\section{E. $\quad$ Chemical Reactions}

1. The chemical reaction of sodium with concrete is nonmechanistic and non-stoichiometric.

2. The reactions of sodium with carbon dioxide, oxygen, and water vapor and of sodium oxide with water vapor go to completion and 
one set of reactants or the other are consumed. That is, either the sodium and sodium oxide are in excess and predominate or else the carbon dioxide, oxygen, and water vapor predominate. At reaction completion the atmosphere can have sodium vapor or water vapor but not both simultaneously. Similarly, the pool can be elther sodium or water but not both.

3. Sodium vapor reacts with carbon dioxide, oxygen, and water vapor, according to their molar ratios, when the concentration of oxygen is less than the concentration of water. When the concentration of oxygen is greater than the concentration of water vapor, sodium reacts with carbon dioxide and oxygen according to their molar ratios, as before, but the sodium and water reaction is omitted; no hydrogen is formed. These oxygen and water vapor concentration effects on the sodium vapor reaction are based on experiments conducted at HEDL [2] .

4. Hydrogen that accompanies sodium vapor leakage from one cell to another will react with oxygen in the second cell and the hydrogen will be completely consumed when the following conditions prevall, according to recent experiments at HEDL [2] •

a. The hydrogen and sodium vapor leak from a cell that is at least $500 \mathrm{~F}$ and has a sodium aerosol concentration of at least $5.5 \mathrm{~g} / \mathrm{m}^{3}$.

b. The leakage goes into an air space that has an oxygen concentration of at least 11 percent.

5. Sodium reacts with hydrogen to form sodium hydride in an equilibrium reaction that is temperatwre dependent [3].

\section{Limitations}

1. One to 4 interconnected analysis cells.

2. Atmosphere, pool, and reaction products are characterized by a single temperature.

3. Atmosphere and pool temperatures should be in the range of $50^{\circ} \mathrm{F}$ to $2500^{\circ} \mathrm{F}$ due to limits of accurate thermodynamic properties:

a. Sodium, solid, liquid, and vapor [4] .

b. Water liquid and vapor from 50 to $300^{\circ} \mathrm{F}$, and vapor itself to $1600^{\circ} \mathrm{F}[5]$. 
4. Up to 24 heat structures with each having up to 25 temperature nodes.

5. Up to 9 tables of varlable heat transfer coefficients.

Future Efforts

Modify code to include mass transfer limited reactions at the surface of the sodium pool: sodium with carbon dioxide, hydrogen, oxygen, and water vapor. This modification would model the sodium fire with the atmosphere temperature different from the pool temperature.

Interface/Overlap

/SOFIRE, SPRAY

\section{$\underline{\text { References }}$}

1. R. D. Peak, "Users Guide to the CACECO Containment Analysis Code," HEDL-TC-859, June 1977.

2. R. W. Wierman and R. K. Hilliard, "Experimental Study of Hydrogen Formation and Recombination Under Postulated LMFBR Accident Conditions," Hanford Engineering Development Laboratory, Richland, Washington, HEDL-TC-730, December 1976.

3. A. C. Whittingham, An Equilibrium and Kinetic Study of the Liquid Sodium-Hydrogen Reaction, Journal of Nuclear Materials, 60, 1976, pp. 119-129.

4. G. H. Golden and J. V. Tokar, Thermophysical Properties of Sodium, Argonne National Laboratory, Argonne, I1linois, ANL-7323, August 1967.

5. R. B. McClintock and G. J. Silvestri, Formulations and Iterative Procedures for the Calculation of Properties of Steam, American Institute of Mechanical Engineers, 345 East 47th Street, New York, N.Y., 1968. 
CLASP

\section{Purpose}

Simulation of transient-thermal/hydraulic behavior for a liquid metal cooled reactor test loop, with detailed application to FFTF Closed Loop Systems.

\section{$\underline{\text { Status }}$}

A. Development: Under development at HEDL.

B. Availability: No documentation is avallable, operational at HEDL on CYBER-74 and CDC-7600 at LBL.

C. Utilization: Used by HEDL for CLS design analysis, control system design and analysis, PPS design and experiment evaluation.

\section{Problems Solved}

Describes the therma1-hydraulic behavior of a sodium-cooled test loop subjected to postulated transients such as those resulting from control system, pump and component fallures or power excursions. Calculates:

1. fluid conditions such as flow and pressure,

2. thermal conditions such as sodium, air and component temperatures,

3. heat fluxes in power generating and dissipating components, and

4. controller settings and outputs.

\section{Mode1s}

\section{Geometry}

The system is modeled as a primary and secondary heat transport loop interconnected by an intermediate heat exchanger. The primary loop has two parallel pump paths. The test section in the primary loop is modeled by a single "average" fuel pin and coolant channel with hot channel factors. Power dissipation is through an air dump heat exchanger in the secondary loop and insulation heat loss. Component models include the following: 
a. Primary EM pumps, motor generator sets and check valves.

b. Piping with insulation.

c. IHX - a multi-node "average" tube model.

d. Secondary EM pump, motor generator set and control vlave.

e. DHX - a multi-node simulation which models finned tubes, sodium,, air, dampers, fans and associated air control system.

f. Cover gas.

g. CLIRA - a multi-node parallel counter flow heat exchanger with heat exchange to the reactor pool.

h. Automatic control systems.

1. PPS systems.

j. Surge and auxillary storage tanks.

\section{Method of Solution}

The governing differential equations (mass, momentum and energy) for one dimensional, incompressible fluid flow are approximated by a finite differencing technique. The resulting equations are solved at discrete points along the sodium and air flow paths. Material properties and heat transfer characteristics at eacch mode are variable with respect to temperature and flow.

\section{Limitations}

1. Test section model has single dynamic average channel and uses hot channel factors. Axial power distribution and nuclear heating are input.

2. Code handles only single phase coolant flow.

3. Flows are assumed incompressible.

4. Fluid and metal temperature expansion effects on surge tank fluid level is not calculated.

5. Heat addition from EM pumps not included in thermal calculations. 


\section{Future Efforts}

1. Include heat addition from EM pumps.

2. Verify code accuracy with FFTF acceptance test data.

3. Document the complete code.

\section{Computer Operation}

1. Code is operational at HEDL on CYBER-74 and CDC-7600 at LBL.

2. Core memory requirements are 130K, operation in batch mode with card decks or via remote terminals, programming language is FORTRAN IV, plotting routine uses DISSPLAY sof tware package.

3. Typical running time for the code is $120 \mathrm{CP}$ seconds.

4. It is intended to validate the code during FFTF acceptance testing. Interface/Overlap

SAS / IANUS

$\underline{\text { References }}$

None 


\section{COASTDWN}

\section{Purpose}

Calculation of transient hydraulic response to blockage, restrictions, changes in pump power, etc. In the SLSF loop.

\section{$\underline{\text { Status }}$}

A. Development: Developed at ANL/RAS. Current development version is COASTDWN.

B. Availability: COASTDWN is operational on the IBM $370 / 195$ at ANL.

C. Utilization: COASTDWN is used to determine flow coastdown response in planned LMFBR LOF and LOPI tests in the SLSF loop and to various off-design operating conditions.

\section{Problems Solved}

The COASTDWN code simulates dynamic coolant response in the SLSF loop to determine transient flow characteristics resulting from gradual or abrupt changes in pressure drop, coolant temperature, pump power or other pertubations in operating conditions or system geometry that do not result in coolant expulsion. COASTDWN solves equations of motion for one-dimensional, unsteady flow of incompressible, single-phase sodium constrained by. inertia and fluid friction while responding to changes in loop operating parameters. The transient initiating mechanism may be a single event or simultaneous or staggered occurrence of multiple events.

\section{$\underline{\text { Mode1s }}$}

The SLSF 1oop and test train geometry are described by 65 regions in the main flow circuit and 9 regions in the bypass channel. Four fluid columns are used to describe the motion of coolant during non-expulsion flow transients.

COASTDWN consists of a steady-state module and a dynamic analysis module. FEFPSTY is used for the steady-state pretransient analysis to calculate the initial conditions. CSMP is used in the dynamic analysis module to solve four first-order, coupled differential equations, one differential equation of motion for each of the individual fluid columns, and supporting relations defining interface pressures and pump performance.

\section{Limitations}

1. Incompressible, single phase flow in system with rigid boundaries. 
2. Although extended to transient conditions, all other limitations described for FEFPSTY apply.

\section{Future Efforts}

None planned.

\section{Computer Operation}

1. Operational on IBM $370 / 195$ at ANL.

2. Logistics: $250 \mathrm{~K}$ of core memory specified for code operation, batch operation, FORTRAN.

3. Typical problem running time is 3 minutes, including program compilation, for calculation of steady-state initial conditions and the first 20 seconds of simulated FTR LOF accident.

Interface/Overlap

FEFFPSTY, FEFPSLUG/

\section{$\underline{\text { References }}$}

1. Safety Assessment Report for the Fuel Element Failure Propagation Loop in the Engineering Test Loop, Appendix B, Argonne National Laboratory Report ANL/RAS 73-21 (Revision 3), May 31, 1974. 
COBRA

\section{Purpose}

A general program for steady-state and transient thermal-hydraulic subchannel analysis of rod bundle nuclear fuel elements.

\section{$\underline{\text { Status }}$}

A. Development: Development and under improvement at BNWL. COBRA IV is current development version.

B. Availability: COBRA I: Released in 1967

COBRA II: Released in 1970

COBRA III: Released in 1971

COBRA III C: Released in 1973; versions available for UNIVAC 1108, IBM 370 , and CDC 6600. Operational at BNWL (1108 and 6600) and ANC (370)

COBRA 3-M: Operational at ANL on IBM 360

COBRA IV-I: Operational at BNWL (CDC 6000 and 7000 machines)

C. Utilization: Utilized extensively in LWR and more recently in LMFBR thermal-hydraulic analysis. ANL has used COBRA for analysis of steady-state and transient single phase sodium flow for wirewrap pin ass emblies.

\section{Problems Solved}

1. Computes the steady-state and transient coolant flow, enthalpy and pressure drop in the subchannel of rod bundles during both boiling and non-boiling conditions with inclusion of the effects of crossflow mixing. The solution is performed as a boundary value problem using as boundary conditions the inlet enthalpy, inlet flow, inlet crossflow and uniform exit pressure. Handles two-phase water flow and sodium fluid flow at present by using a pseudo-homogeneous slip flow model. More advanced two-phase flow models are required to handle two-phase sodium flow, and are under development at PNL.

2. Design and analysis of transient in-pile experiments gives detailed fuel and coolant temperatures to predict fuel melting, local boiling, fuel/clad differential expansions. 
3. Can be used for a wide variety of rod bundle fuel element configurations. Handles distorted bundles, and arbitrary axial, radial and circumferential heat flux distributions. Modifications have been made under COBRA IV to handle a 217-pin wire-wrap bundle.

4. Has been successful in calculating steady-state sodium boiling in a 7-pin (12 channel) bundle with uniform and non-untform radial power.

Mode1s

A. General COBRA-III

Solution Methodology: A lumped parameter treatment of a rod bundle where the flow cross section is divided into subchannels and then the subchannels are divided axially into control volumes. Equations of mass, energy and momentum are written as integral equations for the conrol volumes. These integral equations are space averaged and reduced to a finite difference form. This integral treatment necessitates providing semi-empirical data at control volume boundaries -- friction factors, mixing coefficients, etc. The entire set of control volume equations is generalized using matrix operators to allow an arbitrary layout of subchannels and thus allow a truly three dimensional representation of the bundle.

B. COBRA-III C - PNL version of COBRA-III with following capabilities:

1. Fuel heat transfer model - considers radial conduction in fuel and clad.

2. Mixing models - considers effects of turbulent and thermal conduction mixing throughout the bundle by using empirically determined mixing coefficients. Includes convective transport of enthalpy by diversion crossflow mixing, transverse resistance to crossflow, temporal and spatial acceleration of diversion crossflow, and momentum transport from turbulent and diversion crossflow.

3. Each subchannel is assumed to contain two-phase separated slipflow during boiling.

4. Two-phase flow structure is assumed to be fine enough to define the void fraction as a function of enthalpy, flow rate, heat flux, pressure, position and time.

5. Transients are limited to times that are greater than time for sonic wave to pass through channel. 
6. Numerical solution has no stability limitation on space or time steps for flow in the positive axial direction.

7. Forced flow mixing due to diverter vanes or wire wraps is included.

8. Can analyze bundles with partial flow blockages.

9. Numerical scheme performs boundary value solution with semiexplicit finite difference scheme.

10. Turbulent mixing is analogous to eddy diffusion and is defined through empirical correlations.

11. Considers non-uniform hydraulic behavior.

\section{COBRA-3M}

ANL modification of the thermal-hydraulic subchannel-analysis program COBRA-III. It includes detailed thermal models of fuel pin and duct wall. It is especially suitable for analyzing small pin bundles used in in-reactor or out-of-reactor experiments.

The features of COBRA-3M can be summarized as follows:

o It contains all the analysis capability of the COBRA-III program.

- A thermal model of the fuel pin allows calculation of fuel and cladding temperatures at steady state or during transients by specifying power density.

- It can handle nonuniform mass and power distributions within a fuel pin.

- It takes into consideration the temperature dependency of material properties and conductance of the fuel-cladding gap.

- A thermal model of the duct wall allows calculation of temperatures of the subassembly duct wall at steady state or during transients.

- Heat generation in the duct wall is allowed.

o The effect of heat loss to the surroundings can be simulated by specifying a time-dependent bypass-flow temperature, and a 
heat-transfer coefficient between the duct wall and the bypass flow for each axial node.

- Calcomp plots of steady-state axial or radial coolant temperature profiles can be generated. For comparison purposes, experimental data can also be included in these plots.

- The fuel pin temperature profile definition is obtained from a matrix of 10 radial nodes and 20 axial nodes in each fuel pin.

o The fuel heat of fusion is taken into account, thus permitting the calculation of fuel melting.

- There is restart capability.

In addition to the documented version, there is an undocumented version that has the following features:

- Duct wall and cladding can be different materials.

- Expanded dimensions permit calculation of a symmetric 37 pin bundle with the same amount of core and time as previously used for a 7 pin bundle.

o Free form input.

o Input and output in SI units.

\section{COBRA IV}

COBRA-IV-I includes a11 the previous capabilities of COBRA-III C plus the following expanded computations capability:

- Very large bundles such as a full 217-pin wire-wrapped bundle can now be considered with typical running times of 5 minutes per wire wrap pitch on a CDC-7600. This has been made possible by using storage compaction techniques, auxiliary storage devices and an iterative solution procedure.

o The subchannel layout and card input for wire-wrapped bundles can be generated automatically by using a auxiliary program supplied with the code.

- The program size capability is easily changed by using an auxiliary program to generate a complete, consistent set of 
dimensions and common blocks according to user selected options. These can then be inserted in place of existing dimensions in COBRA to accommodate a wide range of problem slzes.

- Core analysis problems can consider a thermally conducting wall which can conduct heat between two channels on opposite sides of the wall.

- The fuel rod heat conduction model includes axial conduction and variable thermal conductivity. Also, each rod may consist of several materials if desired. The storage requirement for the fuel model has been reduced by a factor of two with no loss in accuracy or increase in running time by using an orthogonal colocation numerical procedure.

- Correlations are included to calculate the physical properties of superheated steam for water reactor applications. Heat transfer correlations are also included for subcooled, boiling and superheated conditions.

- "Dump and Restart" capabilities are included.

- Line printer plotting capability is included to plot pressure drop, mass flux, enthalpy and/or crossflow versus axial position for all of a specified number of gaps and channels.

- The two-phase flow model and implicit computational approach used previously for COBRA-III $C$ are retained.

- A significantly improved numerical solution procedure has been developed for COBRA-IV to enhance its range of application. A pressure-velocity method which is explicit relative to momentum convection is used. This advanced numerical capability is present1y limited to incompressible, but thermally-expandable flows. Two-phase flows are limited to homogeneous, thermalequilibrium conditions.

- The advanced numerical procedure allows arbitrary plenum pressure and/or flow boundary conditions to be used to drive transients and bouyancy-dominated flow redistribution, flow reversals, coolant expulsion, reentry and recirculation, and severe flow blockages can be considered.

\section{Limitations}

There are several areas of analytical work that require considerably more attention and experimental evaluation: 
1. General two-phase flow modeling is a major problem area and work is needed both analytically and experimentally. Presently available models such as homogeneous, separated slip flow, and void drift have a limited range of applicability for transient sodium boiling under LMFBR accident conditions. Separated slip flow modeling is valid provided that separated phases have uniform properties on mass flux in regions they occupy in the subchannels. This model breaks down for gross departures from psuedo-homogeneous flow, such as annular flow where liquid at the walls has a lower velocity than entrained droplets. More complete models are needed to allow a more general treatment of transients, turbulent mixing, thermal non-equilibrium and possibly countercurrent liquid vapor flow under low mass flux conditions. Some of these phenomena are especially important for boiling liquid metals.

2. The general areas of transient code verification are very weak. There are presently no data for even single phase transient flow distribution in rod bundles. Some thermal transient data exist, but the flow behavior must be inferred from analysis. Steady-state correlations for friction factors, subcooled void fraction, bulk void fraction and two-phase friction multiplier must be used for transient calculations when no others are available. Experiments are needed to verify the subchannel methods for both single and two-phase flow transients.

3. More general implicit numerical schemes need to be developed for use in subchannel analysis so that time step restrictions can be removed. An implicit scheme is used in COBRA-III C, but is limited to the positive flow direction. For flow reversal transients, explicit methods are used but are limited to time steps less than the transient time through a mode.

4. Although COBRA-IV-I permits the calculation of large pins and the calculation at conditions such as flow reversals, it provides only limited fuel pin temperature profile information because it has only 4 radial modes in each fuel pin and it cannot accommodate fuel melting.

\section{Future Efforts}

1. Improve physical two-phase flow modeling.

2. Studies of flow distribution in wire wrapped bundles with water and LWR bundles containing flow blockages. 
3. Continued attention to determination of input parameters (friction factors, eddy mixing coefficients, forced flow diversion factors, etc.) to reduce uncertainty of choice for design calculations. This will be accomplished through extensive comparison with experimental data.

4. Continue effort for transient multichannel sodium boiling.

5. Investigate application of finite element methods to the subchannel problem. The basic problem to be overcome is the application of the finite element approach to a convection dominated set of flow equations. Present finite element approaches remove convection by assumption and limit the analysis to diffusion dominated equations.

\section{Computer Operation}

A. COBRA-3M

1. Operational on IBM $370 / 195$ at ANL.

2. Logistics: requires $250 \mathrm{~K}$ bytes of core and batch operation; written in FORTRAN IV.

3. Typical Problem Running Time: For a problem with 4 pins, 14 pin sectors, 8 coolant channels, 20 axial nodes and 11 radial nodes in each fuel pin sector, the running time on the IBM $370 / 195$ is 4 minutes for a transient with 40 time steps in 4 seconds of real time.

4. Code Validation:

a) ANL-8131, W. W. Marr, "COBRA-3M: A Digital Computer Code for Analyzing Thermal-Hydraulic Behavior' in Pin Bundles: ANL, Argonne, I11. (March 1975).

b) ANL-76-16, R. C. Doerner et. a1., "Final Summary Report of Fue1 Dynamics Tests $\mathrm{H} 2$ and E4," Argonne National Lab, Argonne, I11. (February 1976).

B. COBRA-IV-I

1. Operational on CDC-6000 and 7000 machines at PNL.

2. Logistics: requires $202 \mathrm{~K}$ words of core peripheral devices for input and output, and four scratch units; written in FORTRAN. 
3. Typical Running Time: A steady-state calculation for a 7 pin wire-wrapped bundle with 12 coolant channels and 36 axial nodes requires 5.2 seconds of $\mathrm{CDC}-7600$ time. A transient calculation for a 3 pin bundle in flowing sodium, which is surrounded by a thermally conducting can, which, in turn is surrounded by an annulus of sodium was run for 2 seconds of real time, with approximately 200 time steps. The model included 7 sodium channels and 25 axial nodes. The running time was 25.2 seconds on the $\mathrm{CDC}-7600$.

4. Code Validation:

a) C. W. Stewart, et. al., "Core Thermal Model: COBRA IV Development and Applications" PNL, Richland, Washington, (January 1977).

b) C. W. Stewart et. al., "COBRA IV: The Model and the Method," PNL, Richland, Washington, (March 1977).

Interface/Overlap

-/THT, SIMPLE, ORRIBLE

\section{References}

1. COBRA-I: D. S. Rowe, Crossflow Mixing Between Parallel Flow Channels During Boiling, Part I. COBRA--Computer Program for Coolant Boiling in Rod Arrays, BNWL-371, Pt. 1. Pacific Northwest Laboratory, Richland, Washington (March 1967).

2. COBRA-II: D. S. Rowe, COBRA-II: A Digital Computer Program for Thermal Hydraulic Subchannel Analysis of Rod Bundle Nuclear Fuel Elements, BNWL-1229. Pacific Northwest Laboratory, Richland, Washington, (February 1970).

3. COBRA-III: D. S. Rowe, Interim Report. COBRA-III: A Digital Computer Program for Steady-State and Transient Therma1-Hydraulic Analys is of Rod Bundle Nuclear Fuel Elements, BNWL-B-82, Pacific Northwest Laboratory, Richland, Washington, (1971).

4. COBRA-III C: D. S. Rowe, COBRA-III C: A Digital Computer Program for Steady-State and Transient Thermal-Hydraulic Analysis of Rod Bundle Nuclear Fuel Elements, BNWL-1695, PNL, Richland, Washington, (March 1973). 
5. COBRA-III M: W. W. Marr, COBRA-III M: An IBM 360 Computer Code for Analyzing the Thermal-Hydraulics of Pin Bundles, ANL-8131 Argonne National Laboratory, Argonne, Illinois, (March 1975).

6. COBRA IV-I: C. L. Wheeler et. al., COBRA-IV-I: An Interim Version of COBRA for Thermal-Hydraulic Analysis of Rod Bundle Nuclear Fuel Elements and Cores, BNWL-1962, PNL, R1chland, Washington, (March 1976). 
COBRA-3M/HEDL

\section{Purpose}

The COBRA-3M/HEDL Code is a thermal hydraulics code intended for single fuel pin or small fuel pin bundle thermal transient analysis. The code is closely related to COBRA-3M Code(I), from which it was derived, and is specifically tailored for TREAT and SLSF experiment analyses.

\section{$\underline{\text { Status }}$}

A. Development: The COBRA-3M/HEDL code was developed by the Materials Division of the Hanford Engineering Development Laboratory by modifying the COBRA-3M code.

B. Availability: The code is operational, but its deviations from the COBRA-3M code have not been documented except for extensive comments in the main routine detailing the revised input formats.

C. Utilization: The code is used extensively for the design and analysis of TREAT and SLSF experiments. The code is also used for single pin design transient analysis, and in this use, is employed to generate transient thermal input data for BEHAVE-SST and other fuel pin transient mechanical analysis codes.

\section{$\underline{\text { Problems Solved }}$}

The COBRA-3M/HEDL code is used to predict thermal hydraulic behavior of fuel pins, coolant and adjacent structure (duct walls), starting at steady-state and extending through a transient to fuel pin cladding fallure or the onset of coolant boiling. The calculation is extended into low quality coolant boiling by suppressing the expansion of vapor by factors up to 50 (input by user). The validity of built-in and/or available correlations for pressure drop and heat transfer phenomena are not known after the onset of boiling, but are presumed adequate at low qualities.

The code does not model a complete loop and cannot predict recirculating feedback effects. Forcing functions for power, system pressure, coolant inlet enthalpy, and coolant flow permit such variations to be accounted for where information on the variations are available from an independent source. 
Models

Coolant thermal hydraulic phenomena modeling is basically unchanged from COBRA-3M $(1,2)$. The only differences are:

- Sodium properties can be calculated using relationships from Reference 3. This feature is optional; tables of properties may be input if the user prefers.

- As aforementioned, coding has been added to permit the expansion on coolant vaporization to be reduced. Reduction of volume expansion by factors of 25 to 50 allows enough improvement in the numerics to continue the calculation into the low quality boiling region. This feature is optional.

- Heat generation can be specified in coolant, as part of the option allowing energy deposition partition among fuel, structure, and coolant. This is discussed more fully later.

Most of the modifications made to COBRA-3M to produce COBRA-3M/HEDL were made to the fuel pin heat transfer model. Again, the basic machinery has not been altered. Details are given below.

1. Transient Gap Conductance Model

The HEDL transient gap conductance model has been installed. This model is basically the same as the gap conductance model used for steady-state in the SIEX code(4). Gap closure is calculated using differential thermal expansion based on volume average temperatures. Steady-state gap conductance, gas conductivities, and "jump" distances as calculated by SIEX are input to COBRA; in an initial pass through steady-state, the corresponding fuel-cladding gaps are computed and stored along with steady-state temperatures for use as reference values during the transient. This is followed by a second steadystate pass corresponding to the start of the transient. The model accounts for gas conductivity variation with temperature, for radiation heat transfer, and for solid-to-solid conductance (limited to $1000 \mathrm{Btu} / \mathrm{hr}-\mathrm{ft}^{2}-\mathrm{O}_{\mathrm{F}}$ [0.567 watts $/ \mathrm{cm}^{2}-\mathrm{O}_{\mathrm{K}}$ ] maximum) after contact between fuel and cladding. The model used in COBRA is the same as that for SIEX, excepting that the "jump" distance (sum of the pressure sensitive term and the term accounting for incomplete energy exchange at surface) is evaluated at steady-state and used as a constant. 


\section{Fue1 Melting}

The version of COBRA-3M documented in Reference 1 provided only cosmetic treatment of fuel melting. Temperature output was treated to show a thermal arrest, but internal temperatures showed no thermal arrest, being calculated using the liquid specific heat at all temperatures equal to or greater than the solidus temperature. The most recent version of COBRA-3M treats fusion properly, and COBRA-3M/HEDL has been similarly modified.

\section{Energy Partition}

Coding has been modified to provide for partitioning fission energy deposition among fuel, coolant, cladding, and structure. This feature is optional. If a fraction of 1.0 is input, all heat is deposited in the fueled region, except that (as before) a pretransient gamma heating rate may be input for the duct regions. If a fraction of less than 1.0 is input, the balance of the heating rate is deposited in cladding, coolant, and duct, and is prorated on a mass-weighted basis.

\section{Limitations}

The code has been converted to a dynamic allocation basis for the major arrays. Nevertheless, principal maximum dimensions are as follows:

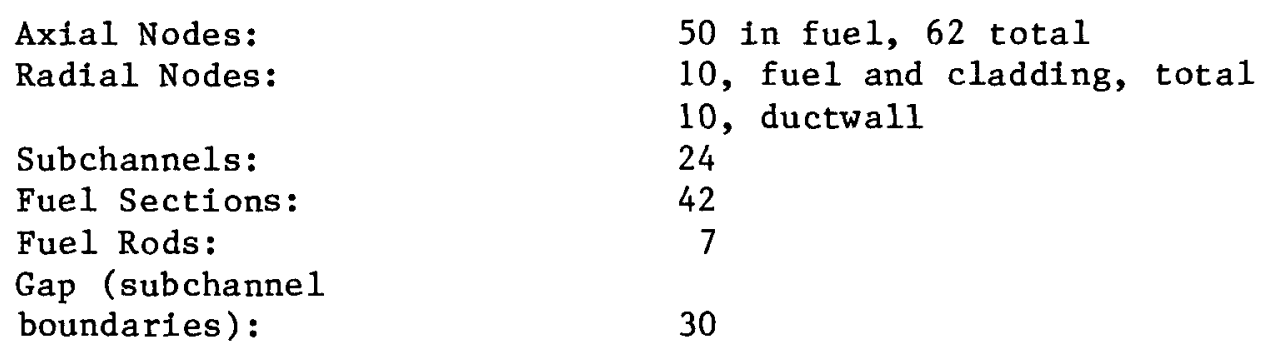

Although COBRA is theoretically capable of modeling wire-wrap forced diversion, the option is almost impossible to operate, and is extremely expensive (long running). The code does not recognize pressure boundaries, other than that flow is balanced among subchannels so that all have the same pressure drop across each axial node.

One set of axially varying restructuring can be specified for irradiated fuel pins. Up to one set of steady-state gap conductance specifications per fuel rod can be specified. 
The principal physical phenomena limitations inherent in COBRA-3M/HEDL are the same as for COBRA-3M.

\section{Future Efforts}

No effort is planned to significantly reduce the present code limitations. Limited documentation is being considered.

\section{Computer Operation}

The code is operational on the Berkeley CDC-7600. Small and large core memory requirements are 113000 octal and 47000 octal, respectively, for a typical ANL $E$ or $H$ series TREAT test analysis. In such a problem set up for 21 fuel sections, 10 radial nodes and 20 axial nodes, 140 time steps required 569 seconds computation time. Running times for other problems could be roughly estimated by ratioing the above mentioned time by the product of the number of radial nodes, fuel sectors, axial nodes and time steps to the corresponding product for the above example.

The code has yielded good matches to TREAT and SLSF test outlet coolant and duct temperatures, and fuel melt fractions (where available). It has been used to analyze ANL TREAT tests H3, H4, H5, E6, E7 and E9, and ANL SLSF test P-1. These comparisons have not been documented at this time.

\section{Interface/Overlap}

The code has been fitted with a routine to generate a file of transient temperatures and melt fraction suitable for input to the BEHAVE-SST code.

The code has no plotting capability at this time.

\section{References}

1. W. W. Marr, COBRA-3M: A Digital Computer Code for Analyzing Thermal - Hydraulic Behavior in Pin Bundles, ANL-8131, March 1975.

2. D. S. Rowe, COBRA-IIIC: A Digltal Computer Program for SteadyState and Transient Thermal - Hydraulic Analysis of Rod Bundle Nuclear Fuel Elements, BNWL-1695, March 1973.

3. W. H. Yunker, Standard FFTF Values for the Physical and Thermophysical Properties of Liquid Sodium, WHAN-D-3, July 6, 1970 . 
4. D. S. Dutt and R. B. Baker, SIEX A Correlated Code for the Prediction of Liquid Metal Fast Breeder Reactor (LMFBR) Fuel Thermal Performance, HEDL-TME 74-55, June 1975. 
COMCAN

\section{Purpose}

The common cause analysis (COMCAN) code analyzes fault tree minimal cut sets for single secondary events that could cause occurrences of each event in the minimal cut set.

\section{$\underline{\text { Status }}$}

A. Development: Both versions were developed at the INEL (EG\&G Idaho, Inc.).

B. Availability: The versions of COMCAN which have been or are in the process of being made operational are:

COMCAN - Released in 1976 (Ref. 1)

COMCAN II - Developmental at the INEL on the CDC Cyber 76.

The code will be operational by September 1977 and will be released by December 1977 .

C. Utilization: The codes are being tested and evaluated.

Problems Solved

COMCAN has performed successfully on sample problems such as that described in Reference 1 . The code uses as input minimal cut sets obtained from the reliability analysis system (RAS) code (Ref. 2). The analyst mist also input secondary event susceptibilities for those basic events appearing in the minimal cut sets. The secondary events are listed generically in four categories in Reference 1 . The code examines the events in each minimal cut set for common susceptibility to generic secondary causes from each category.

Location information can also be input by the analyst. The code uses this information to locate minimal cut sets containing basic events from components which have no physical barrier which separates any two of the components from a single occurrence of a secondary event to which all components are susceptible. Susceptibility indices can be assigned to the basic events. The indices can be used to limit the output to those minimal cut sets which are most susceptible to specific generic secondary causes. 


\section{Mode1s}

Both versions of COMCAN use the common cause failure analysis (CCFA) methodology described in Reference 1.

COMCAN: This version requires, as input, minimal cut sets obtained from other fault tree analysis codes.

COMCAN II: The fault tree itself is input to this version. The code can locate minimal cut sets, of any order, which are susceptible to single secondary events. This is accomplished by separately examining branches of the tree. Pertinent information is saved from each branch; intermediate cut sets that are not susceptible to a common cause are discarded as the code works its way up the tree. Saved information is decoded to provide an output listing all minimal cut sets susceptible to a single secondary failure event.

\section{Limitations}

COMCAN is limited to examining the fault tree minimal cut sets obtained from other qualitative analysis codes. The output of these codes, when large trees are involved, is usually limited to cut sets of order three or less. Thus higher order cut sets are not subjected to CCFA. COMCAN II will not have this limitation.

\section{Future Efforts}

Conversion of COMCAN II to the IBM $360 / 75$.

\section{Computer Operation}

1. COMCAN is operational on the IBM $360 / 75$ and CDC Cyber 76. COMCAN II will be operational on the CDC Cyber 76 by September 1977 .

2. Logistics: COMCAN operates in batch mode, has dynamic storage capabilities, is written in FORTRAN IV, and requries some form of external storage such as disk or drum. It requires the use of the INEL environmental package for the dynamic storage capabilities.

3. Typical Problem Running Time: For the sample problem included in Reference 1, COMCAN took 0.4 seconds on the CDC Cyber 76 (and 1 minute, 16 seconds on an IBM $360 / 75)$, to analyze 40 minimal cut sets. This included compilation, link-edit, and execution with all options exercised. 
4. Code Validation: No comparisons of either version of COMCAN have been made with any other CCFA code.

Interface/0verlap

COMCAN requires minimal cut sets obtained from RAS.

\section{References}

1. G. R. Burdick, N. H. Marshal1, and J. R. Wilson, COMCAN - A Computer Program for Common Cause Analysis, ANCR-1314 (1976).

2. D. M. Rasmuson and N. H. Marsha11, Preliminary User's Guide to the Reliability Analysis System, Aerojet Nuclear Company, RE-S-76-177, September 1976 (Available from ERDA-RDD). 
COMRADEX

\section{$\underline{\text { Purpose }}$}

Analysis of the effects of reactor containment and meteorology on the environmental radiation exposure resulting from reactor accidents.

\section{Status}

A. Development: Developed and under improvement at AI. COMRADEX III is current development version.

B. Availability: COMRADEX III was released in June 1975 (Reference 1). It is operational at $A I$ and $G E$; runs on the IBM $370 / 168$, and $\mathrm{CDC}-7600$.

$\underline{\text { Problems Solved }}$

COMRADEX calculates the attenuation effect of containment barriers and meteorological dispersion on radiation doses due to release of a radioactive inventory from a postulated reactor accident. The code calculates:

1. The "shine" dose resulting from the direct gamma radiation from the containment building.

2. The internal dose resulting from the inhalation of gases and aerosols in the released cloud following meteorological diffusion.

3. The external gamma and beta dose from immersion in the released cloud.

\section{Models}

\section{Inventory}

The initial radioactive inventory available at the time of the accident must be input. Release fractions for gases, halogens, fission products, and fuel and the released mass of sodium are input.

\section{Containment}

The code calculates the activity released to the atmosphere from the containment barriers, accounting for leakage from and cleanup 
(attentuation) processes within up to four barriers of containment. These barriers are modeled as concentric shells (up to four). The leakage and filtration from one shell to an adjacent she11 and from the outside shell to the atmosphere are input as variable leak rates with time. Cleanup processes within each shell may also be input to account for fallout, plateout, and forcced (filtration) cleaning. Cleanup rates are input as variable cleanup factors in time. COMRADEX III will accept leak rate and fallout data as provided from HAA-3 (s ee HAA summary).

\section{Atmospheric Dispersion}

Dispersion in the atmosphere of the radioactive plume released from containment is calculated from the model of Pasquill (References 3 and 4), or site specific attentuation factors may be input. A meandering option is included for the Pasquill model. The weather conditions may be changed three times during run.

\section{Direct Building Dose}

The radiation dose resulting from direct gamma dose potential in the containment building is based on a spherical source with a uniform distribution or radionuclides.

\section{Cloud Dose}

The external gamma dose resulting from immersion in the cloud is calculated from a planar gaussian cloud with credit for air attentuation and buildup of gammas. The external beta dose mode is calculated from an infinite uniform cloud. Local shielding is permitted.

\section{Internal Dose}

The internal dose resulting from inhalation of activity in the cloud is calculated for up to 10 organs. An input library of radiological dose factors is used. The lung dose calculation in COMRADEX III can be performed with the standard ICRP method (Reference 4).

\section{Limitations}

1. COMRADEX does not calculate depletion of the cloud by fallout, rainout, or washout, or the doses which would result from the deposited activity. 
2. The shielding of gamma radiation by air is calculated by assuming attentuation and buildup factors for $3 \mathrm{MeV}$ photons.

3. Perfect reflection of the cloud at the ground surface is assumed.

4. Aerosols are assumed to behave like gases for leakage through containment barriers.

\section{Future Efforts}

Models for depletion of released clouds by aerosol dry fallout are currently being implemented.

Interface/Overlap

CURIE, HAA, SOFIRE, SOMIX/

\section{$\underline{\text { References }}$}

1. J. M. Otter and P. A. Conners, "Description of the COMRADEX III Code," TU-001-130-053 (1975).

2. F. Pasqui11, Atmospheric Dispersion, D. Van Nostrand Company, Ltd., 1962 .

3. W. F. Hilsmeier and F. A. Gifford, Jr., "Graphs for Estimating Atmospheric Dispersion," ORD-545, July 1962.

4. Interna1 Commission on Radiological Protection, Report of Committee II on Permissible Dose for Internal Radiation, ICRP Pub. 2, Pergamon Press, New York, 1959. 
COMRADEX-H

\section{$\underline{\text { Purpose }}$}

Calculates accidental release of radioactivity from containment or confinement buildings and estimates the resulting biological dose to individuals located nearby.

\section{$\underline{\text { Status }}$}

A. Development: Written by Atomics International (AI) in 1967. In 1969 HEDL acquired the code and its development was undertaken for support of FFTF accident analyses. Further development at HEDL has been continuous since 1969.

B. Availability: COMRADEX I was documented in 1967 (Ref. 1). A Users Guide was prepared for the HEDL version in 1974 and has been updated several times since. COMRADEX-H is operational at HEDL on the CYBER-74 and an older version is operational at Brookhaven on the CYBER 7600 .

C. Utilization: COMRADEX-H was used for the FFTF FSAR, for the FFTF Containment Margins Study, and many other FFTF Radiological Studies, it was also used in the CRBRP Risk Assessment and the LMFBR Containment Comparison.

\section{$\underline{\text { Problems Solved }}$}

COMRADEX-H calculates the amount of radioactivity released from a containment or confinement structure. In this calculation it accounts for the fractions of the initial inventory released, multiple chambers within one another in the structure, and within each chamber: radioactive decay and production, fallout or similar removal mechanisms, leakage from the chamber and filtration of the leakage. COMRADEX-H will write the release and inventory information to a "source" file which may be used as input to another run for the purpose of superimposing conditions in an accident sequence.

Having determined the release from and the inventories within the structure COMRADEX-H estimates the potential biological doses to receptors located at various positions with respect to the structure as a function of time of residence. Doses calculated are: 
1. Direct - Gamma "shine" from the radioactive inventory within the structure.

2. Internal - Cumulative doses to body organs fiom radioactivity assimilated by inhalation and retained within the body during a 50 year life expectancy.

3. External - Gama "shine" from the radioactive "Plume" as it.passes the receptor.

In addition, COMRADEX-H shows the contribution of each isotope to the internal Dose to Selected Organs. COMRADEX-H writes plot files with which the program NUKARF will plot the inventories and releases ard with which the program SLYDOSE will plot dose vs. distance curves.

Mode1s

In keeping with its development using a file oriented computer COMRADEX-H was developed as a file oriented code. Input files include a data base, DATCAN, and a library, NULIB. Both of which are unique for a particular reactor or accident scenario. Leakrate and fallout rate information is input as a file, HAAOUT, which may have been written by HAA-3C or any of several other programs. A "source" file from a previous COMRADEX-H analysis may be used to superimpose conditions of an accident scenario. Files output are the "source" file and the plot file, OUTDAT.

1. Initial Inventory - An initial inventory of all significant radioactive species is required. Often a RIBD2 Analysis supplies the inventories of fission products. Inventories of activation products within the coolant and inventories of fuel and transuranic isotopes are estimated by other techniques. Elements are normally grouped as solids, halogens, nobles, and fuel but specific element groups may be established by input. The fraction of the initial inventory of each group to be released to the first chamber must be specified as input.

2. Release Calculation - COMRADEX-H calculates the release of radioisotopes from up to four containment/confinement "chambers" each within the next. The last chamber releases to the environs. Each chamber may be provided with a variable leakrate and fallout rate history. Each chamber may be assigned filters which remove certain elements and pass others; the filtration may be started at some time other than the start of the problem. In determining releases the code accounts for radioactive decay and production, leakage, fallout, and filtration in each chamber. 
3. Direct Dose - The inventory of each isotope in each chamber has been calculated; the potential dose to the receptor is found using a dose rate constant for each isotope, a building shield factor for each chamber, and the attenuation of air over the distance from the outer chamber and the receptor. The building shield factors are determined by calibrating with the program ISOSHLD.

4. Meteorology - Given as input windspeeds and either standard Pasquill Class Data (Ref. 2) or unique site data, COMRADEX-H determines the atmosphere dispersion $(X / Q)$ in accordance with the formulations given in Reg. Guide 1.4 (Ref. 3). Sector averaging, i.e. wind meandering throughout a $22-1 / 2^{\circ}$ sector, may be simulated. The meteorology data is used to determine the radioactive production and decay during windward transit and to determine both the internal and external doses.

5. Internal Dose - The internal doses are based upon the quantity of each isotope released which releases the receptor, the atmospheric dispersion $(X / Q)$, the breathing rates given in Reg. Guide 1.4 , and "F Factors." "F Factors" are dose conversion factors relating the 50 year doses for specific body organs to the curie amount of each isotope inhaled. COMRADEX-H will calculate the doses for up to fourteen organs.

6. External Dose - Considering the plume as an infinite Gaussian cloud COMRADEX-H integrates the contribution from cloud elements over a three sigma range in the downwind, crosswind, and vertical directions. The contribution from individual cloud elements is determined, much the same as the direct dose, using the dose rate constant for each isotope, and the attenuation in air over the distance from the element to the receptor.

\section{Limitations}

1. COMRADEX-H does not account for fallout during downwind transit.

2. The use of dose rate constants to determine the gamma dose potential of isotopes leads to inaccuracies.

3. The use of Simpson rule integration routines leads to instabilities when leakage or fallout rates change readily.

\section{Future Efforts}

The proposed effort will consist of the following: 
1. Streamlining the code - Many of the calculations performed by COMRADEX-H are common to a group of runs. The program will be reorganized or divided so that these common calculations will nlly need to be performed once.

2. New Features - the following features or options should be added to the code:
a. Provide option of using $X / Q$ or Pasquill meteorological data.
b. Provide option of using infinite cloud approximation for external dose.
c. Include a plume deposition term and calculate ground dose from deposited material.
d. Model close-in meteorology more accurately and include a control room dose calculation.
e. Improve direct dose calculational algorithm.
f. Change integration algorithms.

3. Document the COMRADEX-H Code and its Supplements - Full documentation of these codes is necessary for referencability.

4. Library Development - The dose conversion factors now used in the fission product library are the best available, however, the source of much of the data is somewhat dim. This data should be redefined and documented.

\section{Computer Operation}

1. Computers: $\mathrm{CDC}-6600$ and $\mathrm{CDC}-7600$.

2. Logistics: Variable memory requirement 72,200 (octa1) for single changer case to 110,000 words for four chambers. Exception is from batch mode. Several files are required (see above).

3. Typical Problem Running Time: A single chamber problem with centerline receptors will require about 100 (decimal) seconds for execution. Stacks, receptors at crosswind locations and additional chambers will require more time but a practical limit would be about 500 seconds. 
4. Code Variation: The code has been compared with hand calculations for simple cases.

Interface/Overlap

Programs which have been written or modified to supplement COMRADEX-H are:

1. ADDEM - Where severa1 COMRADEX-H executions are necessary to portray an event ADDEM is used to superimpose the plot data so that the NUKARF and SYLDOSE plots present the whole picture.

2. ADJFILE - INTRPO - CONST - HATP - These are all short programs which are used to create special effects using the leakratefallout rate files which are then input to COMRADEX-H.

3. CCLST - CCLST summarizes the CACECO output for information; it also generates leakrate data files for COMRADEX-H.

4. DATFORM - This short program summarizes the ultimate isotopic releases calculated by COMRADEX-H for use as input to the program AEC.

5. HAA3C - Although this code is self-sufficient, a portion of the SSM subroutine generates a leakrate and fallout rate file for COMRADEX-H.

6. ISOSHLD - The ISOSHLD code is used to calibrate the building shield factors input to COMRADEX-H.

7. NEWLYB - NEWLYB converts core inventory data output by the RIBD code into a library for COMRADEX-H.

8. NUKARF - This program generates plots of releases from and inventories in any containment "chamber" utilizing COMRADEX-H output data. These plots are of a suitable quality for direct use in reports.

9. RIBD - This code, long in service at Hanford, was modified to 1) model a fuel cycling scheme like that for a breeder, and 2) provide inventory data for COMRADEX-H.

10. SLYDOSE - SLYDOSE plots the doses by COMRADEX-H against distance from containment. Like NUKARF, the SLYDOSE plots are of a report quality. 
11. TRIMIT - A newly developed code which interpolates and plots leakrate and fallout rate data for COMRADEX-H. TRIMIT also modifles a sodium boiloff rate file to predict the boiloff rate of other elements and compounds.

\section{References}

1. G. W. Spangler, et. al., Description of the COMRADEX Code, Atomics International, AI-67-TDR-108, 1967.

2. Pasquil1, F., Atmospheric Diffusion, (D. Can Nostrand Co. LTD, 1962).

3. Regulatory Guide 1.4, Assumptions for Evaluating the Potential Radiological Consequences of a Loss of Coolant Accident for Pressurization Water Reactors, June 1974. 
CORTAC

\section{Purpose}

Simultaneous analysis of the coupled reactor core thermal-hydraulic, structural deflection and kinetics behavior during reactor startup and transient events.

\section{$\underline{\text { Status }}$}
A. Development: A preliminary ${ }^{(1)}$ version of CORTAC was developed by GE-FBRD and ANL. The current ${ }^{(2)}$ version was developed by GE-FBRD.

B. Availability: The versions of CORTAC which have been or are in the process of being made operational are:
CORTAC :
Operational at GE-FBRD*. Has been documented (Ref. 2) and will be released by December 1977 .
CORTAC 3-D: Being developed at GE-FBRD. W 111 be made operational by September 1978 and will be released by March 1979.
C. Utilization: CORTAC has provided the only tool for analyzing the transient response of an LMFBR core as influenced by the design of the core restraint system.

\section{Problems Solved}

CORTAC predicts core behavior during reactor startup and rise-to-power and during transient events initiated from a steady-state condition. CORTAC is unique in that it treats reactor thermal hydraulics, including assembly-to-assembly radial heat transfer and includes the reactivity feedback due to structural and thermal distortions of the core assemblies. Both the radial heat transfer and structural response are based on an axi-symmetric treatment of the reactor core system.

*W-ARD and AI have received source decks; however, it is not known at this time if the code has been made operational at these locations. 
CORTAC calculations begin from a steady-state reactor core condition based on user specifications which define initial conditions. The steady-state calculations inftialize fuel or control material temperatures, clad temperatures, coolant temperatures, duct wall temperatures, and duct deformation and force distributions. The steady-state calculations also establish the initial neutron precursor concentrations. Calculations then proceed through elther a user specified startup and rise-to-power sequence or a transient. The startup and rise-to-power sequence consists of sequential steady-state cases in which sets of user specified reactor inlet temperature, core restraint former temperatures, flow rates and power are imposed. The transient event is calculated from either a specified reactivity insertion (or power change), a specified perturbation of coolant flow, and/or a specified perturbation of reactor inlet temperature.

\section{Models}

CORTAC treats the reactor core system as an axisymmetric model consisting of a central cylindrical region and up to fifteen concentric annular regions. The central region can be occupied by a fuel or control assembly. The balance of the radial regions consist of inner core, outer core, radial blanket and reflector assembly regions. Different sized fuel rods can be specified for each of the 16 radial regions. The radial periphery is bounded by static restraint rings (core restraint formers). Axially, the reactor core is represented by a grid plate, shield region, lower and upper axial blankets, active core, plenum region, and a top section. There is a total of thirty axial sections.

The thermal-hydraulic simulation includes heat transfer between radial regions, gamma and neutron heating of structure dnd coolant, and timedependent coolant flow rates within and between each radial region. To simulate assembly temperature distributions which dictate the critical channel temperature gradients, each radial region is subdivided into a maximum of nine nodes. These nodes consist of an inboard channel wall, a coolant node adjacent to the outboard su face of the inboard channel wall, four interior nodes ( $f$ uel, cladding and coolant), a coolant node adjacent to the inboard surface of the outboard channel wall, an outboard channel wall, and an outboard bypass coolant node. The transient temperature equations use either of two methods: a recently developed rigorous conduction-convection heat transfer computational technique or a modified version of one of the more standard simplistic techniques. From the lower axial blanket through the plenum region, all of the radial region,temperatures equations are solved simultaneously.

Structural response of the core assemblies is simulated by using a structural subroutine adapted from the computer program NUBOW $(3)$. 
Temperatures from the thermal-hydraulic simulation are the driving functions for the structural response. The structural model includes two-point support of the core assemblies at the grid plate elevation, interactions of adjacent assemblies at load pad planes, and interaction of the peripheral assemblies with the core restraint boundary. Local compliance at the grid plate support points and at the load pads is provided in addition to the beam-type flexibilities of the assembly structural members. Circumferential loading of the assemblies is treated in addition to radial interactions. Gaps between adjacent load pads and nose-piece/receptacle clearances are also treated.

The transient prompt neutron and precursor densities are determined by the standard point kinetics equations and are integrated by the procedure outlined by McCormick ${ }^{4}$. Separate time step controls are provided for the kinetics and thermal-hydraulics since the thermal response is much slower than that of the kinetics. Reactivity feedback calculations are provided for scram, Doppler, axial expansion, radial expansion and material density changes. Provisions are made for inserted or programmed reactivity changes.

CORTAC was developed specifically for the transient analysis of LMFBR core restraint systems for perturbations near normal operating conditions. The type of perturbations considered are: inlet flow changes, inlet coolant temperature changes, reactivity perturbations and programmed power changes. This code, however, can be employed for transient events in which neither fuel melting nor sodium boiling occurs. In addition, CORTAC can be used for low-flow transients as long as buoyancy effects are small compared to forced convection. This means that CORTAC can be used for the analysis of reactor startup and shutdown. The longer term startup and rise-to-power process is handled by running a series of steady-state problems at selected flows and powers.

CORTAC has been programmed to calculate reactivity feedbacks with or without the reactor kinetics option. This means that the various reactivity feedbacks can be examined with programmed power. This option is very useful in studies aimed at evaluating core restraint parameters such as pad-to-pad spacing and axial positioning of the load pad support planes.

Under the reactor kinetics option, power can be altered by perturbing inlet temperature, the flow rates, or by external reactivity addition. These three perturbation modes, of course, can be exercised using programmed power; however, the power is governed by user input. These perturbation modes coupled with the reactor kinetics permit the analyst to evaluate overall reactor stability on a real-time basis. During more extreme transient events in which the reactor power rises sharply 
or the coolant temperature becomes excessive, the code scrams the reactor based on a power, power-to-flow ratio and/or coolant outlet temperature set-points.

The structural deflection calculations, the essential portion of core restraint system evaluations, can be bypassed if it is desired to utilize the code for "standard" reactor core system transient analyses (i.e., without radial feedback).

At the option of the user, the code runs one time step behind on the temperature-dependent reactivity feedbacks or employs an iterative feedback extrapolation. When the first option is employed, the feedback and kinetics calculations are performed before the temperature calculations and care must be exercised in selecting the maximum time step size when external sources (programmed) of reactivity are employed. The reactivity extrapolation option can only be used in conjunction with the less rigorous conduction-convection heat transfer method. The time step size is controlled on allowable changes in flow, inlet temperature, nodal temperatures, and reactivity additions per time step.

The individual modeling assumptions employed in the formulation of CORTAC are listed below:

1. The reactor core system can be treated as axisymmetric.

2. The reactor core system geometry is maintained.

3. The relative power distribution is invariant.

4. The radial power distribution can be represented as piecewise linear.

5. The radial energy flux is uniform over each axial node.

6. Mechanical inertia can be ignored.

7. Heat capacity of the fission gas is negligible.

8. Radial heat transfer between radial regions is negligible for axial nodes below the lower axial blanket and above the fission gas plenum.

9. Axial heat conduction can be neglected.

10. All structural elements can be neglected.

11. Al1 properties are constant except for flow-dependent heat transfer coefficients. 
12. The core restraint formers remain at a constant temperature.

\section{Limitations}

In addition to the limitations inherently imposed by the foregoing modeling assumptions, there are several aspects of the conduction-convection heat transfer modeling that may limit the use of CORTAC. These aspects are discussed in the paragraphs to follow.

In the formulation of the axial convectiun portion of the rigorous conduction-convection heat transfer method, it was found necessary to not permit any axial node to be completely swept out during a single time step. Hence, with this heat transfer option there is an inner loop in the transient temperature calculations that subdivides the time step permitted by the main part of the program. This means that multiple temperature time steps can be performed during a single problem time step. In addition, this option subdivided the coolant axial segments into subsegments corresponding to length equal to the velocity multiplied with the time step size. This is required to track segments with linear temperature profiles. This subdividing results in triple subscripted variables. In order to keep the core memory requirements manageable, it was found necessary to "average" similar segments. This process has been extensively checked out and it was found that the segment averaging produces only slightly different results. However, it should be kept in mind that longer axial segments and/or lower flow rates coupled with short time steps maximize the segment averaging process.

The other significant aspect of the coolant sweep time criteria discussed above is that problem running times can become excessive when high coolant velocities ar 2 employed with short axial section lengths. For example, a velocity of $6 \mathrm{~m} / \mathrm{sec}$, an axial section length of $10 \mathrm{~cm}$, requires 60 loops through the transient temperature calculations for every second of problem time. Since coolant velocities cannot be altered, short axial section lengths should be avoided to minimize running times.

The simplistic conduction-convection heat transfer option is also limited to a multiple of axial node sweep times. In general, it is recommended that the maximum time step be a multiple of 3 or less of the minimum sweep times to maintain sufficient accuracy.

\section{Future Efforts}

Near term efforts are directed toward the release of CORTAC. Long term efforts are underway to develop CORTAC 3-D. CORTAC 3-D will eliminate the axi-symmetric assumption as it will treat individual core assemblies thermal-hydraulically and structurally. 


\section{Computer Operation}

1. Operationa1 Systems: CORTAC is operational on the CDC-7600 at Lawrence Berkeley Laboratory for use at GE-FBRD.

2. Operational Logistics: Core memory is limited by the capacity of the CDC-7600 sma11 core which is $170 \mathrm{~K}$ octal. The present version of CORTAC requires $160 \mathrm{~K}$ octal. This figure applies to both axtal convection options. The mode of operation is batch and the programming language is FORTRAN IV. A special systems routine is called in to generate random numbers between 0 and 1 for use in the structural subroutine RELAX.

3. Typical Problem Running Time: Running times on the CDC-7600 were obtained by examining a spectrum of problems including ramp reactivity insertions, step reactivity insertions, a mild flow ramp and a flow coastdown. Both reactivity feedback options are included; however, only the linear average* axial convection option was employed with a sweep factor of 3.0. Structural calculations were included. A brief description of the geometry is listed below:

$\begin{array}{ll}\text { Number of Axial Nodes } & 27 \\ \text { Number of Rings } & 15 \\ \text { Number of Nodes/Rings } & 17 \\ \text { (Including fuel and clad) } & \end{array}$

The average problem time was 24 seconds and the corresponding average CP seconds was found to be 156 . This results in an average of about 6.5 seconds of computer time consumed for each second of problem time. Since the above figures apply for a sweep factor of 3.0, this scaling depends on the time step size used. It should be noted that the transient temperature subroutine (TTEM) affords the major consumption of time.

4. Code Validation: The CORTAC structural verification portion results have been completed and submitted to ANL for comparison with results obtained with the core restraint structural codes NUBOW 2-D, NUBOW 3-D, and PARABOW. Verification of feedback reactivities, kinetics response, and portions of the transient heat transfer response has been obtained using benchmark problems for comparison. Radial heat transfer between adjacent assemblies is presently in the process of verification by comparing CORTAC results with the WARD TRITON 3-D

*Based on a limited number of comparisons, the more rigorous temperature tracking method is from 5 to 10 times more expensive to run. 
thermal-hydraulic code. In addition, tentative plans have been made to compare CORTAC calculations with transient results in an operating reactor. A plan for completion of the verification is in phase and various CORTAC comparisons were made to date.

\section{Interface/Overlap}

The structural response portion of CORTAC (subroutines STRUCT and RELAX) were developed from the computer program NUBOW ${ }^{(3)}$. However, there are a sufficient number of differences between CORTAC and NUBOW that makes it impractical to utilize the CORTAC steady-state output in NUBOW.

\section{References}

1. P. J. Fulford, J. H. Fox, and T. R. Yackle, "CORTAC - A Core Restraint Transient Analysis Code: Preliminary User's Manual," July 1975, ANL-CT-76-10.

2. J. N. Fox, T. R. Yackle and P. J. Fulford, "CORTAC - A Core Restraint Transient Analysis Code: User's Manual, August 1975, GEAP-14115.

3. G. A. McLennan, "NUBOW: A Fortran IV Program for the Static Structural Analysis of Bowed Reactor Cores," Apri1 1974, ANL-8068.

4. W. T. McCormick, Jr. and K. F. Hansen, "Numerical Solution of the Two-Dimensional Time-Dependent Multi-group Equations," The Effective Use of Computers in the Nuclear Industry, Apri1 21-23, 1969 (CONF-690404), p. 76 . 
COTEC

\section{Purpose}

Calculation of subchannel coolant temperature distribution in wire wrapped core assemblies.

\section{$\underline{\text { Status }}$}

A. Development: Initially developed by WARD-FFTF; later improved by WARD-CRBRP.

B. Availability: Operational at WARD. Input description, but not user's manual, available.

C. Utilization: Used at WARD for subchannel analysis of FFTF driver assemblies, CRBRP and PLBR fuel and blanket assemblies.

\section{Problems Solved}

The COTEC code calculates for wire wrapped rod bundles:

1. Subchannel flow distribution;

2. Subchannel coolant temperature distribution;

3. Rod cladding temperature (accounting for effect of uncertainties hot channel factors - if so desired).

\section{Models}

COTEC is a subchannel analysis code which calculates the hydraulic field by relying on empirically calibrated models rather than on a rigorous solution of the momentum equation. The reason for this simplification is the very significant reduction of computer running time in respect to codes like COBRA and THI-3D which solve the momentum equation. Conservation of mass and energy equations are the solved by COTEC, once the flow field is determined, using a forward marching technique. Four phenomena are considered by COTEC in describing the heat and mass transfer between subchannels. Two of these phenomena are dependent upon the relative position of the wire in respect to the gap between rods: a) pumping, which accounts for variation in flow area and hydraulic diameter of the channel due to spiraling of the wire; and b) sweeping, which accounts for 
the fraction of fluid following the angle of the wire and swept in an adjacent subchannel. The above two mechanisms account for the interchange of thermal energy between adjacent subchannels due to physical interchange of mass. The other two phenomena, which only interchange thermal energy, are thermal conduction and turbulent mixing. These four mechanistic models are calibrated by comparing COTEC predictions against pertinent experimental data.

Once the coolant flow and temperature distribution in the assembly subchannels are calculated, the cladding temperature in each rod can be calculated for nominal conditions or accounting for the effect of hot channel factors, using the same technique and procedure as in NICER. This will allow immediate determination of the hot rod in the assembly (rod with the maximum cladding temperature).

\section{Limitations}

1. Solution of hydraulic field relies on input of experimentally callbrated constants;

2. Can analyze only regular geometries, i.e., cannot consider offset or bowed rods;

3. Does not consider buoyancy effects;

4. Rellability of calculated results is limited to turbulent flow conditions;

5. Limited to analysis of fuel and blanket assemblies;

6. Maximum number of rods per assembly: 271 .

\section{Future Efforts}

1. Extend capability of the code to analyze control and radial shield assemblies, taking advantage of parallel development conducted for TRITON;

2. In general, incorporation in COTEC of pertinent modifications and improvements performed on TRITON.

\section{Computer Operation}

1. W-NES CDC-7600; 
2. Logistics:

a. Core memory requirements: program is dynamically stored; memory requiremens are a function of the number of pins, channels and axial steps;

b. Special peripherals: three sequential and three random access files on high speed rotating mass access;

c. Mode of operation: batch;

d. Programming language: FORTRAN-IV;

e. Compiler requirements: FORTRAN-IV Compiler;

f. Special system routines: standard Westinghouse NES-CDC 7600 system routines; random file accessing routines; W-NES MATRIX routine; $W$-NES mathematical routines;

3. Typical Problem Running Time: a 217 rod (438 channels) fuel assembly, with an assembly lengths of 112.36 inches and an 0.5 inch calculational increment (225 axial steps) requires about $43 \mathrm{sec}$. running time $\left(\sim .049 \mathrm{CRU}^{\circ} \mathrm{s}\right)$ and $71_{8} \mathrm{~K}$ small core storage on the W-NES CDC 7600 .

4. Code Validation: COTEC has been calibrated and verified against a large amount of experimental data including the HEDL $217 \mathrm{pin}$ mixing test, ANL 91 pin tests, ORNL 19 pin heated rod test, WARD $11: 1$ scale air flow mixing and velocity distribution test. COTEC predictions have also been compared against parallel predictions by other subchannel analysis codes such as COBRA, THI-3D, ENERGY, etc.

\section{Interface/Overlap}

TRITON, NICER/COBRA, THI-3D, SUPER ENERGY, ORRIBLE, SIMPLE.

\section{$\underline{\text { References }}$}

1. E. H. Novendstern, "Mixing Model for Wire Wrap Fuel Assemblies," Trans. Am. Nucl. Soc., 15, 866-867 (1972). 
DACRIN

\section{Purpose}

Calculation of the dose to specific organs resulting from acute or chronic radionuclide inhalation.

\section{$\underline{\text { Status }}$}
A. Development: Developed at Battelle Northwest Laboratories.
B. Availability: DACRIN is documented in Refs. 1 and 2. It is operational at BNWL and runs on a CYBER 74 machine.
C. Utilization: Has been used for the assessment of potential and releases during potential transportation accidents. accidental releases from fuel-cycle facilities

\section{Problems Solved}

DACRIN has been developed to estimate the radiological exposure to the respiratory tract and other organs following an accidental or chronic release of radionuclides. The program calculates:

1. atmospheric dispersion,

2. the uptake and retention of inhaled aerosols by various compartments of the respiratory tract,

3. the transport and retention of these inhaled nuclides to and by other organs, including the G.I. tract, and

4. the dose to 18 organs and tissues from inhalation from any one or combination of radionuclides considered by ICRP with a maximum of 10 organs per run.

Mode1s

1. The model of the respiratory tract adopted by the Task Group on Lung Dynamics (Ref. 3) forms the general basis for the mathematical models developed to calculate the dose from the inhalation of radionuclides. 
2. Input to the code, in its simplest form, consists of a few program control variables, the duration of inhalation exposure, ventilation rate, the time-interval within which the dose is delivered, the organs of interest, the quantity of the radionuclides inhaled, its solubility class, and its particle size.

3. The most complex version of the code is that which includes an atmospheric dispersion model. Although the model is based on the generalized Gaussian distribution, Sutton's parameters, Hanford equations, or Pasquill's curves can be used to estimate the standard deviations of the cloud concentration in the crosswind lateral and vertical directions. Values for various weather categories and wind speeds are provided in the text for these three methods.

4. The ICRP G.I. tract model (Ref. 4) is used to describe movement of material within the G.I. tract compartments.

\section{Limitations}

1. The contribution to the pulmonary lung dose from daughter nuclides formed there is computed indirectly by utilizing weighted values of the effective energy emitted by the daughter nuclides in the chain instead of performing a direct calculation as would be preferred when implementing the refined lung model.

2. The code requires the determination or assumption of the mass median aerodynamic diameter of inhaled material.

3. DACRIN does not have the capability to determine the organ dose to a variety of population groups or individuals whose characteristics may vary considerably from those assumed. The code is not capable in its present form of calculating the dose to the organs of individuals of different ages without extensive changes being made in its data base.

\section{Future Efforts}

Further development will be oriented toward the addition of a model to compute exposures via ingestion.

Interface/Overlap

SUBDOSA /ACRA, COMRADEX, INREM, INDOS 


\section{$\underline{\text { References }}$}

1. J. R. Houston, D. L. Strenge, and E. C. Watson, "DACRIN - A Computer Program for Calculating Organ Dose from Acute or Chronic Radionuclide Inhalation," BNWL-B-389, UC-41, December 1974.

2. D. L. Strenge, "DACRIN - A Computer Program for Calculating Organ Dose from Acute or Chronic Radionuclide Inhalation: Modification for Gastrointestinal Tract Dose," BNWL-B-389 SUPP, UC-41 Special Distribution, February 1975.

3. 'Task Group on Lung Dynamics for Committee II of the International Commission on Radiological Protection," Health Physics 12, 173, 1966.

4. The International Commission on Radiological Protection, "Report of Committee II on Permissible Dose for Internal Radiation," ICRP Publication 2, Pergamon Press, Oxford, 1959. 
D EMO

\section{Purpose}

Simulation of transient neutronic-thermal-hydraulic behavior of a pipedloop-type Breeder Reactor.

\section{Status}

A. Development: Developed and under improvement at WARD.

B. Availability: Model description report for DEMO Rev. 4 released with user's manual in January 1976. Program available through Argonne Code Center.

C. Utilization: Used by WARD in support of the CRBRP PSAR, other safety evaluations, plant protection design analysis and to produce design therma! transients for CRBRP component equipment specifications.

\section{Problems Solved}

DEMO is currently used to generate thermal-hydraulic design transients for the CRBRP. A wide range of plant transients, including sodium and steam pipe rupture, can be performed.

\section{Models}

\section{A. Reactor}

1. Core - The core model includes dynamic average and hot channels for both the active core and blanket. Fixed nodalization and time steps are used which have been selected for the class of transients to be run by comparisons with a more detailed variable-nodalization core-only program (FORE-II). Feedbacks include coolant expansion and Doppler (Additional feedbacks, e.g., structure and driveline expansion, can be made available via program change).

2. Internals - Included lower plenum, upper and Lower axial blankets, radial blanket, bypass channel and upper plenum. Heat transfer to internal structures is accounted $f$ or by homogenizing and using an effective heat capacity. Assumes constant flow fractions of total flow for all flow regions. 
3. Bypass channel - Modeled as being unheated, with heat capacity of associated structure and transport time neglected. Exit temperature of coolant leaving bypass is identical to mixed mean temperature of lower plenum.

4. Plena

Lower plenum - represented by perfect mixing model with single mixing node and effective heat capacity.

Upper plenum - model includes coolant level, which considers thermal expansion of sodium and makeup-overflow from sodium purification system, and the cover gas. Two mixing node options are available: (1) single node mixing with effective heat capacity (perfect mixing), or (2) stratified flow model, which is used when jet height of sodium leaving core is less than 20 feet.

B. Heat transport loops - Three loops are simulated by a two loop mode1 in which one loop represents two of the plant loops and a second represents a single plant loop. Heat capacity of the pipe walls and mixing in pipes is generally neglected. (Pipe heat capacity can be made available as an option for events where it is needed to be conservative.)

1. Primary heat transport loops - Each includes piping, check valves, pump tank with free surface and cover gas, and the shell side of the IHX. Hydraulic effects include vessel upper plenum leve1, pump tank leve1, pressure drops in the core, IHX and valves, pump characteristics, gravity head, fluid inertia, and transport time effects in piping.

2. Intermediate heat transport loops - Each has tube side of IHX, piping, shell side of superheater and evaporator, and pump. Hydraulic effects include pressure drops in pipes, IHX, superheater and evaporator.

3. Water/steam system - Each has idealized feedwater control, piping, recirculation pumps, tube side of evaporator and superheater, and a steam drum. Steam leaving superheaters enters a common steam header and flows through piping to the turbine throttle valve. The turbine is represented as simple steam load. Safety, relief and steam bypass valves are modelled.

Steam generator - Each has a steam drum, recirculating pump, isolation and check valves, superheater, and one equivalent 
evaporator. Two optional steam generator modules give a choice of detailed water/steam pressure and flow (for steam break) or a simplified superheater calculation.

\section{Limitations}

1. Sodium boiling is not allowed.

2. Homogenized reactor internals and constant flow fractions may inaccurately calculate flow distribution at very low flows.

3. Numerics are less refined than in IANUS; DEMO uses Euler integration and fixed time steps for the base program dynamics and control. A more sophisticated forward implicit scheme is used for the steam break option.

4. DEMO runs at approximately $1: 1$ real time on the CDC 7600 for the base program. Longer run times for similar transient cases as compared to IANUS result principally from DEMO steam table look-ups.

5. Bypass channel model does not include heat transfer.

\section{Future Efforts}

1. DEMO will be updated to reflect CRBRP equipment design and operational modifications and requirements as needed.

2. Imp roved upper plenum mixing model may be updated if required with data from experimental programs in scale models.

3. Modelling for pipe wall heat capacity is avallable as an addition by coding change.

4. A turbine-feed train model may be added in the future.

5. Imp roved modelling for the react or vessel overflow is being added (optional) as will modelling of the Direct Heat Removal Service (DHRS) which rejects decay heat through an overflow system heat exchanger.

6. The pump tank level/standpipe-bubbler system is being added.

7. The idealized feed control model will be replaced by a more realistic mode1.

8. An improved steam drum and recirculation line model will be avallable for transients needing it. 


\section{Computer Operation}

1. Operational on CDC-7600. Has been used on the ANL IBM 360-75 with Fortran changes including 64 bit precision.

2. SCM length 144216 (Octal).

3. Basic program runs in approximately real time on the CDC-7600. Pipe break options may vary from $4 x$ to $50 x$ real time depending upon the severity of the transient.

4. Applicable portions of the program have been compared with independently developed computer codes; names, FORE-II (reactor), IANUS (primary hydraulics) and SETS (steam generator module). These comparisons have not been formally documented. Independent DEMO verifications performed by ANL are reported in ANL-CT-75-23 and 25 . A detailed plan has been proposed, including analysis, modelling and component tasks, to validate DEMO for CRBRP natural circulation transient calculations.

Interface/Overlap

IANUS (primarily hydraulics)

\section{References}

1. "Clinch River Breeder Reactor Plant Nuclear Island," WARD-D-0005, Rev. 2, August 1974 .

2. "LMFBR Demo Plant Simulation Mode1 (DEMO)," Rev. 4, WARD-D-0005, January 1976. 
DIF3DS

\section{Purpose}

Solution of the multidimensional, multigroup diffusion theory equation and calculation of reactivity coefficients according to first-order perturbation theory.

\section{$\underline{\text { Status }}$}

A. Development: In progress at ANL/AP and ANL/RAS.

B. Availability: Developmental at ANL on IBM 370 .

C. Utilization: A preliminary version has been used to generate neutronics input data for SAS3D calculations at ANL.

$\underline{\text { Problems Solved }}$

DIF3DS performs the solution of the space and energy dependent diffusion equation (real and adjoint) to obtain the neutron flux distribution and calculates the reactor power distribution, the point reactor kinetics parameters, and the first order perturbation theory reactivity coefficients required as input for SAS3D.

\section{Models}

The finite difference form of the multigroup diffusion theory equation is solved for a full reactor model in elther two-dimensional $\mathrm{R} / \mathrm{Z}$ geometry, or three-dimensional triangular/Z geometry. Macroscopic group constants are uniform within a region, which consists of a group of finite difference mesh cells. Numerical solution of the diffusion eigenvalue problem is carried out with a module from the DIF3D code (Ref. 1).

\section{Limitations}

DIF3DS was specifically designed to interface with the steady-state calculation of SAS3D. It accepts input (geometry, material mass and temperature distributions, microscopic cross-section homogenization information) in the form of binary interface files produced by SAS3D. In turn, DIF3DS produces binary files which contain the information (power distribution, reactivity coefficients, point kinetics parameters) required as input for the SAS3D transient calculation. 


\section{Future Efforts}

The cross-section processing, neutron flux solution and perturbation theory modules will be extended and used in a quasistatic diffusion theory space-time neutronics model in SAS4A.

\section{Computer Operation}

1. DIF3DS is currently under development on the IBM $370 / 195$ at ANL and the CDC-7600 at LBL.

2. DIF3DS uses a multilevel (small core/large core/disk) storage strategy which optimizes use of avallable core and disk storage. Current maximum problem size is 37500 spatial mesh points on the IBM $370 / 195$ at ANL.

3. Typ1cally, $5.0 \times 10^{-6}$ to $7.0 \times 10^{-6}$ seconds per space-energy mesh point iteration ape required in the flux solution algorithm. Approximately $5.5 \times 10^{-5}$ seconds per space-energy mesh point are required to calculate the space dependent reactivity coefficient distribution for one material.

4. The DIF3D flux solution algorithm has been verified by comparison with the DIF2D, VENTURE and GRIMHX computer codes as reported in Reference 1. Extensive diffusion theory analysis of ZPR critical experiments has been carried out at ANL-I11inois and ANL-Idaho. Some examples of references reporting such analyses are:

a. A. Trave11i and J. C. Beitel, "Analysis of Sodium-Void Experiments in the FTR Engineering Mockup Critical Assembly," Proc. Nat. Top. Mtg. on New Developments in Reactor Physics and Shielding," CONF-72091, p. 739 (1972).

b. W. G. Davey, et al., "Sodium-Voiding Studies in a PlutoniumFueled Fast Assembly (ZPPR-2) of Demonstration Reactor Size, Composition, and Geometry," ANL-7962, Argonne Nationa1 Laboratory (1974).

c. H. F. McFarlane, et al., "Evaluation of ZPPR Assembly 3 Sodium Void Experiments," Advanced Reactors: Physics, Design and Economics, Pergamon Press, p. 402 (1975).

d. R. E. Kaiser, et a1., "Simulation of an HCDA Sequence on the ZPPR Critical Facility," Proc. Int1. Mtg. on Fast Reactor 
Safety and Related Fhysics, Chicago, I1linois, October 1976, CONF-761001 (in press).

e. C. L. Beck, et a1., "On the Extrapolation of ZPR Sodium Void Measurements to the Power Reactor," Proc. Int1. Mtg. on Fast Reactor Safety and Related Physics, Chicago, Illinois, October 1976, CONF-761001 (in press).

Interface/Overlap

SAS3D

$\underline{\text { References }}$

1. D. R. Ferguson and K. L. Derstine, "Optimized Iteration Strategies and Data Management Considerations for Fast Reactor Finite-Difference Diffusion Theory Codes, Proc. ANL Topical Meeting on Improved Methods for Analysis of Nuclear Systems, Tucson, Arizona, March 28-30, 1977 (to be published). 
DSTRESS

\section{$\underline{\text { Purpose }}$}

Determine the time and location of fuel pin failure during a hypothetical transient overpower accident.

\section{$\underline{\text { Status }}$}

A. Development: The code is being developed by HEDL.

B. Availability: The program modules have been completed and released to the ANL Code Center. Additions, modifications, and imp rovements to the deformation mechanisms are expected to be incorporated when they are developed as the result of transient experiment analysis. A theory and users manual are both available.

C. Utilization: (1) Determine the time and location of fuel pin failure during unterminated transient overpower events.

(2) Extend the range of the empirical fuel failure correlation used in MELT IIIA.

Problems Solved.

DSTRESS calculates cladding strains produced by the fuel when a fuel pin is subjected to overpower transients. The mechanistic fuel model calculates fuel stresses with high creep rates, melting, cracking, and accommodation of thermal expansion by crack volume.

$\underline{\text { Models }}$

Modeling is axisymmetric and uses the method of "successive elastic solutions" with infinitesimal deformation theory and iteration convergence is accelerated using a diagonal Aitken's procedure.

\section{Limitations}

The program is dimensioned for 22 fuel and one cladding nodal points. It is presently limited to one axial location and the fuel temperature history must be input. 


\section{Future Efforts}

First, a systematic method for characterizing the pretransient fuel must be developed. This includes hot fuel cladding gap and void distributions such as central void, porosity and start-up cracks. Next, the cladding lifetime predictions must be correlated to test failure data. This will be followed by modeling of fission gas effects and adaption of DSTRESS to a full pin version.

\section{Computer Operation}

Computer:
Memory:
Relates Programs:
Mode:
$\operatorname{CDC} 6600$

66000 octal

A DISSPLA plotting package is available Batch

Typical Running Time: A TREAT type transient described in the user manual using 12 fuel nodes required 2 minutes. Major time consumption occurs during rapid deformation rates such as central void closure and porosity collapse where smal1 time steps are required.

Code Validation: Code results are compared with analytic solutions for three diverse cases in the users manual. Future work includes comparisons with TREAT experiments.

\section{Interface/Overlap}

Input information is received from SIEX. Codes with similar objectives but different analytic models and technique.

BEHAVE-SST
FP IN
LAFM
LIFE- 4 T
PECTP IN

BEHAVE-SST

FP IN

PECTP IN
(GE)

(ANL)

(LASL)

(ARD, GE, ANL)

(HEDL)

\section{$\underline{\text { References }}$}

1. G. L. Fox, "Interim Report on Analytic Modeling Used for DSTRESS," HEDL-TME 76-95.

2. G. L. Fox, "DSTRESS Users Manual," HEDL-TME 76-95 Addendum. 
DUGUID AND REEVES

\section{Purpose}

Calculates the transport of material dissolved in groundwater through a porous media.

\section{$\underline{\text { Status }}$}

A. Development: Developed at Oak Ridge National Laboratory, Oak Ridge, Tennessee.

B. Availability: Presently available from the authors and documented in Refs. 1 and 2.

C. Utilization: 1. For predicting the radionuclide (tritium, strontium, plutonium) transport from seepage trench $\$$; at the ORNL nuclear waste burial grounds.

2. Comparison of predictions with experimental studies of water outflow rate (hydrograph) from the coweeta soil column.

3. In conjunction with water transport studies being conducted by the USGS at the West Valley, New York, nuclear waste burial site.

\section{$\underline{\text { Problems Solved }}$}

Solves the transport of a dissolved constituent by groundwater under the influence of convective transport, hydrodynamic dispersion, chemical reactions, radioactive decay and adsorption. The computerized solution provides future toxic material concentrations in groundwater and therefore enables the investigator to perform human dose calculations. Two example problems are considered:

1. Comparison to an analytical solution due to Lapidus and Amunds on (Ref. 3) for a one-dimensional flow of a carrier fluid having a constant pore velocity in a medium with a uniform water content through out.

2. A seepage pond situated in the unsaturated zone above the water table provides a source of soil contamination which migrates toward a nearby stream. 


\section{Models}

The mass transport equations are developed to simulate the flow of material dissolved in groundwater in a saturated-unsaturated porous medius. A Eulerian description of fluid flow is adopted. The coordinate system is attached to the solid phase because the velocity of the solid phase is smaller than the velocity of the fluid phase. Darcy flow is assumed. A two-dimensional geometry is considered. Chemically reacting species in the soil solution are assumed to be independent. Local equilibrium is assumed for reversible processes. Only one type of irreversible reaction may occur, viz., that which is analogous to radioactive decay where the rate of change is proportional to the total quantity of the constituent present in both the solid and liquid phases. The numerical technique utilized is the Galerkin finite-element method. The code is programmed in FORTRAN IV.

\section{Limitations}

1. The solution is two-dimensional as opposed to three-dimensional.

2. Large amounts of input data may be required.

3. Requires output from the moisture transport model (Ref. 2).

4. Limited by the assumption made in the moisture transport model that the air-water system is a single phase (i.e., air pockets in the medium are nonexistent).

\section{Future Efforts}

Development of a quasi-three-dimensional code more suitable for buried waste sites.

\section{Interface/Overlap}

Output from the moisture transport model (Ref. 2) is required as input.

\section{$\underline{\text { References }}$}

1. J. 0. Duguid and M. Reeves, "Material Transport through Porous Media: A Finite-Element Galerkin Mode1," Oak Ridge National Laboratory, Oak Ridge, TN, ORNL-4928, March 1976.

2. M. Reeves and J. O Duguid, "Water Movement through SaturatedUnsaturated Porous Media: A Finite Element Galerkin Mode1," Oak Ridge National Laboratory, Oak Ridge, TN, ORNL-4927, February 1975 . 
3. L. Lapidus and N. Amundson, "Mathematics of Adsorption in Beds: VI.- The Effect of Longitudinal Diffusion in Ion Exchange and Chromatographic Columns," J. Phys. Chem. 56, 984-988, 1952. 
EPIC

\section{Purpose}

Characterization of fuel and coolant motions in an LMFBR following $p$ in failure.

\section{Status}
A. Development: Developed at ANL/AP. Current version called EPIC.
B. Availability: Operational at ANL, LBL, SANDIA.
C. Utilization: Provides capability to treat LOF-TOP transient con- ditions as well as TOP, given conditions defined by a whole-core accident codes such as SAS. Used in this capacity at ANL and used to analyze fresh pin failure experiments at SANDIA.

\section{Problems Solved}

EPIC models fuel and coolant motion which result from internal fuel pin pressure (from $f$ ission gas or fuel vapor) and/or from the generation of sodium vapor pressures in the coolant channel subsequent to pin failure in an LMFBR. Given the conditions in the fuel pin and coolant channel at pin failure as a starting point, EPIC will do a complete calculation of the subsequent events in the fuel pin (including melt-in of solid fuel) and in the coolant channel.

\section{$\underline{\text { Mode1s }}$}

The modeling in EPIC includes the ejection of molten fuel from the pin into a coolant channel with any amount of voiding through a clad rip which may be of any length or which may expand with time. One-dimensional Eulerian hydrodynamics is used to model both the motion of fuel and fission gas inside a molten fuel cavity and the mixture of two-phase sodium and fission gas in the channel. Motion of molten fuel particles in the coolant channel is tracked with a Particle-In-Cell technique.

EPIC uses a model of a single fuel pin with its associated coolant which represents part of or a whole subassembly or a group of similar subassemblies. A number of such representative pins can take into account incoherencies within or among subassemblies due to different power levels, voiding histories, coolant flow, etc. EPIC begins at the point of clad failure and models the subsequent events. The user specifies the failure location and length. 
The one-dimensional Eulerian calculation of the hydrodynamics inside the molten-fuel cavity in the pin is explicitly coupled to the one-dimensional Eulerian calculation in the coolant channel by means of a fuel ejection mode1. This ejection model equilibrates the pressure (instantaneously at the end of a given time step) in the Eulerian node or nodes in the fuel pin (which delineate the fallure length) and in the corresponding Eulerian node or nodes in the coolant channel directly in front of the pin failure nodes.

The sodium in the single-phase regions above and below the interaction zone in the coolant channel is treated as an incompressible slug.

\section{Limitations}

1. No calculation of time of pin failure or character of rip.

2. No sodium or fuel film treatment in channel.

3. No plateout and plugging of molten fuel in the channel.

4. No fission gas release in the pin.

5. No heat conduction in solid fuel or between the solid fuel and the molten fuel cavity. This might be important in a slow or moderate transient.

6. No fuel to clad and clad-coolant heat transfer.

7. No clad and unfragmented fuel motion in channel. Fuel is assumed to move only as particles of one user specified size.

\section{Future Efforts}

1. Remove limitations listed above.

2. Improved present fuel vapor voiding model.

3. Improve fuel fragmentation model.

4. Link EPIC to the SAS code so that EPIC will take over an entire channel calculation after SAS brings the channel to the point of pin failure. 


\section{Computer Operation}

1. Code Operational: EPIC is operational on the IBM $370 / 195$ and the CDC -7600 .

2. Logistics: EPIC requires $350 \mathrm{~K}$ bytes of storage for the IBM 370 . The code requires a random member generator which is machine-specific on the IBM and CDC version.

3. Typical Running Time: EPIC does a typical $50 \mathrm{msec}$ problem in about 4 minutes on the 370/195. The Particle-In-Ce1l treatment of fuel motion in the channel requires a significant fraction of the calculational time.

4. Code Validation: P. A. Pizzica, J. J. Sienicki, P. B. Abramson, H. U. Wider, "Comparison of the EPIC and PLUTO Computer codes for TOP Conditions," Trans. Am. Nucl. Soc., June 1976.

\section{Interface/Overlap}

SAS (SASFCI), PLUTO, HOPE, HOTPIM

\section{References}

1. P. A. Pizzica and P. B. Abramson, "EPIC: A Computer Program for Fuel-Coolant Interactions," Proc. International Meeting on Fast Reactor Safety and Related Physics (October 1976).

2. P. A. Pizzica and P. B. Abramson, "The Numerical and Modeling Techniques used in the EPIC code," Proc. Meeting on Improved Methods for Analysis of Nuclear Systems, March 1977, Tuscon, Arizona. 
EXREM III

\section{$\underline{\text { Purpose }}$}

Calculates external radiation doses to populations from environmental releases of radionuclides.

\section{$\underline{\text { Status }}$}

A. Development: Developed by the Environmental Sciences Division of the Oak Ridge National Laboratory (ORNL) at Oak Ridge, Tennessee.

B. Availability: EXREM III is operational on an IBM $360 / 91$ and an IBM $360 / 75$ computer and the code is available from the Radiation Shielding Information Center (RSIC) at ORNL.

C. Utilization:
(1) Performed dose calculations to determine the radiological feasibility of the peaceful applications of nuclear explosives (Plow- share Program).
(2) Provided dose calculations for environmental impact statements for various nuclear facilities.
(3) Used for the assessment of the radiological impact of consumer products.

\section{Problems Solved}

EXREM III calculates dose equivalent from beta, positron, electron and gamma radiation resulting from submersion in contaminated water, submersion in contaminated air, and exposure to a contaminated surface.

These quantities may be calculated for a large number of radionuclides. Multiple releases may also be considered. The total dose resulting from these multiple releases may be calculated for a specified time period. The dose rate may be determined at any point in time after the releases. Decay chain pathways are considered in the determination of doses due to daughter products. 


\section{Mode1s}

The dose equivalent rate is calculated from the product of concentration of radivactivity and a dose-rate factor. Each quantity must be appropriate for exposure to a particular environmental medium (air, water, contaminated surface), type of radiation (beta, positron, electron, gamma) and radionuclide. The specific radionuclide and its concentration and type of radiation will depend upon position within a decay chain. Dose-rate factors are determined by summing the products of particle (electron, positron, or beta) or photon abundance and the corresponding energy over all types of radiation. The media in which a person is exposed is assumed to be infinite or semi-infinite in extent.

\section{Limitations}

1. Contains no atmospheric dispersion model.

2. Doses from exposure to beta and gamma radiation are based on models which assume infinite or semi-infinite media.

3. No consideration is given to environmental removal of radioactivity.

Future Efforts

None presently anticipated.

Interface/Overlap.

Not specifically designed to interface or overlap with any particular code. However, EXREM III calculates dose rate conversion factors which are used in BIORAD (Ref. 4) and AIRDOS (Ref. 5) and may be used in any other code which requires a dose rate calculation from concentration of radioactivity.

\section{$\underline{\text { References }}$}

1. D. K. Trubey and S. V. Kaye, The EXREM TI Computer Code for Estimating External Radiation Doses to Populations from Environmental Releases, ORNL-TM-4322, Oak Ridge National Laboratory, December 1973.

2. W. D. Turner, The EXREM II Computer Code for Estimating External Doses to Populations from Construction of a Sea-Level Canal with Nuclear Explosives, CTC-8, Union Carbide Corporation, July 1969. 
FEFP SLUG

\begin{abstract}
Purpose
Calculation of coolant expulsion characteristics resulting from a pressure transient occurring in the SLSF test subassembly.
\end{abstract}

\title{
$\underline{\text { Status }}$
}

A. Development: Developed at ANL/RAS. Current development version is FEFPSLUG.

B. Availability: FEFPSLUG is operational on the IBM $370 / 195$ at ANL.

C. Utilization: FEFPLUG is used to determine the location and magnitude of SLSF test train resistance needed to duplicate reactor coolant expulsion characteristics for the LMFBR accident being simulated.

\section{Problems Solved}

The FEFPSLUG code simulates dynamic coolant response in the SLSF loop to determine coolant expulsion characteristics resulting from a pressure transient occurring in the test subassembly. It solves equations of motion for one-dimensional, unsteady flow of incompressible, single-phase sodium constrained in inertia and fluid friction while responding to pressure perturbations that produce distinct fluid interfaces. The analyses are based on a single pressure source in the test subassembly and slug motion of fluid in a rigid system.

\section{Models}

The SLSF loop and test train geometry are described by 65 regions in the main flow circuit and nine regions in the bypass channel. Five fluid columns describe coolant motion resulting from a test subassembly pressure traisient that produces coolant expulsion. FEFPSLUG consists of a steady-state module and a dynamic analysis module. FEFPSY is used for the steady-state pretransient analysis to calculate the initial conditions. CSMP is used in the dynamic analysis module to solve the five first-order, coupled differential equations describing motion of each fluid column and the supporting relations defining interface pressure, interface motion, pump performance, and cover gas compression. 


\section{Limitations}

1. Slug motion of fluid with expulsion occurring within the length of the pin bundle.

2. Incompressible, single phase flow in system with rigid boundaries; no shock waves.

\section{Future Efforts}

None planned.

\section{Computer Operation}

1. Operational on IBM $370 / 195$ at ANL.

2. Logistics: 250K of core memory specified for code operation, batch operation, FORTRAN.

3. Typical problem running time is one minute, including program compilation, for calculation of steady state initial conditions and analysis of SLSF hydraulics for 0.25 seconds following a 100 psi pressure perturbation.

\section{Interface/Overlap}

FEFP STY, COASTDWN/-

\section{$\underline{\text { References }}$}

1. Safety Assessment Report for the Fuel Element Failure Propagation Loop in the Engineering Test Reactor, Appendix B, Argonne National Laboratory Report ANL/RAS 73-21 (Revision 3), May 31, 1974. 
FEFP STY

\section{Purpose}

Calculation of steady-state pressure drop, pressure levels, and pumping power requirements for sodium flow in the SLSF loop.

\section{$\underline{\text { Status }}$}

A. Development: Developed at ANL/RAS - Current development version is FEFPSTY.

B. Availability: FEFPTY is operational on the IBM $370 / 195$ at ANL. It has also been made avallable to HEDL and GE/Sunnyvale, but no user's manual has been written.

C. Utilization: FEFPSTY is used by ANL for pretest and posttest analysis of each SLSF P-series experiment.

\section{Problems Solved}

FEFPSTY ${ }^{1}$ predicts the frictional pressure drop in the multiple flow channels and regions comprising the SLSF loop. Calculation starts with a user specified system geometry and steady-state loop flow rate, flow fraction through the test subassembly, and sodium temperature distribution. Frictiona1 pressure drop in each region of the loop is calculated for the circuit from the gas plenum down through the heat exchanger, pump, and downcomer to the bottom of the loop, then through the inlet flowmeter, test subassembly, and other flowmeters back to the gas plenum. Hydraulic resistance of the bypass flow channel that is in parallel with the test subassembly flow is then calculated and the extent of hydraulic imbalance in the system, if any, is determined. Pump power, voltage, and pump head, both gross and net, for the specified operating condition are also calculated.

\section{$\underline{\text { Models }}$}

The SLSF 1oop and test train are described by 65 regions in the main flow circuit and nine reglons in the bypass channel. The Rehme correlation ${ }^{2}$ is used to predict the frictional pressure drop in test subassemblies that contain from seven to 61 wire-wrapped fuel pins. Frictional pressure drop in the rest of the system is calculated using the turbulent flow friction factor relationship developed by Colebrook ${ }^{3}$. Properties 
of sodium are from Golden and Tokar ${ }^{4}$. Operating characteristics of the annular linear induction pump are predicted by a pump model developed from MSA Research test data.

\section{Limitations}

1. Limited to steady-state, single phase, turbulent sodium flow.

2. Code does not calculate sodium temperatures; seven temperatures are specified in code input to describe the system.

3. Pump model based solely on characteristics of the annular linear induction pump in use.

4. Model for calculating frictional pressure drop in the test subassembly valid only for wire-wrapped fuel pins.

\section{Future Efforts}

None planned.

\section{Computer Operation}

1. Operational on IBM $370 / 195$ at ANL.

2. Logistics: $250 \mathrm{~K}$ of core memory specified for code operation, batch operation, FORTRAN.

3. Typical problem running time is 15 seconds, including program compilation, for calculation of hydraulics characteristics at three temperature levels in system having 74 regions.

4. References to code validation include the posttest reports for the SLSF experiments conducted to date and the results of out-of-pile pretest loop operation, including -

- Argonne National Laboratory, Interim Report on SLSF In-Pile Experiment P1 (February 27, 1976).

- G. L. Bordner, et. al., Interim Report on SLSF In-Pile Experiment P2: Part 1, Experimental Results and Analyses, Argonne National Laboratory Report ANL/RAS 77-8 (March 1977).

- R. J. Carpenedo, Interim Report--B3 Test Results for the T3 Loop, EG\&G Engineering Design File 2175 (May 23, 1977). 


\section{Interface/Overlap}

COASTDOWN, FEFP SLUG/THYME

\section{References}

\section{1. $\quad$ FEFPSTY}

Safety Assessment Report for the Fuel Element Fallure Propagation Loop in the Engineering Test Reactor, Appendix B, Argonne National Laboratory Report ANL/RAS 73-21 (Revision 3), May 31, 1974.

\section{Test Subassembly Frictional Pressure Drop}

Klaus Rehme, Pressure Drop Correlation for Fuel Element Spacers, Nuclear Technology 19(1):15-73, January 1973.

3. Friction Factor for Flow in Hydraulic Circuit

Turbulent Flow in Pfpes with Particular Reference to the Transition Region Between Smooth and Rough Pipe Laws, Journal Inst. Civil Engr. (London) 11, 133-156, February 1939. Original not seen, found in L. F. Moody, Friction Factors for Pipe Flow, Trans. ASME 66:671-684 (1944).

\section{Sodium Properties}

G. H. Golden and J. V. Tokar, Thermophysical Properties of Sodium, Argonne National Laboratory Report ANL-7323, August 1967. 
FETRA/SERATRA

\section{Purpose}

Simulates the hydraulic transport of sediments and radionuclides in different types of bodies of water.

\section{$\underline{\text { Status }}$}
A. Development: Developed by Battelle Pacific Northwest Laboratories.
B. Availability: These codes are operational and more complete docu- mentation is being prepared.
C. Utilization: They are being used to study the impact on the water quality of the Columbia River as a result of present and past releases of radionuclides from nuclear facilities at the Hanford reservation.

\section{Problems Solved}

FETRA/SERATRA (Ref. 1) are being utilized to quantitatively predict radionuclide and sediment inventories as a function of time. The physical transport processes modeled include deposition, scouring, and resuspension of sediments and radionuclides.

\section{$\underline{\text { Models }}$}

FETRA is a two-dimensional (2-D), finite-element Galerkin model which simulates radionuclide and sediment transport in estuaries, coastal areas and wide lakes. SERATRA is a 2-D finite-difference model which simulates radionuclide and sediment transport in narrow estuaries, rivers, and deep lakes. The differences between cohesive and noncohesive sediment are taken into account. FETRA considers the lateral and longitudinal dimensions of a water body. SERATRA considers the vertical and longitudinal directions. The developers of these codes contend that the superposition of these two models will give a three-dimensional description of sediment and radionuclide transport in the Columbia River. Separate equations are developed for the transport of sediment, radionuclides in particulate form and dissolved radionuclides. Formulae for erosion and deposition rates of cohesive sediments were adopted from Parthenaides (Ref. 2) and Krone (Ref. 3). Toffaleti's (Ref. 4) formula is used to estimate the flow capacity for noncohesive sediments (i.e., sand). 


\section{Limitations}

FETRA/SERATRA require large amounts of input data. Data for the concentrations of radionuclides adsorbed by each sediment size fraction are essentially unavailable and therefore a complete calibration and verification of these models is not possible at the present. Also, the computer codes are written for a PDP $11 / 45$ computer and require an overlay structure.

\section{Future Efforts}

None planned at this time.

Interface/Overlap

\section{References}

1. Y. Onishi, P. A. Johanson, R. G. Baca, and E. L. Hilty, "Studies of Columbia River Water Quality. Development of Mathematical Models for Sediment and Radionuclide Transport Analysis," Battelle Pacific Northwest Laboratories Report BNWL-B-452, January 1976.

2. E. Parthenaides, "A Study of Erosion and Deposition of Cohestve Soils in Salt Water," Ph.D. Thesis, University of California, 1962 .

3. R. B. Krone, "Flume Studies of the Transport of Sediment in Estuarial Shoaling Processes," University of California Hydraulic Engineering Laboratory and Sanitary Engineering Research Laboratory, 1962.

4. Task Committee for Preparation of the Sedimentation Manual Committee on Sedimentation of the Hydraulic Division, "Sediment Transport Mechanics: H. Sediment Discharge Formulas," J. of the Hydraulics Division, ASCE, Vo1. 97, No HY4, Proceeding Paper 8076, pp. 523-567, 1971 . 
FP IN

\section{Purpose}

Analysis of thermal mechanical behavior of a clad fuel pin under TOP and LOF-driven-TOP situations up to the point of clad failure.

\section{$\underline{\text { Status }}$}

A. Development: Being developed at ANL/RAS. Current developmental version is FPINl.

B. Avallability: Developmental status.

C. Utilization: Currently being used on nonspecific test problems of typical TOP situations.

Problems Solved

FPIN calculates fuel pin temperatures, stresses and displacements under TOP and LOF-driven-TOP situations. The single clad fuel pin considered may be a representative of a particular subassembly or may simulate a fuel pin in an actual transient test. The calculations start with a fuel pin under stress-free conditions at room temperature or steady-state operating conditions. Depending upon the requirements of the problem, the calculations provide the details of the following events:

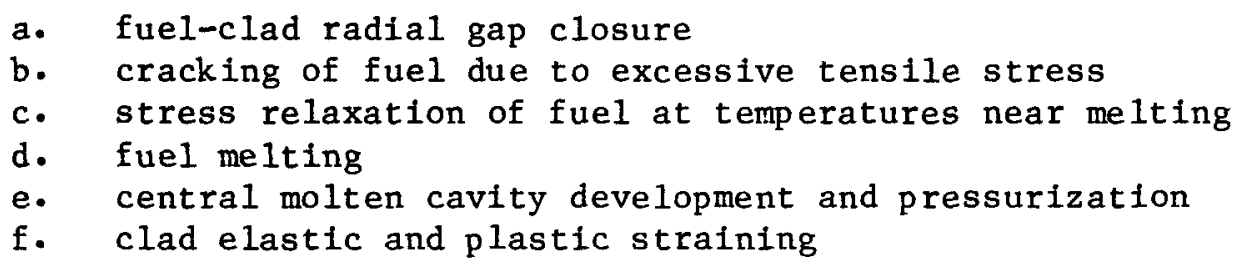

\section{Mode1s}

Since the code covers a wide variety of phenomena, the coding is broken into several blocks. These blocks include the following models: heat transfer, continuous-viscoelastic fuel, cracked fuel, elastic-plastic cladding and central cavity.

\section{Geometry}

A single circular-cylindrical fuel pin with assumed axial symmetry is divided into a small number of axial segments which are coupled thermally through the flowing coolant and coupled mechanically 
through a hydrostatic central cavity pressure. Heat transfer calculations also include a cylindrical flow channel and outer wall (pin-in-a-pipe geometry).

\section{Heat Transfer}

Radial conductive heat flow is calculated for each axial segment of fuel, clad and outer wall. Thermal conductivity and heat capacity are temperature dependent. Melting is allowed in fuel with inclusion of latent heat absorption due to phase change and calculation of the radil of solidus and liquidus temperatures. Coolant is assumed not to boil. The finite-difference equations are fully implicit and the fuel-clad-coolant-outer wall equations are combined into a single tridiagonal system of linear algebraic equations. Optionally, interpolation routines are included so that the mechanical calculations can proceed using a user-supplied therma 1 history.

\section{Continuous-Viscoeleastic Fue1}

Uncracked, load-bearing fuel is assumed to extend from the inner molten fuel to the outer cracked fuel. This fuel behaves elastically with secondary-creep type stress relaxation. The analysis makes the generalized-plane-strain approximation and uses a noniterative twostep algorithm to calculate the creep strains.

4. $\quad$ racked Fue1

A cracked fuel zone between the cladding and continuous fuel is included when the tensile stress in the continuous fuel exceeds a crack stress. Both axial ( $r-z$ plane) and transverse ( $r-\theta$ plane) cracks are allowed. The boundary between the continuous and cracked fuel is located independent of the radial grid structure.

5. Elastic-Plastic Cladding

Elastic and work-hardening plastic behavior are analyzed for the cladding using efther thick circular cylinder equations or a thin shell approximation. The plastic strains are determined using an arbitrary yield surface and an iterative method developed by Mendelson.

\section{Central Cavity}

A simple, volume-accounting, no-motion, hydrostatic model of the centra1 molten cavity is used. Pressure buildup is due to released fission gas and fuel expansion. 


\section{Limitations}

FPIN is restricted to fuel pins with intact clad. Other limitations are implicit in the model descriptions given above. Insufficient experience is available to give limitations concerning numerical algorithms, including computer storage and running times.

\section{Future Efforts}

Short term effort is directed toward documentation and improvement in reliability through a broadening of the test problems considered. Long term effort is directed toward incorporating the various aspects of fission gas behavior and increased speed and reliability of numerical algorithms.

\section{Computer Operation}

1. Runs on IBM $370 / 75$ and $370 / 195$.

2. Logistics: Uses FORTRAN language. The 10 axial segment developmental version runs in the $200 \mathrm{~K}$ region of the interactive TSO system and also under batch operation.

3. Typical Problem Running Time: Insufficient experience available to give a meaningful example.

4. Code Validation: Comparison with in-pile TREAT experiments are planned.

Interface/Overlap

None/DSTRESS, BEHAVE, DEFORM

\section{References}


FRAS

\section{Purpose}

Analysis of transient fission-gas release and swelling in oxide fuel.

\section{$\underline{\text { Status }}$}

A. Development: Developed at ANL/RAS. Current developmental version is FRAS2.

B. Availability: FRAS is operational on the IBM $370 / 195$ at ANL. Code description is available. (Ref. 1) FRAS2 is developmental, on the IBM $370 / 195$.

C. Utilization: FRAS has been used at ANL in a broad variety of transient analyses, including $D E H$ and capsule experiments, TREAT experiments, and hypothetical transients. Parametric studies have also been performed. (Ref. 2 and 3)

FRAS2 is being developed and used to explore the role of bubble relaxation in rapid transients.

Problems Solved

FRAS calculates the evolution of the fission-gas bubble-size distribution, based on surface-diffusion controlled migration and coalescence. Intragranular swelling is calculated from the total bubble volume, and gas release to grain boundaries is calculated as a function of transient time from the transient thermal and stress conditions and the bubble mobility, which is determined from the size distribution. Applicability is primarily to unrestructured fuel, which contains the bulk of the fission gas. FRAS treats a single fuel node, and requires thermal and hydrostatic stress histories from an external source, primarily user input. In FRAS, bubbles are assumed to adjust instantaneously to the equilibrium size following coalescence. Bubble relaxation is calculated explicitly in the FRAS2 version.

\section{$\underline{\text { Mode1s }}$}

The basic model of FRAS is an explicit finite-difference calculation of the bubble-size distribution (Ref. 4). Fission gas is assumed to 
precipitate into mobile bubbles that coalesce as they migrate by a surface-diffusion mechanism. Bubbles are assumed to migrate both randomly and under the driving force of a thermal gradient.

The grains are represented by spheres. Gas is assumed released from grains to grain boundaries by both random and biased migration of bubbles. The bubble mobility is average for the release calculations.

\section{Geometry}

Only one fuel node is modeled; the fuel is assumed uniform over that node. The bubble-coalescence calculation is based on an infinitemedium calculation. Spherical grains are assumed in the geometric modeling of gas release to grain boundaries. Swelling does not include grain-boundary swelling. Although emphasis is on unrestructured fuel, which contains the bulk of retained fission gas, equi-axed fuel could also be analyzed, since the grains can be approximated by spheres.

2. Bubble migration and coalescence

Bubbles move by random (Brownian) motion and under the driving force of a temperature gradient. The only migration mechanism considered is that of surface diffusion of matrix atoms over the bubble-fuel interface (Ref. 1), which dominates for transient conditions and solid fuel. Migration by evaporation-condensation or by vapor diffusion could readily be added if situations were to develop in which sufficiently large bubbles were formed.

Bubble coalescence probability is computed by the method of Gruber (Ref. 4).

\section{Bubble-size distribution}

The bubble-size distribution is computed by an explicit finitedifference scheme, using interpolated transient values for temperature, thermal gradient, hydrostatic stress, and bubble size for each size class. Bubble size classes are specified uniformly on a logarithmic scale according to the number of gas atoms per bubble in the size class. (Ref. 5)

\section{Limitations}

The primary limitation of the FRAS code is the assumption that the bubble size adjusts instantly to the equilibrium size following coalescence or changes in temperature or stress. This limitation is removed in the 
developmental FRAS2 version. Additional limitations are that FRAS is a single-node code, and it does not include re-solution effects, although the latter would be a trivial addition if needed.

\section{Future Efforts}

Continue development of FRAS2, with additional consideration of the behavior of grain-boundary gas, and further development of parametric representation of results. Code validation will continue as additional experimental data becomes available.

\section{Computer Operation}

1. Runs on IBM $370 / 195$.

2. Logistics: Uses FORTRAN language. Load module executes in 106 kilobyte region.

3. Typical Running Time: For representative single-node transient to fuel melting, less than 1 minute.

4. Code Validation: Ref. 3 .

\section{Interface/Overlap}

PFRAS

\section{$\underline{\text { References }}$}

1. E. E. Gruber, "Transient Gas Release from Oxide Fuels: Parametric Representation of FRAS Results," ANL/RAS 75-7 (March 1975).

2. E. E. Gruber, "Migration and Coalescence of Fission Gas Bubbles in Oxide Fuels by Surface Diffusion," Int. Conf. on Phys. Met. of React or Fuel Elements, September 2-7, 1973, Berkeley, U.K.

3. E. E. Gruber, "Calculation of Transient Fission-Gas Release from Oxide Fuels," ANL 8143, Nov. 1974.

4. E. E. Gruber, J. App1. Phys. 38, p 243 (1967).

5. E. E. Gruber, "A Generalized Parametric Model for Transient Gas Release and Swelling in Oxide Fuels," ANL-77-2 (Jan. 1977). 
FSTATE

\section{Purpose}

Analysis of transient two dimensional $(r, \theta)$ single pin fuel behavior during the initial phases of a postulated TOP or experimental simulation of same.

\section{Status}

A. Development: Developed at ANL/RAS.

B. Availability: Developmental at ANL on the IBM 370 .

C. Utilization: Provides the capability to assess the impact of asymmetries on fuel behavior during a TOP or simulation of same.

Problems Solved

Predicts the transient $(r, \theta)$ behavior of LMFBR fuel during a TOP. Focus is directed toward an investigation of asymmetric effects. Temperatures are computed via a thermal driver module. Fission gas release and redistribution is calculated. Fuel and clad mechanical behavior (including transient fission gas swelling) is estimated using an elastic approximation.

\section{Models}

The code is based on a modular structure in which the various interrelated phenomena are grouped into specific modules which are in turn integrated to furnish the final comprehensive analysis.

\section{Geometry}

A representative axial "slice" from a single fuel pin is treated. Coolant channel information is treated as input which may change as a function of time. Different axial "slices" can be taken to provide a third dimension to the analysis.

\section{Heat transfer module}

A 2-D $(r, \theta)$ heat flow model is used. Numerical solution of the resulting transient heat conduction equation is performed using alternating directions methods. Included in the module are: 

a. Latent heat effects;
b. variable gap conductance;
c. variable film conductance; and
d. temperature dependent materials properties.

3. Fission gas module

A 2-D $(r, \theta)$ fission gas release and redistribution model is used. Gas release to the fuel grain boundaries is calculated using PFRAS. Subsequent redistribution and porosity pressurization is modeled via a porous medium flow treatment. As with the heat transfer numerical solution of the resulting flow equation is performed using the alternating directions methods. Included in the module are:
a. Spatial variation of fuel porosity;
b. spatial variation of fuel permeability;
c. inclusion of radial crack effects; and
d. localized clad breach effects may be treated.

\section{Mechanical treatment}

Work is presently in progress on a simplified finite element elastic clad treatment. Fuel behavior is modeled via an elastic method which assumes the presence of fuel cracks.

\section{Limitations}

1. $20 \times 20(r, \theta)$ mesh;

2. $250 k$ region on the IBM 370 ;

3. mechanical treatment still preliminary.

\section{Future Efforts}

1. Firm up fuel/clad mechanical treatment;

2. use code for analysis of: 

a. HCDA situations;
b. experiments.

3. extend code capability to consider multiple axial segments.

\section{Computer Operation}

1. Code is in a developmental stage on the IBM 370 ;

2. Logistics:

a. $250 \mathrm{~K}$ required for full $20 \times 20$ mesh problem;

b. batch operation;

c. FORTRAN IV used.

3. Typical Running Time: For a $20 \times 20$ mesh p coblem treating a mild TOP (60 second period) some ten minutes of IBM 370 time is required for the fuel to proceed from an initial reactor steady-state to a condition of $50 \%$ melt fraction.

4. Code Validation: Included in future effort.

Interface/Overlap

PFRAS, POROUS

\section{$\underline{\text { References }}$}

1. ANL-RDP-48, p.7.7;

2. ANL-RDP-51, p.7.20;

3. ANL-RDP-54, $\mathrm{p} \cdot 6.45$;

4. ANL-RDP-59, p.6.47. 
FUMO

\section{$\underline{\text { Purpose }}$}

A fuel motion module for LMFBR transition phase analysis.

\section{Status}

A. Development: FUMO and FUMO-T were developed at HEDL.

B. Availability: FUMO documented in 1975; operational at $\mathrm{HEDL}$ and LBL . FUMO-T operational at LBL.

\section{Problems Solved}

FUMO and FUMO-T follow the boilup conditions (in a one-dimensional sense) seen in the various stages of the hypothetical transition phase predicted for the unprotected LOF accident for FFTF. FUMO is used in a channeI representation as a plug-in module for SAS3A to follow fuel motion well beyond the initial fuel disruption calculated by SLUMPY and is also used as a stand-alone module to study long-term boiling pool evolution. In both forms, it can be used to examine the potential for energetic recriticality during the final stages of the HCDA while the core is still intact.

The initial conditions are user specified and also may be obtained from SAS3A internal variables. From this point, FUMO calculates the thermal hydraulic behavior of the two-phase molten steel fuel pool and the resulting Doppler and material motion reactivity. The calculation can be carried on for all periods of interest, but presently should be terminated before massive structure meltin. This is the point of final core breach which is not currently predicted by FUMO.

\section{Mode1s}

FUMO and FUMO-T have effectively identical models with the exception that FUMO-T allows the option of pressure boundaries in lieu of $f$ ixed boundaries. The primary difference between the two is the improved numerical techniques used in FUMO-T.

\section{Geometry}

A one-dimensional hydraulics calculation is carried out which assumes fixed boundaries defined by blockages or constant pressures at the boundaries defined by pressure head conditions. The calculation is normalized to the single fuel pin representation while the 
subassembly wall is represented by an effective hydraulic diameter per pin. The same technique can be extended to large pool calculations as we11. The two-phase steel fuel mixture is mapped onto Lagrangian mesh with the maximum of 59 axial nodes allowed. The lateral structure is represented by a fixed mesh with the same size limitations.

2. Heat Transfer

Nuclear heating of the fuel and steel with a constant power shape is assumed to drive the energetics of the pool. Heat transfer mechanism on the nodal level included axial conduction, radial conduction and convection to structure walls, axial vapor transport, conduction and convection interchange with above and below core structure. In addition to this, quenching is allowed due to conduction limited subassembly wall meltin.

3. Two-Phase Representation

The assumed hydraulic mixture consists of three components and two phases. The liquid phase contains liquid steel and fuel, both with the same velocity field but independent density fields. The gas phase consists of fission gas, steel and fuel vapor. The gas phase (represented by one velocity field) is assumed to be at slip flow equilibrium and also is assumed to be the continuous phase defining the pressure conditions. The vapor densities are determined by saturation conditions for the respective liquid components, while the fission gas density is determined solely from gas transport alone.

\section{Reactivity}

Material motion reactivity is assumed to obey first order perturbation theory where the material distribution is mapped onto worth curves.

5. Numerical Techniques

FUMO uses a partially implicit numerical scheme for the equations of motion and iterates to convergence at each time step. The vapor transport energy balance is converged as an inner iteration scheme and the momentum balance is converged in an outer loop scheme.

FUMO-T uses in addition to the techniques used in FUMO a shifted weighting scheme which locally forces a fully implicit calculation where the time exceeds the Courant criteria. This is coupled with a quasilinear technique to accelerate convergence to typically three iterations per time step. These additional features allow much 
larger time steps without stability restrictions of the courant criteria.

\section{Limitations}

The current limitations of FUMO-T are:

1. Parametric heat exchange coefficients are used for the steel fuel energy transfer.

2. Model is limited to one-dimensional effects thus eliminating the possibility of churn turbulent convection cells.

3. Gas drag determined by one characteristic diameter for the liquid droplets.

4. Massive structure meltin is not allowed.

5. Vaporization and condensation rates are controlled by saturation conditions.

6. Radiation heat transfer is not included.

\section{Future Efforts}

Short-term efforts will be directed towards including massive structure meltin and radiation heat transfer.

Long-term efforts will include:

1. Multidimensional effects;

2. Improved steel fue1 heat exchange mode1;

3. Imp roved vapor treatment;

4. Experimental verification.

\section{Computer Operation}

1. FUMO is operational on CDC's -7600 at LBL and CYBER 74 at RL. FUMO-T is operational at LBL.

2. FUMO-T requires $46.5 \mathrm{~K}$ octal of 60 bit words in central memory of a CDC-7600 to compile using RUN76 and $34.5 \mathrm{~K}$ to run. Also, approximately $67 \mathrm{~K}$ octal of extended core storage is required to run. This is based 
on the maximum of 59 Lagrangian nodes. FUMO-T also has a post processor operational at HEDL that generates short prints, two-dimensional plots, three-dimensional plots, and movies on the FR-80.

3. Typical time depends on the maximum time step allowed. For a problem using a one msec time step maximum and 27 nodes, the running time is about 60 secs $C P$ per second of problem simulation.

4. Code Validation: Comparison between FUMO-T and SIMMER-I are planned, as well as comparisons with experiments in SLSF as refined data becomes available. Until that time, simple boiling experiments will be examined.

Interface/Overlap

SAS3A/SLUMPY

\section{$\underline{\text { References }}$}

1. J. Muroaka, R. T. Toyooka, G. 0. Hultgren, FUMO: A Fuel Motion Module for LMFBR Transition Phase Analysis, HEDL-TME 75-132, Hanford Engineering Development Laboratory, Richland, WA, December 1975. 
FURFAN

\section{Purpose}

Analysis of fuel pin performance capability through steady-state and transient operation.

\section{$\underline{\text { Status }}$}

A. Development: Developed at W-ARD; updating is continual as new experimental data become available.

B. Ava1lability: Reference version is operationa1 at $W-A R D$, ANL and CE.

C. Utilization: Used at $W$-ARD for analyses of fuel pins in CRBRP, FFTF and other Breeder Reactor systems; analyses were used in support of the CRBRP/PSAR and FFTF/FSAR.

\section{Problems Solved}

Computes an estimate of the fuel pin lifetime accounting for: (a) environmental factors, (b) prior mechanical history, and (c) analytical uncertainty. FURFAN is capable of treating steady-state operation combined with a specified number of periodic upset events and emergency events.

\section{Models}

FURFAN is based on the life fraction concept which is extended to include those phenomena which are unique to fuel pins in a Breeder Reactor system. The models used to support the analysis are regression equations fit to experimental data obtained primarily with prototypic material. These models include:

1. tensile properties,

2. stress rupture behavior,

3. interstitial transfer,

4. fuel-cladding chemical reaction,

5. sodium-cladding chemical reaction.

\section{Limitations}

1. Cladding material limited to $20 \%$ cold-worked 316 stainless steel. 
2. Steady-state operation limited to six cycles each with a maximum of 275 days.

3. Transients limited to 25 types, each of which may occur 100 times.

\section{Future Efforts}

Updating is continual as new experimental data become available.

\section{Computer Operation}

1. Operational on $\mathrm{CDC}-7600$.

2. SCM length: 111757, LCM length: 241420

3. Running time varies with length of steady-state operation and number of transients; typical CRBRP problem runs 20 sec.

4. Validation discussed in Reference 1 .

\section{Interface/Overlap}

None

\section{References}

1. D. C. Jacobs, "The Development and Application of a Cumulative Mechanica1 Damage Function for Fue1-Pin Failure Analysis in LMFBR Systems," CRBRP-ARD-0115, May 1976. 
FX2

\section{Purpose}

To analyze LMFBR accidents which require the use of spatial kinetics.

\section{Status}

A. Development: EX2 developed at ANL/AP. An improved version, FX2-TH, is under development at ANL/AP to provide coupled neutronics/thermal hydraulics for a wide range of off-normal reactor accidents.

B. Avallability: Released through ANL Code Center (Ref. 1).

C. Utilization: FX2 is used for LMFBR disassembly analysis. It is also useful in the analysis of the Safety Test Facility.

Problems Solved

FX2 solves one or two dimensional time-dependent reactor kinetics problems. The VENUS-II disassembly module allows feedback from an LMFBR disassembly calculation to be modeled. Problems are initiated from a steady-state reactor condition; during the transient various perturbations can be input to model LMFBR accident conditions.

\section{$\underline{\text { Models }}$}

\section{Reactor Physics}

The reactor physics model consists of the one or two dimensional, multigroup, time dependent diffusion equations. Problems can be executed in orthogonal geometry $(x-y$ or $r-z)$, or in triangular geometry. An arbitrary downscatter bandwidth is allowed; and no upscattering is currently allowed. Cross sections can be input either in macroscopic form (through a code dependent interface file), or in microscopic form (an ISOTXS file). Other standard CCCC files, such as DLAYXS and GEODST, are used.

\section{Feedback}

Currently, the VENUS-II disassembly module provides the calculation of fuel temperatures on a Lagrangian mesh. The position, density, and temperature of reactor materials during the transient are 
determined using the equations for conservation of mass, momentum, and energy; and an equation of state. This calculation provides feedback effects to the reactor physics module in two ways:

a. Changes in the volume fractions of materials due to material motion;

b. Doppler feedback due to changes in the fuel temperatures.

\section{Limitations}

The feedback module, VENUS-II, is only applicable to LMFBR disassembly calculations in $\mathrm{r}-\mathrm{z}$ geometry. A flexible data management system has been used such that large problems can be executed on IBM 360-370 series computers. The current version of FX2 would rely heavily on the use of disk storage for the CDC-7600 series computer. This limitation will be to a significant degree eliminated in the new version currently under development.

The reactor physics module is limited to two spatial dimension group diffusion theory with no upscatter.

\section{Future Efforts}

Dynamics: Several modifications to the FX2 program have increased the capability of the code and serve as a base for the implementation of future thermal and hydraulic models. First, the code now has the capability of performing two-dimensional kinetics problems in $\theta-r$ geometry. Also, improvements made in the inner-iteration coding improved the execution speed somewhat for problems in an orthogonal geometry.

A new thermal/hydraulic model is being developed. In preparation for such a new mode1, the VENUS-II model has been removed from $F X 2$, and a clean interface between the neutronics and the thermal and hydraulic effects has been defined. Work is currently in progress to develop reasonable thermal and hydraulic models for FX2. These models should be appropriate for both the Safety Test Facility (STF) and for conventional LMFBR kinetics problems.

The following thermal and hydraulic models have been developed to satisfy both of the above needs. For the STF work, a very simple fuel-temperature mode1 has been developed in which radial heat flow through the fuel is neglected. Therefore, the average fuel temperature can be calculated directly, and there is no need for an explicit coolant-temperature calculation.

To handle the wide variety of operational transients to which FX2 might be applied, a detailed thermal and hydraulic model has been developed. 
Feedback will be allowed from fuel temperature (as is currently programmed into FX2), and also from coolant density. The thermal and hydraulic mode1 that will calculate these quantities will involve an explicit calculation of the conditions of an "average" fuel pin within each fuel assembly. These fuel pins will be considered "closed," with no pressure balancing between assemblies. Other major assumptions inherent in this model are:

a. The coolant is assumed not to boil.

b. The fuel conductivity and specific heat density are assumed to be polynomial functions of the fuel temperature.

c. All heat is deposited directly into the fuel pin.

d. No fuel motion or fuel (or cladding) expansion is allowed.

e. Heat generation in the fuel is radially uniform.

f. Axial and azimuthal heat transfer are neglected.

The temperatures inside the fuel pin and cladding are calculated by applying a finite-difference technique to the heat-conduction equation. The hydraulics equations were taken from the SAS2A manual ${ }^{3}$. The coolant density, specific heat, and thermal conductivity are evaluated as polynomial functions of the coolant temperature. The coolant equations are integrated over each axial segment to calculate the coolant temperature up the channel.

\section{Interface/Overlap}

FX2 uses CCCC files to accept cross section and geometry input data, thus making it compatible with a large number of other reactor physics programs.

\section{References}

1. D. R. Ferguson, T. A. Daly and R. W. Schaefer, "FX2 - A Quasistatic Multidimensional Multigroup Diffusion Theory Code with Feedback," FRA-TM-87, Argonne National Laboratory, April 1976.

2. D. R. Ferguson, T. A. Daly and E. L. Fuller, "Imp rovement of and Calculations with Two-Dimensional Space-Time Kinetics Code FX2," CONF-730414, Ann Arbor, Mich., Apri1 9-11, 1973.

3. F. E. Dunn et. a1., The SAS2A LMFBR Accident-Analysis Computer Code, ANL-8138 (Oct. 1974). 
FX2-POOL

\section{Purpose}

Scoping studies of extended motion $\mathrm{CDA}^{\prime} s$ in $\mathrm{FBR}^{\prime}$ s and recriticalities in fuel/steel pools.

\section{$\underline{\text { Status }}$}

A. Development: Developed at ANL/AP: Current versions called

1) FX2-POOLVENS ( $f$ or extended motion CDA's)

2) FX2-POOL (for recriticality studies in pools)

B. Availability: Operating at ANL and GfK (Karlsruhe)

C. Utilization: FX2-POOLVENS has been used at ANL to scope fuel to steel heat transfer effects upon the evolution of system damage potential (work energy) for various HCDA conditions.

FX2-POOL has been used at ANL to scope the problems of recriticality in boiling homogenized fuel/steel pools and to examine the importance of the Behrens effect. Both versions are in use at Karls ruhe for similar purposes and a modification is being developed there to examine PAHR pools.

\section{Problems Solved}

POOL models a homogenized (no vapor/liquid slip) boiling fuel steel mixture including vaporization/condensation and fuel/steel heat transfer. It follows the thermodynamic and hydrodynamic behavior of this mixture using large time steps (limited only by the Courant condition as applied to the velocity field). As a stand alone code, it can be used to scope the motions following a prompt burst in a FBR or motions before and after a recriticality in a boiling pool.

POOL is coupled to FX2 (space time neutronics) for the study of the interactive neutronic/thermodynamic and hydrodynamic behavior near prompt critical.

\section{Mode1s}

POOL was developed as a scoping tool in an attempt to determine major roadblocks and to seek out the governing phenomena in post prompt burst 
core behavior. Toward that end, the following simplifying assumptions were made:

a. The core materials are treated as inviscid liquids with fuel and steel moved together from cell to cell, and sodium excluded from the calculation.

b. The hydrodynamic motions are driven by the local sum of the partial vapor pressures of fuel and steel. These partial pressures are assumed to be the equilibrium saturation pressure corresponding to the individual liquid temperature.

c. Energy and mass and momentum convection are calculated using a semi-implicit, donor cell differenced set of primitive variable equations employing the Particle-In-Cell technique of Harlow, et. al., (7) in a totally Eulerian formulation.

d. Heat Transfer between fuel and steel in the pool is treated as the sum of a parametric radiative and convective energy transfer terms where the parameters represent a steel droplet (chunk) size and a convective heat transfer coefficient.

e. Boundary heat transfer from the pool is similarly parameterized.

f. Compression waves are ignored and the Courant condition is applied only to the gross material velocity fields.

\section{Limitations}

a. No vapor/liquid slip

b. Saturation thermodynamics for individual materials

c. No treatment of sodium

d. Cannot follow compression waves

e. Cannot follow splashing rebounding of material off boundaries due to problems with treatment of combined compressible/ incompressible flows.

\section{Future Efforts}

a. TWOPOOL - Currently under development - treats vapor/11quid slip and the accompanying thermodynamic phenomena. 
b. Conductivity limited heat transfer to allow nonsaturation thermody namics.

c. Continued study of numerical analysis of compressible/incompressible flow.

d. Include sodium

Computer Operation

1. Operation IBM 370-195 at ANL on Batch.

2. Logistics: POOL takes $350-750 \mathrm{~K}$ core storage

FX2-POOL takes $1100-1400 \mathrm{~K}$ total (nondynamic) storage.

Both are linked to the ANL Graphics packages for making movies and plots of results. Summary results are put on tape for use with interactive graphics.

3. Typical Problem Running Time

For a 400 grid point 9 group problem

a. FX2-POOL takes $\sim 6$ seconds per time step (variable due to neutronics)

b. POOL takes $\sim 1.2$ seconds per time step (up to $0.5 \mathrm{~ms}$ real

time and limited by Courant condition for the velocity field)

4. Code Validation

FX2-POOL was compared to VENUS-II and VENUS-III and to VENUS-II and $\mathrm{PAD}$ for prompt burst conditions. No validation by comparison to experiment.

Interface/Over1ap

FX2-POOL is being used at ANL in conjunction with SAS (for initial data) and TRANSIT (for penetration into the plenum region) for additional studies of work energy evolution.

FX2-POOL performs similar calculations to FX2-VENUS-III, VENUS-II, and $\mathrm{PAD}$ but is able to follow more extensive motions.

FX2-POOL scopes some of the problems studied with SIMMER. 


\section{References}

1. P. B. Abramson, "FX2-POOL - A Two-Dimensional Coupled Hydrodynamic Thermodynamic and Neutronic Computer Model for Hypothetical Core Disruptive Accident Analysis," Nucl. Sci. Eng. (February 1977).

2. P. B. Abramson, "The Importance of Heat Transfer in Hypothetical Core Disruptive Accident (HCDA) Analysis," submitted to Nuc1. Tech. 
GRASS

\section{Purpose}

Analysis of transient fission gas release and swelling in oxide fuel.

\section{$\underline{\text { Status }}$}

A. Development: Developed and under imp rovement at ANL/MSD.

B. Availability: Operational at ANL on IBM 370. Models have been documented (Ref. 4).

C. Utilization: The code was developed to serve as a subroutine of LIFE (see LIFE summary), but may operate independently of LIFE if the initial fuel operating conditions are provided. The code has been verified and used by ANL for sensitivity studies of the various parameters affecting fission-gas swelling and release during steady-state and transient conditions.

\section{Problems Solved}

The code calculates the detailed behavior and effects of fission gases in oxide fuel pins during steady-state and transient conditions.

GRASS predicts the fission gas release (i.e., movement of fission gases to and $f$ rom grain boundaries and grain edges and/or to the fuel central void) and fuel swelling (i.e., fuel volumetric expansion due to fission gas accumulation and subsequent fuel displacement) as a function of time and operating conditions. The predictions are based on models of microscopic fission gas behavior which include the following:

a. Bubble migration (motion) by all competing mechanisms

b. Bubble coalescence and growth

c. Nonequilibrium effects

d. Bubble radiation-induced re-solution

e. Bubble interaction with structural defects (i.e., grain boundaries and dislocations)

f. Channel formation on grain boundaries and the evolution of interconnected porosity along the grain edges. 
These models are used to compute the evolution of the bubble-size distribution for all types of bubbles (i.e., those pinned to structural defects and those that are unpinned) in the fuel, which is then used to compute total fuel swelling and gas release. GRASS requires the following as input: fuel temperature, temperature gradient, fission rate, fuel density, grain size, and hydrostatic stress state.

\section{Models}

The basic model of GRASS (Ref. 1-4) assumes that fission gas atoms nucleate to form bubbles that move both by random (Brownian) motion and by the driving force of a temperature gradient. The bubbles may collide and coalesce to form larger bubbles, with the bubble gas pressure balanced by capillary and hydrostatic stress in the fuel. Bubbles are attracted to and pinned by structural defects, especially dislocations and grain boundaries, where they may continue to grow by coalescence. Included in the calculation of growth is a negative term describing radiation-induced re-solution, and terms describing the limited rate of growth of coalescing bubbles due to nonequilibrium effects.

Bubbles on grain boundaries migrate to the grain edges where they can either be released to the exterior of the fuel, or they can be trapped and contribute to fuel swelling. If a saturation density of fission gas is attained on the grain boundaries, channels are formed which vent the fission gas directly to the grain edges. The accumulation of porosity along the grain edges contributes to the evolution of the interconnected grain-edge tunnels, which in turn allows more fission gas to be released. If the temperature gradient is large enough, bubbles which grow to critical size can be pulled of the structural defects and migrate to the central void.

\section{Geometry}

The full fuel radial cross section is treated by dividing it into up to 15 fuel regions. All equations are 1-D (radial), the calculations representing an axisymmetric segment of a fuel pin with uniform axial properties.

\section{Bubble motion and coalescence}

Bubble mobility and velocity are computed through the bubble diffusion coefficient on the basis of three separate migration mechanisms for bubble motion, all of which occur whether or not there is a driving force present.

a. Surface diffusion of fuel matrix atoms around the interface between gas and fuel. 
b. Empirical diffusivities

c. Evaporation-condensation or vapor phase diffusion of evaporated fuel molecules across the bubble.

The functional form of the bubble diffusion coefficient is derived from several sets of diffusion data and theoretical considerations as a function of bubble radius (Refs. 2, 5). For a given bubble size range, one of the three migration mechanisms is assumed to dominate, and the bubble diffusion coefficient is determined accordingly. The bubble coalescence probability is computed following Gruber (Ref. 6).

Bubble transport from one fuel region to another is allowed.

3. Bubble-size distribution

The bubble size distribution is determined as a function of time in each of the fuel regions for the following three types of bubbles:

a. Bubbles not pinned to structural defects

b. Bubbles pinned to dislocations

c. Bubbles pinned to grain boundaries

The bubbles are divided into equal size groups on a log scale and properties are averaged over each group.

Bubble sizes are defined according to the number of gas atoms contained, with the gas assumed to obey the extrapolated EOS of Harrison (Ref. 7), which is essentially the van der Waals EOS with the constants being temperature and pressure dependent.

\section{Bubble interaction with structural defects}

The dislocations and grain boundary (i..., the microscopic fuel structural defects) are assumed to be randomly dispersed within the fue1. Bubbles are attracted to these defects due to the stress gradients surrounding them. Bubbles impinging on these defects are assumed "pinned" (i.e., they are attached but may still migrate along the defect and coalesce) if they are smaller than some critical size derived by Weeks, et. al. (Ref. 8). They are pulled away from the defect by the thermal gradient driving force when they reach the critical size. 


\section{Bubble resolution}

Gas bubbles may be reduced in size by irradiation-induced gas atom resolution in which the rate of gas atoms lost is assumed to be proportional to the fission rate and a resolution constant.

\section{Nonequilibrium effects}

Relaxation times for coalescing bubbles are calculated as a function of the bubble sizes, the fuel temperature, and properties of vacancy concentration and diffusion in the $\mathrm{UO}_{2} \cdot$ These relaxation times reflect the degree of nonequilibrium in the fuel and decrease the rate of growth of coalescing bubbles.

7. Channel formation

When a saturation density of fission gas is attained on the grain boundaries channels are formed whic: vent the fission gas directly to the grain edges.

8. Interconnected porosity

GRASS calculates the evolution of the interconnected porssity along the grain edges as a function of grain size, fuel density, pore size distribution, and grain-edge porosity. Fission gas reaching grain edges where the porosity is calculated to be open is released to the exterior of the fuel. Gas that is trapped along the grain edges contributes to fuel swelling.

\section{Bubble release}

The majority of gas is released via the interconnected porosity along the grain edges. Some gas may also be released to the central void due to bubble migration in a temperature gradient.

\section{Method of solution for fuel swelling}

From the models on the behavior of individual gas bubbles and atoms, differential equations are written to describe the rate of change of the number of bubbles in each size range. The diffusion coefficlents and bubble radil are calculated for the input fuel temperature grain size, and stress at the beginning of each time step. The code then integrates through time the rates of bubble coalescence, pinning and subsequent release. The total bubble volume or fuel swelling is 
calculated from a summation over the contribution from each of the bubble types and all size groups, with swelling calculated separately for each fuel region.

\section{Verification and calculations}

GRASS has been verified for steady-state LWR irradiations (Refs. 2, 3,9 ) and for out-of-pile transient heating tests (Ref. 3) on irradiated LWR fuels.

Sensitivity analyses have been performed for steady-state (Refs. 2, $3,9)$ and transient conditions (Refs. 2, 3, 5, 9, 10).

\section{Future Efforts}

Models will be upgraded if necessary, based on comparison with experiments. Interface/Overlap

SAS, LIFE, FRAS

\section{References}

1. R. B. Peoppe1, "An Advanced Gas Release and Swelling Subrou: ine," Proc. Conf. on Fast Reactor Fuel Element Tech., Am. Nuc. Soc., Hinsdale, I11., pp. 311-326 (1971).

2. J. Rest, M. G. Seitz, S. M. Geh1, L. R. Kelman, "Development and Experimental Verification of SST-GRASS: A Steady State and Transient Fuel Response and Fission-product Release Code," to appear in Proc. OECD-CSNI Mtg. on the Behavior of Water Reictor Fuel Elements Under Accident Conditions, Norway (September 1976).

3. J. Rest, "Light-Water-Reactor Safety Research Program: Quarterly Progress Reports."

4. Poeppel and Pat1, Trans. ANS 15 (June 1972).

5. J.W. Dias and R. B. Peoppel, "Transient Swelling Studies with the GRASS Code," ANL-7992 (March 1973).

6. E. E. Gruber, "Calculated Size Distributions for Gas Bubble Migration and Coalescence in Solids," J. of Applied Phys., 38, 243 (January 1967).

7. Harrison JNM $\underline{31}$ (1969). 
8. R. W. Weeks et al., "Migration Velocities of Bubble-Defect Configurations in Nuclear Fuels," J. of Nucl. Mater., 36 (2), 223-229 (1970).

9. J. Rest, "Behavior of Fission Gas in LWR Fuel During Steady-State Operating Conditions," Trans. Am. Nucl. Soc. 23 (1), 171-172 (June 1976).

10. J. Rest, M. G. Seitz, S. M. Geh1, "Release of Fission-gas from High-Burnup Fuel during Transient Heating," Trans. Am. Nucl. Soc. 26 (1), 323-324 (June 1977). 
GROWS

\section{Purpose}

Analysis of the growth of internally heated molten core debris pools into concrete structures, steel structures, or sacrificial material beds.

\section{Status}

A. Development: Developed and under improvement at ANL/RAS. GROWS II is under development

B. Availability: Early version distributed in late 1974. GROWS II is in a developmental stage and should be available in 1978 .

C. Utilization: Has been used by WARD for early evaluations of designs for core-retention systems for FFTF and for CRBRP.

\section{Problems Solved}

Predicts the dimensions and temperature as a function of time of a pool of molten core debris which is heated internally by the radioactive decay of fission products and activated nuclides and which is growing into an underlying structure. In the early version, only structures made of relatively low conductivity, fuel soluble ceramic materials such as $\mathrm{U}_{2}, \mathrm{MgO}, \mathrm{Al}_{2} \mathrm{O}_{3}$, basalt, etc., could be treated. In GROWS II, a model of transient heat transfer in concrete which takes account of internal heat sinks in the concrete and the release of gases is included. Also, a treatment for insoluble structural material such as steel is being developed.

Independent one-dimensional calculations are made in the downward and sideward directions from the pool center. The growth in each direction is then combined at the end of each time str, to calculate the changed shape and dimensions of the pool.

\section{Models}

GROWS :

\section{Geometry}

The pool is considered to have the shape of a right circular cylinder at all times. 


\section{Poo1 Heat Transfer}

The heat transfer in the three directions is calculated based on the pool dimensions and the volumetric heat generation rate. Upward heat $f l u x$ is based on the Kulacki-Goldstein correlation. Downward heat $f l u x$ is considered to be by conduction. Sideward heat transfer is calculated on the basis of thermal convection on a vertical wall. The heat fluxes from the pool in the downward and sideward directions are assumed to cause melting of the solid boundaries resulting in pool growth. The upward heat flux is tabulated. Tests are made to determine if the pool begins to boil.

3. Heat Conduction in the Structure

Heat conduction in the structure is neglected, limiting applicability to structures of relatively low thermal conductivity.

\section{Physical Properties}

Subroutines are included to evaluate the changing physical properties of the pool as solid material is melted and mixes with the original pool.

GROWS II :

\section{Geometry}

The pool is considered to have curved side walls with flat upper and lower surfaces forming a body of revolution which is symmetrical about the centerline.

2. Poo1 Heat Transfer

The heat transfer in the three directions is calculated based on experimental correlations developed since the original GROWS. The upward heat flux is based on the correlation and the transient results of Kulacki and Emara. The sideward heat flux is based on the correlations reported by the Mayinger group and on the experimental results of Farhadieh and Baker. The downward heat flux depends upon the ratio of the pool density to the density of melted structural material and is calculated on the basis of the Farhadieh results. As the pool density approaches that of the melted solid, the downward heat transfer becomes a conduction process. Downward heat $f l u x$ is also a function of the rate of gas bubbling through the melt in the case of concrete. This is treated on the basis of preliminary experimental correlations. 


\section{Heat Conduction in the Structure}

Heat conduction into the structure is calculated by two independent one-dimensional implicit finite element routines. The calculated temperature gradients in the sideward and downward directions are combined at each time interval to yield an approximation of the two-dimensional temperature field within the solid structure enclosing the pool. Concrete is modeled using a variable thermal conductivity to account for the heat transport effects of water migration within the concrete according to the analysis of Cheung and Baker. Heat sinks within the concrete are taken into account using a variable specific heat. Water vapor and $\mathrm{CO}_{2}$ release are calculated according to the location of appropriate isotherms within the concrete.

4. Physical Properties

Variable properties of the solid phase are treated as noted above and variable pool properties are treated as in GROWS.

5. Chemical Reactions

Chemical reactions between the core debris pools and the $\mathrm{H}_{2} \mathrm{O}$ and $\mathrm{CO}_{2}$ evolving from the concrete are taken into account. Composition changes and heat effects are calculated.

\section{Limitations}

1. Transient pool shapes are constrained to an idealized body of revolution.

2. Heat transfer is considered in three independent directions and combined in an approximate fashion to represent two-dimensional behavior.

3. Uncertainties exist on the effects of concentration gradients within the core debris pool and on the effects of solid crusts at the boundaries and particularly at the upper surface of the pool.

4. Some of the pool heat transfer correlations are based on limited experimental data.

\section{Future Efforts}

Development of GROWS II is to be completed in 1978. Experimental and analytical programs at ANL and at other sites in the US and abroad 
are being closely followed for new data and correlations to reduce uncertainty about the modeling of heat transfer within pool.

\section{Computer Operation}

1. Development is proceeding on the IBM 370 system.

2. FORTRAN IV language with no special requirements.

3. Typical running time is a few minutes.

4. Code Validation: Individual models are compared with available heat transfer and materials interaction data. Code versions are planned for direct comparison with experiments on core debris interactions with concrete and with results of simulation experiments of pool growth.

Interface/Overlap

\section{References}

1. R. Kumar, L. Baker, Jr., and M. G. Chasanov, "Ex-vessel Considerations in Postaccident Heat Removal," ANL/RAS 74-29 (October 1974). 
HAA-3

\section{Purpose}

Predicts aerosol behavior and transport following various LMFBR HCDA's and establishes the capability of containment related design features of LMFBR structures to limit aerosol contributions to the site dose.

\section{$\underline{\text { Status }}$}

A. Development: Developed and under improvement at AI.

B. Availability: HAA-3B available from Argonne Code Center.

C. Utilization: LMFBR containment design evaluation and radiologica1 consequence assessment for FFTF and CRBR.

\section{Problems Solved}

Predicts aerosol behavior and transport following various LMFBR HCDA's. The code computes the following:

1. Plated, settled, suspended, and leaked masses

2. Time-dependent geometric mean deviation, number concentration, and geometric mean radius for the log-normal distribution of the suspended material

3. Time-dependent $50 \%$ radius for the suspeuded material

4. Time-dependent number and volume distributions (functions of radius) for the settled, plated, and leaked material

5. Time-dependent effective radii for the suspended, settled, and plated material

6. Time-dependent aerodynamic equivalent radii for the suspended material

7. Leaked mass source for calculation in a second compartment.

\section{$\underline{\text { Models }}$}

The Smoluchowski (Reference 1) integro-differential equation for spherical particle aerosol behavior is solved in the moments method approximation during the high concentration phase. This method 
assumes the time-dependent particle density distribution to be log-normal. The physical model includes:

1. Particle generation: Source assumed to be $\log -$ normal with constant or variable rate of production.

2. Brownian and gravitational agglomeration.

3. Settling, plating, and leakage removal mechanisms.

HAA-3B includes a stirred settling model for calculating aerosol removal when the agglomeration rate equals the settling rate (multiplied by a user-selected constant). In this case, the log-normal distribution assumption is relaxed, and settling and leakage become the only removal mechanisms, with agglomeration being neglected. HAA-3B also allows the user to select correction factors for nonspherical particle shapes and orientation to account for changes in viscous drag, target area, and collision rate due to particle bending their trajectories by aerodynamic forces. An òptional klyachko correction for inertial drag is provided.

\section{Limitations}

1. Drop coalescent mode1 (aerosol particles are assumed to be spherical) requires correction for particle density and shape factor.

2. Time-dependent particle number distribution is assumed to be always log-normal until Stirred Settling Model is called.

3. The Cunningham gas viscosity correction exponential term is neglected.

4. Diffusion is assumed to account for wall plating (i.e., no thermophoresis term - no temperature gradient driving force close to containment wa11).

5. Turbulent agglomeration omitted.

6. Aerosols assumed to leak as if they were gases.

7. Resuspension neglected.

8. Charge effects neglected.

9. Validated for low to moderate concentrations in sma 11 to moderate sized vessels only. 


\section{Future Efforts}

1. Develop aerosol leakage model accounting for difference from gases.

2. Compare to large scale experiments.

3. Examine charge effects.

4. Add turbulent agglomeration term.

5. Compare to other codes.

6. Add thermophoretic term.

7. Add realistic gas mixing (stratification) for outer containment.

8. Examine effects of high concentrations.

9. Add evaporation and condensation.

\section{Computer Operation}

1. Operational on IBM 360 and $C D C-7600$ computers.

2. Requires $200 \mathrm{~K}$ by tes core allocation on IBM, no special periphera1, batch operation. Coded in FORTRAN-IV. SC-4020 CRT instructions included as comment cards. Requires 123,000 total units on CDC.

3. A 1-hr Na fire producing a $50 \mathrm{k} / \mathrm{gcc}$ peak concentration followed for 47 hours requires $20 \mathrm{sec}$ on IBM. The Gaussian stirred setting model solution consumed the largest amount of time.

4. References for Code Validation

(a) R. S. Hubner, E. U. Vaughan, L. Baurmash, "HAA-3 User Report," AI-AEC-13038 (3/73)

(b) L. Baurmash, R. P. Johnson, R. L. Koonts, C. T. Nelson, "Summary Report for Laboratory Experiments on Sodium Fires," TR-707-130-007 (8/73), Atomics International Internal Report

(c) R. L. Koontz, et. a1., "Aerosol Modeling of Hypothetical LMFBR Accidents," AI-AEC-12977 (8/70)

(d) "Analytical Studies of Aerosol Behavior Predictions for Fast React or Safety," Battelle Columbus Laboratories, BMI-1932, March 1975 
(e) "Aerosol Behavior Modeling for Fast Reactor Safety," L. D. Reed, J. A. Gieseke, Battelle Columbus Laboratories, BMI-666, Quarterly Progress Report for July-September 1975 , October 30,1975

Interface/Overlap

SOFIRE, COMRADEX/HAARM-2

\section{$\underline{\text { References }}$}

1. M. Smoluchowski, Physik. Z., 17, 557 (1916)

2. AI-AEC-MEMO-12880, Hubner, R. S., "An Approximate Solution to the General Equation for the Coagulation of Heterogeneous Aerosols," September 26, 1969

3. AI-AEC-13038, Hubner, R. S., et. al., "HAA-3 User Report," March 30, 1973

4. AI-AEC-12977, Koontz, R. L., et. al., "Aerosol Modeling of Hypothetica1 LMFBR Accidents," August 31, 1970

5. N707TI130041, J. M. Otter, "Understanding the HAA-3B Input Parameters Used to Characterize the Aerosol Particle Size Distribution," August 1975 
HAARM

\section{Purpose}

The HAARM codes predict aerosol behavior within an LMFBR containment for assumed accident conditions and give masses of fuel materials and sodium oxides released from the containment, thereby allowing the effects of containment geometry, assumed accident conditions, leak rate, and aerosol source rate to be evaluated for importance in limiting or attenuating the source to the ambient atmosphere.

\section{Status}

A. Development: All versions were developed at BCL. The current development verion is HAARM-3.

B. Availability: The versions of HAARM which have been or are in the process of being made operational are:

HAARM-1: Operationa1 at BCL (Ref. 1) but not released in lieu of HAARM- 2 .

HAARM-2: Operationa1 on various CDC or IBM computers at U.S. NRC, GE, Sunnyvale, ORNL, University of Missouri (Columbia), SUNY (Buffalo), Science Applications, Inc. (Palo Alto), Cadarache Nuclear Center (France), U.K.A.E.A., Argonne Code Center. Released in 1975 (Ref. 2).

HAARM-3: Developmental at BCL on CDC-6400. Will be operational by November 1977, and released by December 1977 .

C. Utilization: The HAARM codes provide evaluations of containment designs and information for radiological assessments for LMFBR designs.

\section{Problems Solved}

Each version of HAARM predicts aerosol behavior within an enclosed volume (cover gas region, containment vesse1, head cavity, etc.) in which a release of particles into the air or gas has been assumed to occur instantaneously or over some time period. The codes calculate particle growth by agglomeration, deposition on floor and walls, and leakage over a time 
period prescribed by a selected decrease in airborne mass concentration. The HAARM- 2 code predicts time-dependent values for

1. Plated, settled, suspended, and leaked masses;

2. Suspended particle number concentration, geometric mean radius, and geometric standard deviation for the log-normal distribution describing the size distribution;

3. Size distributions for the settled, plated and suspended masses;

4. Particle-particle collision efficiencies as calculated within the code for use in the gravitational agglomeration rate terms;

5. Correction term (alpha) for settling velocities as calculated within the code to account for porous agglomerate structure;

6. Fractions of leaked, deposited, and suspended masses that are fuel material if a mixture of fuel material and sodium oxide particles constitute an initial burst release of aerosol within the enclosed volume.

\section{$\underline{\text { Models }}$}

The integro-differential equation describing growth by agglomeration of a heterogeneously-sized aerosol is solved using the method of moments approximation to integrate over the size distribution which is assumed log-normal. The resulting ordinary differential equation is then integrated over time steps. The physical model used in the HAARM-2 code includes:

1. Particle source assumed to be instantaneous, continuous (at variable or constant rate) over a prescribed time or both and with a log-normal size distribution.

2. Brownian and gravitational agglomeration.

3. Particle sedimentation velocity calculated for Stokes settling of spheres but corrected for the expected pqrous agglomerate structure by use of a correlation of Kops, et. al. (3) with which the code calculates the correction at each time step from the number of primary particles in the mean-sized agglomerate.

4. Gravitational agglomeration rates are based on a geometrical area swept out by larger particles as they settle through suspended smaller particles with the collision efficiency adjusted by use of the equation of Fuchs ${ }^{4}$ for interception. 
5. Removal is by wall plating, sedimentation, and leakage. Wall plating includes the mechanisms of Brownian diffusion and thermophoresis. Sedimentation rates are size dependent with adjustments to settling velocity to account for porous agglomerate structure. Leakage employs no attenuation with the suspended concentration and volumetric leakage rate giving the mass leaked.

For low suspended concentrations, a stirred settling model is used for calculating aerosol removal with the assumption of no agglomeration. In this case the log-normal assumption is relaxed and sedimentation and leakage are the only removal mechanisms.

\section{Limitations}

The major code limitations have been imposed to facilitate achieving a computer solution that allows short running times. Limitations in terms of known aerosol behavior mechanisms excluded from the code and simplifying assumptions made are as follows:

1. It is assumed that the gas and aerosol within the enclosed volume is well mixed.

2. It is postulated that the particle size distribution is log-normal (until the stirred settling model is employed).

3. The corrections to settling velocity for porous agglomerates and rates of thermal deposition are made for all particles using the mean size as the calculation basis and are not substantiated by experimental evidence for aerosols formed from materials of interest in an LMFBR.

4. The analytical expression for particle-particle collision efficiency is only an approximate theoretical estimate unsubstantiated by direct experimenta1 measurements.

5. Particle plate-out or wall deposition rates are dependent on an $\underline{a}$ priori choice of a wall-plating parameter or diffusional distance for each of the Brownian diffusion and thermal deposition mechanisms. Values for these parameters cannot be estimated without considerable uncertainty.

6. Turbulent agglomeration is neglected.

7. Particle size distribution or airborne mass concentration is unchanged in the leaked gas flow. 
8. Particle resuspension from surfaces and the effects of radiation and electrica1 charge are neglected.

\section{Future Efforts}

The HAARM- 3 code under development will employ experimentally-derived expressions for particle density and diameter as functions of particle mass to account for the porous structure of agglomerates. In addition, experimentally-verified thermal-deposition velocities will be employed. Turbulent agglomeration rates will be included and airborne concentration reductions as a function of time will be used to allow presentation of the results in terms of values for exponential removal rate constants determined by curve fitting.

\section{References}

1. L. D. Reed, J. A. Gieseke, "HAARM-1 Users Manual," BMI-X-658 (May 15, 1975).

2. L. D. Reed, J. A. Gieseke, "HAARM-2 Users Manua1," BMI-X-665, Task 56, (October 31, 1975).

3. J. Kops, G. Dibbets, L. Hermans, and J. F. van de Vate, J. Aeroso1 Sci., $\underline{6}$ (1975).

4. N. A. Fuchs, The Mechanics of Aerosols, The MacMillan Company, New York' (1964). 
HAMDC

\section{Purpose}

Analysis of pressure transients in sodium piping networks.

\section{Status}

A. Development: Developed at HEDL.

B. Availability: Released.

C. Utilization: Has been used by HEDL and W-ARD for HCDA response analysis of FFTF auxiliary and closed loop systems and to check HCDA response of the primary piping system as predicted by other codes.

\section{Problems Solved}

Calculates pressure transients in liquid sodium piping systems resulting from pressure disturbances introduced at one or two points in the system.

\section{Mode1s}

1. Fluid Flow and Numerical Method

The governing partial differential equations are the 1-D, compressible, time-dependent conservation equations of continuity and momentum. These equations are reduced to the fluid-hammer (slightly compressible) equations and solved by the method of characteristics as outlined in Reference 2 .

2. $\underline{E O S}$

The code contains liquid sodium properties only, but could easily be expanded or changed to include any fluid properties.

\section{Piping System}

Forms pipe networks from individual straight pipe sections joined together at junctions. Junctions options are as follows:
a. Diameter discontinuity: an expansion or contraction
b. E1bow 


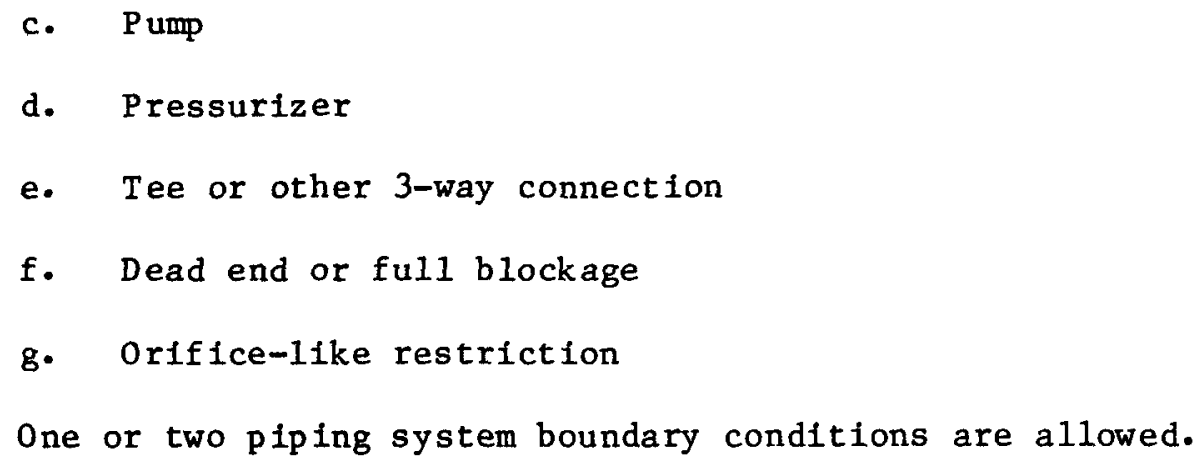

\section{Pressure Source}

Arbitrary pressure-time histories may be input at one or two positions in the piping system.

\section{Cavitation}

A column separation method is used (Reference 2).

\section{Pipe Dilation}

The speed of sound calculation is corrected to account for elastic behavior of pipe walls.

\section{Limitations}

1. Number of nodal points in the system model is limited only by the availability of computer memory. Problems have been run for models containing up to 300 pipe sections, each with a maximum of 20 nodal points.

2. Does not allow pipe wall plastic deformation.

\section{Future Efforts}

No definite work has been identified.

\section{Computer Operation}

1. The code has been operational on CDC machines.

2. Memory requirements depend on problem size. A model with about 6,000 nodal points required $310,000_{8}$ locations on a $C D C 6600$. The operational mode is batch. The code is written in Fortran and incorporates CALCOMP plotting routines. 
3. Running time depends on problem size. A 337 mesh point system model required 110 seconds of $C D C 6600$ time for a run out to 0.1 seconds.

\section{Code Verification}

HAMOC has been compared to experimental data and to more detailed computer codes as discussed in Reference 3 .

\section{Interface/Overlap}

REXCO, TUBE/NAHAMMER, NATRANSIENT, TRANSWRAP

\section{$\underline{\text { References }}$}

1. "HCDA Requirement and Loading for FFTF Design Evaluation," HEDL-FS-257, Revision 1, July 1976.

2. Streeter and Wylie, Hydraulic Transients, McGraw-Hill, N.Y., 1967.

3. H. J . Johnson, "HAMOC, A Computer Program for Fluid Hammer Analysis," HEDL-TME-75-119, December 1975. 
HEDPIN

\section{Purpose}

To estimate the pinwise power distribution in fast reactor triangular pitched pin bundles.

\section{$\underline{\text { Status }}$}

A. Development: HEDPIN was developed by HEDL which is operated by Westinghouse Hanford Company. Only one version of the HEDPIN Code exists.

B. Availability: HEDPIN is operational on the Richland CYBER computer, and has been sent offsite to two other ERDA contractors. Documentation is available (Reference 1). A selfcontained reference case sample problem is available upon request from the author.

C. Utilization: HEDPIN is currently used for calculating pinwise power densities in FFTF fuel and absorber assemblies. Results from these calculations are used on the thermal-hydraulic analyses of such assemblies, and for the determination of core wide statistical power capability.

Mode1s

HEDPIN fits a 2-dimensional polynomial equation to a surface of neutron group fluxes interior to and surrounding each assembly of interest. The polynomial fitting is done using the least squares reduction method. Pinwise group fluxes are found by interpolation from the resulting polynomial. Reaction rates or power densities are calculated for each pin by using input constants and integrating over the energy groups.

\section{Limitations}

HEDPIN predicts pinwise power density within a $3 \%$ accuracy in regions where the flux profile is flat. In other regions where steep flux gradients exist, HEDPIN is accurate to within $10 \%$. For a complete discussion, see Reference 1 .

Computer storage allocation is small for HEDPIN. A 76 assembly core can be analyzed with less than a $25{ }_{8} \mathrm{~K}$ word computer storage requirement. 


\section{Future Efforts}

No HEDPIN code work is in progress at this time.

\section{Computer Operation}

1. HEDPIN is operational on the Richland-Cyber Computer.

2. Logistics

a. HEDPIN core memory requirement is dependent on job size since variable dimensioning is employed to internally set the field length for each job.

b. HEDPIN requires three subroutines from the Math-Sciences Library .

c. The mode of operation is in FORTRAN-IV except for one subroutine in COMPASS.

3. Running time for a 76 assembly batch job with 217 pins per each assembly is about 10 minutes on a CDC 6600 computer.

4. Code Validation: There is little experimental evidence to validate the code; therefore, no experimental comparisons have been made, although a comparison was made between HEDPIN and a fine mesh neutronics calculation (Reference 1).

5. HEDPIN receives neutronics data from 2DB (Reference 2) and 3DB (Reference 4). Also cross-section data in the form generated by 1DX (Reference 5) is also used.

\section{References}

1. M. W. Cappiello, "HEDPIN: A Computer Program to Estimate Pinwise Power Density," HEDL-TME-76-49, May 1976.

2. W. W. Little, Jr. and R. W. Hardie, 2DB User's Manual--Revision 1, BNWL-831, Rev. 1, Battelle Northwest Laboratory, Richland, WA, 1969.

3. D. R. Marr, A User's Manual for 2DBS, A Diffusion Theory Shielding Code, BNWL-1291, Battelle Northwest Laboratory, Richland, WA, February 1970 .

4. R. W. Hardie and W. W. Little, Jr., 3DB, A Three-Dimensional Diffusion Theory Burnup Code, BNWL-1264, Battelle Northwest Laboratory, Richland, WA, 1970. 
5. R. W. Hardie and W. W. Little, Jr., 1DX, A One-Dimensional Diffusion Code for Generating Effective Nuclear Cross Sections, BNWL-954, Battelle Northwest Laboratory, Richland, WA, 1969. 
HERMES

\section{$\underline{\text { Purpose }}$}

To calculate radionuclide release and radiation dose resulting from the operation of large numbers of nuclear facilities in a region.

\section{$\underline{\text { Status }}$}

A. Development: Environmental and Economic Analysis.

B. Availability: Released to ACC.

C. Utilization: The subelements of the code may be used as a package or separately as an engineering analysis tool that provides regional estimates of the effects on the biosphere, in terms of the radiological dose to man, of the use of nuclear power for electrical energy generation.

$\underline{\text { Problems Solved }}$

Calculation of radiation dose to the population of a given region.

$\underline{\text { Models }}$

HERMES is structured in modular form. The subelement codes are essentially independent, being linked only in the transfer of data. In most cases, these codes may be used independently of the total HERMES model, if required, for specific problems not requiring the entire model. Furthermore, individual codes can be modified to meet changing conditions without affecting other parts of the model. The individual subelements are discussed below:

- Projections of Plant Selection, Siting and Scheduling

Projections of steam plant generation requirements are processed through the use of a chain of computer codes utilizing linear programming techniques, the optimum mixture of plant types within the region is selected. Separately, an inventory of potential plant sites is selected in the study region based upon projected load center locations and criteria defining site requirements. Each plant selected through the LP program is then assigned to a site by a computer code (SITE). Another code (MOPOSH) assigns typical monthly average capacity factors to each plant to meet monthly demand characteristics of the area where the plant site is located. 
- Radioactive Effluent Release

The computer code DOSIS calculates monthly average effluent rates for each radionuclide as a function of plant type and age, average capacity factor of the plant for the month of interest, and waste treatment process used. Similarly, the code REPARE calculates effluents from reprocessing plants, based on radionuclide inventories in the incoming fuel, fuel throughput rate, and type of waste treatment used. Both the DOSIS and REPARE codes "follow" each radionuclide from generation through each component of the cleanup and holding facilities of the plant under consideration, to the point of emission. Radionuclide inventories in retained wastes are also calculated.

- Radionuclide Emission Source Map

The output of the foregoing codes (SITE, MOPOSH, DOSIS, and REPARE) are combined by the RADREL code to provide a computer data tape in the format required by codes that model air and water transport of the radionuclides after discharge. The RADREL "map," or output tape, lists the location of each plant site, plant types and characteristics (including year of startup and stack height) and a month-by-month, site-by-site listing of monthly average emission rates for each radionuclide considered.

- Receptor Map

Radiation dose evaluation via the HERMES model requires the development of a "receptor map" defining the patterns of demographic characteristics, food production and consumption, work habits, and recreational practices in the region being studied. Population data, and much of the other needed data, are normally assembled at the county level; the country, therefore, was chosen as the basic unit for the receptor map. Each receptor area - single or multiple county - should then be analyzed to determine the singular point that most effectively represents the population distribution. This point, designated as a "centroid," then serves to uniquely represent the receptor area. Data representing the pertinent statistics of each centroid can then be assembled into a data bank and placed on magnetic tape. The receptor area is not required to be a county, it may be any area that can be adequately described for the purpose of the study.

- Transportation from Source to Receptor

Radionuclides emitted at a source are transported to a receptor by air transport, water transport, or both. Two computer codes were 
developed to simulate the mechanisms involved in these transport processes.

The air transport code (ARTRAN) utilizes monthly climatological data applied to standard mathematical modes for diffusion, deposition, and transport. This model calculates the radionuclide concentrations at each centroid by summing the contributions from each emission source. Included in these concentrations are the residual amounts of deposited materials contributed by each nuclear facility since its startup.

The water transport model (WTRAN) accepts data from the source map tape describing the location of each water emission source and rates of radionuclide emission. From the receptor map tape, it obtains the location of each centroid where concentration calculations are required. ARTRAN supplies calculated data on radionuclide deposition at each centroid. In addition, data are read in defining river flow characteristics, sediment types and concentrations, and hydrologic data on surface and ground waters for the watersheds within the study area. WTRAN then calculates the diffusion of radionuclides from the emission points, and resultant concentrations in solution and on sediments at each location requested; calculates over-bank deposition of radionuclides during flood season; and estimates radionuclide concentrations in surface water and ground water drinking sources resulting from the solution and transport of deposited radionuclides.

Dose to Man

The final mode1, DOSE, utilizes the processed data from all preceding codes and was developed to calculate the dose to man resulting from the radionuclide emissions from nuclear facility sites. This code considers the radionuclide contribution to total body dose and to the dose to six specific organs - the GI tract, bones, liver, skin, thyroid, and lungs.

The primary pathways to dose considered in the DOSE code are:

(1) direct immersion in air and water containing radionuclides;

(2) inhalation of radionuclides in air; (3) direct external exposure

to radiation (e.g., from radionuclides deposited ground surfaces, river banks, etc.); and (4) ingestion of radionuclides in food and water. The ingestion pathway incorporates a large number of specific food-chain pathways, and considers the effects of radionuclide deposition on plant surfaces and on soil, incorporation of radionuclides into plant and animal tissues, and concentration effects that occur in specific food chains. 
Dose evaluations may be made for up to four age groupings of the population.

At each centroid, dose evaluations are made for the average person and maximum individual in each age group.

Dose in this program is calculated from exposure to or ingestion of radionuclides in the Year 2000. No contribution to dose from exposure in previous years is considered.

Paralleling each dose calculation, dose commitment for the succeeding 50 years resulting from this exposure is calculated.

\section{Limitations}

The maximum number of receptor areas, "Centroids" that may be considered is 300 with 150 source sites and 50 nuclides. Up to 3000 receptor areas may be used with appropriate reductions in source sites and nuclides.

\section{Future Efforts}

At present no effort is contemplated to reduce the above limitations.

\section{Computer Operation}

1. The codes are operational on the following computers:

$\begin{array}{llll}\text { UNIVAC } & 1108 \\ \text { CDC } & \text { CYBER } 74- & & \\ \text { CDC } & 7600 & - & \text { Richland, WA. } \\ & & & \end{array}$

2. Mode of Operation - Batch

Programming Language - FORTRAN

Core Requirements -

3. Running Time - Varies with number of modules utilized, size of problem and output desired. May be only a few seconds up to 3 hours.

4. There is no known code or experiment that can validate the code. However, the dose module results have been checked by ORNL and TVA; the WTRAN module by ORNL, TVA and SRL; the ARTRAN module by NOAAATDL and found to accurately compute the requisite data. 
Interface/Overlap

None known.

$\underline{\text { Reference }}$

1. HEDL-TME-71-168, HERMES -- A Digital Computer Code for Estimating Regional Radiological Effects From the Nuclear Power Industry, December 1971 . 
HOPE

\section{Purpose}

An integrated program for studying the predisassembly behavior of a whole LMFBR core or a single fuel pin involved in a TOP accident.

\section{Status}

A. Development: Developed and under improvement at UCLA.

B. Availability: Operational at UCLA.

C. Utilization: Used at UCLA for TOP HCDA sensitivity studies of the SNR-300 core for prediction of clad failure, fuel movement and related phenomena as a function of reactivity ramp rate, burnup, power and clad failure location. Similar in many aspects to other integrated codes, as SAS and MELT, but has new time-dependent fragmentation model for FCI.

\section{Problems Solved}

The phenomena treated by HOPE for studying TOP fuel movement include:

1. Reactor k.inetics.

2. Steady-state fuel behavior.

3. Steady-state and transient fuel, clad and single phase coolant heat transfer.

4. Fuel melting and formation of a molten fuel-fission gas cavity.

5. Clad deformation and fallure.

6. Fuel and fission gas ejection.

7. Fuel fragmentation and FCI.

8. Fuel movement and reactivity feedbacks.

HOPE is applicable to all burnup and operating power conditions of either LMFBR whole cores or single pins in which sodium boiling does not occur prior to clad failure. 
$\underline{\text { Mode1s }}$

1. Geometry

Fundamental unit is a fuel pin with its associated coolant. A subassembly model includes a single representative fuel pin, coolant channel and associated hexcan structure, with all fuel pins in one subassembly assumed to act coherently. Interactions between channels in whole core analysis are not modeled since hexcans are assumed to maintain their integrity, with core transient thermal and hydraulic boundary conditions being fixed.

2. Steady-state

Initial state of reactor is user-specified. Fuel restructuring and central void formation models are available. Several models for fission gas release from fuel pins are available. Center void pressure is determined by assuming pressure equilibrium with the gas plenum, due to long periods of steady-state operation and temporary fuel cracks formed during shutdown.

3. Pre-clad failure transient

a. Heat transfer: heat conduction equation solved in a manner of SAS $1 \mathrm{~A}$.

b. Neutronics: point kinetics includes Doppler, sodium voiding and fuel movement reactivity feedbacks.

c. Coolant dynamics: single phase conservation equations are used to determine coolant conditions.

d. Fuel mechanics: a simplified fuel-clad thermal expansion model is used where clad is considered to behave as a thin shell and solid fuel is allowed to transmit stress to the clad assuming no slip between them. Plastic deformation of the clad is described using a high strain rate, irradiated, temperature dependent yield surface. Pressure in the fuel pin cavity is transmitted through the solid fuel to the clad, with the fuel considered strengthless. When the cavity-induced stress exceeds that caused by differential fuel-clad thermal expansion, the clad stress is assumed to be caused entirely by cavity pressure. Clad failure time and location is predicted by setting a clad permanent deformation or stress failure criteria can be selected. Clad failure flow area is user-specified. 
e. Fuel pin cavity mode1: cavity is assumed to be homogeneous and Impermeable, with size and state determined by combination of central vold fission gas. The cavity pressure is determined from the Berthelot EOS for a gas.

\section{Fue1/fission gas ejection}

Similar to SAS/FCI model: the time-dependent Bernoulli equations with additional flow choking considerations is used to model the assumed homogeneous, compressible removal of fuel/fission gas mixture.

5. Fuel fragmentation

A time-dependent fragmentation model in which ejected fuel fragments only when liquid-liquid contact with sodium occurs. This can cause delayed fragmentation events when vapor bubbles collapse from heat losses to cooler steel regions high in the core. Fission heating of ejected fuel particles is accounted for, delaying their solidification. The fragmentation model slows the rate of energy transfer to the coolant and thus slows fuel sweeping.

Assumes that molten fuel will be highly disturbed and fragmentation will not occur if the bulk sodium temperature is less than a $\mathrm{few}$ degrees subcooled or the fuel is not molten. Also, fragmentation can be stopped at a pre-specified void fraction considering homogeneous distribution of fission gas and sodium vapor in the interaction $z$ one. When fragmentation is permitted, the mass of fuel particles is divided exponentially during a specified time interval (obtained from experiments) into more particles of smaller volume. This determines the heat transfer area available.

6. $\quad \underline{F C I}$

Simflar to SAS/FCI model: a single zone interaction model, in which the length of the zone is initially specified as the clad failure length. Fuel is uniformly distributed in the zone. Sodium above and below the interaction zone is incompressible. An energy equation, in which the heat is transferred between clad, upper and lower zone interfaces and fuel particles, is coupled with an inertial constraint equation and an EOS, and all three are solved by Gauss elimination to find the average coolant properties in the interaction zone. Heat transfer between the fuel particles and sodium takes into account the fuels thermal conductivity and convective heat transfer is based on a Nusselt number correlation. Implicit in the FCI model is the assumption that the fragmentation process itself is not energetic. 
7. Fuel movement in coolant channel

All particles are bounded in cells with cell boundary motion describing axial fuel movement. Within each cell, the fuel mass is represented by a uniform dispersion of particles, all with the same time-dependent radius. The movement of the particles is determined by calculating the drag, gravity, and buoyance forces on the particles. A correlation is used for the situation where particles become closely packed.

\section{Limitations}

1. No allowance for multiple clad failures or a time-dependent failure area.

2. The fuel motion/fuel-coolant interaction modeling is similar to the SAS/FCI model and thus it has all the limitation of that model.

\section{Future Efforts}

None specified.

\section{Interface/Overlap}

- /SAS, MELT

\section{$\underline{\text { References }}$}

1. E. T. Rumble, "A Hypothetical Overpower Excursion Model for Liquid Metal-Cooled Fast Breeder Reactors," Ph.D. Dissertation in Engineering, UCLA (June 1974).

2. E. T. Rumble, et. a1., "Fuel Movement Investigations During LMFBR Overpower Excursions Using a New Model," Proc. Conf. Fast Reactor Safety, Beverly Hills, California (April 1974).

3. E. T. Rumble, et. al., "Sensitivity Analysis of an LMFBR to Whole-Core Overpower Excursions," Trans. American Nuclear Society, 1974 Winter Meeting, Volume 19. 
HOTP IM

\section{$\underline{\text { Purpose }}$}

A 1-D, two-phase compressible hydrodynamics model for the motion of a molten fuel/fission gas mixture inside a fuel pin following cladding rupture during a hypothetical TOP accident.

\section{$\underline{\text { Status }}$}

A. Development: Developed at HEDL for implementation into MELT.

B. Availability: Operational at HEDL. Original version ${ }^{1}$ incorporated $^{2}$ into MELT-III, and improved version ${ }^{2}$ in process of being incorporated into MELT-IIIA.

C. Utilization: Used by HEDL to do sensitivity analysis of molten fuel dynamics inside fuel pins for FFTF TOP accidents.

\section{Problems Solved}

HOTPIM can be used to study the following regarding molten fuel dynamics inside a TOP fuel pin:

1. Nonuniform pressures, densities, and velocities as a function of time and location along length of fuel pin.

2. Clad rupture size.

3. Amount and composition of the molten fuel/f ission gas mixture, which escapes through the clad rupture into the coolant channel.

\section{$\underline{\text { Models }}$}

HOTPIM uses Hartree's form of the method of characteristics (D. R. Hartree, Numerical Analysis, Second Edition, Oxf ord U. Press, 1958), which is modified to consider three characteristics in order to allow anisotropy in 1-D, two-phase flow. The conservation equations of mass, momentum and energy are reduced to characteristic form, with the characteristic equation being solved simultaneously on a constant Eulerian grid by using an iterative scheme. 
Relative motion between the molten fuel and gas is treated as a perturbation to homogeneous flow, modeled as the drift of independent bubbles in 1-D vertical flow in a static liquid. A volumetric drift flux is determired from a set of correlations, and a new void fraction is ccmuted at each time step.

The major assumptions used in HOTPIM are as follows:

1. The flow is strictly one-dimensional.

2. The flowing medium is a two-phase, two-component fluid, with no mass transfer between the components.

3. The gas is ideal and does not condense, and the liquid is nonvolatile.

4. The flow remains in the bubbly flow regime.

5. Flow through the cladding rupture is strictly transverse, with no velocity component parallel to the cladding wall.

6. The bubbles attain their terminal drift velocity instantaneously.

7. The correlations for steady-state drift in a hydrostatic pressure gradient apply for transient drift of fission/fill gas bubbles in molten fuel in a hydrodynamic pressure gradient.

8. There is no relative motion between pure liquid and the solid fuel grains existing when the bulk temperature of the fuel is between the solidus and the liquidus.

The following must be input:

1. Internal pin conditions at time of clad rupture (i.e., dimensions of molten region, initial void fraction and heating rate).

2. Location and size of rupture.

3. Change in dimensions of molten region as a function of time (consistent with rate of addition of molten fuel and fission gas into molten cavity).

4. Pressure outside rupture.

\section{Limitations}

HOTPIM limitations are given in the list of assumptions under Models. 


\section{Future Efforts}

Incorporate improved version of HOTPIM into MELT IIIA.

\section{Interface/Overlap}

MELT/PLUTO and EPIC.

\section{References}

1. H. J. Willenberg and A. Padilla, Jr., "Analysis of Transient Compressible Two-Phase Flow with Heat and Mass Sources Using the Method of Characteristics," Proceedings of the Conference on Computational Methods in Nuclear Engineering, CONF-750413, Vol. I, Charleston, South Carolina, April 15-17, 1975.

2. H. J. Willenberg, "Improvements in HOTPIM Internal Fuel Motion Code," Fast Reactor Safety Technical Progress Report - April, May, June 1976, HEDL-TME 76-56, Hanford Engineering Development Laboratory, Richland, WA, March 1977. 


\section{ANUS}

\section{$\underline{\text { Purpose }}$}

Simulation of transient neutronic - thermal-hydraulic behavior for a loop-type liquid metal cooled reactor plant, with detailed application to FFTF-type systems.

\section{$\underline{\text { Status }}$}

A. Development: Developed by WARD. Currently under review and updating for FFTF FSAR support.

B. Availability: Proprietary code, available only through lease or purchase arrangements; operationa 1 at WARD. The IANUS code is identified as an excepted item under ERDA contracts with Westinghouse.

C. Utilization: Used by WARD and HEDL for FFTF thermal transient design, pipe rupture and natural circulation analysis, and PPS and control system design.

Problems Solved

Analysis of:

1. Loss-of-electrical power transient.

2. Single or multiple pump seizure or coastdown.

3. Pipe rupture.

4. Natural circulation.

5. Control system malfunctions.

6. Tornado events (loss of secondary loops).

7. Control rod transients.

8. Tertiary (DHX) system failures.

Mode1s

Reactor is modeled as follows: 
1. Core - modeled by single "average" fuel pin and coolant channel with neutron point kinetics, reactivity feedbacks, fission product decay heat kinetics, and hot and peak channel factors.

2. Internals - radial reflectors, radial shielding and vessel shielding are homogenized, with heat generation, heat capacity and coolant transport effects included.

3. Plena - mixing models for inlet and outlet plena are chosen by Input with heat transfer to structure included.

4. Any number of heat transport loops, but only one of which may be behaving differently from others, are modeled with each containing the following:

a. Primary pump, pump motor, rheostat, isolation and check valves and piping.

b. IHX - a multi-mode "average" channel is calculated per loop.

c. Secondary pump, pump motor, rheostat, isolation valve and piping.

d. DHX - models sodium, finned tubes and air with a multi-mode "average" module per loop.

e. DHX air fans, outlet dampers, inlet vanes, and associated air control systems.

f. Cover gas.

g. Plant automatic controls.

h. PPS systems.

\section{Limitations}

1. Core model has single dynamic average channel and uses hot and peak channel factors.

2. Code handles only single phase coolant flow, with SAS used for excursions beyond boiling.

3. Bypass flow structure is homogenized.

4. Reactivity inserted must be less than $+\$ 1.00$, due to point kinetics formulation. 
5. Fuel restructuring and melting not allowed in code.

6. Transient, hydraulics treats only nonacoustical phenomena due to incomp ressible flow assumption.

7. Fluld and metal temperature expansion effects on vessel and pump tank fluid levels are not calculated.

\section{Future Efforts}

Test verification of pipe rupture hydraulics.

\section{Computer Operation}

1. IANUS is operational on:

A. the Westinghouse Advanced Reactors Division CDC-7600

B. HEDL CDC 6600

C. Brookhaven National Laboratory (undergoing commissioning)

2. Logistics:

A. Core memory requirements: $150 \mathrm{~K}$ octal

small core memory - no special peripherals

B. Mode of operation: batch

C. Programming language: FORTRAN IV

D. Compiler requirements: CDC FTN 4.1

E. Special plotting sof tware: Westirghouse plotting package

3. Typical Problem Running Time: For long term runs (i.e., those with transients greater than one minute) running time on the Westinghouse Advanced Reactors Division CDC-7600 computer is approximately one-tenth real time; on the HEDL CDC-6600, running time is about one-half real time.

For a double ended pipe rupture at vessel inlet with pony motors on, 100 percent load, and 3 loop operation, the real transient time is about 100 seconds; for a $0.6 \mathrm{ft}^{2}$ rupture at the vesse 1 
182

inlet, 3 loop operation, primary pony motors off, and $60 \%$ load, the transient time (real) is about 75 seconds.

Interface/Overlap

\section{SAS / DEMO}




\section{$\underline{\text { Purpose }}$}

Analysis of hydrodynamic-structural response to pressure loadings resulting from $\mathrm{HCDA}^{\prime} \mathrm{s}$ in reactor containment and components.

\section{Status}

A. Development: All versions were developed at ANL/RAS. ICECO-II is a current development version.

B. Availability: ICECO-H (hydrodynamics) and ICECO-HT (heat transfer) are two versions of ICECO operational at ANL on IBM 360. ICECO-H has been documented in 1975 (Ref. 1). ICECO-II is an extended version of ICECO-H, developmenta1 at ANL on IBM 370.

C. Utilization: The ICECO codes have been used exclusively by ANL due to its developmental status until 1977.

\section{$\underline{\text { Problems Solved }}$}

The ICECO-II is a coupled Eulerian-Lagrangian code for analyzing the hydrodynamic-structural response of reactor containment and components. The Eulerian coordinate system is used for the analysis of the fluid motion while the Lagrangian coordinate system is employed for the calculation of the structural response. The code is intended to perform fluid-structure interaction that may involve large displacements and excessive material distortions. The ICECO-II version is developed to extended analytical capabilities of REXCO-type analysis for primary system hydrodynamic-structural response to pressure loads resulting from nuclear excursions. The REXCO hydrodynamic analysis, which is based on explicit time-differencing scheme and a Lagrangian coordinate system, is not applicable to problems involving large fluid motion (see REXCO summary). The ICECO hydrodynamics, which is based on implicit time-differencing scheme and an Eulerian coordinate system, is particularly suited for problems involving long time duration events and large fluid motions and thus can continue the hydrodynamic-structural analysis after REXCO becomes inadequate. Thus, use of the two codes allows a complete response analysis for the full range of postulated nuclear excursion energies up to the point of system pressure equilibrium.

ICECO is also devoted (1) to perform structural analysis to high-energy excursions involving excessive distortion, such as bubble contraction and 
sodium spillage, and (2) to provide detailed analysis of fluid-structure interaction and response of major piping components such as valve and heat exchanger.

The ICECO codes have been applied to the following HCDA analysis problems:

1. Studies of low-energy excursions.

2. Effect of coolant compressibility on pressure wave propagation.

3. Dynamics of HCDA-induced core vapor bubble motion within the reactor vessel.

4. Sodium spillage through head-vessel opening and penetration holes on the vessel cover as a consequence of slug impact on head.

5. Responses of primary containment and components such as the radial shield, core barrel, core-support structure during an HCDA.

6. Interpretation of HCDA simulation experiments for German Demonstration plant SNR-300. (Ref. 2).

Models

\section{ICECO-H:}

\section{Geometry}

All formulations are for 2-D, cylindrical axisymmetric geometry.

2. Hydrodynamics

The governing equations for fluids are the full, compressible, transient, nonlinear differential equations for conservation of mass, momentum and energy. The momentum conservation equations include nonlinear convective and viscous diffusion terms. The full viscous stress tensor is incorporated instead of a simple artificial viscosity for elimination of shock discontinuities, and an optional mass diffusion term can be employed to enhance numerical accuracy for certain problems. The conservation equations are solved along with an arbitrary EOS to yield the desired field variables.

\section{Method of solution for hydrodynamics}

Solution of the conservation and EOS equations is based on the ICE (Implicit, Continuous-Fluid, Eulerian) technique (Ref. 3). A11 
equations are expressed in Eulerian coordinate form and then set into numerical form by finite-difference equations which use an implicit time differencing scheme. Substitution of advanced-time densities and velocities, pressures, densities and internal energies. The implicit treatment of the density variation provides a solution capability for problems involving the full range of flow regimes from the incompressible limit to hypersonic. A generalized timecentering capability is available for elimination of undesirable low-order truncation errors. The ICECO solution methodology possesses the advantages of: (a) the inviscid boundary condition between the fluid-solid interfaces are easy to handle, (b) suitable for both plane and cylindrical symmetric geometries, (c) large time steps can be chosen without compromising numerical stability and (d) the fluids may distort without limit.

\section{Reactor Structures}

All reactor internal structures and head are rigid and openings within internal structures are at least the size of an Eulerian cell. An option allows the code to be coupled with a subroutine which allows treatment of a flexible reactor vessel and core barrel as elastic-plastic, cylindrical, thin shells. Another option treats axial motion on the right head, with the holddown bolts modeled as a restraining force on the head. Plug jump (i.e., sudden head motion due to slug impact) can be accommodated with numerical stability and an irregular cell treatment eliminates the restriction that sodium spillage area be at least the size of a fixed Eulerian cell.

\section{ICECO-II:}

1. Geometry

S ame as ICECO-H.

2. Hydrodynamics

Same as ICECO-H.

3. Method of solution of hydrodynamics

Same as ICECO-H.

4. Reactor structures

The response of reactor structures is analyzed by a finite-element program using a co-rotational (Lagrangian) coordinates system. The 
code is suited for problems involving large displacements with both geometry and material nonlinearities. All internal and external structure can be considered either as rigid or deformable. The primary vessel, core barrel, and core-support structure are modeled as elastic-plastic cylindrical thin shells using the shell element. The radial shield and other thick solid structures can be modeled as heavy fluids or as elastic-plastic solfds using the quadrilateral continuum elements. Perforated openings on the core-support structure can be included in the model to allow wave transmission between the upper and lower plenums. Reactor cover is considered as rigid. Another option treats axial motion of the rigid head, with the holddown bolts modeled as a restraining force on the head. Plug jump (i.e., sudden head motion due to slug impact) can be accommodated with numerical stability and an irregular cell treatment eliminates the restriction that sodium spillage area be at least the size of a fixed Eulerian cell.

\section{Fluid-structure interaction}

The ICECO-II codes provides a generalized hydrodynamic scheme to treat the irregular cells created by the movements of the structure with respect to the fixed Eulerian coordinates. The developed scheme thus allows the hydrodynamic analysis to be linked with any structural dvnamic program. In the analysis, a relaxation equation for the pressure adjacent to the structure is derived from the boundary condition at the fluid-structure interface. This equation, in conjunction with the Poisson equation of the ICE method, is solved iteratively. The convergence is attained when boundary conditions at all interfaces are satisfied. Option is provided to handle the perforated openings on the core-suport structure. Capabilities of treating fluid motion at geometrical discontinuities such as sharp corners are also provided to adequately analyze the wave diffraction phenomenon.

\section{ICECO-HT:}

This version consists of ICECO-H with FCI and condensation models incorporated.

1. $\quad$ FCI mode1s

Same as for REXCO-HT.

2. Condensation model

As the FCI zones expand and uncover steel, heat is transferred from the sodium vapor to the cold steel, thereby condensing sodium and 
reducing the FCI zone pressure. Different values of the area and mass of exposed steel can be prescribed for each Eulerian cell.

\section{Limitations}

ICECO-H, and ICECO-II:

1. All material within a single Eulerian cell is homogeneous.

2. Restricted to single-field calculations (single-field restriction implies that ICECO cannot handle the interpenetration of two different homogeneous materials across an interface).

3. Turbulent flow capabilities have not been incorporated.

4. Computer storage allocation: ICECO-H 800 Eulerian zones ICECO-II presently 300 Eulerian zones.

\section{Future Efforts}

1. Multi-field capabilities

2. Turbulent flow capabilities

3. Increase computer storage allocation for ICECO-II.

\section{Computer Operation}

1. ICECO-H: Operational on IBM 360

ICECO-II: Operational on IBM 370

2. Logistics: ICECO-H core memory is $500 \mathrm{~K}$ ICECO-II core memory is $750 \mathrm{~K}$

3. Typical Problem Running Time: Analysis of a typical FFTF reactor configuration $\left(10^{\prime}-0^{\prime \prime}\right.$ radius and $27^{\prime}-0^{\prime \prime}$ high) using mesh size $10 \times 22$ for the solution extending to $22 \mathrm{msec}$ needs 18 minutes computing time

4. Code Validation:

(a) Comparisons of code solution to SRI experiment of wave propagation in elastic-plastic pipe - published in Ref. 4.

(b) Comparisons of code solution to ANL experiment on the bubble expansion and contraction - published in Ref. 5 . 
(c) Comparisons of ICECO solutions to experiments and REXCO code on the slug impact problem and pipe response - published in Ref. 6 .

(d) Comparisons of ICECO solutions to experimental findings on the German Demonstration plant SNR-300 for six different configurations appeared in Ref. 2 .

(e) Comparisons of ICECO solutions to SRI Reactor vessel tests will be made.

Interface/Overlap

VENUS/REXCO

References

ICECO documentation:

1. C. Y. Wang, ICECO - An Implicit Eulerian Method for Calculating Fluid Transients in Fast Reactor Containment, ANL-75-81, Dec. 1975, Argone Nationa1 Laboratory, Argonne, I11inois.

2. A. H. Marchertas, C. Y. Wang, J. C. Bratis, H. Y. Chu, J. Guildys and S. H. Fistedis, ERDA/ANL Contribution to the Interpretation of HCDA Simulation Experiment for SNR-300, ANL/RAS 76-13 (Apri1 1976).

3. F. H. Harlow and A. A. Ams den, A Numerical Fluid Dynamics Calculation Method for a11 Flow Speeds, J. Comp. Phys. 8 , 197 (1971).

4. C. Y. Wang, M. T. A. Moneim and Y. W. Chang, An Implicit finitedifference Method for Fluid Dynamics Calculation in the Primary Coolant System, Proc. if ANS Topical Meeting on Compat. Methods in Nucl Eng., Charleston, S. C., Conf-750413, Vol. I (Apri1 1975) II-85.

5. Y. W. Chang et a1., Analysis of LMFBR Primary System Response To an HCDA Using a Eulerian Compuicer Code, Nucl. Eng. and Design, Vol. 38, No. 1, pp 55-70 (July 1976).

6. H. Y. Chu et al., A Generalized Eulerian Method in Reactor Containment Analysis and its Comparison with Other Numerical Methods, Int1. Meeting on Fast Reactor Safety and Related Physics, Chicago, I11inois (October 5-8, 1976). 
ICEPEL

\section{Purpose}

Coupled hydrodynamic-structural response analysis of piping systems to internally travelling pressure pulses.

\section{$\underline{\text { Status }}$}

A. Development: Uuder development at ANL/RAS.

B. Availability: Operational at ANL on IBM 370/195; and at LBL on CDC-7600. Documentation will be available in 1977.

C. Utilization: Safety Analysis of Nuclear reactor piping systems under extreme accident conditions.

\section{Problems Solved}

ICEPEL couples 2-D compressible hydrodynamics with structural response analysis of thin shell to compute the following for pressure loading in any range:

1. The mechanical response of fluid filled elastic-plastic pipe systems to pressure pulse applied simultaneously at ends of pipes. The propagation and interaction of such pressure pulses with one another and with the different components of the system is estimated. The pipe system consists of pipes, elblows of any angle, valves, pipe flow area changes, heat exchangers, tees and surge tanks.

2. The propagation of pressure pulses within fluid-filled deformable valves with or without interior rigid wall simulation.

3. Pressure pulse propagation within a fluid-filled intermediate heat exchanger (IHX) with deformable exterior walls, interior rigid wall simulation, and with or without tube bundles.

4. Effects of tee branches and closed loop branches on the pressure pulse propagation in piping systems.

5. Surge tank, or gas plenum, protection of critical piping components. 


\section{Models}

\section{Geometry}

Straight pipes, valves, pipe flow area changes, and heat exchangers are modelled as 2-D axisymmetric. The elbow is 2-D and considers flow in the radial (radially outward from the center of curvature of the elbow) and tangential direction with secondary motion ignored. The surge tank is a simple minded $1-D$ and is considered connected to the piping system through a short pipe and a tee.

\section{Hydrodynamics}

Implicit Continuous Fluid Eulerian (ICE) Einite difference technique which utilizes the full Navier-Stokes Equation with both the viscous and nonlinear convective terms considered is employed. The technique is suited for different forms of equation of state.

\section{Method of Solution}

Iterative solution of the resulting five points Poisson's equation yields the new pressures which upon substitution in the equations of state and momentum results the new densities and velocities. At the deformable wall boundary the fluid is forced to move with the deformable wall in a direction normal to it while sliding freely along the wall.

4. Piping Loop Mechanical Response

The walls of straight pipes, valves, pipe flow area changes and heat exchangers can be treated as rigid or deformable. In the deformable analysis, the walls are modelled as thin axisymmetric shells of revolution undergoing large deformations. The wall material is elastic-plastic and strain-hardening. Nonlinearities arising from large deformations and due to material properties are both accounted for. The elbow walls are considered to have rigid walls.

\section{Elbow Mode1}

The 2-D model approximates the transient flow in an elbow of arbitrary angle. The analysis accounts for the effects of centrifugal forces, but neglects the secondary flow in the elbow region.

6. Generalized Piping Component Mode1

This component is used to model valves, pipe flow area changes and heat exchanger. It is a 2-D axisymmetric model with 9 possible 
exterior wall configurations, interior rigid wall simulation option, and with optional heat exchanger tube bundle effect model.

7. Tee Mode1

Is modelled as a junction connecting three pipes. The mass of the fluid inside the tee is conserved at all times and the axial momentum equation is satisfied at pipe ends connected to the junction.

8. Surge Tank Mode1

A simple minded 1-D axisymmetric model that can be used to model gas plenums. It is considered to be connected to the pipe system

through a short pipe and a tee junction.

\section{Limitations}

1. Elbow walls are nondeformable.

2. Flexural motion and stresses of piping system are not considered.

Future Efforts

1. Modelling of pumps.

2. Deformable elbow walls.

3. Consideration of flexural motion of piping systems.

4. Coupling with ICECO to provide integrated analysis of primary containment systems.

\section{Interface/Overlap}

REXCO, ICECO, and MICE

\section{$\underline{\text { References }}$}

1. C. Y. Wang, et. a1., An Implicit Finite Difference Method for Fluid Dynamics Calculation in Primary Coolant Systems, ANS Topical Meeting on Mathematical Computation Methods, April 1975, Charleston, S.C.

2. M. T. A-Moneim, ICEPEL, A Two-Dimensional Computer Program for the Transient Analysis of a Pipe-Elbow Loop, ANL-75-35.

3. M. T. A-Moneim, Coupled Hydrodynamic-Structural Response Analysis of Piping Systems, ANL Report to be published. 
INDOS

\section{Purpose}

Estimation of the internal radiation dose to man.

\section{Status}

A. Development: Developed at 0ak Ridge National Laboratory, Oak Ridge, Tennessee, as INDOS 1 , INDOS 2, and INDOS 3 .

B. Availability: The INDOS codes are documented in Ref. 1 and are available from the Radiation Shielding Information Center, Oak Ridge National Laboratory, P.0. Box X, Oak Ridge, TN 37830. They are operational on the ORNL PDP-10 System.

C. Utilization: Incorporated into the assessment methodology of the Environmental Sciences Division at ORNL for generating dose conversion factors.

Problems Solved

The INDOS codes are conversational FORTRAN IV programs which use ICRP-10$10 \mathrm{~A}$ models to estimate the radiation dose to an organ of the body of a reference individual resulting from the ingestion or inhalation of any one of various radionuclides. Two patterns of radionuclide intake are simulated: intakes at discrete times and continuous intake at a constant rate. The codes provide:

1. tabular output of dose rate and dose vs time,

2. graphical output of dose vs time, and

3. punched-card output of organ burden and dose vs time.

\section{Models}

The models employed are those referenced in ICRP Publications 10 and 10A (Refs. 2, 3). Dose and dose rates are computed as functions of time.

\section{Limitations}

1. Dose to lungs and G.I. tract are not computed.

2. Age-dependent calculations are not convenient. 
3. Some retention functions given in ICRP Publications 10 and $10 \mathrm{~A}$ are subject to scrutiny.

\section{Future Efforts}

No future development intended.

Interface/Overlap

-/INREM, DACRIN, COMRADEX

\section{$\underline{\text { References }}$}

1. G. G. Killough and P. S. Rohwer, "INDOS - Conversational Computer Codes to Implement ICRP-10-10A Models for Estimation of Internal Radiation Dose to Man." ORNL-4916, UC-71, March 1974.

2. Recommendations of the International Commission on Radiological Protection. Report of Committee 4 on Evaluation of Radiation Doses to Body Tissues from Internal Contamination due to Occupational Exposure. ICRP Publication 10, Pergamon Press, London (1968).

3. Recommendations of the International Commission on Radiological Protection. Report of Committee 4 on the Assessment of Internal Contamination Resulting from Recurrent or Prolonged Uptakes. ICRP Publication 10A, Pergamon Press, London (1971). 
INREM-II

\section{Purpose}

To estimate the internal radiation dose to each of a number of target organs of man resulting from the intake of radionuclides by inhalation or ingestion.

\section{$\underline{\text { Status }}$}

A. Development: Health and Safety Research Division, Oak Ridge National Laboratory. Current version is INREM II.

B. Avallability: Developmental. Numerous successful runs on the ORNL IBM 360-91 and -75 .

C. Utilization: Currently being used to compile internal dose conversion factors for about 100 radionuclides in an NRC-sponsored research project.

\section{$\underline{\text { Problems Solved }}$}

Corresponding to an intake of a radionuclide by inhalation (in particulate form) and ingestion, the code estimates the radiation dose to a specified set of target organs of man resulting from the uptake and retention of the radionuclide and its daughters in various source organs of the body .

Required data are physical information about the nuclide and its progeny (half-lines, branching ratios), metabolic information related to the uptake and retention of each nuclide species in the chain, and dosimetric $S-f$ actors ( $r e m / \mu C 1-d a y)$ for each species and each source-target organ combination considered. The intake rate ( $\mu \mathrm{C} i$-day) may be specified as a step function of time. Integration of the dose rate may proceed over any specified time interval (e.g., 50 years). Output is presented as (1) a summary of the input data and (2) a source target dose matrix with a column of total contributions for each organ.

\section{Mode1s}

Deposition of an inhaled particulate in the major respiratory regions and its subsequent biological removal are simulated in accordance with the Task Group Lung Model [Marrow et. al., Health Physics, 12, 173-207 (1966); ICRP Publication 19, Pergamon Press (1972)]. Movement of radioactivity through the GI tract is represented by a four segment catenary model with 
first-order kinetics and mean transit times as suggested by Eve, Health Physics, 12, 131-162 (1966). Retention of a multiple is other organs is assumed to be governed by normalized linear combinations of decaying exponentials. The individual dynamics of each species in a chain are taken into account in calculating radioactive decay, formation of daughters, and transfer of radioactivity among the body's compartments.

For its dose estimates, INREM-II requires as input data appropriate sets of S-factors (rem/ Ci-day) such as those defined by Snyder et. al., ORNL-5000 (1974).

Solutions of the system of differential equations are approximated by subdividing the integration interval into a number of subintervals, within which the dynamics of biological transfers among compartments are approximated. Exact solutions of the radioactive decay equations are obtained for each subinternal, in order to accommodate the much wider spreads of time constants that are sometimes present in these processes.

\section{$\underline{\text { Limitations }}$}

The code is not designed to estimate and display dose rate as a function of time. Also, the present version does not permit variation of the biological parameters with the age of the reference individual.

\section{Future Efforts}

An age-dependent version of INREM-II is planned, though it should be mentioned that data to support age-specific dose estimates in this level of detail are very scarce at present. The estimation of dose-rate will be considered in the context of NRC's needs.

\section{Computer Operation}

1. List of computers: IBM 360-91, -75 under OS-MVT.

2. Logistics: Approximately $200 \mathrm{~K}$ bytes of core memory required for execution. Batch mode, card input, line-printer output (132 print positions +1 carriage-control character). IBM FORTRAN-H, two IBM 360 Assembler routines which can be edited out or replaced by counterparts in another system. No special sof tware.

3. Typical Problem Running Time: Varies with the number of nuclide species in the chain, the numbers of source and target organs considered, and the number of subintervals into which the integration time interval is divided. A problem consisting of 
10 species, 8 source and 22 target organs required 3.94 CPU-sec on the IBM 360-91 for the estimation of 50-year dose commitments for one inhalation and one ingestion case.

4. Code Validation: None.

Interface/Overlap

AIRDOS/INREM-I.

\section{References}

1. G. G. Killough, Jr.. et. a1., INREM-II: A Computer Implementation of Recent Models for estimating the Dose Equivalent to Organs of Man from an Inhaled or Ingested Radionuclides, ORNL/NUREG/TM-84 (in preparation). 
LA-COBRA

\section{$\underline{\text { Purpose }}$}

Simulation of fuel behavior and thermal-hydraulics in a fast reactor fuel subassembly for experimental analysis and phenomenological studies.

\section{$\underline{\text { Status }}$}

A. Development: This extended version of COBRA (BNWL) is under development at LASL in Group Q-7.

B. Availability: Developmental at LASL on CDC-7600. Expected operational date for the fist version in November 1977 .

C. Utilization: Not currently available for use.

Problems Solved

LA-COBRA will calculate the response of a hex-lattice fuel pin bundle in a subassembly can, initially intact, to a variety of transient conditions. It will be possible to calculate behavior of a sodium-cooled subassembly in transient under-cooling or over-power conditions, through sodium voiding and fuel failure. Aso, initially voided or gas-cooled subassemblies will be treated. Fuel and cladding motion will be treated in future versions.

Models

In addition to the COBRA-IV-I treatment of subassembly hydraulics, LA-COBRA will include new models for (1) fuel pin failure based on a three-dimensional version of LAFM (LASL); (2) thermal radiation among pins and to the can wall and (3) azimuthal heat conduction in fuel pellets. Specific features of the models are temperature dependent material properties, multiregion fuel pellets, fuel-cladding differential thermal expansion, fission gas induced fuel swelling, fission gas release to the central void, failure due to melting, sodium vapor effects in thermal radiation, and axial thermal radiation.

Limitations

In the first version of LA-COBRA, fuel and cladding relocation due to melting, failure or fission gas induced fuel dispersal is not treated. In the thermal radiation model, angularly dependent emissivities, absorptivities, and reflection are not considered. 
The size of the fuel pin bundle (i.e., number of pins) which can be used will be limited only by the available computer storage capabilities. It is expected that it will be possible to use LA-COBRA on a CDC-7600 to analyze safety tests with as many as 271 pins.

\section{Future Efforts}

Work will proceed in the future to complete development of the heat transfer model and to couple the new models with COBRA-IV-I in order to form the first operational version of LA-COBRA.

\section{Computer Operation}

A wide variety of options will be available in LA-COBRA which will determine the extent of detail and the number of pins to be represented in the calculation. It is therefore anticipated that the problemdependent computation requirements will span a wide range.

Code validation will include comparisons to COBRA-IV-I results and an analysis of the impact of the new features in LA-COBRA. In addition, analyses of TREAT series experiments will provide for further comparisons.

\section{Interface/Overlap}

Use of LA-COBRA results to initiate SIMMER (LASL) calculations of extended motion of core materials will be possible when fuel and cladding motion models are implemented in future LA-COBRA versions.

\section{References}

1. R. D. Burns, P. K. Mast and J. L. Tomkins, "Reactor Safety and Technology Quarterly Progress Report, April 1 - June 1977," Los Alamos Scientific Laboratory report, to be published. 
LAFM

\section{$\underline{\text { Purpose }}$}

Prediction of the time and location of cladding failure for LMFBR fuel pins subjected to power and/or flow transients.

\section{$\underline{\text { Status }}$}

A. Development: The current development version, LAFM-I, which is applicable to the analysis of TOP's, has been developed at LASL in Group Q-7.

B. Availability: The two versions of LAFM which are in the process of being made operational are:

LAFM-I: Developmental at LASL with successful operation on CDC-7600. Will be made fully operational by October 1977 but will not be released in lieu of LAFM-II release.

LAFM-II: Developmental at LASL on CDC-7600. Wil1 be made operational by october 1978 .

C. Utilization: The LAFM-I code has been used to study the effects of nonprototypic conditions (fluence-to-burnup ratio, circumferential fuel crack, pin length) on fuel pin failure.

\section{Problems Solved}

The LAFM code predicts the response of LMFBR fuel pins to therma 1 transients up to the time of cladding failure. An initial fuel pin characterization and a transient power history (no neutronic calculation) must be supplied by the user. The prediction of fuel pin response involves the calculation of:

1. The transient temperature distribution in the fuel pin and coolant channel.

2. The fission gas release and swelling due to transient heating.

3. The dimensional changes of the fuel and cladding due to temperature, gas release and fuel-cladding mechanical interaction.

4. The time dependent pressure at the cladding inner surface. 
5. The cladding strain including the permanent outer cladding strain.

6. The time dependent life fraction of the cladding (which indicates how close to failure the cladding is).

The LAFM code is limited to describing pins which are azimuthally symmetric and which can be described by only considering an effective coolant channel (i.e., no pin-to-pin effects, cross-flow-mixing, etc.). See LA-COBRA for a code without these limitations.

\section{Models}

The models used in LAFM-I and LAFM-II are the same except for the transient temperature and fission gas calculations.

\section{Geometry}

The LAFM calculation is based on a single azimuthally symmetric pin surrounded by its associated coolant and structure (used primarily for the analysis of capsule tests).

\section{Heat Transfer}

The heat transfer calculation accounts for:

a. Dimensional changes due to thermal expansion, fission gas swelling, fuel-cladding mechanical interaction and phase change;

b. Latent heat absorption due to phase change;

c. Variable fuel-cladding gap thermal conductance;

d. Temperature dependence of fuel and cladding thermal properties (conductivity and heat capacity);

e. Radial variation of fuel properties (density, conductivity, heat capacity) due to microstructure.

The pin is divided into an arbitrary number of axial segments and the radial temperature distribution in each segment is calculated. By precalculating the coolant temperature at every time step using a simple heat balance, the fuel and cladding temperature can be calculated explicitly. 


\section{LAFM-I :}

LAFM-I uses a finite difference formulation of the radial heat conduction equation based on the Crank-Nicholson extrapolation scheme.

\section{LAFM-II :}

The finite difference solution mentioned above will also be an option in LAFM-II. In addition, a collocation temperature solution of the radial heat balance equation will be provided. Central or off-center melting can be calculated with radial temperature profiles explicitly represented in the solid and molten regions and the region(s) between solidus and liquidus. This second option in LAFM-II should reduce the necessary computer storage requirements for the heat transfer calculation and will provide a spatially continuous temperature distribution in the fuel and cladding.

3. Fue1-C1adding Mechanical Interaction

The fuel-cladding mechanical interaction model calculates the pressure at the fuel-cladding interface and the plastic strain in the cladding. Only thermal expansion, fission gas swelling and elastic deformation are considered in the fuel. Elastic or plastic deformation of the cladding is allowed.

The plastic flow model in the cladding is based on the use of the Tresca yield condition. This allows one to calculate a solution to the stress-strain problem which requires very few interactions. In the limit where linear strain hardening is assumed for the cladding, an analytical solution results.

4. Fission Gas Release and Swelling

\section{LAFM-I :}

LAFM-I uses a correlation based on phenomenological experiments to predict gas release as a function of local fuel temperature. No calculation of fuel swelling is made, although a time varying swelling distribution may be input to use in the fuel-cladding mechanical interaction model.

\section{LAFM-II:}

LAFM-II will contain an internal calculation of $f$ ission gas release and swelling based on bubble growth, coalescence and migration. 


\section{Prediction of Failure}

The failure criterion used in LAFM is based on the linear stress-rupture life fraction rule using the Larson-Miller parameter. This involves calculating the stress-rupture lifetime of the cladding at a given stress and temperature, dividing this lifetime by the length of time these conditions exist, and integrating this ratio over time until the integral becomes equal to one. Thus, the cumulative damage done throughout the transient is calculated.

\section{Limitations}

Currently, the major LAFM limitations, which restrict its applicability to the analysis of TOP's only, are:

1. No calculation of fission gas swelling is provided;

2. The correlation used to predict fission gas release is of marginal accuracy;

3. Fuel creep is not considered in the calculation of the fuel-cladding boundary pressure.

other phenomena currently not modeled which may be of importance in some cases are:

1. Fuel vapor pressure;

2. Molten fuel draining prior to cladding failure.

\section{Future Efforts}

Planned future efforts are centered on eliminating the above mentioned limitations. These new models will all go into LAFM-II.

\section{Computer Operation}

1. LAFM-I is operationa 1 on the LASL CDC-7600 computer.

2. Overlaying of the LAFM-I code is not necessary. A11 coding and variable storage fits into small core memory.

3. A typical problem involving seven axial segments and seven seconds of real (experiment) time with $20 \mathrm{msec}$ time steps requires about 30 seconds of 7600 computer time. 
4. The LAFM-I code has been used to predict the time and location of fuel pin failure in several TOP TREAT experiments. Reference 2 contains details of these analyses.

\section{Interface/Overlap}

The LAFM-I code is currently being interfaced with a LASL version of the COBRA-IV-I code. The resulting LA-COBRA can predict failure on a pin-bypin basis in a multipin bundle. (See LA-COBRA).

\section{$\underline{\text { References }}$}

1. P. K. Mast and J. H. Scott, "Fuel Pin Failure Models and Fuel-Failure Thresholds for Core Disruptive Accident Analysis," Los Alamos Scientific Laboratory report, LA-UR-76-2174 (October 1976).

2. P. K. Mast, "The Los Alamos Fuel Mode1, A Transient Fuel Pin Behavior Code," Los Alamos Scientific Laboratory report, to be published. 


\section{Purpose}

Analysis of thermal and mechanical performance of fast-reactor fuel pins as a function of reactor operating history.

\section{$\underline{\text { Status }}$}

A. Development: LIFE-1 and -2 were developed at ANL/MSD. LIFE-3 development and beyond is the result of a working group composed of AI, ANL, GE-FBRD, HEDL, W-ARD, and ERDA/RDD.

B. Availability: LIFE-1 was released in 1970 (Reference 1). LIFE-2 (Reference 2) will not be released in 1ieu of the release and documentation of LIFE-3 during 1976. LIFE-3 (Reference 3) is operational on the IBM $370 / 195$ at ANL and the CDC-7600 at LBL and W-ARD, and is available through the Argonne Code Center. Development of LIFE- 4 and LIFE- 4 Transient is in progress, which will extend the capabilities to the complete design duty cycle including normal operations (startup, steady power, power changes, and shutdown) and design basis transients up to cladding breach.

C. Utilization: The LIFE codes have been used extensively to provide initial fuel pin characteristics for whole-core and single fuel pin accident analysis codes, sensitivity analysis for fuel pin materials and performance, correlation with other similar codes and for design and interpretation of in-pile experiments. LIFE-3 is the national fuel pin performance code and as such is considered the standard or reference tool for prediction of LMFBR fuel pin steady-state performance characteristics.

\section{Problems Solved}

The LIFE codes are designed to compte the detailed thermal and mechanical behavior of a fuel pin over the long times during any specified history of fast flux irradiation in a normal reactor power cycle. The codes have been primarily applied to stainless steel clad oxide fuel, but any other material systems can be treated. LIFE-1 calculations include the following as a function of time and axial position. 
1. Temperature distributions in fuel and clad.

2. Fuel restructuring rates and dimensions.

3. Hot-pressing or densification of fuel.

4. Fission product generation and distribution in the fuel.

5. Clad swelling due to void nucleation and growth.

6. Fuel swelling due to accumulation of fission products.

7. Migration of fuel constituents.

8. Fission gas release from fuel and resulting fission gas plenum pressure.

9. Interface pressure between fuel and clad.

10. Stress and strain distributions from thermoelastic, creep (thermal and irradiation induced), and swelling deformations in fuel and clad.

11. Dimensions of the clad, each fuel zone and the central void, including fuel and clad length changes.

LIFE-1 can also treat encapsulated fuel pins as an option.

LIFE-2 is an extension of LIFE-1 to include the following:

1. Fuel cracking and crack healing.

2. Cumulative damage failure criteria for the clad.

3. Improved fuel-clad contact thermal conductance.

4. Capsule, as well as clad swelling, for encapsulated fuel pins.

5. Reduction of power in a fuel pin in relation to total reactor operating power as burnup increases.

LIFE-3 contains improvements over LIFE-2 with capabilities for:

1. Clad corrosion.

2. Primary thermal creep. 


\section{$\underline{\text { Mode1s }}$}

\section{LIFE-3}

\section{Geometry}

The cylindrical fuel pin is divided into axial sections to account for axial variations in power, fuel pin geometry, coolant pressure and coolant temperature. The plenum always forms a single axial section regardless of length, whereas the fueled part of the pin is divided into 6 axial sections of equal length. In each axial section, the assumptions of axial symmetry and generalized plane strain reduce all equations to $1-D$. An initial gap between the fuel and clad is allowed and the gap may open or close any number of times, depending on the reactor operating conditions. The central void, which develops during fuel operation, is assumed to be open to the gas plenum so that the gas plenum pressure loads the fuel interna1ly.

\section{Heat Transfer}

The radial quasi-static temperature distribution in the fuel and clad is obtained by a 1-D, steady-state calculation at each time step, and is based on the average power level and inlet coolant temperature expected during the time step, the fuel zone dimensions, the fuel-clad gap size, the clad dimensions and the fuel density. The fuel and clad are divided into an arbitrary number of radial, equal mass sections for the thermal calculation. The temperature calculations in the fuel are used to determine temperature gradients which affect fission-product migration rates.

\section{Fue1 Restructuring}

As-fabricated porosity migrates up a temperature gradient by an evaporation-condensation mechanism. The formal description of this phenomenon developed by Nichols is used as the basis for the LIFE model. The substantial uncertainties in the fundamental properties controlling the migration rate have been minimized by a calibration procedure in which the key parameters are adjusted so that the model predictions match experimental observations of center void size, columnar grain radii and porosity distributions. The net effect of porosity migration is to reduce peak fuel temperatures by increasing density and enlarging the center void.

The migration of fission gas bubbles is similar in principle to the pore migration phenomenon, except that the rate process is controlled by the surface fission of solid atoms from the hot to 
cool side of the bubble. The formalism due to Nichols is again used in the LIFE model, with key constants adjusted to match high burnup restructuring data. The effect of bubble migration on fuel temperatures is variable. The tendencies are to reduce temperatures parallel pore migration, but the deposition of bubbles into the center void adds to the free fission gas content of the pin and reduces the conductivity of the gas at the fuel-cladding interface.

4. Grain Growth

Fuel grain growth is represented in LIFE as a classical equiaxed growth process driven by the minimization of grain surface area. In-reactor this process may be modified by pinning of boundaries by fission products, and this is taken into account by adjustment of the rate constants. Grain growth does not affect thermal performance directly, but its effect on fuel creep rate is seen indirectly by influencing pellet deformation.

5. Fission Product Production and Gas Release

The amount of solid and gaseous fission products generated during each time interval is calculated, along with the amount of fission gas released to the plenum. The amount of gas released from each fuel region is a function of both amount of gas in and density of the region.

6. Plenum Pressure

The plenum pressure is determined by the perfect gas law from the amount of fission gas released to the plenum and the volume average of the plenum and central void gas.

7. Stress-Strain Analysis

The fuel regions and the clad are as treated concentric cylinders with average therma 1 and mechanical properties for each region determined by integration. The field equations assume axial symmetry and a state of generalized plane strain existing in the cylinders. The stress analysis of the fuel and clad includes the effects of fuel swelling caused by accumulation of fission products, hot pressing of fue1, (i.e., compaction by decreasing of fuel porosity), thermoelastic and creep deformations of both fuel and clad (including therma 1 and irradiation enhanced creep) stress relaxation and several options for clad swelling due to void formation and growth. Almost any creep law is allowed. 
8. Fuel Hot Pressing

Hot pressing decreases the porosity initially present in the fuel, and is based on a diffusion process.

\section{Fuel Swelling Due to Fission Products}

Swelling due to solid fission products is treated by specifying the net solid volume created per fission and multiplying by the number of fissions occurring in each fuel region. Gaseous fission-product swelling for the restructured regions is determined by a simple gaslaw approach, while in the unrestructured region, the gas bubbles are so small that they are assumed incompressible and thus contribute to swelling in a manner similar to solid fission products.

10. Fuel Cracking and Healing

At the end of each time step, the code computes whether fuel cracking would occur in any of the three principal directions. If the power has changed, the local thermal stresses are computed and superimposed for each fuel region, and cracking is predicted from a fracture strength correlation for the ultimate tensile strength (Reference 10). The stress component perpendicular to the crack vanishes in the fuel region and the elastic strain existing prior to cracking is then redistributed. The mechanical properties of the cracked fuel are then modified to represent the cracked fuel as an isotropic material. Cracked fuel is allowed to creep faster than uncracked fuel by modification of the creep rate, which is assumed to be related to the shear modulus. When a fuel pin operates without a change in power during a time step, crack healing is allowed. When the cracks heal, the mechanical properties of the fuel are again restored to their usual values.

11. Clad Failure Criteria

The failure criteria is a linear cumulative damage law relating clad hoop stress and time-to-rupture or incremental strain and strain limits.

\section{Limitations}

\section{$\underline{\mathrm{LIFE}-3}$}

1. The thermal and generalized plane strain analysis neglect possible circumferential variations and ignore the finite length of the fuel pellets and/or the initial particle behavior or vibratorily compacted fuel. 
2. When the fuel contacts, but does not stick to the clad, compatibility between axial sections is not required by the code.

3. Nu clad or fuel melting is allowed.

4. Effects of stoichionetric changes during burnup are ignored.

\section{Future Efforts}

The following are scheduled for improvement:

1. Overall material property correlation and mechanistic model upgrading and improvement.

2. Improved clad ID and OD corrosion and failure criteria.

3. Time-dependent plastic flow of fuel and clad.

4. Oxygen redistribution.

5. Plutonium redistribution.

6. Solld fission product migration, precipitation and release.

7. Improved fuel cracking, healing.

8. High burnup gap conductance.

9. Fuel-fission product reactions.

10. Improved fuel swelling.

11. Transient fuel swelling, gas release.

\section{Computer Operations}

1. Computers: The LIFE-3 code is operatioilal on the CDC-7600 and the IBM $370 / 195$.

2. Logistics: $150_{8} \mathrm{~K}$ words on the CDC-7600, normal input and output devices, a peripheral wrapup/restart if the option is selected.

3. Running Time: $500 \mathrm{sec} C P U$ on CDC-7600 for a case analyzing five axial fuel sections for a fuel rod lifetime of 5000 hours. 
4. Code Validation: Many of the models are empirical ones which have been calibrated to experiments by adjusting certain important parameters in the models in order to reproduce experimental results. These models and calibrations are discussed in the references.

\section{Interface/Overlap}

SAS, MELT, GRASS/SIEX, BEHAVE-SST

\section{References}

\section{LIFE-1:}

1. V. Z. Jankus and R. W. Weeks, LIFE-1, A FORTRAN IV Computer Code for the Prediction of Fast-Reactor Fuel-Element Behavior, ANL-7736 (November 1970).

2. V. Z. Jankus and R. W. Weeks, "LIFE-1, A History-Dependent Analysis of Fast Reactor Fuel Element Behavior," ANS Trans. 13, 2 (November 1970) 830 .

3. R. W. Weeks, V. Z. Jankus, M. Katsuragawa and J. D. B. Lumbert, "Analysis of Mixed-Oxide Fuel Element Irradiations Using the LIFE-1 Computer Code," Proc. ANS Topical Meeting on Fast Reactor Fue1 Element Technology, New Orleans, April 1971.

\section{LIFE-2:}

4. V. Z. Jankus and R. W. Weeks, "LIFE-II, A Computer Analysis of Fast Reactor Fuel-Element Behavior as a Function of Reactor Operating History," Nuclear Engineering Design, 18 (1), 86 (1972).

5. R. F. Hilbert, et. al., "Evaluation of Material Property Correlations Used in LIFE-II," GEAP-13967, 'une 1973.

\section{Fuel Restructuring:}

6. Nichols, F.A., Behavior of Gaseous Fission Products in Oxide Fuel Elements, WAPD-TM 570 (October 1966).

\section{Plutoniun Migration:}

7. Poeppe1, R. B., Swelling Mechanisms and Models for Oxide Fue1, ANL-7577 (Apri1-May 1969). 


\section{Fuel Thermal Conductivity:}

8. A. Biancheria, et. a1., Westinghouse Report WARD-4135-1

(September 1969).

\section{Hot Pressing:}

9. R. C. Rossi and R. M. Fulrath, Final Stage Densification in Vacuum Hot-Pressing of Alumina, J. of Am. Ceram. Soc., 48 (1965) 558.

\section{Fue1 Cracking:}

10. R. F. Canon, J. T. A. Roberts and R. J. Beals, Deformation of UO 2 at High Temperatures, J. Am. Ceram. Soc., 54 (1971) 105.

Time-to-Rupture Correlation:

11. C. Y. Cheng and R. W. Weeks, RDP Progress Report (ANL), July 1971 .

\section{LIFE-3:}

12. M. C. Billone, S. L. Harbourne, V. Z. Jankus, R. B. Poeppel, T. S. Roth, W. J. Shack, J. D. Stephen, B. Surdquist, F. R. Taraba, J. E. Turner, and S. Zawadzki, LIFE-III Fue1-Element Performance Code, to be published as ERDA-77-56 (1977).

13. V. Z. Jankus, "Fast-Reactor Fuel-Element Analysis Using Multiregion Formulation in LIFE-II," 2nd Int1. Conf. on Structural Mechanics in Reactor Technology, Vol. VI, Part A, Supp1. (D2/5), Berlin, Germany (Sept. 1973).

14. V. Z. Jankus and W. J. Shack, "Development of a Finite-Strain Fue1-Element Mode1," to be presented at the 4 th Structura1 Mechanics in Reactor Technology Conference in San Francisco, California (August 1977). 
LONAC

\section{Purpose}

To investigate systems dynamics under conditions of low forced flow or natural convection.

\section{$\underline{\text { Status }}$}

A. Development: Developed and under imp rovement at ORNL.

B. Availability: Documentation and comparison with experimental data from the THORS Facility is underway.

C. Utilization: ORNL-developed code for analysis of transients in the THORS Facility, a large sodium test loop used for various out-of-pile studies.

\section{Problems Solved}

1. Natural convection-driven transients. Fast execution allows simulation of long-duration transients.

2. Single-phase forced or mixed convection.

\section{Models}

1. One-dimensional transient conservation equations are used.

2. Sodium density is solely a function of temperature. Viscosity is temperature-dependent.

3. Experimental data may be used for loss coefficients for elbows, tees, etc. Frictional pressure drops are computed from curves fit to Moody diagram.

4. Cover gas pressure in the expansion tank can be taken as a constant or can be computed from perfect gas relation.

5. A single fuel pin is used to represent the entire electricallyheated pin bundle.

6. Pump model uses a simple iterative technique to find the necessary head to drive a desired flow. 
7. Heat dump allows either a fixed heat withdrawal or a fixed outlet temp erature.

8. Valve settings may be input; a test-section bypass line is included.

\section{$\underline{\text { Limitations }}$}

1. No voiding model at present.

2. Program currently is written for THORS geometry, but could be readily adapted to other systems using similar components.

3. No heat gains or losses are currently included except at test section nodes and heat dump node.

4. Thermal inertia of piping and structure are not included.

5. Intact geometry assumed.

\section{Future Efforts}

1. A simple voiding model is under consideration.

\section{Computer Operation}

1. Operationa1 on IBM $360 / 91$.

2. $80 \mathrm{~K}$ required for $\mathrm{GO}$ step, batch operation, results are stored for separate plot job.

3. Typical Run Time: 1 second on IBM $360 / 91$ for 40 seconds of real time using 30 nodes. Large thermal inertia of sodium in expansion tank may necessitate a minute or more of run time.

4. Code Validation: None.

Interface/Overlap

None.

\section{References}

None. 
MELT

\section{Purpose}

Analysis of core neutronic-thermal-hydraulic behavior during the initial phases of a postulated whole-core accident; primarily, the transient overpower hypothetical accident.

\section{$\underline{\text { Status }}$}

A. Development: MELT-I was developed at BNWL; MELT-II, MELT-III, MELT-IIIA, MELT-IIIB were developed at HEDL. MELT-IIIB is the current development version at HEDL.

B. Availability: MELT-I documented appeared in $1968^{(1)}$; operational at HEDL.

MELT-II documented appeared in $1972^{(2)}$; operational at HEDL.

MELT-III released in $1975^{(3)}$; operational at HEDL, $\mathrm{LBL}$, BNL.

MELT-IIIA released in $1976^{(4)}$; operational at LBL.

MELT-IIIB is operational at LBL.

C. Utilization: Primary code used for TOP HCDA analysis in FFTF.

\section{Problems Solved}

Each version of MELT predicts transient core behavior from a normal operating condition through the early phase of a whole-core involvement accident initiated by a hypothesized fault condition which leads to a severe power-to-flow mismatch. Each version of MELT computes the neutronic-thermal-hydraulic behavior of the core until either (a) permanent neutronic shutdown occurs with no loss of subassembly duct integrity; (b) loss of subassembly duct integrity occurs due to melting or over-pressurization; or (c) a prompt-critical burst occurs.

MELT calculations start with initialization of core conditions based on the user's specification which define the pretransient operating conditions of the reactor system. Calculations then proceed through the transient history of the reactor. An unprotected TOP accident in an LMFBR can be studied. Study of an unprotected LOF HCDA is limited 
to a backup capability in the form of scoping and support analysis only. MELT calculations have assumed that the overall core subassembly geometry remains intact. This limitation is derived from the $1-D$ nature of the code which performs the calculation of axial material motion while neglecting any radial motion.

Models

Al1 versions of MELT are built on a modular structure in which the various models for the accident phenomena are programmed into specific subroutines which are coupled to provide an integrated accident analysis code. This form allows for easy upgrading and improvement of specific models without affecting the overall code structure. A11 MELT codes contain at least the following basic models: steady-state initialization, neutronics, reactivity feedback, heat transfer, and fuel failure.

MELT-I:

1. Geometry

The entire core is modeled by a single representative fuel pin and its associated surrounding coolant in a cylindrical axisymmetric geometry. A maximum of 10 radial nodes ( 8 fuel nodes, 1 cladding node, and 1 coolant node) and 40 axial segments are permitted.

\section{Steady-State}

Input parameters are used to compute the initial temperature distribution for an average core location and other initial constants.

\section{Heat Transfer}

A detailed heat transfer balance is calculated only for an average location in the reactor, i.e., for the average axial heat generation location within the pin situated at a core radius which corresponds to the radial average heat generation rate. All other temperatures are obtained using a space-time separable projection scheme, except when melting is reached. Then, the local power densities are used to delay local temperature increases until the heat of fusion has been deposited. Thermal properties, such as conductivity and heat capacity, are assumed to be independent of temperature. The coolant is assumed to be stagnant.

\section{Neutronics}

A one-energy group, space-independent (point) kinetics model is use to describe the reactor neutron kinetics. The net reactivity is th sum of the four following contributions. 


\begin{abstract}
a. Programmed input.
b. Doppler feedback, based on the volume-average temperature over a given fuel pin axial segment.

c. Sodium voiding based on an input fuel worth curve.

Empirical failure criteria correlations are used in establishing the start of fuel collapse.
\end{abstract}

\title{
MELT-II:
}

This version represents a complete revision of the MELT-I program along with the addition of direct interface capabilities with VENUS (5).

\section{Geometry}

The entire core is modeled by up to ten separate channels, each having a geometry similar to the MELT-I channel. A maximum of 15 radial nodes (12 fuel nodes, 1 fue1-cladding gap node, 1 cladding node, and 1 coolant node) and 20 axial segments are permitted.

\section{Steady-State.}

Same as MELT-I.

\section{Heat Transfer}

A detailed two-dimensional heat transfer calculation is carried out for each axial node of each representative fuel pin. The equations are solved implicitly by a Gaussian elimination scheme. Variable thermal conductivity for the fuel and variable specific heat for the fuel, cladding, and coolant can be specified. The present model requires constant gap and film coefficients. The coolant is permitted to flow past the fuel pin.

\section{Neutronics}

The standard one-energy group, point kinetic formulation, with up to six groups of delayed neutrons is used to describe the reactor neutron kinetics. For slow power variations, a zero neutron lifetime approximation is used to allow large time steps for many fast reactcr accidents of interest. The net reactivity is a sum of the four following contributions: 


\section{a. Programmed input.}

b. Doppler feedback based on the volume average temperature over a given fuel pin axial segment including the reduction of feedback due to coolant voiding.

c. Sodium expulsion, assuming a slug-type flow regime due to sodium boiling, release and expansion of fission gas, or interaction of molten fuel with sodium. The sodium void worth curves are channe1 (spatially) dependent.

d. Fuel motion prior to failure due to fuel or cladding expansion in the axial direction and following failure due to either gross slumping or molten fuel flowing through a cladding rupture into the coolant channel. The fuel worth curves are channel (spatially) dependent.

5. Fuel Failure

Empirical failure criteria correlations are used to establish elther the start of gross fuel collapse or molten fuel squirting.

\section{VENUS Interface}

If disassembly conditions are established, the fine structure temperature information is integrated to conform to the $R-Z$ spatial mesh structure used in VENUS and this input, along with the power distribution and all reactivity feedback components, is used directly as the starting point for the disassembly phase in VENUS. In addition, the core is scanned for liquid sodium content to determine the effective Doppler coefficient and to establish whether a sodiumin or sodium-out equation-of-state should be employed at each particular mesh point in the hydrodynamics calculation.

\section{MELT-III:}

This version is similar in structure to MELT-II, with some improved models.

\section{Geometry}

The entire core is modeled with up to twenty separate channels, each modeling a representative fuel pin with its associated coolant and structure (e.g., wire wrap and proportional amount of subassembly duct). Each channel can be modeled with up to 15 radial nodes as in MELT-II and 72 axial segments, 20 representing the core region and 
the remainder representing the rest of the reactor vessel excluding piping. Up to two radial structure nodes may be thermally connected to each coolant node. The 20 channels may be connected to any one of three coolant loops coupled by neutronics model.

\section{Steady-State}

Steady-state fuel characteristics are provided by direct machine coupling to SIEX II ${ }^{(6)}$, which calculates restructuring patterns. MELT-III then calculates steady-state temperatures for the rest of the reactor and steady-state pressures and flow velocities for the coolant channels.

\section{Heat Transfer}

Same as MELT-II except a transient gap conduction model is included.

4. Neutronics

A lumped parameter kinetics routine with spatially weighted reactivity feedback models including Doppler broadening, fuel redistribution and coolant density decrease and expulsion is used in the neutronics model. The method used to solve the kinetics equations is stable for very substantial increases in the power per step. Accuracy is coutrolled by forcing a recalculation of the temperature, feedback terms, etc., at a reduced time step if the power computed using an extrapolated feedback in the first pass does not agree, within a specific criterion, with the power computed using the actual feedback. Further, time step size increases can be accomplished for the slow moving portions of the transient by utilization of a zero neutron lifetime approximation. Reactivity feedback due to density changes or motion of core constituents is computed by searching input worth tables.

5. Coolant Voiding

a. One operational model for sodium voiding -- molten fuel/ fission gas release from failed fuel (FCI). FCI zone is a homogeneous mixture of fuel, fission gas, sodium vapor, and condensed sodium.

b. Fission gas release directly from fission gas plenum prior to FCI (to initiate a bubble).

c. Limited boiling model. 
6. Hydraulics
a. Pins within the driver fuel subassemblies are hydraulically coupled at the inlet and outlet plenums.
b. Flow path around primary loop is completed..
c. Two separate primary loop flow paths are available to simulate a pipe break in one loop or to simulate one of the independent closed loops.
d. Modeling emphasis is on inlet plenum to pool level detail.

7. Fission Gas Release

Models for gas release from plenum and from $f$ uel matrix are provided by empirical correlations.

\section{Fue1 Failure}

Failure signals are provided by empirical failure criteria correlations.

\section{Fuel Motion}

Fuel motion is allowed to occur in three ways: movement of fuel axially inside the pin, movement of molten fuel from ruptured pin into channel, movement of fuel within channel. After cladding failure, fuel/gas mixture moves inside fuel pin through orifice in cladding wall and into coolant stream. HOTPIM hydrod; namics model $(7)$, for molten fuel flow inside cladding, is currently used.

10. FCI Mode1 with Parametric Fragmentation and Mixing

\section{MELT-IIIA:}

This version is a greatly optimized version of MELT-III with some new or improved models.

\section{Geometry}

The channel limit has been increased to 100; otherwise, same as MELT-III.

\section{Steady-State}

Improved version of SIEX has been incorporated into the code. 
3. Heat Transfer

Same as MELT-III.

4. Neutronics

Same as MELT-III.

5. Coolant Voiding

Same as MELT-III.

6. Hydraulics

Same as MELT-III.

7. Fission Gas Release

Improved parametric models for gas release from the fuel matrix added to models in MELT-III.

8. Fue1 Failure

New correlation added to other parametric models in MELT-III.

9. Fuel Motion

Same as MELT-III.

10. FCI Mode1

Parametric mode1 of MELT-III was improved.

MELT-IIIB

This version is the current developmental version of MELT. It is an optimized version of MELT-IIIA with some new models. Documentation of this versionwwil be started in July 1977 .

1. Geometry

Same as Melt-IIIA.

2. Steady-State

Same as Melt-IIIA. 
3. Heat Transfer

Same as MELT-IIIA.

4. Neutronics

Same as MELT-IIIA.

5. Coolant Voiding

Same as MELT-IIIA.

6. Hydraulics

Transient pressure loss model was added and external loop piping model was improved from the MELT-IIIA version.

7. Fission Gas Release

Same as MELT-IIIA.

8. Fuel Failure

New transient fission gas pressure model added to the MELT-IIIA models.

9. Fuel Motion

Same as MELT-IIIA, except for addition of a model to calculate the drag on spherical fuel particles in the coolant channel after fuel pin failure.

10. FCI Mode1

Mechanistic uniform interaction region with heat transfer from spherical fuel particles was added along with improved model for calculation of heat generated from plated material.

\section{Limitations}

Current limitations of MELT-IIIB are:

1. A point kinetics formulation is used.

2. Detailed loading on the cladding cannot be done because only one fuel material type is treated and fuel expansion, due to density reduction or fission gas release, is not taken into account. 
3. A natural source of pin failure incoherency, due to statistical fluctuations and differing power ratings within subassemblies and ring of subassemblies, is ignored, although the program can be modified to partially account for the latter effect.

4. Detailed sodium boiling model required for analysis of LOF accidents is not included in MELT-IIIB.

\section{Future Efforts}

Short-term efforts are directed towards release of MELT-IIIB.

Long-term efforts include:

1. Treatment of intrasubassembly incoherency.

2. Incorporation of advanced fuel motion mode1 (e.g., HOTPIM II ${ }^{(8)}$ ).

3. Incorporation of more mechanistic boiling and fuel plateout/ blockage mode1s.

4. Additional experimental tie down with TREAT and out-of-pile data.

\section{Computer Operation}

1. MELT-IIIA is operational on CDC- $7600^{\circ} \mathrm{s}$ at LBL and BNL, and CYBER 74 at RL. MELT-IIIB is operational at LBL.

2. Machine storage requirements for MELT-IIIB include $153 \mathrm{~K}$ octal of 60 bit words in central memory of a CDC-7600 and approximately $35 \mathrm{~K}$ decimal words per channel for peripheral storage are required on nine logical units for wrapup and plotting purposes during a 30 step transient run. The MELT system is designed for batch usage. MELT-I and -II were written in Fortran V, while MELT-III, -IIIA, and -IIIB are written in CDC Fortran IV. MELT-IIIB has a generalized routine to save on tape any information that may be required for plotting. Plotting routines are separate programs maintained at RL.

3. For MELT-IIIB, cases with 18 axial fuel segments, 45 overall axial segments, 15 radial nodes, and full use of radial structural nodes, typical CDC-7600 running times are approximately 0.6 seconds per channel for steady-state calculations, 0.15 seconds per channel per time step up to the time of fuel pin failure, and 0.35 seconds per channel per time step after fuel pin failure. The momentum conservation subroutine (MOMENT) is the major consumer of time. 
4. Code Validation

\section{References}

J. C. Sonnichsen, et. al., "Analytic Modeling of the MARK-IIA TREAT Loop for Fuel Motion and Sodium Expulsion Studies," HEDL-SA-6475, presented at ANS Fast Reactor Safety Meeting, Beverly Hi11s, CA, April 1974.

R. E. Baars, A. Padilla, Jr., Fuel Pin Post-Failure Transient Behavior, HEDL-TME 75-110, Hanford Engineering Development Laboratory, Richland, WA, November 1976.

R. E. Baars, "HEDL Empirical Correlation of Fuel Pin TOP Failure Thresholds -- Status 1976," HEDL-SA-861, Hanford Engineering Development Laboratory, Richland, WA, August 1976.

N. P. Wilburn, "Comparison of SAS3A and MELT-III Predictions for a Transient Overpower Hypothetical Accident," HEDL-SA-842, presented at ANL/INS Meeting on Fast Reactor Safety and Related Physics, Chicago, IL, October 1976.

Comparisons between MELT-IIIB and planned experiments TREAT R12, H6, and $E 9$, and CAMEL loop tests, are planned as test data are made available.

Interface/Overlap

VENUS, SIEX, HOTPIM/SAS, HOPE

\section{References}

1. Alan E. Waltar, MELT-I, A Simplified Meltdown Code for Fast Reactor Safety Analysis, BNWL-944, Battelle-Northwest, Richland, WA, 1968.

2. Alan E. Waltar, et. al., MELT-II, A Two-Dimensional Neutronics-Heat Transfer Program for Fast Reactor Safety Analysis, HEDL-TME 72-43, Hanford Engineering Development Laboratory, Richland, WA, Apri1 1972.

3. Alan E. Waltar, et. al., MELT-III, A Neutronics, Thermal-Hydraulics Computer Program for Fast Reactor Safety Analysis, HEDL-TME 74-47, Hanford Engineering Development Laboratory, Richland, WA, october 1974. 
4. C. H. Lewis, et. a1., MELT-IIIA: An Improved Neutronics, Therma1Hydraulics Modeling Code for Fast Reactor Safety Analysis, HEDL-TME 76-73, Hanford Engineering Development Laboratory, Richland, WA, December 1976.

5. W. T. Sha and T. H. Hughes, VENUS: A Two-Dimensiona1 Coupled Neutronics-Hydrodynamics Computer Program for Fast Reactor Power Excursions, ANL-7701, Argonne National Laboratory, Argonne, IL, October 1970.

6. D. S. Dutt, et. al., SIEX, A Correlated Code for the Prediction of Liquid Metal Fast Breeder Reactor Fuel Thermal Performance, HEDL-TME 74-55, Hanford Engineering Development Laboratory, Richland, WA, December 1974.

7. H. J. Willenberg, et. al., "Analysis of Transient Compressible Two-Phase Flow with Heat and Mass Sources using the Method of Characteristics," Proc. of Conf. on Computational Methods in Nuclear Engineering, CONF-750413, Vo1. I, Section II, p. 107, Charleston, SC, April 1975.

8. H. J. Willenberg, Improvements in HOTPIM Internal Fuel Motion Code, HEDL-TME 76-56, Hanford Engineering Development Laboratory, Richland, WA, March 1977. 
MESODIF

\section{$\underline{\text { Purpose }}$}

Analysis of atmospheric effluent dispersal on a regional scale considering spatial and temporal meteorological variations.

\section{Status}

A. Development: Developed at NOAA, Air Resources Laboratories, Idaho Fa11s, Idaho.

B. Availability: MESODIF was documented in 1974 (Ref. 1). It is operational at ARL on the IBM $360 / 75$.

C. Utilization: MESODIF calculations have been compared with the standard practice of using a single station stability wind-rose technique. It has been used at NRC in the process of preparing proposed Regulatory Guides and versions of it have been used by some power companies in the assessment of atmospheric dispersion near proposed power plant sites.

$\underline{\text { Problems Solved }}$

MESODIF disperses plume effluent through the advective transport of plume segment (puff) centers and through the diffusion of effluent puffs about their individual centers. Periodic sampling of the distribution of the puffs is done to determine radionuclide concentrations at specified grid points. It has been used to model continuous point sources and instantaneous line sources as well as instantaneous and short-term release sources.

\section{Models}

\section{1. $\quad$ Release}

The source emission strength is specified as input data for MESODIF. This value may be specified hour-by-hour if desired.

\section{Advection}

The location with time of each puff released is determined using a time series of wind measurements from a randomly spaced array of wind stations (Ref. 2). The hourly averaged winds at the stations are interpolated onto a rectangular grid and the movement of the puffs is computed through a time and space interpolation of the wind fields. 


\section{Diffusion}

The growth and subsequent dilution of each puff at each downwind location is determined using a Gaussian diffusion model (Refs. 3 and 4). For vertical dispersion, a capping stable layer or restricting 1id to upward diffusion is considered (Ref. 5).

\section{Limitations}

1. MESODIF does not evaluate depletion of the cloud by fallout, rainout, washout, and chemical and photochemical changes.

2. A number of wind sensors are required if MESODIF is to be applied on the regional scale.

3. The upper limit on the number of puffs MESODIF can handle is 400 .

\section{Future Efforts}

MESODIF is undergoing continuous development and refinement. Any potential user should contact the senior author at Idaho Falls for the latest information on the program.

\section{Interface/Overlap}

$-1-$

\section{$\underline{\text { References }}$}

1. G. E. Start and L. L. Wende11, "Regional Effluent Dispersion Calculations Considering Spatial and Temporal Meteorological Variations," NOAA Technical Memorandum ERL ARL-44, Air Resources Laboratories, Idaho Falls, Idaho, May 1974.

2. L. L. Wende11, "Mesoscale Wind Field and Transport Estimates Determined from a Network of Wind Towers," Monthly Weather Rev., 100(7): 565, 1972.

3. D. H. Slade (ed.), Meteorology and Atomic Energy 1968, TID-24190, U.S. Atomic Energy Commission/Division of Technical Information, July 1968.

4. G. R. Yansky, E. H. Markee, Jr., and A. P. Richter, C1imatography of the National Reactor Testing Station, TID-12048, U.S. Atomic Energy Comission, Idaho Fa1ls, Idaho, 1966.

5. D. B. Turner, Workbook of Atmospheric Dispersion Estimates, Public Hea1th Service Publication No. 999-AP-26, PB-191482, National Air Pollution Control Administration, Cincinnati, Ohio, 1969. 
MI CE

\section{Purpose}

Analysis of multifield fluid flow and structural responses in a containment system during a hypothetical core discuptive accident.

\section{$\underline{\text { Status }}$}

A. Development: Under development at ANL/RAS.

B. Availability: The MICE code is still in its early stage of development. The present version which solves two-material fields fluid flow with material interpenetration and structural responses is operational and under testing at ANL on the IBM 370 .

C. Utilization: The MICE code has been applied to several sample problems with two-material flelds fluid flow in a containment system. The reactor wall and core barrel are treated as flexible structures which undergo elastic-plastic deformations.

\section{Problems Solved}

The MICE code solves multifield fluid flow and structural responses in a containment system during core disassembly. After completion of the code, phenomena such as phase transition due to sodium boiling and heat transfer between material fields will be modeled.

\section{Mode1s}

The MICE code uses a 2-D axisymmetrical cylindrical coordinates. Mesh is evenly divided in radial and axial directions. Fluids in each region in a containment system are modeled by several material fields with different volume fractions. Structures in the containment system are represented either by rigid obstacles or flexible shells. The numerical technique used for the solution of the multifleld fluid flow consists of two principal steps. In the first step, the material fields in each cell are treated independently; in the second step, a pressure equilibration is performed among all fields in each cell.

\section{Limitations}

Current limitations of the MICE code are: 
1. No treatment of heat transfer between material fields.

2. No phase transition is calculated.

3. Mesh size is limited to 20 and 50 in radial and axial directions, respectively.

Future Efforts

Future efforts include:

1. Incorporation of a heat transfer model.

2. Calculation of the phase changes.

3. Incorporation of more types of structural elements.

\section{Computer Operation}

1. The code is operational on IBM 370. Since the code is written in FORTRAN language, it should be operational on CDC or other computer machines by removing the double-precision statement in the main program and in each subroutine.

2. Core memory requirement for a mesh size 20 x 50 and two material fields is about $375 \mathrm{~K}$.

3. Running time for each problem depends strongly on the volume fraction in each cell and the time step increments. At present, no definite criterion has been established.

4. Verification of the wave propagation in a straight pipe for a single material field has been reported on p. 7.56, ANL-RDP-51, 1976.

\section{Interface/Overlap}

None.

\section{$\underline{\text { References }}$}

No documentation specific to the MICE code is currently available; however, the following references discuss the numerical techniques employed in the code:

1. F. H. Harlow and A. A. Ams den, Flow of Interpenetrating Material Phases, J. Comp. Phys, 18, 440 (1975). 
2. F. H. Harlow and A. A. Amsden, Numerical Calculation of Multiphase Fluid Flow, J. Comp. Phys. 17, 19 (1975).

3. T. Belytschko and B. J. Hsieh, Non-Linear Transient Finite Element Analysis with Convected Coordinates, International Journal for Numerical Method in Engineering, 7 , 255 (1973).

4. J. R. Travis, F. H. Harlow and A. A. Ams den, Numerical Calculation of Two-Phase Flow, Los Alamos Scientific Laboratory Report, LA-5942-MS (1975).

5. A. V. Kalinin, Derivation of Fluid-Mechanics Equations for a Two-Phase Medium with Phase Changes, Heat Transfer-Soviet Research 2 , 83 (1970).

6. R. I. Nigmatulin, Equation of Hydrodynamics and Compression Shock in Two-Velocity and Two-Temperature Continuum with Phase Transformations, Fluid Dynamics 2 , 20 (1967).

7. F. H. Harlow and A. A. Ams den, A Numerical Fluid Dynamics Calculation Method for All Flow Speed, J. Comp. Phys. 8 , 197 (1971). 
MOCARS

\section{Purpose}

The Monte Carlo Simulation (MOCARS) code is used to determine the distribution and simulation limits for a system unavailability function or a user-supplied function.

\section{Status}

A. Development: MOCARS was developed at the INEL (EG\&G Idaho, Inc.).

B. Availability: MOCARS is currently operational and will be released by December 1977 (Ref. 1).

C. Utilization: The code is currently being tested and evaluated.

\section{Problems Solved}

MOCARS can either be used to calculate the distribution and simulation limits for a system unavailability using the minimal fault tree cut sets or a user-supplied function. The fault tree cut sets can either be entered directly via the Reliability Analysis System (RAS) Code (Ref. 2) or card input from another fault tree code such as PREP (Ref. 3).

The user can also enter any function for which distribution and simulation limits are desired. Any number of input variables can be entered for a MOCARS problem in conjunction with twelve (12) common statistical distributions to evaluate the user function.

Mode1s

The MOCARS code uses any of twelve (12) statistical distributions to sample data for evaluation of the cut set system unavailability function or the user-supplied function. These distributions are: the uniform, exponential, normal, Cauchy, gamma, beta, lognormal, binomial, Poisson, Weibull, Pearson Type IV, and empirical.

\section{Limitations}

MOCARS is limited to determining the distribution and simulation limits for a system unavailability using the minimal cut sets or a user-supplied function using the statistical distributions given above. If cut sets 
are entered, no more than seven (7) events per cut set can be entered. However, no input restrictions exist for a user-supplied function input.

\section{Future Efforts}

Conversion of MOCARS to the IBM $360 / 75$.

\section{Computer Operation}

1. MOCARS is currently operational on the CDC Cyber 76 .

2. Logistics: MOCARS operates in batch mode, has dynamic storage capabilities, "free form" input capability, and microfilm graphics capability to plot the frequency and cumulative sample histograms. Also, MOCARS is written in FORTRAN IV and requires some form of external storage such as disk or drum. It requires the use of the INEL environmental package for the dynamic storage capability, the "free form" input and the Integrated Graphics System (IGS).

3. Typical Problem Running Time: For the cut set sample problem included in Reference 1, MOCARS took approximately three (3) seconds to analyze fifty-five (55) cut sets. For the user-supplied function sample problem included in Reference 1, MOCARS took approximately two (2) seconds. This included link-edit, and execution with all options exercised.

4. Code Validation: No comparison of MOCARS has been made with any other Monte Carlo code.

\section{Interface/Overlap}

For cut set input, MOCARS has the capability to interface with RAS to obtain the minimal cut sets.

\section{$\underline{\text { References }}$}

1. S. D. Matthews, MoCARS: A Monte Carlo Simulation Code for Determining the Distribution and Simulation Limits, RE-A-77-001, (May 1977).

2. D. M. Rasmuson and N. H. Marsha11, Preliminary User's Guide to the Reliability Analysis System, RE-S-76-177, (September 1976).

3. W. E. Vesely and R. E. Narum, PREP and KITT: Computer Codes for the Automatic Evaluation of a Fault Tree, IN-1344, (August 1970). 
MOTION

\section{Purpose}

Analysis of the dynamic response of reactor head, vessel and support systems to HCDA pressure loads.

\section{$\underline{\text { Status }}$}
A. Development: Developed at HEDL.
B. Availability: Documented in Reference 1. Operational at HEDL on CYBER-74.
C. Utilization: MOTION is the primary code used by HEDL for prediction of forces and movements of the FTR head, vessel and supports under HCDA loadings. It was also used in scale-up to full-sized FTR of results from scale-model experiments which simulated the mechanical response of FTR to HCDA pressure loads (Ref. 2).

\section{$\underline{\text { Problems Solved }}$}

The code calculates the following as a function of time for HCDA pressure loads:

1. Displacements, velocities and accelerations of the reactor vessel, vessel support ring, vessel support structures and reactor head.

2. Stresses and strains in bolt systems which tie components together, including the head stretch bolt system.

\section{Mode1s}

\section{Geometry}

All models are $1-D$, allowing only vertical displacements.

\section{Structure Mode1}

The code models the large reactor structures with up to five lumped mass points with elastic-plastic springs and damping elements connecting the masses. The five masses asre usually taken to be the reactor vessel, vessel support ring, vessel support structure, and the reactor head, with two masses used for the head to simulate head doming effects. 


\section{Bolting Systems}

Bolting systems which tie components together are represented as springs with bi-linear force-deflection characteristics to provide for elastic and plastic strains.

4. Reinforced Concrete Support Structures

Represented by force-deflection characteristics.

5. Input

Requirement code input includes a force-time history for any two masses, stress-strain properties of bolting systems at high strain rates, force-deflection characteristics and damping coefficients.

\section{Limitations}

1. The code performs a simple 1-D, lumped mass and spring calculation and therefore cannot handle the details of continuum material dynamic response.

2. The bolt model does not accurately simulate plastic strain effects for relaxing loads since bolts are treated as springs which provide the same force-deflection characteristics for decreasing strain following plastic strain as for initial force-deflection characteristics.

\section{Future Efforts}

None planned.

\section{Computer Operation}

1. Operational on the CYBER-74.

2. Logistics: $140{ }_{8} \mathrm{~K}$ core memory; operation in batch mode with card decks or via remote terminals; graphic output on either microfiche paper or CRT graphics terminal. Uses DISSPLA plotting sof tware.

3. Running time is typically about 60 seconds per case.

4. Validation: See References 1 and 2 .

Interface/Overlap

$-1-$ 
References

1. R. N. Madsen, "MOTION, A Dynamic Response Code for a Reactor Support Structure," HEDL-TI-76033, December 1976.

2. G. L. Fox, D. D. Stepnewski \& L. M. Polentz, "Scale-up of Test Results from Simulation Experiments of an HCDA in the FFTF," HEDL-TME-74-54. 
NABOND

\section{Purpose}

To study the behavior of sodium bonded fuel elements and the effects of the sodium bond on fuel and clad temperatures.

\section{Status}
A. Development:
FBR Engineering Development
Combustion Engineering, Inc.
Windsor, Connecticut 06095
B. Availability: See above address.
C. Utilization: The code has been used to:
(1) Analyze fuel and clad temperatures during a loss of bond (LOB).
(2) Study bond dynamics during a TOP.
(3) Analyze TREAT-SCIA test.
(4) Analyze LOB in EBR-II irradiations.

\section{Problems Solved}

NABOND solves the steady-state and transient heat transfer for the fuel pin and its associated coolant. This includes the temperature and phase change for the fuel pellet, bond material, cladding and coolant. Coolant configurations include flowing coolant or stagnant coolant in either of two capsule geometries. Various bond models are available. Material properties are temperature dependent. Bond boiling is permitted, but coolant boiling cannot be considered.

\section{Mode1s}

The following models are available for the bond behavior:

1. Gas bonding in both steady-state and transient solution.

2. Sodium bonding in the steady-state and gas bonding during the transient (LOB event).

3. Sodium vapor present at axial locations where $T>T_{\text {SATURATION }}$.

4. Bond conductance varies as a function of time from bond boiling to simulate film evaporation and sleeve effects $(1)$. 
5. A single slug bond boiling model with sodium film evaporation and condensation. Slug acceleration and pressurization effects are included.

6. If a user specified radial node of the fuel has melted, the fuel is assumed to radial slump or swell out to contact the clad, and a user specified bond contact conductance is used.

The heat transfer for the fuel, clad and capsule (if being considered) is an explicit finite element technique as described in the ARGUS code.(2) A melting fraction is calculated at each finite element. After half the fuel in a user specified radial mesh point has melted, radial fuel slumping occurs and the fuel is expanded to contact the clad. A user specified contact conductance is then used to describe the heat transfer between the fuel and clad. Heat transfer mesh points can be located symmetrically along the core axis or positions at the users discretion.

The coolant flow rate is specified in a table in the input as a function of time (or is zero for capsules) and the coolant temperatures are calculated. Coolant boiling is not considered.

The power is also specified in a table and there is no reactivity feedback effects considered. The power shape can be varied both radially and axially across the pin. Radial variations are used to analyze thermal reactor tests. The axial shape can be symmetric or user specified.

The fuel, clad, bond, coolant and capsule regions are assigned materialtype numbers in the input. All material properties are evaluated as algebraic functions in a single subroutine. Equations for most commonly used materials already exist. Additional materials can be easily included, but will require recompiling a subroutine. All the properties of a given material are evaluated as a function of temperature and pressure in a single call to the property subroutine. In the code, the material properties at each point in time and space are evaluated at the previous time step temperature.

\section{Limitations}

The code is limited to analyzing pin temperatures and bond behavior when the power and flow is specified and the coolant does not boil.

Computer limitations are minima1. The code dynamically allocates the matrix sizes according to the input. For most problems, core size less than 10,000 words (base 10) is used. 


\section{Future Efforts}

None.

\section{Computer Operation}

1. CDC-7600 computer.

2. Core memory depends on number of mesh points desired, $10 \mathrm{~K}$ (base 10) is typical. No special peripherals or plotting is used; in batch operation, problems can be stacked. FTN compiler used but FORTRAN is very basic. No special system routines are used.

3. Running time $\simeq 0.2 \mathrm{msec} / \mathrm{mesh}$ point/time step.

4. Validation: Normal tests for convergence and stability have been made. The steady-state solution has been compared to the exact analytical solution. Transient results have been compared with

\section{Interface/Overlap}

This code does not directly interface with any other code.

\section{$\underline{\text { References }}$}

1. Siegmann, E. R., Nickerson, G. M., Safety Studies, Quarterly Progress Report, System Design of Carbide Fuel, January March 1977.

2. Schoeberle, D. F., et. a1., "The Argus Program," ANL-6654, November 1963.

3. Published LOB results:

J.A. Vitti, et. al., "Preliminary Assessment of Proof Testing LMFBR Carbide Fueled Subassemblies in FTR Driver Positions," CEND-370 (CO0-2426-5), December 1974. 
NICER

\section{Purpose}

Steady-state thermal design of fuel rods in Breeder Reactor fuel and blanket assemblies.

\section{$\underline{\text { Status }}$}

A. Development: Developed and under improvement at ARD as improved $\mathrm{T} \& \mathrm{H}$ models become available.

B. Availability: Proprietary code, available only through lease or purchase arrangements; operational at ARD. The NICER Code is identified as an excepted item under ERDA contracts with Westinghouse.

C. Utilization: Used exclusively by ARD in the T\&H steady-state design of CRBRP and PLBR fuel and blanket assemblies and EBR-II and FFTF irradiation experiments design.

\section{Problems Solved}

The NICER code performs the following calculations and analyses:

1. Assembly mixed mean temperature;

2. Frictional pressure drop along the rod bundle (plus grid spacer losses if gridded assemblies);

3. Radial temperature profile across the rod (bulk coolant, cladding OD, midwall and ID, fuel surface and at various radial positions up to fuel centerline) at a specified number of axial positions (typically 30 over a $64^{\prime \prime}$ length);

4. Minimum power-to-me1t;

5. Film hot spot factors corresponding to specified coolant enthalpy rise hot channel factors;

6. Fission gas release and plenum pressure;

7. All calculations above can be performed for nominal conditions or including uncertainties (hot channel/hot spot) factors; direct, 
fully statistical or semi-statistical (at a specified level of confidence) factors can be considered;

8. Flow distribution among inboard, side and corner channels of gridded assemblies.

Models

NICER has a modular form, such that all principal calculations are performed by a subroutine or group of subroutines ("calculational module"). This allows ease of updating and improving existing models, deletion of obsolete or addition of new ones. Following are the principal modules of NICER:

\section{Geometry}

For a hexagonal assembly and a specified number of rods, the code calculates number, area and hydraulic diameter of the various types of subchannels (inboard, side and corner);

\section{Axial Power Profile}

From physics input data, the code calculates the axial power profile, be it continuous (blanket rod) or discontinuous (fuel rod), in any rod in the core;

3. Assemb1y Mixed Mean Temperature

The assembly outlet temperature is simply determined through enthalpy rise calculation;

\section{Pressure Drop}

The pressure drop in a wire wrapped assembly is calculated adopting the Novendstern method ${ }^{(1)}$; in a gridded assembly it is calculated adopting standard friction factor correlations for bare rods and theoretical calculations (or experimentally determined values) for the grid form losses;

\section{Rod Temperature Profile}

The axial coolant temperature profile along the considered rod is either calculated in NICER or the profile determined by subchannel analysis codes is input as boundary condition. Starting from the bulk coolant temperature at each axial elevation, the cladding and 
fuel temperature are calculated through mono-dimensional heat transfer equations employing empirical correlations to characterize heat transfer coefficients;

\section{Fuel Temperature Calculations}

Fuel pellet behavior is represented through simplified models reproducing the more sophisticated models in the LIFE code, such as gap conductance, gap closure, fuel restructuring, etc.;

\section{Power-to-Me1t}

Minimum power-to-melt is calculated as a function of the rod operating conditions on the basis of the HEDL ${ }^{(2)}$;

\section{Fission Gas Release}

Fission gas released from the unrestructured fuel is calculated on the basis of EBR-II irradiation data; $100 \%$ release from restructured fuel is conservatively assumed ${ }^{(3)}$;

\section{Plenum Pressure}

Fission gas pressure in the plenum is calculated from the perfect gas law, using an average (axially and circumf erentially) temperature for the plenum as calculated by subchannel analysis code;

10. Flow Distribution in Gridded Assembly

A parallel flow network is solved to determine the flow distribution to inboard, side and corner channels. An equal pressure drop boundary condition is satisfied accounting for both rod bundle frictional and grid form losses. The same type of calculation for wire wrapped assemblies is not necessary since it is performed in subchannel analysis code and the subchannel analysis code results input to NICER;

\section{Hot Channe1/Hot Spot Factors}

Assembly mixed mean and local rod temperatures, fission gas pressure can be calculated accounting for uncertainty factors. From the individual direct and statistical factors, NICER calculates the combined semi-statistical factor at the desired level of confidence; 


\section{Linkage With Other Codes}

NICFR is linked to the physics codes and COTEC to obtain necessary input in an efficient, automatic way.

\section{Limitations}

1. Circumferential and axial heat transfer in the rod is neglected;

2. Fuel behavior modeis are necessarily simplifications of the more sophisticated LIFE models;

3. Blanket fuel mode1s are extrapolated from fuel models due to lack of experimental data.

\section{Future Efforts}

1. Incorporation of simplified LIFE models as they become available;

2. Keep updating/improving code modules as more experimental data become available;

3. Link NICER to fuel design mechanical codes to automatically provide NICER output.

\section{Computer Operation}

1. $\quad \mathrm{CDC}-7600$ and $\mathrm{CDC}-6600$;

2. Memory requirements: $\sim 50 \mathrm{~K}$ octa1. Language: FORTRAN IV except input routines written in COMPASS. Special peripherals: one sequential file;

3. Typical problem running time: one to two seconds to perform all calculations described for a fuel or blanket rod;

4. References discussing aspects of code validation:

E. H. Novendstern, "Turbulent Flow Pressure Drop Model for Fuel Rod Assemblies Utilizing a Helical Wire Wrap Spacer System," Nuc1. Eng. Design, 22, pp. 19-29 (1972).

R. D. Leggett, et. a1., "Linear Heat Rating for Incipient Fuel Melting in $\mathrm{UO}_{2}-\mathrm{PuO}_{2}$ Fuel, "Trans. Am. Nucl. Soc., 15, pp. 752753 (1972). 
D. S. Dutt, et. a1., "A Correlated Fission Gas Release Model for Fast React or Fuels," Trans. Am. Nucl. Soc., 15, pp. 198-199 (1972).

CRBRP PSAR Section 4.4 .

\section{Interface/Overlap}

COTEC, TRITON, FURFAN, LIFE-III, /-.

\section{$\underline{\text { References }}$}

1. M. D. Carelli, C. W. Bach, R. A. Markley, "Analytical Techniques for Therma1/Hydraulic Design of LMFBR Assemblies," Trans. Am. Nuc1. Soc., 17, pp. 423-424 (1973). 
ORRIBLE

\section{Purpose}

To perform thermal-hydraulic analysis of steady flow in wire-wrapped, heat generating rod bundles.

\section{Status}

A. Development: Developed and under improvement at ORNL.

B. Availability: Released. Currently, there are eleven operational versions of ORRIBLE: 6 for 19 rod bundle configurations, and 5 for 37,91 and 217 rod bundles. All eleven have been documented (latest in 1974).

C. Utilization: ORNL developed code for analysis of the THORS Facility, which is used for out-of-pile simulation of LMFBR subassembly thermal-hydraulics at normal and off-normal operating conditions.

\section{Problems Solved}

1. Predicts the flow and temperature distribution for steady-state single phase flow in wire-wrapped heat-generating rod bundles having any combination of flow subchannels blocked at the inlet.

2. Due to its rapid execution, is useful in making parametric studies and in correlating data from tests of unblocked THORS bundles.

3. The eleven versions of ORRIBLE will calculate the following rod bundle configurations:
a. 19-, 37-, 91-, and 217-rod bundles,
b. hexagonal ducts,
c. scalloped ducts, and
d. left-handed pitch wire wrap.

Mode1s

1. Transverse interactions between flow subchannels are due to turbulent interchange, pressure-induced diversion cross-flow, directed sweeping cross-flow due to wire-wrap, and transverse 
thermal conduction. Expressions for the transverse interactions are used in the equations of conservation of mass and energy to establish the thermal and hydrodynamic characteristics of the system.

2. Salient feature of ORRIBLE is the implicit use of the equation of conservation of axial momentum by obtaining an expression for pressure-diversion cross-flow in terms of the axial mass velocity in the two adjacent flow channels. By so doing, pressure is eliminated as a variable, and the solution is obtained without recourse to iterative techniques.

\section{$\underline{\text { Limitations }}$}

Two of the basic assumptions of the code are:

1. Pressure induced cross-flows are computed assuming that a two-channel model is applicable to a multi-connected system.

2. Sweep cross-flow is taken to be significant only while the spiral wire is within $120^{\circ}$ from the inter-channel gap, with the maximum value occurring when the wire wrap is in the gap between two adjacent rods.

\section{Future Efforts}

A 61-pin bundle version is under development.

\section{Computer Operation}

1. Operational on IBM 360 .

2. For the 19-rod versions, less than $140 \mathrm{k}$ bytes of core are required. Language is FORTRAN IV.

3. As this is a forward-marching code with no iterations, for the 19-rod versions execution times are measured in seconds.

4. A comparison of analytical experimental results is to be found in

"Temperature Distribution in the Duct Wall and at the Exit of a 19-Rod Simulated LMFBR Fuel Assembly (FFM Bundle 2A)," M. H. Fontana, et. al., Nuclear Technology, 24, 176-200, November 1974 .

\section{Interface/Overlap}

SIMPLE, COBRA. 


\section{$\underline{\text { References }}$}

1. J. L. Wantland, "ORRIBLE - A Series of Computer Programs for Flow and Temperature Distribution in LMFBR Fuel Rod Bundles of Different Sizes and Configurations," ORNL-TM-4384, March 1974.

2. J. L. Wantland, "ORRIBLE - A Computer Program for Flow and Temperature Distribution in LMFBR Fuel Rod Bundles," ORNL-TM-3516, October 1971. 
ORSLAP

\section{Purpose}

To investigate sodium loop dynamics occurring during forced flow transients.

\section{$\underline{\text { Status }}$}

A. Development: Developed and being modified at ORNL.

B. Availability: Developmental: Documentation (ORNL/TM-5322).

C. Utilization: ORNL developed program for analysis of transients in the THORS Facility, a large sodium test loop for out-of-pile studies.

\section{Problems Solved}

1. Forced flow and power transients. Execution time approximately $1 \mathrm{~min}$ $360 / 91 \mathrm{CPU}$ per $1 \mathrm{sec}$ of transient.

2. Single- and two-phase flow and heat transfer.

Mode1s

1. One-dimensional, fixed volume, homogeneous, equilibrium, transient conservation equations are used.

2. Complete equation-of-state search is included.

3. Experimental data may be used for loss coefficients for elbows, tee, etc. Fictional pressure drops are computed from curves fit to Moody diagram.

4. Cover gas pressure in the expansion tank and pump bowl are computed from ideal gas law.

5. One-hundred electric pin models are allowed.

6. Pump model is input by normalized head vs time curves. Five pumps are allowed.

7. Time-dependent value positions are allowed. 
8. Heat exchanger time-dependent secondary side conditions are allowed. Heat exchanger is multi-node.

9. Program is structured in multi-node, multi-path, modular form. The problem geometry is specified on input.

\section{Limitations}

1. Fixed time step.

2. Explicit integration of conservation equations.

3. Forced flow transients.

4. Heat transfer other than electric core and heat exchanger is neglected.

5. Intact geometry is assumed.

\section{Future Efforts}

1. Variable time step.

2. Implicit integration of conservation equations.

3. Imp roved equation-of-s tate search.

\section{Computer Operation}

1. IBM $360 / 91$.

2. FORTRAN IV Level H

270K; DA 100080 byte records

DA 10001336 byte records

Batch process

Calcomp plots

3. 1 min $C P I / 1$ sec real time transient for a 30 node-flow path mode1.

4. Code Validation: None.

\section{Interface/Overlap}

SAS

$\underline{\text { References }}$

1. ORNL/TM-5322. 


\section{Purpose}

Nuclear excursions in various fissioning systems as well as dynamic, nonfissioning systems asre described with interactive neutronics, thermodynamics, and hydrodynamics in 1-D spherical, cylindrical, and planar geometries.

\section{Status}

A. Development: Developed at LASL. PAD evolved from the RAC code ${ }^{1}$.

B. Availability: Operational at LASL on a CDC-7600, BNL on a CDC-7600, Sandia on a DCD -7600 , and University of Arizona on a CDC-6400. Released to the Argonne Code Center in January 1977 .

C. Utilization: Has been used extensively by LASL for analysis of destructive and nondestructive experiments involving promp-critical reactivity insertions and has been applied to analysis of reactivity transients for various power reactor concepts (fast, intermediate, light water and solution reactors).

Problems Solved

1. Calculation of nondestructive experimental prompt-critical transients for temperature rise and total fissions.

2. Calculation of destructive experimental prompt-critical transients for explosive energy release and prediction of threshold for an explosion.

3. Calculation of destructive and nondestructive regimes for postulated molten fuel recriticality accidents.

4. Calculation of kinetic energy imparted to the sodium slug (sodium hammer) for postulated reactor prompt-critical excursions.

5. Calculation of simple thermodynamic systems to compare conversion of internal energy to kinetic energy with thermodynamic theory for work done by adiabatically expanding systems. 
6. Reactor prompt-critical transient parametric studies varying Doppler coefficient, FCI heat transfer rates, and reactivity insertion ramp rates to provide bounding estimates of explosive energy releases for various initial core conditions.

\section{Models}

The basic computational technique in PAD is similar to that used in the AX-1 $\operatorname{code}^{2}$.

\section{Geometry}

PAD is $1-D$, with options for spherical, planar and cylindrical geometries. The calculated system is divided into a set of computational nodes or lumped mass points.

\section{Neutronics}

A neutron kinetics formulation with up to six groups of delayed neutrons is used to describe the time variation of the power in a fissioning system. Throughout a calculation the spatial power distribution and the material motion reactivity feedback are obtained from explicit $S_{n}$ transport calculations. Temperature feedback (Doppler, fuel pin expansion) is calculated from mathematical models which include spatial reactivity weighting options.

\section{Hydrodynamics}

In a11 geometries the coordinate system is Lagrangian. The pressure differential between adjacent regions provides the hydrodynamic driving force.

\section{Calculational Scheme}

The fission energy deposition raises the individual region temperature and pressure and the cyclic calculation for each mass point proceeds through acceleration and velocity, then geometric change, resulting in reactivity change and then again to energy deposition, temperatures and pressure. The temperature calculation includes thermodynamic work as well as deposition of fission energy.

\section{Heat Transfer}

PAD allows two different materials within a mass point, with the fission energy deposited in one material allowed to be transferred 
to the other when preset conditions are reached. The rate of heat transfer between materials, as between fuel and sodium, may take several optional forms.

\section{Equation of State}

The EOS consists of a set of functions and coded decisions which, with specific constants, describes a material in the condensed and the vapor state and provides an orderly transition between these states. Pressure is given as a function of temperature and density. Specific heats are defined with piecewise continuous polynomials. Latent heats are defined with a Watson's formula. Allowance is made for a solid-liquid phase change by providing the option for a heat sink at a specific temperature. The functional form for the condensed state pressure is only adequate for small changes in density and pressure. The expression for the vapor pressure is modeled on either the ideal gas law or a van der Waal's equation. PAD has internal library data for uranium metal, uranium dioxide, graphite, sodium, and water.

\section{Limitations}

1. Limited to 1-D calculations.

2. Only two materials are allowed per mass point.

3. No heat transfer between regions (mass points).

\section{Future Efforts}

Maintenance of code.

\section{References}

1. C. G. Chezem and W. R. Stratton, "RAC, A Computer Program for Reactor Accident Calculations," Los Alamos Scientific Laboratory report LAMS-2920 (January 1963).

2. D. Okrent, R. Lazarus, et. al., "AX-1, A Computing Program for Coupled Neutronics-Hydrodynamics Calculations on the IBM 704," Argonne National Laboratory report ANL-5977 (May 1959).

Model Description and Experimental Validation:

3. W. R. Stratton, et. al., "Reactor Power Excursion Studies," given at International Conference on Engineering of Fast Reactors for Safe and Reliable Operation, Karls ruhe, October 9-13, 1975. 
PECTCLAD

\section{$\underline{\text { Purpose }}$}

The purpose of PECTCLAD is to predict the thermal/mechanical response of the FFTF fuel pin cladding to both steady-state and transient reactor behavior.

\section{Status}

A. Development: PECTCLAD was developed at HEDL.

B. Availability: PECTCLAD is operational at HEDL. It has been documented (Ref. 1) and is ready for release.

C. Utilization: PECTCLAD is used for:

1. EBR-II fuel pin analysis.

2. Tornado and loss of flow transient fuel $p$ in analyses in support of FFTF design.

3. Data correlation of creep, tensile, burst and Fuel Cladding Transient Tester (FCTT) data of Type 316 stainless steel cladding.

4. Modeling the cladding in code PECTPIN.

\section{Problems Solved}

PECTCLAD performs a thermal/mechanical analysis of a thick-walled cylinder. PECTCLAD models the plastic, elastic, creep and thermal behavior of fuel pin cladding materials. The cladding is the primary structural member that provides spatial constraints to the fuel pellets, isolates the sodium coolant from the pellets, and provides a containment vessel for the fission-product gases. The neutron, coolant pressure and temperature histories and spatial distributions define the environment of the fuel pin. This environment provides fuel pin cladding external loads and reflects the reactor operating history. The environment also introduces irradiation, hardening, and porosity effects into the cladding material. PECTCLAD was developed to predict the thermal/mechanical response of the fuel pin cladding to this environment history. 


\title{
$\underline{\text { Mode1s }}$
}

The postulates 1) conservation of mass, 2) balance of momentum, 3) conservation of energy, 4) entropy inequality, and 5) response functions are used to derive the governing equations (Ref. 2). The assumptions of axial symmetry and generalized plane strain are used to simplify the motion to a function of material radius and time. The outer-surface boundary conditions are the outer coolant temperature and the external pressure. The inner-surface boundary conditions are the inner coolant temperature and the internal pressure or the number of moles of gas contained in the closed cylinder. The axial boundary condition is in terms of given axial strain or pressure (either an open or closed-end condition is considered). These formulations result in an integral equation for the rate of volume change (trace of the stretching tensor). The spatial integrals are approximated by closed Newton-Cotes quadrature formulas. Therefore, the integral equation becomes a matrix equation which is solved by the Gauss elimination technique. The resulting rate equations are then solved by a fifth order predictor-corrector method called HDES5 (Ref. 3). The transient temperature solution can be accomplished by either the explicit or implicit scheme. A steady-state temperature solution is also available.

\section{Limitations}

PECTCLAD is programmed for 5 radial nodes. Changing the number of nodes requires reprogramming. Examples of the required changes for 3,6 , and 9 nodes are listed in Ref. 1 . Type 316 stainless steel material laws are programmed into PECTCLAD. Therefore, a different material requires reprogramming. A limited irradiation correlation has been performed.

\section{Future Efforts}

Develop and improve Type 316 stainless steel correlation with irradiation effects.

\section{Computer Operation}

1. Computer: Control Data corporation (CDC) CYBER 74-18.

2. Logistics:

\author{
a. Machine requirement: 65,000 octal (27,136 decima1) \\ of 60 bit CYBER words; \\ b. Peripheral storage: none;
}


c. Programming language: FORTRAN-IV;

d. Operating system: SCOPE.

3. Running time: Typical running times are approximately twenty (20) seconds ( 5 seconds for simple elastic problems and 50 seconds for complex plastic problems).

4. Code Validation: Three benchmark problems used to validate the LIFE-II code have been compared with PECTCLAD results.

Interface/Overlap

PECTPIN, TEMP

\section{$\underline{\text { References }}$}

1. F. E. Bard, B. C. Gneiting and B. Y. Christensen, PECTCLAD: A Computer Code to Determine Fuel Pin Cladding Deformations and Stress, HEDL-TME 75-46, Hanford Engineering Development Laboratory, Richland, Washington, January 1977.

2. F. E. Bard, Some Aspects of Continuum Physics Used In Fue1 Pin Modeling, HEDL-TME 74-30, Hanford Engineering Development Laboratory, Richland, Washington, June 1975.

3. B. C. Gneiting and F. E. Bard, HDES5 - A Subroutine To Solve A System of Differential Equations, HEDL-TME 75-45 Hanford Engineering Development Laboratory, Richland, Washington, May 1975. 
PECTPIN

\section{Purpose}

The purpose of PECTPIN is to predict the thermal/mechanical response of a Fast Breeder Reactor (FBR) fuel pin to the normal, upset, emergency, and hypothetical faulted design conditions.

\section{Status}

A. Development: PECTPIN was developed at HEDL.

B. Availability: PECTPIN is developmental at HEDL.

C. Utilization: PECTPIN is used to analyze TREAT tested FBR fuel pin.

\section{Problems Solved}

The computer code PECTPIN calculates temperature, stress, and strain of a FBR fuel pin during normal, design basis, and hypothetical transients. These fuel pins are composed of uranium, plutonium mixed oxide pellets encased in stainless steel cladding. The cladding is the primary structural member that provides spatial constraints to the pellets, isolates the sodium coolant from the pellets and provides a containment vessel for the fission events. The neutron density distribution and history and the coolant pressure and temperature histories define the fuel pin environment. This environment provides the fuel pin external loads and reflects normal reactor operation such as startups, shutdowns, power cycles, steady-state operation, and off-normal events such as loss of coolant transients and reactivity transients. PECTPIN was developed to predict the thermal/ mechanical response of a fuel pin to this environmental history.

\section{Mode1s}

PECTPIN is an update and an improvement to earlier versions of PECT, which have existed since 1968 (Ref. 1) and have been used to analyze fuel pin behavior (Refs. 2, 3, 4, 5). Several past reports have described the theory (Refs. 5, 6, 7,8,9), the temperature solution (Ref. 10) and the integration method (Ref. 11).

PECTPIN is a combination of three complex models: a thermal and heat transfer model called TEMP (Ref. 10), a stainless steel cladding model called PECTCLAD (Ref. 8) and a uranium, plutonium mixed-oxide fuel model. The thermal and heat transfer model calculates fuel pin transient temperatures. TEMP will handle a fuel as simple as a solid 
cylinder and as complex as a central void surrounded by fuel which is broken into three regions by two circumferential cracks. Any fuel situation between these two extremes can be analyzed along with any number of cladding, heat sink, coolant or capsule regions surrounding the fuel.

The cladding model has been correlated with tensile, burst, creep and Fue1 Cladding Transient Tester (FCTT) data of Type 316 stainless steel. The current irradiation creep and swelling laws for $20 \%$ cold worked Type 316 stainless are available for use. The cladding mechanical analysis assumes axial symmetry and generalized plane strain. Therefore, the stress effects due to the presence of a wire wrap and the effects of cladding bowing due to asymmetrical distribution of temperature and fluence are ignored.

The fuel model is under development. The same assumptions of axial symmetry and generalized plane strain are used for the fuel mechanical analysis. These assumptions simplify the fuel pin motion to a function of material radius and time. The motion relates spatial (deformed or eulerian) coordinates to the material (undeformed or lagrangian) coordinates and time. The material formulation is used in the fuel pin model. This formulation describes the behavior of a fuel (cladding) particle throughout its life-time. Finite deformation theory, which is described in terms of the logarithine measure of strain, is used in the fuel model because of the extreme plasticity of the central portion of the fuel and because part of the fuel column melts during transient tests.

The user of code PECTPIN can specify various models by a simple input instruction. Some of these models are hardening, life fraction, nonelastic behavior, creep, plasticity, open or closed end condition, open or closed cavities, swelling, fabrication file, restart, slip or stick axial boundary condition and fuel pellet cracking.

PECTPIN is a one-dimensional formulation. The resultant integral equation for the rate of volume change becomes a matrix equation by using closed Newton-Cotes quadrature formulas to approximate the integrals. The matrix equation is solved by a Gauss elimination technique. The rate equations are solved by a fifth order predictor-corrector method (Ref. 11).

\section{Limitations}

PECTPIN is limited to one-dimension. Hence, the fuel/cladding contact (gap closure) model is an approximation, the pellet to pellet interface is not modeled and the fuel pellet cracks interfacing the cladding is 
not modeled. Type 316 stainless steel cladding and uranium, plutonium mixed oxide fuel material laws are programmed into PECTPIN. Therefore, different materials require reprogramming.

\section{Future Efforts}

PECTPIN will continue to perform pre and post test analyses of TREAT tested fuel pin.

Computer Operation

1. Computer: Control Data Corporation (CDC) CYBER 74-18.

2. Logistics:

a. Machine requirement: $102 \mathrm{~K}$ octal (33792 decima1) of 60 bit cyber words.

b. Peripheral storage: none.

c. Programming language: FORTRAN IV

d. Operating system: SCOPE.

3. Running time: Typical running times as of June 1977 are 300 seconds and will be increased as more models are checked out and used.

4. Code Validation: The TEMP subroutine and the PECTCLAD model have been validated. However, the complete system (PECTPIN) has not been validated.

Interface/Overlap

PECTCLAD, TEMP

\section{$\underline{\text { References }}$}

1. F. E. Bard, Jr., PECT-1 A Fortran IV Computer Program to Determine the Plastic-Elastic Creep and Thermal Deformations in Thick-Walled Cylinders, BNWL-1171, Battelle Memorial Institute, Pacific Northwest Laboratories, Richland, Washington, December 1969.

2. G. E. Culley, J. E. Hanson, R. D. Leggett and F. E. Bard, Response of and EBR-II Irradiated, Mixed Oxide Fuel Pin to an Overpower Transient in TREAT, WHAN-SA-84, Prepared for presentation at the ANS Topical Meeting April 13-15, 1971, New Orleans, Louisiana. 
3. F. E. Bard and D. S. Dutt, PECT-2 Analysis of the H-3 Transient Test, HEDL-TME 72-28, Hanford Engineering Development Laboratory, Richland, Washington, February 1972.

4. B. C. Gneiting and F. E. Bard, PECT-2T Pretest Analysis of the HUT-CAL-2 Transient Test, HEDL-TME 74-15, Hanford Engineering Development Laboratory, Richland, Washington, April 1974.

5. B. C. Gneiting and F. E. Bard, Pretest Analysis of the HUT L2 Transient Test, HEDL-TME 76-71, Hanford Engineering Development Laboratory, Richland, Washington, September 1976.

6. F. E. Bard, B. C. Gneiting, and C. M. Cox, A Thermoelastic Material Properties Correlation for Uranium/Plutoniun Mixed Oxides, HEDL-TME 74-12, Hanford Engineering Development Laboratory, Richland, Washington, February 1974.

7. F. E. Bard, Some Aspects of Continuum Physics Used In Fue1 Pin Modeling, HEDL-TME 74-30, Hanford Engineering Development Laboratory, Richland, Washington, June 1975.

8. F. E. Bard, B. C. Gneiting and B. Y. Christensen, PECTCLAD: A Computer Code to Determine Fuel Pin Cladding Deformations and Stress, HEDL-TME 75-46, Hanford Engineering Development Laboratory, Richland, Washington, December 1976.

9. F. E. Bard, Modeling of LMFBR Fuel Cladding Mechanical Behavior Under Transient Conditions, HEDL-SA-1159, Hanford Engineering Development Laboratory, Richland, Washington, February 1977, Prepared for presentation to the Structural Mechanics in Reactor Technology meeting at San Francisco, California, August 15-19, 1977 .

10. F. E. Bard, B. Y. Christensen and B. C. Gneiting, TEMP: A Computer Code to Calculate Fuel Pin Temperatures During a Transient, HEDL-TME 75-85, Hanford Engineering Development Laboratory, Richland, Washington, (Draft).

11. B. C. Gneiting and F. E. Bard, HDES5 - A Subroutine To Solve A System of Differential Equations, HEDL-TME 75-45, Hanf ord Engineering Development Laboratory, Richland, Washingt on, May 1975. 
PFRAS

\section{Purpose}

Simplified analysis of transient fission-gas release and swelling in oxide fuel.

$\underline{\text { Status }}$

A. Development: Developed at ANL/RAS.

B. Availability: Operational on the IBM 370/195 at ANL. Code description is available (Ref. 1).

C. Utilization: PFRAS has been used at ANL to provide modeling capability for fission-gas release to grain boundaries and intragranular swelling in multi-node codes, including POROUS and FSTATE.

\section{Problems Solved}

PFRAS solves the same problem as FRAS; that is, the transient gas release from grains to grain boundaries and intragranular swelling as functions of the transient time for a single fuel node. The code is much simpler than the FRAS code, to which it is calibrated, because the bubble-size distribution is not calculated. Instead, PFRAS uses interpolation in two tables of parameters determined from the FRAS code, in conjunction with a dimensionless-time analysis, to calculate the desired results. Applicability of the code is identical to that of the FRAS code, with the difference that PFRAS requires about an order of magnitude less computer storage and time for execution. PFRAS is therefore well suited for inclusion in multi-node pin-mechanics codes, such as FPIN, POROUS, and FSTATE.

\section{Mode1s}

PFRAS is based on the assumption that the bubble-size distribution rapidly approaches an asymptotic shape (Ref. 2). A dimensionless time is defined to characterize cumulative effects of transient history, and two parameters are defined to represent the mean bubble mobility and swelling. These parameters are functions of the dimensionless time and of the hydrostatic stress, and are tabulated from results of FRAS code calculations. The PFRAS code uses these tables as input, interpolating to obtain appropriate values of the parameters. 
The gas release calculation is carried out explicitly, as in FRAS, assuming biased-migration release. Random-migration release is included implicitly because the mobility is defined from FRAS calculations, which include random migration. Results are therefore valid for any grain size.

All models in FRAS are implicitly included in PFRAS, in the tables of parameters obtained from FRAS calculations.

\section{Limitations}

PFRAS 1imitations are identical to those of FRAS, to which it is calibrated.

\section{Future Efforts}

Include bubble-relaxation rate effects in PFRAS when FRAS2 calculations are sufficiently developed.

\section{Computer Operation}

1. Runs on IBM $370 / 195$.

2. Logistics: Uses FORTRAN language. Load module can be executed in 80 kilobyte region.

3. Typical Run Time: For representative single-node transient to fuel melting, less than 10 seconds.

4. Code Validation: Ref. 1. See also FRAS.

\section{Interface/Overlap}

POROUS, FSTATE, FRAS

\section{References}

1. E. E. Gruber, "A Generalized Parametric Model for Transient Gas Release and Swelling in Oxide Fuels," ANL-77-2 (January 1977).

2. E. E. Gruber, J. App1. Phys. 38, p. 243 (1967). 
PIFITE

Purpose

Analysis of the thermal and pressure consequences in a gas pipe subjected to sodium flooding as the result of an HCDA.

\section{Status}

A. Development: Developed at HEDL.

B. Availability: Operational at HEDL and WARD. Available upon request.

C. Utilization: Used by HEDL and WARD for HCDA analysis of cover gas and low level flux monitor piping penetrations in the reactor head.

\section{Problems Solved}

The code calculates flooding (transient fluid entry) of a gas pipe by liquid sodium driven under HCDA pressures, the forces on the pipe elbows due to transient momentum and pressure effects of flooding and the pipe wall temperatures as the sodium heats the pipe.

\section{Models}

\section{Geometry}

The gas pipe is a single continuous pipe composed of any number of straight pipe sections connected at elbows and is of uniform diameter along its entire length. The straight pipe sections may be of any length and elevation slope and the elbows may be of any turn angle. All equations are one-dimensional.

2. Fluid Flow and Method of Solution

The differential equations for sodium flow assume that this sodium is a fluid slug that flows along and thereby fills the gas pipe. These equations are solved using the fourth-order Runge-Kutta-Gill method.

\section{Heat Sources and Pipe Insulation}

The pipe may have a heater (Calrod) and insulation along part or al1 of its length. 


\section{Heat Transfer}

The heat transfer equations assume the following:

a. Convection from sodium to the pipe wall (inside surface).

b. One-dimensional conduction through the pipe wa11.

c. Convection from pipe wall (outside surface) to air trapped inside the insulation.

d. Convection from air trapped inside insulation to the heater and insulation.

e. Radiation from pipe wall (outside surface) to heater and insulation.

f. One-dimensional conduction inside cylindrical heater and through cylindrical layers of insulation.

g. Convection from insulation to surrounding gas atmosphere.

\section{Limitations}

1. The gas pipe has a constant diameter along its entire length.

2. The gas pipe cannot branch.

\section{Future Efforts}

No code refinements are planned.

Interface/Overlap

$-1-$

\section{$\underline{\text { References }}$}

1. R. D. Peak, contributor, "HEDL Quarterly Technica1 Report, April, May, June 1973," HEDL-TME 73-4, Volume 2, August 1973, p. 2-4.

2. I. M. Tang, "PIFITE Code, Application in Clinch River Breeder Reactor," WARD-D-0144, Westinghouse Electric Corporation, Advanced Reactors Division, Madison, Pennsylvania, June 1976. 
PLOFA

\section{Purpose}

Analysis of fuel motion in a single fuel pin during the initiation phase of an LMFBR loss of flow accident.

\section{$\underline{\text { Status }}$}

A. Development: PLOFA is being developed at the Georgia Institute of Technology.

B. Avallability: Developmental.

C. Utilization: Provides fuel motion data in the analysis of loss of flow accidents.

Problems Solved

The motion of molten fuel strongly affects the reactivity changes during a LOF accident, and hence the future course of the accident. PLOFA provides a two-dimensional analysis of this unsteady motion of fuel, clad, and fission gases.

Models

The two-dimensional analysis of fuel motion is based on a model channel consisting of an isolated single fuel pin with cladding and associated subassembly containment structure. It is assumed that a calculation performed on this single pin is representative of all pins in the entire assembly.

Equations of motion and energy transfer have been formulated to describe the material motion in a channel. The two main materials of interest (fuel and steel) could be in a solid, liquid or vapor form, while the third material (fission products) is essentially gaseous. These different phases and components exist in various proportions and at different temperatures and pressures throughout the channel.

A compromise is reached between a single fluid concept and an entirely distinct fluids method. It is important to preserve component and phase distinction, but impractical to apply boundary conditions at interfaces. Accordingly, there is the distinction between the various materials, but the interaction between them is treated via exchange functions. These exchange functions are based on the interaction 
between an essentially discrete medium placed in a continuous medium. The flexibility afforded by these exchange functions permits manipulation to achieve any desired degree of linkage between two materials. The material interface positions cannot be described exactly, but the proportions of the various materials in any region are known, as are their distinct field variables.

The seven materials in the channel are liquid fuel, liquid steel, solid fuel, solid steel, vapor fuel, vapor steel and gaseous fission products.

The mathematical model is far too complex to yield a direct analytical solution; meaningful results can only be achieved by numerical methods. A numerical scheme must address itself to the problems of choosing a suitable mesh to zone the region of interest, locating the field variables in this mesh, approximating the differential equations of motion and energy transport by finite difference equations with the desired accuracy, analyzing the stability of the difference equations, and formulating an iterative scheme to solve the difference equations.

The numerifal scheme follows the multi-field approach of Harlow and Amsden, $(7,8)$ based on an extension of the implicit, continuous fluid, Eulerian (ICE) technique. (9)

The cylindrical region is zoned into a mesh of fixed cells, and the finite difference approximations of the equations of density and momentum transport are iteratively solved in each cell by an implicit treatment of velocity and pressure. The energy equation is then solved explicitly. Appropriate boundary conditions are applied at container boundaries and certain material interfaces, such as between a substantial solid region and a liquid or a vapor region.

\section{Limitations}

No allowance for incoherent behavior of fuel pins in a channel.

\section{Future Efforts}

Continued development of the mode1 and numerical treatment is anticipated with the objective of reducing the computing time required for the solution of a complete problem. Also verification of the model by comparison with experimental results will be continued.

\section{Computer Operation}

1. PLOFA is being developed on the CDC CYBER 70/Mode1 74 . 
2. Currently requires approximately 150,000 octal words of CYBER memory. The program is written in FORTRAN IV. In places, specific CDC I/O routines and FORTRAN statements are used, but their equivalent should be available on other computational systems. Post processing plotting capabilities are provided both in the form of hard copy (Calcomp) and graphics terminal display (PDP 10/11 with GT42 graphics termina1).

3. The running time is dependent on the phases in which the materials are present. Compressible vapors generally require more computational time for a given problem time than do the incompressible fields. The code is being optimized to lessen the present deve1opmental calculational time.

4. References 5 and 6 of reference section.

\section{Interface/Overlap}

The LASL computer code KACHINA ${ }^{(10)}$ provides similar analysis for a two field confined flow model.

The SLUMPY module of ANL's SAS code ${ }^{(11)}$ treats one-dimensional (axial) fuel motion in a slumping channel.

\section{$\underline{\text { References }}$}

1. Lal, D. and R. W. Carlson, "Two Dimensional Fuel Motion Analysis During Loss of Flow Accidents in a Liquid Metal Cooled Fast Breeder Reactor," Quarterly Progress Report submitted to the Energy Research and Development Administration, ORO-4958-1 (October 1975).

2. Lal, D. and R. W. Carlson, "Two Dimensional Fuel Motion Analysis During Loss of Flow Accidents in a Liquid Metal Cooled Fast Breeder Reactor," Quarterly Progress Report submitted to the Energy Research and Development Administration, ORO-4958-2 (January 1976).

3. La1, D. and R. W. Carlson, "Two Dimensional Fuel Motion Analysis During Loss of Flow Accidents in a Liquid Metal Cooled Fast Breeder Reactor," Quarterly Progress Report submitted to the Energy Research and Development Administration, ORO-4958-3 (Apri1 1976). 
4. Lal, D. and R. W. Carlson, "Two Dimensional Fuel Motion Analysis During Loss of Flow Accidents in a Liquid Metal Cooled Fast Breeder Reactor," Quarterly Progress Report submitted to the Energy Research and Development Administration, ORO-4958-4 (July 1976).

5. La1, D. and R. W. Carlson, "Two Dimensional Fuel Motion Analysis During Loss of Flow Accidents in a Liquid Metal Cooled Fast Breeder Reactor," Quarterly Progress Report submitted to the Energy Research and Development Administration, ORO-4958-5 (October 1976).

6. Lal, D. and R. W. Carlson, "Two Dimensional Fuel Motion Analysis During Loss of Flow Accidents in a Liquid Metal Cooled Fast Breeder Reactor," Quarterly Progress Report submitted to the Energy Research and Development Administration, ORO-4958-6 (January 1977).

7. Harlow, F. H. and A. A. Amsden, "Numerical Calculation of Multiphase Fluid Flow," Journal of Computational Physics, 17, 1 , $19-52$ (1975).

8. Harlow, F. H. and A. A. Amsden, "Flow of Interpenetrating Material Phases" Journal of Computational Physics, 18, 440-464 (1975).

9. Harlow, F. H. and A. A. Amsden, "A Numerical Fluid Dynamics Calculational Method for all Flow Speeds," Journal of Computational Physics, 8 , 2, 197-213 (1971).

10. Amsden, A. A. and F. H. Harlow, "KACHINA - An Eulerian Computer Program for Multifield Fluid Flows," LA-5680, Los Alamos Scientific Laboratory, Los Alamos, New Mexico (1974).

11. Stevenson, M. G., W. R. BohI, F. E. Dunn, T. J. Heames, G. Hoppner and L. L. Smith, "Current Status and Experimental Basis for the SAS LMFBR Accident Analysis Code System," Proc. Fast Reactor Safety Meeting, CONF-740401-P2, Beverly Hills, California (April 1974). 


\section{Purpose}

Therma1-hydraulic analysis of cold pool LMFBR (as typified by EBR-II) primary loop transients with intact piping.

\section{Status}

A. Development: The code was developed at the Applied Physics Division of Argonne National Laboratory. Current development version is PLOOP.

B. Availability: The code is operational at ANL but has not yet been released.

C. Utilization: The code was recently used to analyze up to 40 seconds of transient time a startup-transient problem in which the pump-motor angular speed and the sodim mass flow rate in the primary loop increase from zero to their steady-state values when the motor is turned on at zero time. The reactor power transferred to the coolant was specified to be zero during the first second and was then linearly increased to full power in the next two seconds and kept constant for the rest of the transient.

\section{Problems Solved}

The code computes the spatial and temporal variation of mass flow rate and temperature of the coolant in the primary loop and of the coolant on the tube side of the IHX, the temporal variation of the pump-motor angular speed and of mass of sodium in the main tank. The capabilities of the code include explicit accounting of the primary pump and the electric motor characteristics, heat exchange with the intermediate loop, heat exchange of all components with the main tank sodium, natural circulation, startup-transient and flow coastdown transient.

\section{Models}

The thermodynamic properties of liquid sodium are assumed to depend only on its temperature and not on its pressure. Since flow work is negligible compared to heat transfer, the specific enthalpy of the coolant is assumed equal to the specific internal energy. Pressure waves have been eliminated from the code by using only one $1-D$ integral momentum equation between any pair of free surfaces (or around a closed 
circuit if there is not any free surface) to determine flow rate. The cold pool LMFBR primary loop consists of only one closed circuit of flow which is divided into a user specified number of heat transfer nodes, and a differential equation is written for the internal energy of every node based on the donor cell concept. Using the known spatial variation of flow rate (values of the node boundary flow rates) at the beginning of the time step, $t^{n}$, the integral momentum equation expresses the time derivative of the flow rate at a reference node boundary in terms of the various pressure differences and the pump head.

In the first cycle of calculations to advance from time $t^{n}$ to $t^{n+1}$, the time derivatives are evaluated at the beginning of the time step. In the second and higher cycles of calculation over the same time step, the averages of the values of the time-dependent variables at the times $t^{n}$ and $t^{n+1}$ are used in evaluating the derivatives. Any number of cycles over a time step may be specified in the code.

The mass flow rates at node boundaries other than the reference are computed (in every cycle of calculation) recursively starting from the flow rate at the reference node boundary, with the help of the differential equations of mass conservation for the heat transfer nodes.

\section{Limitations}

1. The code does not model boiling of the coolant and may calculate temperatures greater than the boiling point to indicate boiling.

2. Heat conduction in the fuel $p$ in is not modeled, and the code requires coupling to a code like SAS for the calculation of fuel pin heat transfer.

3. In order to generate the full power steady-state operating values of the primary loop coolant flow rates and temperatures, the PLOOP code has to be run for a long transient time from a zero flow and uniform temperature condition.

4. Hot pool LMFBR (as typified by the French PHENX) primary loop cannot be analyzed with the existing code.

\section{Future Efforts}

The limitations (3) and (4) will be removed in near future. The limitations (1) and (2) are not planned to be removed. The overall structure 
of the code has been designed with the consideration that the code will require coupling to the SAS code.

\section{Computer Operation}

1. The code has been made operational on IBM $370 / 195$ computer system.

2. Logistics: The code requires about $250 \mathrm{~K}$ of core memory and is programmed in FORTRAN IV 1anguage. It does not require any special peripherals, mode of operation, any special compiler or system routines.

3. The problem described under the section "Problems Solved" required about $212 \mathrm{sec}$ of IBM $370 / 195$ computer system time using a load module produced by the FORTRAN H Compiler. This problem had 34 heat transfer nodes and was run up to $40 \mathrm{sec}$ of transient time using a time step of 0.05 sec.

\section{References}

1. Physics of React or Safety, Quarterly Report for October-December 1976, ANL-77-22, Argonne National Laboratory, Illinois. 
PLUTO

\section{Purpose}

Analysis of: (a) molten fuel ejection from a TOP fuel pin into a flowing sodium coolant channel or into a partially voided channe1; (b) mild fuel-coolant interactions; (c) flow of fuel/sodium/fission-gas mixture in a coolant channel.

\section{$\underline{\text { Status }}$}

A. Development: Initial development was at Northwestern University (Ref. 1). PLUTO-1 was developed at ANL/RAS. PLUTO-2 is current development version at ANL/RAS.

B. Availability: PLUTO-1 (Ref. 2) is operational at ANL on IBM 370 , at LBL on CDC-7600 and at BNL. PLUTO-1 will not be released in lieu of release of SAS 4A, which will contain PLUTO-2. A stand-alone version of PLUTO-2 (Ref. 3) is operational at ANL on IBM 370 . PLUTO-2 will be released as a module of SAS $4 \mathrm{~A}$.

C. Utilization: PLUTO-1 has been used to analyze in-pile TOP experiments and for CRBR PSAR TOP calculations. PLUTO-2 will be incorporated into SAS.

\section{$\underline{\text { Problems Solved }}$}

The PLUTO codes predict the phenomena associated with the movement of molten fuel out of a TOP fuel pin which has loaded the clad sufficiently to rupture it and provide a fuel ejection path to the sodium coolant. Specific phenomena calculated by PLUTO are:

1. Flow of fuel/fission-gas mixture from the fuel pin central cavity through the ruptured clad and into flowing sodium coolant.

2. Motion of fuel particles (resulting from an FCI), fission gases, sodium vapor and liquid sodium in the coolant channel following fuel ejection from the ruptured fuel pin. Multiple interaction zones are treated where sodium vapor is generated by FCI heat transfer and sodium vapor is lost by condensation.

3. PLUTO-2 additionally models normal sodium boiling and allows long cladding ruptures which may occur in LOF-driven-TOP"s. PLUTO-2, also, models bubbly fuel flow in voided coolant channels and it allows fuel plateout on the cladding. 


\section{Mode1s}

\section{Motion in pin}

Motion of molten fuel/fission-gas within the pin cavity is treated as 1-D homogeneous, compressible flow with nonuniform flow crosssection; hydrodynamic equations are solved in Eulerian form.

\section{Ejection into coolant}

Calculation of fuel and fission-gas ejection is based on assumption that the fuel pin nodes and coolant nodes adjacent to the clad rupture are in pressure equilibrium. The amount of fuel/fissiongas mixture ejected in a time step is set equal to the amount which is necessary to establish the pressure equilibrium. No backflow into the pin is allowed.

\section{Motion in coolant channel}

Treats the motion of materials in the coolant channel as $1-D$ (axia1) two-component slip-flow. The liquid sodium, or mixture of liquid sodium, sodium vapor and $f$ ission-gas, is regarded as one component and is modeled with compressible, 1-D hydrodynamics in Lagrangian form. The other component is fuel in the form of particles, the motion of which is calculated by solving the momentum equation for representative ("master") particles. The interactive force between the two phases is a particle drag law based on a fluidized-bed correlation.

The entire coolant channel is covered with a moving mesh of Lagrangian cells which track the liquid sodium in the coolant slugs and sodium fission-gas flow in the interaction zone. Each cell containing fuel particles is treated as a single interaction zone which gives an axial resolution to the FCI and allows the fuelcoolant heat-transfer to be space-dependent.

\section{Limitations}

\section{$\underline{\text { PLUTO-1 }}$}

1. Available only as a stand-alone version. Since it has not been coupled to SAS, there are no heat-transfer calculations for fuel and clad temperatures and the pressures at the inlet and exit plenums must be assumed constant. 
2. Since calculations are only for a single fuel pin and coolant channel, radial incoherence of pin failures and of fuel and sodium flow in a subassembly are neglected.

3. The molten region in the fuel pin is not allowed to enlarge during the calculation.

4. Clad ruptures longer than one pin node spacing cannot be treated.

5. Does not account for fuel freezing and plugging in the coolant channe1.

6. Sodium film on the clad cannot be treated; sodium vapor condensate does not stick to the clad but is assumed to instantaneously mix with sodium in the coolant channel at that axial location.

7. Lagrangian formulation in coolant channel requires complicated rezoning.

\section{Future Efforts}

None.

\section{Computer Operation}

1. Operational on IBM $370 / 195$ and CDC-7600.

2. $200 \mathrm{~K}$ bytes of storage are necessary on the IBM $370 / 195$ and $41 \mathrm{~K}_{8}$ words on $\mathrm{CDC}-7600$.

3. Running times for a 0.1 see real time calculation: 5 min. on IBM $370 / 195$ and 3 min. on CDC-7600.

4. Comparisons of PLUTO-1 with experiments are described in Ref. 6 and Ref. 5. A comparison with the SAS/FCI code is documented in Ref. 2 and a comparison with the EPIC code in Ref. 6 .

\section{Interface/Overlap}

PLUTO-I needs as input the pin and coolant channel conditions at the time of cladding rupture. These conditions can be provided by codes such as SAS or CORRA. Codes which treat the same phenomena as PLUTO-1 are SAS/FCI, EPIC and PLUTO-2. The HOTPIM code only treats the fuel motion inside the pins and the fuel ejection into the channels. 
$\underline{\text { Mode1s }}$

$\underline{\text { PLUTO-2 }}$

1. Motion in pin

The treatment in PLUTO-2 represents an improvement over that in PLUTO- 1 because it allows an enlargement of the molten pin region and the addition of fission-gas and newly melted fuel to the molten pin region. Moreover, the fuel motion inside three representative pins per subassembly is treated. This represents an attempt to model noncoherent pin failures.

\section{Ejection into coolant channel}

The fuel ejection calculation is also based on the assumption of pressure equilibration between the fuel pin code adjacent to the clad rupture. Different from PLUTO-l ejection can occur from many pin nodes and ejection into voided channels is allowed.

3. Motion in the coolant channel

PLUTO-2 mainly differs from PLUTO-1 in that both components of the two-component slip flow ( $\mathrm{Na} / \mathrm{f}$ ission-gas and fuel) are modeled with Eulerian hydrodynamics using fixed mesh grids. This allowed the proper inclusion of heat transfer between the moving flow components and the clad and structure. Other new features are:

(a) The treatment of a static sodium film which can evaporate or can be entrained by the vapor flow in the channel.

(b) A variable flow cross section treatment in the coolant channel.

(c) Besides modeling a particulate fuel flow regime, PLUTO-2 also models a bubbly fuel flow regime. If the heat transfer between the bubbly fuel flow and clad and structure leads to freezing of the fuel in a certain node, the fuel will stick to the steel surfaces in that node.

PLUTO-2 treats the liquid sodium above and below the interaction zone as inccmpressible slugs with variable flow cross section. This treatment is somewhat inferior to the compressible treatment of the sodium slugs in PLUTO-1. However, the incompressible treatment in PLUTO-2 allows considerably longer time steps than can be used in PLUTO-1. 


\section{Limitations of PLUTO-2}

1. All coolant channels in a subassembly are being represented by one cirannel; i.e., no radial incoherency in the coolant and fuel flows is allowed.

2. The determination of fission-gas release from molten fuel inside the pin, the FCI calculation, and the fuel freezing calculation are all based on simplified parametric models.

3. Cladding ablation by molten fuel cannot be treated at present.

4. The fuel pin geometry and the subassembly can walls have to remain intact.

\section{Future Efforts}

1. Coupling of PLUTO-2 with SAS 3D.

2. Inclusion of fuel vapor pressure.

3. Inclusion of a more refined freezing and plugging mode1.

4. Inclusion of an operation to treat the sodium slugs in a compressible manner.

\section{Computer Operations}

1. Stand alone version operational on IBM $370 / 195$.

2. $230 \mathrm{~K}$ bytes of storage are necessary on the IBM $370 / 195$.

3. Running time for a $0.1 \mathrm{sec}$. real time calculation: $1.5 \mathrm{~min}$.

4. Comparison with PLUTO-1 (not yet determined).

Interface/Overlap

Same as listed for PLUTO-1.

\section{References}

1. H. U. Wider, An Improved Analysis of Fuel Motion During an Overpower Excursion, PhD Thesis, Northwestern University (June 1974). 
2. H. U. Wilder, et. a1., An Improved Analysis of Fuel Motion During an Overpower Excursion, Proceedings of the Fast Reactor Safety Meeting, Beverly Hills, California (Apri1 1974).

3. D. R. Ferguson, et. al., The SAS 4A LMFBR Accident Analysis Code System: A Progress Report, Proceedings of the Fast Reactor Safety Meeting, Chicago (October 1976).

4. H. U. Wilder and A. E. Wright, Analysis of a Sodium Reentry Event in the H4 TREAT Test, TANSAO 22, p. 428, San Francisco (1975).

5. A. B. Rothman, et. a1., Results of Recent TOP and COF Experiments in TREAT, Proceedings of the Fast Reactors Safety Meeting, Chicago (0ctober 1976).

6. P. A. Pizzica, et. a1., Comparison of the EPIC and PLUTO Computer Codes for TOP Conditions, TANSAO 25. New York (1977). 
POROUS

\section{Purpose}

Analysis of the pressure field and mass distribution of gas within interconnected porosity and the central cavity of the fuel pin during a reactor transient, as well as analysis of the loading of intact fuel pin cladding by fill gas and released fission gas during the transient.

\section{Status}

A. Development: A1l versions were developed at ANL/RAS. Current development version is POROUS-5. Previous versions are obsolete. (Refs. 1 and 2).

B. Availability: Operational at ANL.

C. Utilization: The POROUS codes have been employed in cladding failure studies for TOP accidents in a GCFR as well as fuel dispersal potential studies in various TREAT tests and CRBR. (Refs. 3 and 4).

\section{Problems Solved}

The POROUS- 5 code predicts the pressure field and mass distribution of gas witin the interconnected porosity and central cavity of a fuel pin during a reactor transient. The gas may consist of one or two components. When intact cladding is present, its loading by the pore gas or the central cavity as is computed up to the point of cladding failure. Ejection of gas and molten fuel from the cavity after cladding failure is also computed.

\section{Mode 1s}

1. Unmelted Fuel: The model equations consist of the equation of continuity for flow with a mass source (the fission gas being released from fuel grains to the interconnected porosity), Darcy's law and the ideal gas law. The gas is assumed to be at the temperature of the fuel. When two components are present, a species continuity equation must also be solved.

Transport of gas is in the radial direction only. Where axial gradients are significant, the fuel pin may be divided into a number of axial segments and the model equations applied to each segment. The segments are coupled through the central cavity and the fuelcladding gap, or the coolant channel if no cladding is present. 
2. Central Cavity: The central cavity consists of the void originally present plus all fuel at or above the solidus temperature. Expansion of the fuel upon melting is accounted for. Molten fuel and gas within the central cavity are assumed to be homogeneous with the gas bubbles large enough to apply the ideal gas law to compute the pressure of the central cavity.

3. Fission Gas Release: The release of fission gas present within fuel grains is computed from the PFRAS model (See PFRAS Summary). Holdup on grain boundaries is currently neglected and so the gas is released directly to interconnected porosity.

4. Cladding Loading: Cladding failure time and location (which axial segment fails) is computed from a linear cumulative damage law and a Larson-Miller parameter correlation of transient test data and conventional mechanical properties data for unirradiated stainless steel (Ref. 5). The pressure this model employs is the larger of either the central cavity pressure that would be imposed on cladding through strengthless fuel or the pore pressure at the outer radius of the fuel.

5. Fuel Ejection: The fuel ejection model employed is a direct simplification of the SAS/FCI ejection model (Ref. 6). The simplification is made by considering the ejected material to consist of two components only: molten fuel and froth fission gas.

6. Numerical Solution Methodology: The transport equations are second order, nonlinear, partial differential equations or parabolic type. They are solved by applying the Crank-Nicolson finite-difference method (Ref. 7) in an iterative fashion.

\section{Limitations}

1. The thermal history of the fuel and cladding must be supplied.

2. The mechanical deformation of the fuel and cladding must be supplied.

3. Array size limits the number of axial segments to 10 and the number of finite-difference nodes in the solid fuel to 30 per axial segment.

\section{Future Efforts}

It is planned to link the POROUS -5 code to a suitable fuel mechanics code to explicitly account for mechanical deformation of the fuel. 


\section{Computer Operations}

1. Operational on the IBM $370 / 195$.

2. The code is written in FORTRAN IV, runs in the batch mode and requires $250 \mathrm{~K}$ by tes of core to execute.

3. Run time for a typical GCFR TOP analysis is 2 to 3 minutes. This system was modeled with 8 axial segments and 30 nodes per segment. The computations were extended to beyond time of first cladding failure.

4. Code Validation: Ref. (1).

Interface/Overlap

None

$\underline{\text { References }}$

1. J. R. Hofmann and C. C. Meek, "Internal Pressurization in Solid Mixed Oxide Fuel due to Transient Fission Gas Release," Nucl. Sci. Engr., to be published.

2. J. R. Hofmann, Transient Pressurization and Transport of a Two Component Gas Within Interconnected Porosity of Solid Mixed Oxide Fuel, ANL/RAS 77- (to be published).

3. J. R. Hofmann and L. W. Deitrich, Trans Am. Nucl. Soc., 24, 278 $(1976)$.

4. L. W. Deitrich and R. W. Ostensen, An Assessment of Fission-GasDriven Fuel Disruption and Dispersal in a Hypothetical LMFBR Loss-of-Flow Accident, ANL/RAS 77-4 (1977).

5. J. L. Straalsund, R. L. Fish and G. D. Johnson, Nuc1. Technol., $\underline{25}, 531$ (1975).

6. L. L. Smith, et. al., Proc. Conf. on Mathematical Models and Computational Techniques for Analysis of Nuclear Systems, Ann Arbor, Michigan, Apri1 9-11, 1973 USAEC Report CONF-730414-P1, pp. 137-158.

7. J. Crank and P. Nicolson, Proc. Cambridge Philos. Soc., 43, p. $50(1947)$. 
PROSA

\section{Purpose}

To approximate accident consequences as functions of system and model parameters with analytical functions ("response surfaces") and calculate sensitivities and probability distributions of the consequences from these functions.

\section{$\underline{\text { Status }}$}

A. Development: Development organization of the PROSA code (PROSA 1) is ANL/RAS.

B. Availability: PROSA 1 is operational at ANL. Documentation is under way and the code will be released late in 1977.

C. Utilization: Used for a probabilistic analysis of LMFBR core disruptive accident consequences (1inked with SACO) and for probabilistic analysis of sodium fire (1inked with SPOOL-FIRE II).

Problems Solved

As input data, the program needs the probability distributions of the variable parameters (such as reactivity and heat transfer coefficients) considered as sources of uncertainties in an accident analysis. The first part of the program calculates knot-point coordinates of the parameters. These are served as input for consequence analysis codes such as SACO, SPOOL-FIRE etc., to calculate interesting consequences in the specified knot-points.

These consequence values are used by the second part of PROSA to solve (1) the approximating functions ("response functions"); (2) the sensitivity/importance of each parameter with respect to the consequence variables; (3) the statistical moments of the input parameters up to the fourth order; (4) the mean values and the standard deviations of the consequences and; (5) the correlation coefficients for all pairs of the consequences.

By use of random-number sampling and simulation technique, the program also calculates; (6) the probability distributions and the first four moments of the consequences; (7) the joint distributions and; (8) the statistical-error estimates for the distributions. 
$\underline{\text { Models }}$

In the simplest case, a single multivariate second-degree surface is "fitted" to the knot-point consequences. It is also possible to use regionwise response surfaces, separate second-degree surfaces for every "quadrant" of multivariate parameter space.

The program includes a technique to handle nonindependent or correlated input parameters. Conditional distributions can also be calculated. Up to four simultaneous criteria or conditions can be specified for the consequences and/or input parameters.

The code can also be used for calculating optimal importance distributions for the input parameters. These importance functions are useful in the Importance Sampling Monte Carlo simulation (not part of PROSA).

\section{Limitations}

Maximum number of variable input parameters is 12 and up to six consequence variables can be analyzed simultaneously. Eight different distributions are available for the input parameters. The correlations (if any) between the input parameters are limited to linear correlation. None of these limitations is considered very serious. The basic limitation is that all kinds of consequences cannot be approximated well by second-degree surfaces.

\section{Future Efforts}

Short term efforts are directed toward release of PROSA 1. Long term efforts include a weighting routine to improve the multiquadrant response surfaces, importance sampling development, automated use of transformations for input variables and/or consequences, and the use of response functions other than polynomials.

\section{Computer Operation}

1. The code is being operated on IBM $370 / 195$.

2. The programming language is FORTRAN IV. The core memory requirement is less than $400 \mathrm{~K}$.

3. The typical running time in the case of six input parameters and six consequence variables is 60 seconds for 40,000 simulations. 
4. Code Validation

(1) J. K. Vaurio and C. Mueller: "A Probabilistic/Deterministic Procedure for Analyzing LMFBR Core Disruptive Accidents," Paper presented at the International Meeting on Fast Reactor Safety and Related Physics, Chicago, October 1976.

Interface/Overlap

The PROSA can be linked with any consequerce analysis code with minor input/output matching.

\section{References}

1. ANL Progress Reports:

$$
\begin{aligned}
& \text { ANL - RDP - } 48 \text { p. } 7.3 \\
& \text { ANL - RDP - } 52 \text { p. } 7.13 \text { and } 7.17 \\
& \text { ANL - RDP - } 47 \text { p. } 6.5 \text { and } 6.7
\end{aligned}
$$

See also Code Validation (Computer Operation). 
PUDEQ

\section{Purpose}

Computes dose equivalent to body organs from intake of plutonium via inhalation or wound.

\section{Status}

A. Development: Developed at Battelle Pacific Northwest Laboratories.

B. Availability: Initial documentation presented in Reference 1.

C. Utilization: Used to analyze employee records of individual inhalation and wound exposure incidents. Designed to use data recorded on the Hanford Internal Exposure (HIE) System.

\section{Problems Solved}

1. Searches HIE data for individual employee exposure incidents and appropriate medical information.

2. Checks whether exposure was via inhalation or wound.

3. Initial ${ }^{239} \mathrm{Pu}$ and ${ }^{241} \mathrm{Pu}$ pulmonary burden computed from in vivo data if adequate.

4. An annual dose commitment for ${ }^{239} \mathrm{Pu}$ and ${ }^{241} \mathrm{Pu}$ to each organ for a given intake is computed for each calendar year out to fifty years post intake or to the year of death.

5. The fifty year dose commitment is calculated and a report of individual and combined dose commitments is printed.

Models

See documentation. Insofar as was possible, the recommendations of the Advisory Committee on Dose from Plutonium and Other Transuranics was followed.

\section{Limitations}

Only plutonium and the immediate important daughters are considered. However, the program could be expanded to include other transuranic nuclides. 


\section{Future Efforts}

None defined.

Interface/Overlap

None defined.

\section{References}

1. J. R. Houston and K. R. Heid, "PUDEQ: A Computer Code for Calculating Dose Equivalent from Internal Deposition of Plutonium at Hanford," Battelle Pacific Northwest Laboratories Report, BNWL-B-450, October 1975. 
RAS

\section{Purpose}

Qualitative and quantitative analysis of fault trees and phased missions.

\section{$\underline{\text { Status }}$}

A. Development: Developed at the INEL by EG\&G, Idaho, Inc.

B. Availability: RAS is operational on the CDC Cyber 76 computer system at the INEL and wili be released by December 1977.

C. Utilization: RAS is a unified system for reliability and phased mission analysis which uses the fault tree as its main source of input.

\section{Projlems Solved}

RAS has been tested on numerous test problems, and has been used in reliability studies at INEL and for other ERDA projects. It : as also been used to analyze the phased mission of a SHRS of an LMFBR.

\section{Models}

The models used in RAS are described in detail in the references. RAS utilizes fault tree minimal cut sets which are obtained using MOCUS (Ref. 2) or FATRAM. Reliability characteristics for the basic events, for the cut sets, and for the system are calculated using KITT-1 (Ref. 3) or POCUS (Ref. 4). Qualitative reduction of the number of minimal cut sets and sorting of the cut sets is accomplished using SRTPRN (Ref. 5). The phased mission techniques used in RAS are discussed in Reference 6. These include mission cut set cancellation and four bounds on mission reliability. The various options in RAS are controlled by key words which can be used in any logical order desired by the user.

\section{Limitations}

The maximum number of time phases that RAS can handle for phased mission analysis is five. The maximum number of time points that can be handled per phase is 25. The size of fault tree that can be analyzsd depends upon the amount of computer memory available. At present, there is no capability to utilize external storage in step to obtain the minimal cut sets. 


\section{Future Efforts}

The addition of external storage capability in the step to determine minimal cut sets is planned. Also conversion of RAS to the INEL IBM $360 / 75$ computer system is planned.

\section{Computer Operation}

1. RAS was developed on the CDC Cyber 76 under the FTN compiler of the Scope 2.1 operating system.

2. Logistics: RAS operates in batch mode, has dynamic storage capabilities, is written in FORTRAN IV, and requires some form of external storage such as disk or drum. It requires the use of the INEL environmental package for the dynamic storage capabilities.

3. Typical Problem Running Time: A three-phase sample problem, described in detail in Reference 1 , for an LMFBR was run on RAS. The code used $135 \mathrm{~K}$ octal words of core memory and executed in 3.3 seconds.

4. Code Validation: Results from RAS for several sample problems have been compared with the results from other codes for the same sample problems.

\section{Interface/Overlap}

COMCAN for common cause analysis.

\section{References}

1. D. M. Rasmuson and N. H. Marsha11, Preliminary User's Guide to the Reliability Analysis System, Aerojet Nuclear Company, RE-S-76-177, September 1976 (Available from ERDA-RDD).

2. J. B. Fussel1, E. B. Henry, N. H. Marsha11, MOCUS: A Computer Program for Finding Minimal Cut Sets from Fault Trees, Aerojet Nuclear Company, ANCR-1156, August 1974.

3. W. E. Vesely and R. E. Narum, PREP and KITT: Computer Codes for the Automatic Evaluation of a Fault Tree, Idaho Nuclear Company, IN-1349 (August 1970).

4. J. B. Fusse11, et. al., SUPERPOCUS: A Computer Program for Calculating System Probabilistic Reliability and Safety Characteristics, Nuclear Engineering Department Report, University of Tennessee (May 1977). 
5. C. A. Dolan, SRTPRN: A Program to Sort and Prune Fault Tree Cut Sets, EG\&G Idaho, Inc., TREE-1012, (December 1976).

6. G. R. Burdick, J. B. Fusse11, D. M. Rasmuson, and J. R. Wilson, "Phased Mission Analysis: A Review of New Developments and an Application," IEEE Trans. of Reliability, R-26, Apri1 1977, pp. 43-40. 
REXCAT

\section{Purpose}

Analysis of single core subassembly hydrodynamic-structural response to internal FCI accidents.

Status

A. Development: Developed at ANL/RAS.

B. Availability: REXCAT consists of REXCO-HT and SADCAT coupled in a single package. It is operational at ANL on the IBM 370 .

C. Utilization: The code has undergone testing and comparisons with REXCO and STRAW codes.

$\underline{\text { Problems Solved }}$

REXCAT consists of REXCO-HT and SADCAT coupled into a single package. The internals of the subassembly are treated by REXCO-HT, which models the internals as a homogeneous, compressible, inviscid fluid in 3-D, axisymmetric, cylindrical geometry. An FCI zone is included along the center axis of the subassembly to generate axisymmetric driving pressures. SADCAT models the structural response of the duct wall. This coupled analysis provides an extension of REXCO-HT since the cylindrical vessel of REXCO-HT is replaced by a hexagonal duct.

\section{Mode1s}

\section{Geometry}

3-D axisymmetric hydrodynamics with a hexagonal vessel boundary.

2. Subassembly Internals

Same as REXCO-HT (s ee REXCO summary).

3. Duct Wall

Same as SADCAT (see SADCAT summary).

\section{Limitations}

Same as for SADCAT and REXCO-HT. 


\section{Future Efforts}

1. Improve coupling procedure.

2. Couple with new versions of STRAW, employing its capabilities in selected modeled regions for doing near full 3-D analysis.

\section{Interface/Overlap}

STRAW/REXCAT

\section{References}

1. A. H. Marchertas and R. T. Julke, Response of a Hexagonal Fuel Subassembly Wall due to an Axisymmetric Pressure Source, Trans. Am. Nuc1. Soc., 21, 313-314 (June 1975).

2. A. H. Marchertas and R. T. Julke, Response of a Hexagonal Fuel Subassembly Coupled with Internal Hydrodynamics, Trans., 3rd Int1. Conf. on SMIRT, Paper E 1/7, London (Sept. 1975).

3. A. H. Marchertas and R. T. Julke, Computer Code Formulation for Three-Dimensional Hexcon Response Coupled with Internal Hydrodynamics, ANL-76-17 (May 1975).

Also see references in SADCAT and REXCO summaries. 
REXCO

\section{Purpose}

Analysis of reactor primary containment hydrodynamic-structural response to pressure loadings resulting from HDCA's.

\section{Status}

A. Development: A11 versions of REXCO were developed at ANL/RAS. Current development version is REXCO-HEP.

B. Availability: The REXCO series was designed for the IBM 370 , but CDC-7600 versions are available.

- REXCO-H was released in 1973.

- REXCO-HT is operational at ANL and W-ARD.

- REXCO-HEP is operationa1 at ANL, LBL, W-ARD and at several European sites.

- REXCO-HEP-HT is operational at ANL.

C. Utilization: The REXCO series has been used extensively in support of the FFTF FSAR and the CRBR PSAR for evaluation of the primary containment structural damage consequences resulting from HCDA-generated pressure loadings.

\section{Problems Solved}

All versions of REXCO use a 2-D (axisymmetric) compressible hydrodynamics formulation coupled with mechanical response models of various primary containment structures to calculate the propagation of shock waves, loads imposed on different parts of the reactor components and the resulting structural damage. The pressure sources which drive the REXCO codes are Input or calculated internally, as by REXCO-HT and REXCO-HEP-HT for the case of an FCI-generated pressure source. For each problem, the codes compute the accelerations, velocities, displacements, changes of volumes, densities, strains, pressures, and specific energies at every spatial point for a specific time internal. For elastic-plastic materials, the codes also calculate deviatoric stresses and distortion energies. These computations are repeated for every time interval until (a) the maximum time specified is reached, (b) the reactor vessel ruptures, or (c) the vessel head holddown system fails. Outputs of displacements and pressures 
can be given pictorially, showing the movements and deformations or magnitudes of pressures at all spatial points at any instant of time. A REXCO code will evaluate:

1. Core barre1 deformation

2. Reactor vessel deformation

3. Pressure at the inlet and outlet nozzels

4. Loads on core support structures

5. Sodium slug impact force history on head

6. Holddown bolt system deformation

7. Energy partition history of upward and downward axial fluid slug kinetic energies, radial fluid slug kinetic energies, core barrel strain energies, vessel strain energy, internal energy and head motion energy.

REXCO has also been used for analysis of experiments in which the elasticplastic response of fluid-filled pipes to high-pressure pulse loads were studied.

Models

All versions of REXCO have the following features in common:

1. Geometry

Al1 formulations are for 2-D, cylindrical, axisymmetric geometry.

2. Hydrodynamics

The governing equations for the fluids are the compressible, inviscid, non-heat conducting conservation equations of mass, momentum and energy. The numerical problems of calculating shock discontinuities is eliminated, without jeopardizing the conservation laws, by the artificial viscosity method of von Neumann and Richtmyer, which spreads the shock discontinuity over several spatial grids by replacing the discontinuous pressure jump across a shock by a rapid but continuous pressure change. Various mathematical forms of the artificial viscosity are available depending on the type of problem under consideration. 
3. Vessel and Core Barrel Models

Due to the relatively small thickness of the core barrel and reactor vessel relative to the radial dimensions of the reactor, an option in the codes allow these structures to be treated as thin shells. The governing equations are the equations of equilibrium for a shell of revolution undergoing large deflections. The thickness of the shell is idealized by layers of subshells that can carry only normal stresses in the planes parallel to the tangential plane of the shell structure. These subshells are connected by material which carries only shears. The vessel material is considered to be elastic-plastic, strain-hardening and strain-rate sensitive. The strain-hardening shell is represented by a model in which the thickness of the subshell is further decomposed into subregions of elastic-perfectlyplastic materials having different yield stresses, but common strains. The von Mises yield condition and the incremental strain theory of plasticity is used.

4. $\quad$ EOS

To describe the behavior of the reactor materials, particularly in the reactor core and under high-temperature conditions, various optiona $1 \operatorname{EOS}^{\prime} s$ are built into the codes.

\section{Method of Solution}

In the numerical analysis, all equations are expressed in Lagrangian coordinate form and then set into numerical form by finite-difference equations which use an explicit time differencing scheme. The reactor system is represented by a network of quadrilateral meshes (i.e., Lagrangian zones). For media inside the reactor containment, the White stability criteria is used for time-step selection to ensure stability of the finite-difference equations. For the shell equations, the stability criteria of shell structures must also be satisfied.

Unique features of the various versions of the REXCO series codes are as follows:

\section{$\underline{\text { REXCO-H }}$}

This early version assumes all solid materials in the reactor, except for the core barrel which may be treated as a thin shell, to behave like compressible, inviscid non-heat conducting fluids. This assumption is made due to the behavior of solids subjected to high pressure (kilobars) shock compression which allows their mechanical 
properties to be approximated by a compressible fluid model. This approximation breaks down, however, as the solid material recovers from the compressive shock loading or is under tension, where the tensile strength of the solid becomes important.

\section{$\underline{\text { REXCO-HEP }}$}

This version is an improvement over REXCO-H in that solids within the reactor can be treated as elastic-plastic materials. In addition, REXCO-HEP has the following features:

1. Options for artificial viscosity

a. Quadratic artificial viscosity

b. Linear artificial viscosity

c. Navier-Stokes artificial viscosity, which is a special linear viscosity formulation used when shearing action is introduced into a material, as in an elastic-plastic material.

d. Membrane artificial viscosity, which is a special linear viscosity formulation for shell structure.

\section{Mesh regularization}

The major advantage of codes like the REXCO series which solve the governing differential equations in a Lagrangian coordinate system is the limitation imposed on the degree of distortion of the quadrilateral Lagrangian zones as computation proceeds through a problem calculation and extended material motions occur. Severe distortions may not always be physically real, but may be caused by the method of solution rather than the physics of the problem. Such is the case for the commonly occurring "hour-glass" distortions which may grow until the numerical computation becomes unstable. It is thus necessary to have some means to eliminate or minimize zone distortions and control or regulate non-physical distortion effects so that reliable calculations can be made when computation time is to be extended. The two methods used in REXCO-HEP for these purposes are:

a. Mesh regularization: a scheme which is built into the code to control, regulate or suppress hour-glass and other non-physically real distortions 
b. Rezoning: the REZONE code (see REZONE summary) may be used to transform the distorted Lagrangian grids in the fluid (hydrodynamic) regions into new, undistorted grids. In cases where distortions are large, but physically real, rezoning may be required since the use of mesh regularization can introduce errors into the true solution

3. $\quad \underline{E O S}$

The following EOS's have been built into REXCO-HEP to describe behavior of reactor materials in the core and at high temperatures:

a. Equation for vaporizing core

b. Tabulated pressure as a function of volume

c. Tabulated pressure as a function of time

d. Ideal gas

e. Mie-Gruneisen

f. Murnaghen

g. TNT explosives

4. Reactor head mode1

Two options are available to model head motion:

a. Non-deformable: the head is modeled as a rigid solid circular plate, which can move uniformly in the axial direction by stretching of the head bolts.

b. Deformable: in a special version, the head is treated as an elastic-plastic material by a $2-D$, axisymmetric finiteelement program DYNASMY

5. Crushable material

Crush tubes under the head are modeled as a structure which has deformation resistance up to some critical axial compression.

6. Sliding

Sliding is allowed at the fluid-structure boundaries. Two sets of mesh points are employed in the calculation at the fluid-structure 
interfaces: one set of mesh points belong to the fluid and the other to the structural material. The motion of the two sets of mesh points are assumed to be independent to each other in the direction tangential to the interface, but in the normal direction they are assumed to move together.

\section{Other special features}

Two special features are available:

a. Segmented radial shield: radial shield material can be modeled as segmented solids with no strength in the circumferential direction. Sliding lines can be placed at both surfaces of the radial shield material.

b. Penetration Holes in the core-support-structure: Coresupport-structure can be treated as a perforated structure with penetration holes.

\section{$\underline{\text { REXCO-HT }}$}

This version consists of an FCI model incorporated directly into REXCO-H. This coupling of an FCI model with 2-D reactor structural response allows a more accurate calculation of the actual constraints on the FCI expansion than a 1-D calculation, which must assume acoustic on inertial constraints. REXCO-HT has the following features :

1. Interaction region mode1

The region in which the FCI takes place is divided into several rectangular zones, each zone initially specified with a unique fuel temperature, sodium temperature, fuel solid fraction and volumetric fraction of sodium vapor.

2. Heat transfer mode1

Two basic options are available for description of heat transfer in the FCI zones:

a. ANL parametric model: allows fuel fragmentation and mixing with sodium to occur at a finite rate.

b. Quasi-state-state model: assumes that all fuel is instantaneously fragmented into small spheres of the same radius and is dispersed uniformly inside the sodium mass of the zone. 
In both of the above models, the only resistance to the heat transfer from the fuel to the liquid sodium is due to the thermal conductivity of the fuel. When sodium vaporizes, however, the vapor layer around the fuel will create additional resistance to heat transfer, which can be taken into account using a vapor blanketing option. This model assumes a percentage of the fuel particles equal to the volumetric fraction of sodium vapor present in an FCI zone will not participate in the heat transfer process.

\section{REXCO-HEP-HT}

This, the most advanced version of REXCO, consists of an FCI model directly incorporated into REXCO-HEP. The interaction region and heat transfer models are the same as for REXCO-HT.

\section{Limitations}

All versions of REXCO have the following limitations:

1. Due to Lagrangian formulation, cannot treat accurately large material displacement problems.

2. Axisymmetric geometry does not allow treatment of 3-D effects.

3. All materials are considered isotropic.

4. Core region is assumed to be a homogenized material.

5. Detail of core support structure cannot be modeled precisely.

6. Complex interacting head holddown bolt systems, as in CRBR, cannot be modeled precisely.

Specific limitations of REXCO-HT and REXCO-HEP-HT are:

1. Heat transfer between FCI zones is not allowed.

2. Fuel-coolant slip within zones is not modeled.

\section{Future Efforts}

The following are planned for REXCO-HT and REXCO-HEP-HT:

1. Introduce neutronics in the fuel during FCI.

2. Introduce delay time or each FCI zone. 
3. Imp rove sodium EOS.

\section{Computer Operations}

The computer program is written in FORTRAN IV language for the IBM Machine 370 , Mode 1 195. It uses $500 \mathrm{~K}$ core storage on the 370 machine for a Lagrangian mesh of 750. The CPU time is approximately $0.6 \mathrm{msec}$ per mesh-cycle. CDC version of REXCO-HEP is available. It is operational on CDC 6600 and 7600 computers.

REXCO predictions have been compared with many excursion data. The results of comparisons are given in Ref. 10-14.

\section{Interface/Overlap}

VENUS/ICECO

\section{References}

\section{$\underline{\text { REXCO-H and REXCO-HEP }}$}

1. Y. W. Chang and J. Gvildys, "REXCO-HEP: A Two Dimensional Computer Code for Calculating the Primary System Response in Fast Reactor," ANL/RAS 75-11, (March 1975).

2. J. Gvildys and Y. W. Chang, REXCO-HEP Users Manual, ANL/RAS 75-1 (January 1975).

3. Y. W. Chang, J. Gvildys and S. H. Fistedis, Two-Dimensional Hydrodynamics Analysis for Primary Containment, ANL-7498 (November 1969).

4. G. Cinelli, J. Gvildys and S. H. Fistedis, Inelastic Response of Primary Reactor Containment to High-Energy Excursion, ANL-7499 (November 1969).

5. J. Gvildys and S. Fistedis, Inelastic Response of Primary Reactor Containment to High-Energy Excursions, ANL-7499, Supplement (June 1971).

\section{$\underline{\text { REXCO-HT }}$}

6. T. J. Marciniak, Heat Transfer Problems in LMFBR Containment Analysis, ANL-8037 (July 1973). 
7. J. Bratis, T. J. Marciniak and J. Gvildys, "REXCO-HT: A Hydrodynamic Containment Code Including Molten Fuel-Coolant Interaction," ANL/RAS 75-13, (March 1975).

8. J. C. Bratis, T. J. Marciniak, Reactor Structural Response to Molten-fuel-coolant Interactions, invited paper El/4, 2nd Intl. Conf. on Structural Mechanics in Reactor Technology, Berlin (1973).

FCI Mode1s

9. D. H. Cho, R. O. Ivins, and R. W. Wright, A Rate-limited Model of Molten-fuel/Coolant Interactions: Model Development and Preliminary Calculations, ANL-7919 (March 1972).

Code Validation

10. J. E. Ash and R. T. Julke, Comparison of a Two-Dimensional Hydrodynamics Code (REXCO) to Excursion Experiments for Fast Reactor Containment, ANL-7911 (January 1972).

11. J. E. Ash, Y. W. Chang and R. T. Julke, Comparison of a TwoDimensional Hydrodynamics Code (REXCO) to Excursion Experiments for Fast Reactor Containment, ANL-7911, Suppl. I (July 1972).

12. G. Nagumo and C. Fiala, Comparison of FFTF Simple-Mode1 Tests with REXCO Predictions, ANL-8071 (January 1974).

13. T. J. Marciniak, J. Gvildys, G. Nagumo and J. E. Ash, Analysis of FFTF Primary-Containment Complex-model Experiments, ANL-8062 (January 1974).

14. G. Nagumo and C. Fiala, REXCO Predictions of Elastic and Elastoplastic Deformation of Fluid-filled Pipes and Comparisons with Experiments of 1/10th-scale FFTF Pipe Models, ANL-75-61 (September 1975). 
REZONE

\section{Purpose}

To rezone distorted Lagrangian fluid mesh grids which occur in REXCO-HEP computations during long time duration and/or extended material motion calculations.

\section{$\underline{\text { Status }}$}
A. Development: Developed at ANL/RAS •
B. Availability: Operational at ANL on IBM 370 and at LBL on CDC-7600; a program description has been documented (Ref. 1).
C. Utilization: Used by ANL and GE-BRD to extend REXCO-HEP calculation capabilities in support of FFTF and CRBR safety analysis.

\section{Problems Solved}

REZONE provides a means to eliminate or minimize computational problems which arise in REXCO-HEP (see REXCO summary) due to severe Lagrangian nodal mesh or grid distortions in the fluid (hydrodynamic) regions. Such distortions occur because of the inherent nature of solving finitedifferenced mathematical equations in a Lagrangian or moving coordinate system whereby the computational nodal points are embedded in and thus move with the system materials. Large material motions therefore lead to distortions of the quadrilateral zones or grids which connect the mesh nodal points. These distortions may be physically real, as in the case of an interface between two different media where material properties discontinuities occur. However, it is also possible for these distortions to be nonphysical, being caused by the method of solution rather than the physics of the problem. An example is the frequently occurring "hour-glass" distortion of a quadrilateral mesh. The mesh regularization scheme built into REXCO-HEP is effective in controlling, regulating or suppressing these nonphysical distortions. However, since mesh regularization can introduce errors in the true numerical solution, rezoning of the distorted meshes is of ten the only true solution to such problems. Rezoning allows REXCO-HEP calculations to be extended for calculations of low-energy $\mathrm{HCDA}^{\prime}$, where large material motions occur over the time scale of interest, or for calculation of high-energy excursions where the system response is of interest for the full time scale up to dynamic equilibrium. 


\section{Models}

The rezoning process involves establishing a new set of undistorted Lagrangian meshes in accordance with rezoning instructions, and then determining the new mesh properties from those of the old, distorted mesh. New properties are determined by an averaging method which is user dependent. The user must decide himself when to rezone and how to rezone, with the code merely executing the user's instructions by performing the necessary computations. The procedure for deciding when to rezone must be based both upon experience gained by comparing alternative computational procedures and by the laborious method of examining key variables at each time-step to see that numerical values are physically reasonable and consistent with conservation laws. The averaging method is required since a zone variable can have only a single value for all material inside the zone. Averaging will always involve approximations and thus a trade-off of errors is required to achieve maximum overall computational accuracy.

REZONE has the following features:

1. Distorted meshes: distorted meshes to be rezoned must be either a norma 1 quadrilateral mesh (a11 interior angles are less than $180^{\circ}$ ) or a re-entrant mesh (only one interior angle exceeds $180^{\circ}$ ).

2. New meshes: the boundary of the new meshes must coincide with that of the old meshes to be rezoned.

3. Averaging method: the values of the zone velocities, pressures, densities, initial masses, initial positions and internal energies of the new meshes are calculated by several optional methods including user input and an averaging procedure. Averaging is based on an area averaging method with the old zone divided into $32 \times 32$ subquadrilaterals and then superimposing the old meshes on the new ones.

\section{Limitations}

1. Meshes to be rezoned are limited to either the normal mesh (all interior angles are less than $180^{\circ}$ ) or the re-entrant mesh (only one interior angle exceeds $180^{\circ}$ ).

2. Only fluld (hydrodynamic) materials can be rezoned.

3. If the new mesh contains two or more different materials, the type of material and EOS of that mixed zone must be specified. 
4. If meshes to be rezoned contain shell structures, the locations of the mesh points on the shell wall must be unchanged, or else the shell must be removed.

5. The accuracy of the rezoning process is largely dependent upon the experience and judgment of the user.

\section{Future Efforts}

None specified.

Interface/Over1ap

REXCO-HEP / -

References

1. J. Gvildys and Y. W. Chang, "REZONE: A Computer Code for Rezoning the Distorted Lagrangian Meshes," ANL/RAS 75-14 (March 1975). 
RIBD

\section{Purpose}

Analysis of fission product inventories in reactor fuel as a function of irradiation history.

\section{$\underline{\text { Status }}$}

A. Development: Developed and under improvement at HEDL.

B. Availability: RIBD-1 was documented in 1969 (Ref. 1). RIBD-2 (Ref. 5) is operational at GE-BRD and at HEDL on the CYBER 74 and is available through the Radiation Shielding Information Center. The latest version of RIBD-2 is available at HEDL (Ref. 6).

C. Utilization: Used for FFTF FSAR and CRBR PSAR analysis to provide input to dose calculations.

Problems Solved

The RIBD codes calculate fission product is gtopic concentrations in fuel resulting from two fission sources (e.g., $\mathrm{U}^{238}$ and $\mathrm{Pu}^{239}$ ) with down-chain decay by beta emission and isomeric transfers and interchain coupling resulting from neutron-induced transmutation reactions. The calculations follow a flexible irradiation history through an unlimited number of step changes of unrestricted duration and variability including shutdown periods, restarts at different power levels and/or any other level changes. The code output consists of fission product isotopic concentrations, activities, beta and gamma powers, and energy releases for the specified decay times.

Mode1s

RIBD-2 has the following capabilities:

\section{Isotope Library and Data}

A 770 isotope master 1ibrary is avallable. The user has a cholce of fission product yields from various data (Ref. 2-4) for a thermal neutron spectrum, a fission neutron spectrum or $14 \mathrm{Mev}$ neutrons. Thermal or FTR core-spectrum weighted cross sections are available. For the FTR, data libraries are based on ENDF/B-IV, 
with neutron capture cross sections based on one energy group values averaged over the FTR spectrum.

\section{Isotopic Concentration Calculation}

Isotopic concentrations are calculated by standard down-chain decay from beta emission and isomeric transfer. Interchain coupling due to neutron capture reactions is accounted for. The chain sources are due to the direct yields of two fissioning nuclides. The code follows the irradiation history through an unlimited number and variety of power changes including outages. The isotope buildup portion of the code does not use the standard Bateman equation for its solution form and is therefore not limited to simple, nonbranching chains. The concentration of each nuclide is calculated from a choice of three alternative series solutions depending on the magnitude of the parameters involved. During shutdown decay calculations, when neutron capture is not possible, equations with characteristics similar to the Bateman equation are used. The fission product calculations are based on the fission rate within the entire mass or volume of fuel of interest. Therefore, the inventory can be calculated for a unit volume of fuel, a unit mass of fuel, a unit length of fuel, or any other assembly of interest. In each case, it is assumed in the calculation that all fuel is in exactly the same environment.

A feature is available which allows RIBD-2 to model a refueling scheme like that expected of LMFBRs wherein only a portion of the fuel is changed at each refueling; using this feature RIBD-2 can produce inventory and power predictions for "end-of-equilibrium cycle." Another feature allows RIBD to write inventory information to a file which, after processing by the program NULIBE can be input to the COMRADEX-H program.

\section{Limitations}

1. Does not include inter-chain coupling by neutron decay.

2. Only includes inter-chain coupling by the ( $n$, gamma) process and not by ( $n$, alpha) or ( $n, p)$ reactions.

3. Does not include production of transplutonium isotopes nor decay heat or activity associated with such isotopes; however, it does calculate the decay heat of U-239 and Np-239.

4. Isotopic ground states are allowed to have no more than seven source paths, with up to five source paths allowed for isomeric states. 
5. No beta decay is allowed from one isomeric state to another isomeric state.

\section{Future Efforts}

None defined.

Interface/Overlap

COMRADEX, I SOSHLD /

1. Computers: $\mathrm{CDC}-6600$

2. Logistics: RIBD-2 requires 150,000 (Octa1) to load and execute. Execution is from batch mode. One file, the library (LIBE), is required and one is used as an output option (NULIBE).

3. Typica1 Problem Running Time: Executing from the binary a typical problem required 99 (decimal) seconds. Problem complexity will affect running time both ways.

4. Code Validation: The code has been comared with hand calculations and new versions have reproduced results of older versions.

\section{$\underline{\text { References }}$}

\section{$\underline{\text { RIBD-1 }}$}

1. R. 0. Gumprecht, "Mathematical Basis of Computer Code RIBD," Dun-4136, June 17,1968 .

\section{Yield Data}

2. Y. A. Zysin, et. a1., "Fission Product Yields and Their Mass Distribution," Consultants Bureau, New York, N. Y., 1964.

3. D. A. Anderson Jr., "Fission Product Yields from Fast Neutron Fission of $\mathrm{Pu}^{239}$," LA-3383, Los Alamos, N. M., December 1965.

4. L. W. Weaver, et. al., "Estimated Total Chain and Independent Yields for Several Neutron Induced Fission Processes," USNRDL-TR-633, March 1963.

5. HEDL-TME 75-26.

6. Memorandum, H. C. Martin to HEDL Holders of HEDL-TME 75-26, "Changes to Computer Code RIBD," May 4, 1976. 


\section{Purpose}

Fast analysis of core neutronic-thermal-hydraulic behavior during initial phases of a postulated loss-of-flow accident. Intended for parametric sensitivity studies.

\section{$\underline{\text { Status }}$}

A. Development: Development organization of the SACO code (SACO 1) is ANL/RAS.

B. Availability: Operational at ANL for the initial phases prior to fuel/clad motion.

Developmental at ANL on IBM 370 for the fuel motion phase. Documentation is underway and the code will be released late 1977 .

C. Utilization: Used in sensitivity studies for a CRBR-type reactor and linked to a probabilistic code (PROSA) to study distributions of accident consequences.

\section{Problems Solved}

SACO calculation starts from a stead-state initialization of core conditions based on the user's specifications which define the pretransient operating state-of-the-reactor system. A steady-state therma1-hydraulics calculation initializes core temperatures. Calculations then proceed through the transient history of the reactor response to a specified reduction in coolant flow. Throughout the SACC calculations, the basic assumption is that the subassembly radial geometry remains intact; that is, subassembly ducts do not lose their integrity. As in SAS, this limitation of SACO is derived from 1-dimensional (axial) nature of the code. The computations are terminated at the poit of (a) permanent neutronic shutdown, or (b) a prompt-critical neutronic burst.

\section{Mode1s}

\section{Modeling principles}

The SACO code is intended for parametric sensitivity studies. The requirement for high speed (say, one minute per accident case) in a mechanistic accident analysis tool has prompted the search for 
computationally simple semi-mechanistic and analytical models (to avoid iterative finite difference schemes wherever possible). SAS calculations for CRBR have been used as benchmark data for SACO development.

\section{Geometry}

The entire core is modeled by ten "channels," representative fuel pins surrounded by associated coolant and structure (i.e., lumped wire wrap and associated subassembly duct) in cylindrical axisymmetric geometry. Twenty nodes are provided for three axial regions to treat the active core region and adjacent lower and upper blanket regions.

\section{Coolant dynamics}

Prior to sodium voiding, the coolant-temperatures (as well as the average fuel and clad temperatures in each node) are normally calculated using analytical models such as the Fractional Energy concept. The flow/pump coastdown is given as input. After coolant voiding begins, heat capacity effects dominate coolant temperature calculations. Clad temperatures follow coolant temperatures and adiabatic heatup is assumed in completely voided dryout regions. Lumped heat transfer parameters and material properties are used, specifled at a fixed representative temperature.

\section{Fuel temperatures}

The average fuel temperature calculation (in each node) is normally based on the difference between the nuclear energy produced and the heat conducted to the cladding and coolant. As an option, there is a two-dimensional fuel temperature model that calculates radial fuel temperature profiles, solidus and liquidus fronts when fuel melting has begun, average fuel temperatures and the clad temperatures after clad melting has begun. This model is based on polynomial profiles with time-dependent coefficients.

\section{Neutronics}

A one-energy group, space-independent (point) kinetics model is used to describe the reactor neutron kinetics. The net reactivity is the sum of (a) programmed input, (b) Doppler feedback, (c) coolant density/voiding feedback and (d) fuel relocation feedback. The Doppler and material-reactivity-worth tables are obtained from separate neutronics codes. The iterative feedback calculation for each time step is similar to that used in SAS. 


\section{Fuel dynamics}

Axial fuel motion is calculated following gross fuel melting in the contral region of the pin. The current model assumes fuel "slurry" expansion with user specified parameters.

\section{Limitations}

Currently limited to ten channels.

The code has been tested and compared with SAS in analyzing a CRBR-type reactor. It is not clear how well the models work if a system to be analyzed deviates considerably from CRBR.

\section{Future Efforts}

Work is underway to incorporate more mechanistic fuel motion and coolant hydraulics models into SACO. Other short-term efforts are directed toward release of SACO.

Lone-term efforts include:

1. Treatment of initiators other than loss-of-flow.

2. Extension to the transition and disassembly phases of an accident.

3. Testing and development of the code for systems of different designs and fuel cycles.

\section{Computer Operation}

1. The code is being operated on IBM $370 / 195$.

2. The programming language is FORTRAN IV. The core memory requirement is less than $400 \mathrm{~K}$.

3. Typical running time is about 30 seconds when the two-dimensional fuel temperature subroutine (TWODTF) is rot used, 50 seconds if it is used.

ANL Progress Reports: ANL-RDP-44, p. 7.8, and ANL-RDP-45, p. $7 \cdot 9$.

4. Code Validation:

C. Mueller, J. E. Cahalan, J. M. Kyser: "A Closed-Form Methodology for LMFBR Accident Analysis," Trans. Am. Nuc1. Soc. 23, 236 (1976). 
C. Mueller: "An Integral Model for Predicting Voiding Phase Conditions during an LMFBR LOF Transient," Trans. Am. Nucl. Soc. 24 , 281 (1976).

\section{Interface/Overlap}

The power shapes and the Doppler and material-reactivity-worth tables are obtained from a neutronics code or as a part of SAS steady-state output. As an option, SACO reads parametric knot-point values from a probabilistic code PROSA, and provides selected consequence values for PROSA.

\section{References}

1. ANL Progress Reports: ANL-RDP-44, P. 7.8; ANL-RDP-45, p. 7.9;

ANL-RDP-46, p. 7.11; ANL-RDP-47, p. 7.3; ANL-RDP-49，p. 7.7; ANL-RI:P-50, p. 7.1; ANL-RDP-54, p. 6.3; ANL-RDP-58, p. 6.7; ANL-RDP-60, p. 6.5 .

2. J. K. Vaurio and C. Mueller: "A Probabilistic/Deterministic Procedure for Analyzing LMFBR Core Disruptive Accidents," Paper presented at the International Meeting on Fast Reactor Safety and Related Physics, Chicago, October 1976 .

3. See Also Code Validation (Computer Operation). 
SADCAT

\section{$\underline{\text { Purpose }}$}

Transient or static analysis of 3-D LMFBR structures subjected to mechanical or thermo-mechanical loading.

\section{Status}

A. Development: All versions developed and under improvement at ANL/RAS .

B. Availability: The versions of SADCAT and their availability are:

SADCAT-E1: Operational at ANL/RAS on IBM $370 / 195$. Will be released by October 1977 . Documentation is available (Ref. 1 and 2).

SADCAT-E2: Developmenta1 at ANL/RAS on IBM $370 / 195$. Will be made operational at ANL in 1978 .

SADCAT-I2: Developmenta1 at ANL/RAS on IBM 270/195. Will become operational by December 1977 . Documentation is available (Ref. 3 and 4).

C. Utilization: SADCAT has been used to study the 3-dimensional structural response of the following LMFBR components: subassembly ducts, pool-type LMFBR deck structures, and CRBR head cover.

\section{Problems Solved}

3-D analysis of subassembly duct transient structural response to rapid pressurization. The structural damage to the accident subassembly duct is determined, as well as the potential for subassembly-to-subassembly damage propagation. (Ref. 1).

The ability of a pool-type LMFBR shield-deck to sustain an energetic HCDA has been assessed. Several deck-support designs were evaluated. Results for deck displacements and energy partitioning were presented. (Ref. 5).

A preliminary investigation of the transient structural response of the Clinch River Breeder Reactor's head closure to a Hypothetical Core Disruptive Accident was conducted. A finite-element model was developed 
that accounts for the important structural features of the head closure assemb1y. The transient response of the head is studied using the ANL/RAS code SADCAT. Results for plug displacement histories, deformed profiles and plastically deformed regions were presented. (Ref.6).

Models

\section{SADCAT-E1:}

This version is based on a finite-element procedure for transient analysis of plates and shells in three-dimensional space, applicable to large displacements and nonlinear material properties. This procedure uses a convected coordinate formulation enabling the use of a simple strainnodal displacement, as well as nodal force-stress relations. The plate/ shell element can be subjected to linear in-plane displacements and cubic transverse displacements. The orientation of lumped masses is described by unit vectors, so that arbitrarily large rotations can be treated. The discretized equations of motion are integrated explicitly in time with a central difference formula. Membrane artificial viscosity is used to stabilize occasional oscillations.

\section{SADCAT-E2:}

This version is an extension of SADCAT-E1. Two additional elements were incorporated into the code: a three-dimensional, Lagrangian fluid-element and a three-dimensional continuum element. The additon of the fluid element into the code adds the capability to treat fluid-structure interaction problems in three-dimensional space. The continuum element w111 be used to treat the structural effect of concrete in three-dimensional configurations. Since the fluid, continuum and plate elements are finite elements, they can be combined arbitrarily to represent complex, threedimensional reactor structures.

\section{SADCAT-I2:}

This version is based on the formulation of a finite-element procedure for the implicit transient and static analysis of plate/she11-type structures in three-dimensional space. The triangular plate/shell element can sustain both membrane and bending stresses. Both geometric and material nonlinearities can be treated, and an elastic-plastic material law has been incorporated. The formulation permits the element to undergo arbitrarily large rotations and translations, but in its present form it is restricted to small strains.

The discretized equations of motion are obtained by a stiffness method. An implicit integration algorithm based on trapezoidal-integration 
formulas is used to integrate the discretized equations of motion in time. To ensure numerical stability, an iterative solution procedure with equilibrium checks is used.

The thermal stress analysis capability is based upon the following formulation. A general temperature-dependent constitutent relationship is derived from a Gibbs potential function and a temperature dependent yield surface. This form is applicable to problems of small strain. A similar form of a hypoelastic-plastic type is developed for large strains. The temperature dependency of the yleld surface is based upon a temperature-dependent, material-hardening model. The model uses a temperature-equivalent stress-plastic strain diagram which is generated from isothermal uniaxial stress-strain data. A procedure is presented for modelling the spatial and temporal dependent temperature field.

\section{Limitations}

SADCAT cannot model in detail the subassembly internal fuel pin structures. Thick plate-type structures cannot be treated efficiently. Fluid motion cannot be excessively large.

\section{Future Efforts}

1. Incorporate a three-dimensional beam and truss elements.

2. Incorporate sliding between fluid and structural elements.

3. Develop an Eulerian fluid element.

\section{Computer Operation}

1. Operational on IBM $370 / 195$.

2. Logistics: The SADCAT code is dynamically core allocated. The base core size requirement is $200 \mathrm{~K}$ (IBM 370/195). Core storage for each problem is added to the base core size.

3. Typica1 Problem Running Time: For the explicit integration scheme, one plate, element-time step take $2 \mathrm{msec}$ on an IBM $370 / 195$ computer. For the implicit scheme, $90 \mathrm{msec}$ are required per plate element-time step.

4. Code Validation: Benchmark problems are presented in Refs. 1, 3 and 4 below. Experimental data from the Subassembly-to-Subassembly Meltthrough Test will be used to check-out the thermal stress analysis 
capability. Experiment data from Stanford Research Institute's CRBR test will be used to validate the head cover model.

Interface/Overlap

STRAW/REXCAT

$\underline{\text { References }}$

1. A. H. Marchertas and T. B. Belytschko, Nonlinear Finite-Element Formulation for Transient Analysis of Three-Dimensional Thin Structures, ANL-8104 (June 1974).

2. A. H. Marchertas, Input Instructions for SADCAT ( for 3-D Core Assembly Transients), ANL-8104 Supplement (Apri1 1976).

3. R. F. Kulak and T. B. Belytschko, An Implicit Three-Dimensional Finite-Element Formulation for the Nonlinear Structural Response of Reactor Components, ANL-76-85 (July 1976).

4. R. F. Kulak, D. R. Schoeberle, J. M. Kennedy, T. B. Belytschko and C. Fiala, A Finite-Element Formulation for the Thermal Stress Analysis of Two- and Three-Dimensional Thin Reactor Structures, ANL/RAS 76-25 (October 1976).

5. R. F. Kulak, T. J. Marciniak and T. B. Belytschko, On Structura1 Response of Large LMFBR Head Closures to Hypothetical Core Disruptive Accidents, to appear in the Transactions of the 4 th Int 1. Conf. on structural Mechanics in Reactor Technology, Paper E $1 / 7$ (August 1977).

6. R. F. Kulak, Application of ANL's SADCAT Code to the CRBR Head Cover, ANL/RAS 77-1 (January 1977). 


\section{Purpose}

Analysis of core neutronic-thermal-hydraulic behavior during the initial phases of a postulated whole-core accident.

\section{Status}

A. Development: All versions were developed at ANL/RAS. Current development version is SAS $4 \mathrm{~A}$.

B. Availability: The versions of SAS which have been or are in the process of being made operational are:

SAS 1A: Released in 1969 (Ref. 1).

SAS 2A: Operationa1 at UCLA, LBL, W-ARD and ANL. Has been documented (Ref. 2), but will not be released in lieu of SAS 3D release.

SAS 2D: Operational at LBL and ANL. Will not be released in lieu of SAS $3 D$ release.

SAS 3A: Operation at LASL, LBL, BNL and ANL. The vartous modules of SAS $3 \mathrm{~A}$ have been documented independently in ANL/RAS reports. SAS $3 \mathrm{~A}$ will not be released in lieu of SAS 3D release.

SAS 3D: Operational at ANL and LBL. Initial release with limited documentation June, 1977. Additional documentation is being produced.

SASRUP 3: Developmental at ANL.

SAS 4A: Developmental at ANL.

C. Utilization: The SAS codes have provided the primary tools for initiating phase analysis of LOF and TOP HCDA's in support of the FFTF and CRBR SAR's. 


\section{Problems Solved}

Each version of SAS predicts transient core behavior from an unfaulted, normal operation condition through the early phases of a whole-core involvement accident initiated by a hypothesized faulted condition which leads to a severe power-to-flow mismatch. Each version of SAS consists of overlayed modules which compute the neutronic-thermal-hydraulic behavior of the core up to the point of either (a) permanent neutronic shutdown with no loss of subassembly duct integrity, (b) loss of subassembly duct integrity due to melting attack or internal pressurization or (c) a prompt-critical neutronic burst.

SAS calculations start from a steady-state initialization of core conditions based on the user's specifications which define the pretransient operating state of the reactor system. A steady-state therma1-hydraulics calculation initializes fuel temperatures, fuel and clad thermal expansion, and the coolant temperatures, pressures and flow rates. Calculations then proceed through the transient history of the reactor response to a power-to-flow perturbation resulting from either a specified reactivity insertion (or power increase) and/or a specified reduction in coolant flow. Throughout the history of SAS calculations is the basic assumption that the overall core subassembly geometry remains intact; that is, subassembly ducts do not lose their integrity, although any individual subassembly may have an internally disrupted condition, as fuel dispersal following clad discuption. This limitation of SAS is derived from 1-D nature of the code which performs calculations of axial material motion within the confines of a strong duct barrier but neglects radial motion.

\section{Models}

All versions of SAS are based on a modular structure in which the models for describing the various interrelated accident phenomena are programmed into specific modules (each module may contain one or more subroutines) which are then coupled to provide an integrated, comprehensive accident analysis. All SAS codes contain at least the following basic modules: fuel heat transfer, coolant dynamics, fuel deformation, and neutronics.

\section{$\underline{\text { SAS 1A }}$}

1. Geometry

The entire core is modeled by a single "channel" which consists of a single full length fuel pin surrounded by its associated coolant and structure (i.e., lumped wire wrap and associated subassembly duct) in cylindrical axisymmetric geometry. The channel is assumed to represent the average behavior of a core fuel pin. All fuel pins 
within a given subassembly are assumed to behave identically (i.e., no intrasubassembly incoherence).

\section{Fue1 Heat Transfer}

Since axial and angular conduction of heat are assumed relatively unimportant compared to radial heat flow, a 1-D (radial) heat-flow model is used. The channel is divided into axial segments and temperature calculations are made for each section in a marching procedure following coolant flow. The storrer effect of heat transfer from downstream coolant to the fuel in the axial blanket is automatically included. The 1-D transient heat conduction equations are finite differenced in an explicit scheme using the CrankNicholson method and take into account:

a. Dimensional changes due to thermal expansion and phase change

b. Latent heat absorption due to phase change

c. Variable fuel-clad gap size and thermal conductance

\section{Coolant Dynamics}

The main function of the coolant dynamics calculation is to provide an axial profile of transient sodium voiding due to coolant expulsion by fission gas release into the coolant channel or by sodium boiling. Two different models are used for different parts of the sodium boiling process. A slip-flow, two-phase model is used for the initial portion and up to a short time after flow reversal (i.e., ejection of coolant from the channel inlet) when a reasonably large void fraction (larger than .9) exists. When the vapor-void fraction is approaching 1.0, a switch is then made to a simple slug model to continue the boiling calculation. The basic assumption in developing this "slug-ejection" model is that there is a differential pressure across the liquid slugs which tend to move them out of the channel, the driving pressure being generated by the coolant vapor pressure.

\section{Fuel Deformation - DEFORM I}

DEFORM calculates transient stresses and deformation in the fuel and clad of a fuel pin during a power-to-flow mismatch. Calculated are the thermoelastic deformation of the fuel and the elastic-plastic deformation of the clad, using fuel pin temperature profiles as provided by the heat transfer module of SAS. DEFORM I analysis is based on a stress-free steady-state operating condition without any consideration to pre-irradiation effects. 


\section{a. Geometry}

As in the heat transfer module of SAS, the fuel pin is divided into coupled axial segments. Each axial segment may contain a central cavity with some molten fuel, solid fuel, a gap and clad. All materials are assumed isotropic and zonewise homogeneous. Local effects, as due to finite size of fuel pellets, are neglected. Since the radial temperature variations for a reactor fuel rod are much more severe than the axial, equations with appropriate boundary conditions are solved in closed form for radial variations, but only approximately by iteration with respect to axial variations of stress and deformation. Depending on the conditions of the fuel and clad, anyone of nine cases may pertain to each of the axial segments representing a broad range of potential conditions for solid fuel with a central hole containing molten fuel. These nine cases represent three options for each axial segment: (1) the existence of a radial gap, (2) the elastic deformation of the clad due to closing of the gap and (3) the plastic deformation of the clad due to excessive loading.

\section{b. Fuel Deformation}

The following assumptions are made:

i. Fuel behaves as a perfectly elastic material.

ii. A quasi-static deformation analysis is applicable which implies that there is no explosive loading on the fuel elements to produce shock waves.

iii. The time scale of the loading is short enough that longterm effects as radiation growth and viscoelastic creep can be neglected.

iv. Fuel is initially assumed to be stress-free at normal operating conditions. This assumption is justified only if the stresses produced by the change from room temperatures to operating conditions are annealed out.

v. Thermal expansion coefficient of fuel is average or constant value. 
The elastic deformation description of the fuel includes two models :

i. Elastic deformation with no melting: the thermoelastic field equations of equilibrium in cylindrical, axisymmetric coordinates with zero shearing stresses are used with appropriate boundary conditions to determine radial displacements, axial elongations and circumferential stresses.

ii. Elastic deformation with partial fuel melting: the assumptions made to determine structural response of a cell in which partial melting has occurred are (1) the material in the cell behaves mechanically as a liquid with density and bulk modulus between those for solid and liquid states, (2) all cells where melting has occurred in any axial segment are acted on by the same fluid pressure, which can vary axially, (3) fuel does not cross cell boundaries and (4) axial expansion of an axial segment does not vary radially. Assumption (3) and (4) imply that migration of liquid fuel through a central hole is not permitted.

c. Fuel-Clad Gap

The gap is assumed to be occupied by a bonding material or inert gas which is squeezed out as fuel expands.

\section{d. Clad Deformation}

The following assumptions are made:

i. The clad tube can be treated as if it were an elastic-plastic membrane (thin she11) made of an elastic, perfectly plastic material. The circumferential stress is constant across the tube wall thickness and plastic yielding occurs when the circumferential stress reaches a critical stress. Plastic yielding is limited due to the resultant reduction in pressure from the thermally expanding fuel.

ii. Clad material is incompressible; i.e., during plastic deformation wall thickness decreases as clad expands, causing eventual rupture. 
iii. Clad thins uniformly around the circumference during exp ansion.

5. Fuel Dynamics

Axial fuel motion and displacement are calculated following gross fuel melting in the central region of the pin. The model assumes molten fuel to be in the form of a partially molten "slurry" within an intact clad. Axial pressure gradients are assumed to arise from the radial restraining force of the clad which is imposed on the solid-1iquid fuel material.

6. Neutronics

A one-energy group, space-independent (point) kinetics model is used to describe the reactor neutron kinetics. The net reactivity is the sum of the five following contributions:

a. Programmed input (initial ramp or scram).

b. Doppler feedback, based on the volume-averaged temperature over a given fuel pin axial segment.

c. Coolant density/voiding feedback, based on sodium worth per axial segment.

d. Axial fuel expansion feedback, based on fuel worth per axial segment.

e. Structura1 expansion feedback due to core radial expansion.

SAS 2A

This version is a multiple-channel outgrowth of SAS $1 \mathrm{~A}$ with new sodium voiding models.

\section{Geometry}

The entire core is modeled by up to ten separate channels, each having a geometry as in the SAS $1 \mathrm{~A}$ channel. The core subassemblies are divided in up to ten groups, with each channel representing the average behavior of a particular group. The basis for grouping is to match subassembly operating characteristics, such as power-toflow ratio or burnup conditions. The precise method for selecting the grouping requirements is user-specified. The multiple-channel treatment of SAS $2 \mathrm{~A}$ allows for variations in pin power, coolant flow rate and fuel irradiation history across the core. 
2. Fuel Heat Transfer

Same as SAS $1 \mathrm{~A}$.

\section{Coolant Dynamics}

A multiple-bubble slug ejection model is used to calculate voiding due to bolling and/or fission gas release from failed fuel pins. Voiding is assumed to result from the formation of bubbles that fill the entire cross-section of the coolant channel, with up to nine bubbles, separated by liquid slugs, allowed in a channel at any time. Each bubble may contain sodium vapor and/or fission gas. The liquid film left on the clad and structure following bubble formation is assumed to be a static film whose thickness varies only due to vaporization and condensation. Film dry-out is predicted on this basis.

4. Fue1 Deformation

Same as SAS $1 \mathrm{~A}$.

5. Fuel slumping

After meeting a user-specified slumping criterion in a channel, a user-specified reactivity feedback is allowed through the neutronics calculation.

\section{Neutronics}

Same as SAS $1 \mathrm{~A}$, with additional reactivity feedback for fuel slumping treated by a user-supplied worth table.

\section{$\underline{\text { SAS 2D }}$}

A variable-channel version of SAS $2 \mathrm{~A}$ (Ref.4). Has same physical models as SAS $2 \mathrm{~A}$, but with improvements in data-storage methods, computer memory requirements and the number of channels which can be specified.

\section{Geometry}

The maximum number of channels is limited mainly by the amount of computer memory available. Currently, 34 channels are allowed, but this could be changed easily if more memory is available. 
2. Fuel Heat Transfer

Same as SAS $2 \mathrm{~A}$.

3. Coolant Dynamics

Same as SAS $2 \mathrm{~A}$.

4. Fue1 Deformation

Same as SAS $2 \mathrm{~A}$.

5. Fuel Slumping

Same as SAS $2 \mathrm{~A}$.

6. Neutronics

Same as SAS $2 \mathrm{~A}$.

$\underline{\text { SAS } 3 A}$

An advanced version of SAS $2 \mathrm{~A}$ with much improved models.

1. Geometry

Same as SAS $2 \mathrm{~A}$.

2. Fuel Heat Transfer

Same as SAS $2 \mathrm{~A}$.

3. Coolant Dynamics

Same as SAS 2A, with new film dryout model (Ref. 9) which calculates a moving film under the influence of vapor stripping (drag) by streaming vapor, wall friction, gravity and axial pressure gradients. Droplet entrainment is not included.

4. Fuel Deformation

Same as SAS $2 \mathrm{~A}$. 


\section{Fue1 Motion-SLUMPY}

SLUMPY, when integrated into the SAS $3 \mathrm{~A}$ coolant dynamics, clad motion, heat transfer and neutron kinetics modules, provides an assessment of the consequences of axial fuel motion in a voided subassembly following clad melting. Its applicability is limited chiefly to slowly developing undercooling transients. Some features of SLUMPY are:

a. Flexible slumping initiation criteria.

b. Models fuel debris explicitly as a multi-phase mixture.

c. Estimates acceleration of the relocating fuel pins above the failure point of the fuel.

d. As long as the subassembly hexcan furnishes an initial barrier for fuel motion during a power burst, possible termination of the burst due to fuel dispersal can be determined as part of a consistent calculation.

\section{e. Geometry}

Initial unperturbed geometry is same as multiple-channel concept of SAS 3A. The basic calculational model is the "channel," which consists of a single fuel pin surrounded by its associated coolant and structure in cylindrical, axisymmetric geometry. SLUMPY calculates axial fuel motion within each channel, assuming radial motion is prohibited by the resistance of the structural wall, which represents the mechanical restraint of the subassembly duct.

\section{f. Fue1 Motion Mode1s}

At fuel motion (slumping) initiation, pressures due to retained fission or fill gas in the fuel and any fission gas in a central void is assumed to cause radial expansion to fill the voided channel volume with the material in the axial node(s) (including fuel, fission gas and/or stainless steel) which first satisfy a slumping criteria. Subsequent fuel motion is determined by considering fuel in three distinct regions: (a) a middle "s lumped" or compressible region, (b) an upper falling solid fuel segment and (c) a lower stationary solid fuel segment. 


\section{(i) Middle Region Motion}

The middle slumped region moves according to areadependent 1-D (axial) compressible hydrodynamics in Lagrangian formulation, which includes gravity, wall friction, intra-channel heat transport to SAS structure and channel-to-channel heat transport once the SAS $3 \mathrm{~A}$ structure exceeds the melting temperature. Clad is assumed to be mixed with fuel if fuel melting has occurred at the same time or before clad melting; otherwise, fuel is pure oxide. As additional fuel nodes satisfy the slumping criteria, the slumped region is rezoned and grows. Limiting boundaries axtally for the slumped region are dependent on user input, or if explicit clad motion is specified, the boundaries are determined by the time dependent positions of calculated clad blockages. The slumped region mathematical treatment is based on mass, momentum and energy conservation in a simplified three-component (fuel, steel and fission gas) formalism, with fuel and fission gas assumes that fuel exists as either solid fuel particles or liquid fuel droplets of one characteristic diameter. Some of the simplifying assumptions in the conservation equations are:

(1) in the energy equations, fission gas has negligible heat capacity, there is no heat transfer via conduction and the heat transfer terms are approximated by a heat transfer coefficient and temperature difference, with heat assumed to flow from restructured fuel to unrestructured fuel and from unrestructured fuel to steel,

(2) work terms in the energy equations are neglected except at the transition between the two-phase regions where sma11 differences in energy result in large pressure differences,

(3) fuel and steel velocity in the energy equation is approximated by a mass-averaged velocity,

(4) viscous and friction terms are approximated by a wall friction term representing the viscous effects from an assumed velocity profile and an explicit axial viscosity dissipation component based on mass-averaged velocity, 
(5) due to assumed negligible fission gas inertia, fission gas momentum conservation equation is treated as quasi-steady-state, and

(6) fission gas release is assumed proportional to the retained gas in the fuel.

\section{(ii) Upper Region Motion}

The upper segment moves by the forces of gravity, friction, pressure forces exerted by the slumped region and by any user-specified forces. Movement of the upper segment either into or out of the slumped region changes the area available for the slumped region. The upper segment is assumed to separate from the upper SAS axial blanket if clad motion occurs prior to fuel motion and no user specified forces act downward on the SAS blanket. Constraints placed on the motion of the upper segment are: (1) upward motion beyond a user specified distance is prohibited and (2) downward movement into a lower stationary segment is prohibited.

\section{(iii) Lower Region Motion}

The lower segment is stationary and restricts the area available for the slumped region. The area occupied by the lower segment includes or excludes the clad area depending on whether the fuel pin was clad or, alternatively, clad motion had occurred before slumping initiation.

\section{g. Slumping Initiation Criteria}

\section{(i) Base Case}

The basic case initiates fuel motion within any channel following satisfaction of each of three basic conditions:
(1) channel sodium voiding has occurred,
(2) clad has melted and
(3) a fuel thermal condition is satisfied. 
The fuel thermal condition may be either:

(1) melting in the unrestructured fuel,

(2) user-specified fuel temperature to be exceeded at a specified radial node at any axial position, or

(3) a user-specified fraction of molten fuel to be reached at any axial node.

\section{(ii) User Options}

(1) a minimum necessary sodium vapor mass flow rate to simulate sodium vapor breakup of the fuel column or

(2) no requirement of clad melting; user must ensure that sodium voiding has occurred before slumping is initiated.

\section{h. Heat Transfer}

The SAS 3A transient heat-transfer module calculates temperatures in both the upper moving segment and the lower stationary segment. A simplified theory is used to treat intra-channel heat transport from fuel to the SAS 3A steel structure (hexcan plus wire wrap) and channel-to-channel heat transfer. Interchannel heat transfer is based on an assumed equivalence to convective plus radiative heat transfer in a pipe, and is terminated after the structure exceeds melting. At this point, channel-to-channel (i.e., subassembly-to-subassembly) heat transfer occurs and can be treated by at least five various models available in SLUMPY.

\section{i. Fission Gas Treatment}

The fission gas retained in the fuel is determined at steadystate by the SAS 3A SSFUEL module. User specifies what fraction of this gas is available for dispersal of fuel and how gas is to be released, with available options including the fraction instantaneously available upon slumping initiation, and the specification of time constants for release of gas from solid and molten unrestructured fuel. Released fission gas pressurizes the available space via the perfect gas law contained in the EOS. 
j. Neutronics

Fuel motion reactivity, Doppler feedback and changes in fuel power as a function of axial position are treated by perturbation theory. Channel-dependent axial distribution curves are defined for:

(a) the fuel worth per unit fuel mass,

(b) the local fuel Doppler coefficient per unit fuel mass, and

(c) the fuel power per unit fuel mass.

The integral fuel reactivity and Doppler feedback are evaluated by multiplication with the time dependent fuel spatial distribution and each fuel segment and/or compressible node is assigned a power based on the reactor power level at the spatial location of the fuel in question. The reactor neutron flux shape is assumed to be unchanged by fuel melting and fuel motion.

k. $\quad \underline{E O S}$

The EOS is composed of five parts which include a background pressure (from sodium vapor or user specified), a fission gas pressure, a vapor pressure from fuel and/or steel (from ANL EOS), a single-phase pressure if a pure liquid and/or solid exists, and a pseudo-viscous pressure to provide a more stable numerical solution for large pressure gradients.

6. Neutronics

S ame as SAS $2 \mathrm{~A}$.

7. Clad Dynamics--CLAZAS

CLAZAS, when integrated with the SAS $3 \mathrm{~A}$ coolant dynamics and other interfacing modules, provides an assessment of the consequences of axial clad motion within a subassembly resulting from coolant voiding and subsequent clad melting following a LOF HCDA. Phenomena which may be studied with CLAZAS include:

(i) Heat sink effects of molten clad.

(ii) Clad relocation reactivity effects. 
(iii) Influence of clad plug or blockage formation on voiding dynamics, sodium re-entry and fuel motion.

In general, molten clad is assumed to move under the influence of gravity, the channel sodium vapor pressure gradient, streaming sodium vapor friction forces, friction at the clad-fuel interface, and any fuel pressures from the SLUMPY compressible region. The clad motion is modeled by discrete clad segments which move axially and may combine or pile-up into blockages when more than one clad segment occupies the same space. Clad in a SAS channel is initially represented by three radial nodes and up to 20 axial nodes in the core and blanket.

The main computational problem in CLAZAS is the clad velocities for the various segments. The two basic cases considered are:

\section{(i) Normal Motion}

The force balance equation on an individual clad segment gives an expression for the clad acceleration. The equation includes terms for gravitational acceleration, interfacial shear force or drag resulting from sodium vapor streaming against molten clad, viscous drag from molten clad moving against solid fuel, clad or wire wrap and the sodium vapor pressure gradient.

\section{(ii) Restricted Motion}

CLAZAS has built in various restrictions to the motion of an individual clad segment; e.g., temporary termination upon approaching a liquid sodium interface. Due to the lack of an explicit continuity equation in CLAZAS, these restrictions must be added until a more unified mode1 is constructed.

In both the normal and restricted notion cases, it is possible to combine moving clad segments. The criteria for this combination is somewhat arbitrary, but the basic structure of CLAZAS and SAS has led to a set of criteria specified in CLAZAS.

\section{a. Clad Motion Initiation Criteria}

The various options available for initiation of axial clad motion at a given axial node are:

i. The middle radial node (comprising $70 \%$ of the segment) has gone completely through the melting transition. 
This represents the case of melting from the inside out.

ii. The outer radial node (comprising 5\% of the segment) has gone completely through the melting transition. This represent melting from the outside in.

A non-axial type clad motion may be initiated by initiation of fuel motion (via SLUMPY) at a given axial node, if clad motion is already occurring somewhere in the channel before any fuel motion criteria is satisfied. In this case, axial clad motion is suppressed and the clad is mixed with the fuel if fuel motion is initiated before the first clad motion time step in a voided channel, while fuel motion is suppressed from any node where a clad blockage temporarily exists.

\section{b. Clad Motion Termination Criteria}

In general, a clad segment is assumed to stop motion according to the following criteria:

i. Temporarily, if an unvoided region is reached and sodium contact is made.

ii. Temporarily, when a clad segment temperature is more than $100^{\circ} \mathrm{C}$ below the freezing point (i.e., the clad may be able to move after technically freezing, but at $100^{\circ} \mathrm{C}$ below this freezing point, motion is very unlikely), which is determined by calculating a variable viscosity for moving clad as a function of a segment internal energy.

iii. Permanently, if the end of the SAS blanket is reached.

To simulate effects of radial incoherence and by-pass flow, user input can be used to stop upward clad motion at any axial position before the upper end of the blanket is reached.

\section{c. Heat Transfer}

The heat transfer relationships are based on the assumption of good thermal contact between moving clad and the underlying material. Each clad segment is assigned an initial internal energy based on the clad temperature and heat of fusion, and heat transfer is then based on the fraction of each axial node occupied by a clad segment in two separate heat transfer 
coefficients corresponding to underlying surfaces consisting of oxide fuel and/or solid clad. Heat transfer from stationary oxide fuel to moving clad is based on standard gap conductance arguments, while heat transfer from stationary clad to moving clad is based on convective liquid metal heat transfer.

\section{d. Reactivity Treatment}

Reactivity due to molten clad motion is computed by summing over a clad worth table, as previously determined by perturbation theory, with a special treatment for clad segments in core regions of high worth gradients.

\section{Steady-State Fue1 Characterization}

Direct fuel restructuring calculations are made with correlations for fuel swelling, clad swelling and fission gas release and retention. Fuel restructuring is based on restructuring temperatures at each axial node for equiaxed - and columnar - grain fuel.

\section{Primary Loop Hydraulics}

PRIMAR (Ref. 11) provides hydraulic coupling between coolant channels, with allowance for compression of cover gas volume and primary-loop hydraulics for a single loop containing a pump, IHX and piping.

\section{FCI}

A mode1 (Ref. 12) treats molten fuel ejection into the coolant channel and the resulting FCI phenomena.

$\underline{\text { SAS 3D }}$

A variable-channel version of SAS $3 A$ using the data storage method of SAS 2D.

The models used in SAS 3D are the same as those in SAS 3A, with the following exceptions:

1. SAS 3D can currently handle up to 34 channels, and the maximum number of channels could be increased easily if more computor memory were available. SAS $3 \mathrm{~A}$ is limited to 10 channels.

2. The maximum number of the fuel axial nodes has been increased from 20 to 24 , and the maximum number of coolant nodes has been increased from 30 to 36 . 
3. SAS 3D can interface with the DIF3DS neutronics code (see DIF3DS writeup) to obtain consistent steady-state thermal-hydraulics and neutronics conditions for the start of a transient.

\section{$\underline{\text { SASRUP } 3}$}

A version of SAS 3D containing the PRIMAR-3 primary loop hydraulics module for treating flow transients caused by severe pipe ruptures. The PRIMAR-3 model includes:

1. Multiple primary loops, with flows calculated for each loop.

2. Pipe rupture in one loop.

3. Explicit treatment of pump characteristics for computing pump head and torque as a function of flow and impeller angular velocity. Pump cavitation is also treated.

4. Compression of the sodium in the vessel inlet plenum.

5. Compression of the cover gas over the core and pumps.

6. Gas flow between cover gas volumes and a reservoir.

\section{$\underline{\text { SAS } 4 A}$}

SAS $4 \mathrm{~A}$ will be an upgraded version of SAS 3D with the following additional capabilities:

1. A consistent treatment of voiding due to simultaneous boiling and gas release from failed fuel pins.

2. An improved fuel pin mechanics module for irradiated fuel, including swelling due to gas release, fuel cracking, and motion of molten fuel within the central fuel pin cavity.

3. An improved clad motion module.

4. An improved module for fuel motion in voided subassemblies.

5. The PLUTO-2 module for fuel-coolant interactions (see PLUTO description).

6. Space-time kinetics; a DIF3DS-type module coupled with both the steady-state and the transient calculations in SAS. 


\section{Limitations}

Current limitations of SAS 3D are:

1. No treatment of intrasubassembly incoherence or pin-to-p in effects on voiding and on clad and fuel motion (i.e., only axial material motions are calculated and radial or 2-D motions are ignored within a subassembly).

2. Neutronics is limited to point kinetics (i.e., no allowance for flux spatial variations).

3. SLUMPY applicability is limited to slowly developing undercooling accidents where fuel motion occurs in a completely voided subassembly after clad melting. SLUMPY currently cannot handle accurately the following fuel motion regimes:

a. TOP-type fuel motion which involves fuel movement inside relatively strong clad, clad failure, and fuel movement into the coolant channel.

b. Fuel motion in medium-power subassemblies undergoing a power burst during an LOF, where fuel pin breakup occurs without complete voiding and only a small degree of clad melting. The fundamental limitations which prohibit application in this regime are:

(i) integration of SLUMPY fuel motion with the SAS sodium voiding model is crude and possibly inadequate to properly assess the degree of slip between sodium vapor and fuel,

(ii) fuel motion inside the pin (a strong clad boundary) is not allowed; SLUMPY presumes that clad mixes uniformly with fuel when fuel motion occurs,

(iii) SLUMPY does not take into account the possibility of strong 2-D effects due to radial incoherence of fuel motion,

(iv) SLUMPY does not explicitly calculate freezing and plugging of fuel, which may occur in the relatively cold sodium flow channels in the blanket and fission-gas plenum regions.

c. Energetic prompt-critical core disassembly fuel motion, as predicted by VENUS. 
To summarize, the general limitations of SLUMPY are as follows:

a. 1-D model cannot calculate possible radial incoherency effects within a dis rupted assembly.

b. Reactivity treatment, based on perturbation theory, is not precise.

c. Slip of all possible vapor species in any possible mode is not treated.

d. Clad-fuel mixtures cannot vary in composition axially.

e. Freezing and plugging of fuel is not explicitly calculated.

f. All fuel motion is compressible.

g. Geometry is limited to that of SAS 3A.

h. The SAS FCI module and SLUMPY cannot operate in the same channe1 simult aneously.

i. SLUMPY applicability is primarily for the highest power subassemblies in a FTR-type core under an LOF transient; considerable modification is required for applicability to the full range of subassemblies powers in larger cores.

4. The major modeling limitations of CLAZAS are:

a. The 1-D (axial) nature of the model, with a single channel representing the behavior of one or more subassemblies, does not allow calculation of possible radial incoherency of clad motion within a single subassembly.

b. Clad is treated as discrete segments instead of as a continuum.

c. Reactivity treatment is based on perturbation theory.

d. Crude treatment of differential clad and fuel motion when both clad and fuel move simultaneously.

5. The major limitations of DEFORM-1 are:

a. The model is mainly applicable to unirradiated fuel; fuel restructuring and fission product gas in the central cavity are not accounted for in DEFORM-1. 
b. Plastic behavior of fuel is not accounted for.

c. Mechanfcal equations are quasi-static (i.e., entire system is in mechanical equilibrium at all times).

d. Plane-strain approximation is used, with shear stress neglected, except for approximate treatment of friction between fuel and clad.

e. All materials are isotropic and zonewise homogeneous.

f. Local effects, as due to finite fuel pellet size, are neglected.

g. No hot-pressing (porosity compression) model.

h. No microscopic model for fission-gas swelling of fuel; swelling is approximated by adjusting the fuel thermal expansion coefficient.

i. No bulk motion of molten fuel in central cavity.

j. No fuel cracking model.

6. The major limitations of PRIMAR-3 are:

a. No transient coolant temperature calculations in the primary loop; the model is mainly applicable to fast transients that are over in a time shorter than the loop transit time.

b. No treatment of the secondary loop and the steam generators or air dump heat exchangers.

\section{Future Efforts}

1. Many of the SAS 3D, SLUMPY, CLAZAS, and DEFORM-1 limitations will be removed in the new models in SAS $4 \mathrm{~A}$.

2. PRIMAR-4 will include transient temperature calculations for the primary loop, as well as a treatment of the IHX and the secondary loop.

3. A long-term effort will be made on the treatment of intrasubassembly incoherence or pin-to-pin effects. 


\section{Computer Operation}

SAS 3A has been made operational on the ANL IBM 370-195, CDC-7600's at LBL, BNL, and LASL, the IBM 370-168 at ERDA Germantown, and the IBM 360-91 at UCLA. SAS 3D is operational on the ANL IBM 370-195 and the LBL CDC-7600.

SAS $3 A$ requires $1300-1400 \mathrm{~K}$ by tes of memory on an IBM 360 or 370 system. It requires $150 \mathrm{~K}_{8}$ words of SCM (small core memory) and $400 \mathrm{~K}_{8}$ words of LCM (large core memory) on a CDC 7600. The core requirements are largely independent of the size or type of problem being run, since the code was written with fixed dimensions for 10 channels, and space is allotted for 10 channels, even if only one channel is used.

SAS 3D uses a more flexible data management scheme than SAS $3 \mathrm{~A}$, and the memory requirements depend on the size of the problem and the options used. The memory requirements on an IBM 360 or 370 are $750 \mathrm{~K}-$ $900 \mathrm{~K}$ bytes plus $55 \mathrm{~K}-67 \mathrm{~K}$ by tes per channel. The $750 \mathrm{~K}$ figure excludes coupling with external neutronics (DIF3DS), and the $55 \mathrm{~K}$ per channel does not include FCI, SLUMPY, or CLAZAS options. The higher figures include all of the options. On a CDC-7600, SAS 3D requires $144 \mathrm{~K}_{8}$ words of SCM. The number of LCM words required is $134 \mathrm{~K}_{8}$ plus $16 \mathrm{~K}_{8}-21 \mathrm{~K}_{8}$ per channel plus $144 \mathrm{~K}_{8}$ for the SCM image plus buffers. Again, the $16 \mathrm{~K}_{8}$ per channel does not include FCI, SLUMPY, or CLAZAS; $21 \mathrm{~K}_{8}$ per channel does include these options. The largest SAS 3D case that can be run on the ANL or LBL computers uses 33 channels with FCI, SLUMPY, and CLAZAS options. Such a case requires about $3000 \mathrm{~K}$ by tes on the IBM $370-195$, or $400,000_{10}\left(1,400,000_{8}\right)$ words of LCM on the CDC-7600.

On the CDC-7600, SAS 3D is overlayed, and the most frequently used overlays are stored in LCM; a special subroutine OVERLAY has been written for this purpose. SAS $3 \mathrm{D}$ usually is not overlayed in the IBM $370-195$.

It is possible to reduce memory requirements and/or run larger cases with a given amount of memory by overlaying to disk or by storing some of the data on temporary scratch files on disk. Both options have been tried on the ANL computer. It was found that because of the very large amount of disk I/O required, and because of the low ratio of disk I/ 0 speed to CPU speed, reducing memory requirements significantly by storing either overlays or data on disk increases the running time and 
cost by a factor of 5-10 on the IBM 370-195. Such options would probably also be expensive on a CDC-7600.

The SAS codes are written in FORTRAN. Currently the IBM FORTRAN H and the CDC FORTRAN EXTENDED, version 4 (FTN4) compilers are used for SAS 3D.

No plotting is done internally by the SAS codes, but binary files are written containing results for use by separate plotting programs.

\section{Typical Problem Running Time}

For a 33 channel CRBR flow coast-down case, including steady-state initialization, pre-boiling coast-down calculations, and a period of about 3 seconds containing boiling, clad motion, fuel motion, and fuel-coolant interactions in some of the channels until neutronic shut-down, a typical SAS 3D running time is 3 hours on an IBM 370-195 or $1-1 / 2$ hours on a CDC-7600. A single-channel case for an in-pile flow coast-down simulation test will run $5-10$ minutes. The running time is approximately proportional to the product of the number of channels times the number of time steps: before boiling the CDC-7600 running time is about .06 seconds/channel/step. After the start of boiling, clad motion, fuel motion, or FCI the running time per step increases considerably. SAS 3D runs about twice as fast on a CDC-7600 as on an IBM 370-195.

The bulk of the computing time in SAS is not concentrated in any one subroutine or section; there are four or five sections that can each consume appreciable amounts of computer time, depending on the case being run. Before the start of voiding, the fuel pin heat transfer calculations consume over half of the computer time. Much of this time is spent in obtaining fuel thermal properties (conductivity, heat capacity, density) as functions of temperature, fuel type, and fraction of theoretical density for each radial node of each axial node for each time step. The boiling calculation can add appreciably to the running time, and the film motion model consumes a significant fraction of the computing tine when it is used. The fuel slumping and FCI modules can also consume appreciable amounts of computer time.

\section{Code Validation}

\section{$\underline{\text { References }}$}

1. M. G. Stevenson, W. R. Boh1, F. E. Dunn, T. J. Heames, G. Höppner, and L. L. Smith, "Current Status and Experimental Basis of the SAS LMFBR Accident Analysis Code System," Fast Reactor Safety, USAEC-CONF 740701, Beverly Hills, California (April 1974). 
2. G. Höppner, W. L. Chen, F. E. Dunn, and M. A. Grolmes, "TREAT R5 Loss-of-Flow Experiment in Comparison with SAS Pretest Analysis," Trans. Am. Nucl. Soc. 18, 213 (1974).

3. G. Höppner, "SAS3A Analysis of R-Series Experiments," ANL/RAS 74-14 (August 1974).

4. F. E. Dunn, "LMFBR Voiding Rate Reduction Due to Inlet Plenum Hydraulic Effects," Trans. Am. Nucl. Soc. 23, 334 (June 1976).

5. G. Höppner, F. E. Dunn, and T. J. Heames, "The SAS3A Sodium Boiling Model and its Experimental Basis," Trans. Am. Nuc1. Soc. 20, 519 (April 1975).

6. F. E. Dunn, "Comparison of Coolant Temperatures Calculated by SAS2A and IANUS," ANL/RAS 73-29 (1973).

Additional experimental comparisons will be made as new experiments are performed and as new models become available in SAS. A comparison between SAS boiling predictions and results of the P2 experiment is underway.

Interface/Overlap

VENUS, DIF3DS/MELT ,FREADM,HOPE,DEMO, I ANUS

\section{References}

SAS 1A

1. J. C. Carter, G. J. Fischer, T. J. Heames, D. R. MacFarlane, N. A. McNea1, W. T. Sha, C. K. Sanathanan, and C. R. Youngdah1, SAS 1A, A Computer Code for the Analysis of Fast Reactor Power and Flow Transients, ANL-7607 (1970).

\section{$\underline{\text { SAS } 2 A}$}

2. F. E. Dunn, G. J. Fischer, T. J. Heames, P. Pizzica, N. A. McNeal, W. R. Boh 1 , and S. M. Prastein, The SAS 2A LMFBR Accident Analysis Computer Code, ANL/RAS 73-39 (1973).

3. F. E. Dunn, T. J. Heames, P. A. Pizzica, and G. Fischer, "The SAS 2A LMFBR Accident Analysis Code," Proc. of Conf. on New Developments in Reactor Mathematics and Applications, CONF-710302, p. 120 (1971). 
SAS 2D

4. F. E. Dunn, R. D. George, and L. W. Person, The SAS 2D LMFBR

Accident Analysis Computer Code, ANL/RAS 75-37 (1975).

SAS 3A

5. M. G. Stevenson, W. R. Boh1, F. E. Dunn, T. J. Heames, G. Höppner, L. L. Smith, "Current Status and Experimental Basis of the SAS LMFBR Accident Analysis Code System," Proc. of the Conf. on Fast Reactor Safety, Beverly Hills, California (April 1974).

6. W. R. Boh1, F. E. Dunn, G. J. Fischer, T. J. Heames, J. F. Jackson, R. B. Nicholson, L. L. Smith, M. G. Stevenson, J. K. Travis, and A. Watanabe, "Progress in Analysis of Severe Accidents," Proc. Int. Conf. on Engineering of Fast Reactors for Safe and Reliable Operation, Karls ruhe, Germany (October 1972).

7. F. E. Dunn, W. R. Boh1, T. J. Heames, G. Höppner, M. G. Stevenson, L. L. Smith, J. R. Travis, W. Woodruff, L. W. Person, J. M. Kyger, and D. R. Ferguson, The SAS 3A LMFBR Accident Analysis Computer Code, ANL/RAS 75-17 (1975).

Multiple-Bubble slug Ejection Coolant Voiding Mode1

8. F. E. Dunn, G. J. Fischer, T. J. Heames, and P. A. Pizzica, A Multiple Bubble Slug Ejection Model for Coolant Voiding, Trans. Am. Nucl. Soc., 14 (1) 241 (1971).

Film Motion Voiding Model

9. G. Höppner and F. E. Dunn, Sodium Film Model in SAS 2A Voiding,

Trans. Am. Nucl. Soc., 16 (2) (Nov. 1973).

10. G. Höppner, Sodium Film Motion Model of SAS 3A, ANL/RAS 74-22 (September 1974).

Primary Loop Hydraulics

11. F. E. Dunn, J.R. Travis, and L. L. Smith, The PRIMAR-2 Primary Loop Module for the SAS 3A Code, ANL/RAS 76-5 (1976).

\section{Fuel-Coolant Interaction}

12. L. L. Smith, J. R. Travis, M. G. Stevenson, F. E. Dunn, and G. J. Fischer, "SAS/FCI, A Fuel-Coolant Interaction Model for 
LMFBR Thole-Core Accident Analysis," Proc. Topical Meeting on Mathematical Models and Computational Techniques for Analysis of Nuclear Systems, CONF-730414-P1, Ann Arbor, Michigan (Apri1 9-11, 1973).

13. L. L. Smith, SAS/FCI: The SAS 3A Fue1-Coolant Interaction Model, ANL/RAS 75-33 (August 1976).

Fue1 Motion Mode1

15. W. R. Boh1, SLUMPY: The SAS 3A Fuel Motion Model for Loss-of-Flow, ANL/RAS 74-18 (August 1974).

16. W. R. Boh1 and M. G. Stevenson, "A Fuel Motion Model for LMFBR Unprotected Loss-of-Flow Accident Analysis," CONF-730414-P2, Ann Arbor, Michigan (April 1973).

$\underline{\text { SAS } 4 \mathrm{~A}}$

17. D. R. Ferguson, W. R. Boh1, C. H. Bowers, J. F. Cahalan, F. E. Dunn, T. J. Heames, J. M. Kyser, W. L. Wang, and H. U. Wider, "The SAS 4A LMFBR Accident Analysis Code System: A Progress Report," Int1. Meeting, Fast Reactor Safety and Related Physics, Chicago, Illinois, (October 1976). 
S IEX

\section{Purpose}

Analysis of the steady-state thermal performance characteristics of mixed oxide fuel pins in a fast neutron environment.

\section{$\underline{\text { Status }}$}

A. Development: Developed and under continuing improvement at HEDL.

B. Availability: Released to ACC and documentation is available (Ref 1).

C. Utilization: SIEX II has been used by HEDL as a data analysis and design tool for systematic analysis and prediction of EBR-II tested fuel pins, performance predictions for FTR driver fuel pins under normal operating conditions, design of fuel element experiments in FTR and for initialization of the MELT code.

\section{Problems Solved}

SIEX II is a steady-state heat transfer code for thermal performance and dimension change (swelling and thermal expansion) calculations of mixed oxide fuel elements in a fast neutron environment. Fuel restructuring, fuel and clad displacements due to swelling and thermal expansion, fuel-clad gap heat transfer and fission gas release are included to provide an assessment of fuel, clad and coolant temperatures throughout the history of fuel element. Modeling emphasis is placed on correlations to measurable quantities from EBR-II irradiation tests and the inclusion of these correlations in a physically based computation scheme. The code is completely modular in construction, allowing the user options for material properties and correlated models. Required input is limited to geometric and environmental parameters.

SIEX II provides estimates of thermal performance characteristics with the requirement of only a small amount of computer core storage and running time. The resulting thermal analysis of SIEX II provides groundwork for:

1. Subsequent steady-state or transient stress analysis

2. Prediction of steady-state or transient failure modes and times

3. Safety related accident analysis, as with MELT (see MELT summary) 
The following are calculated by SIEX II:

1. Coolant temperature

2. Cladding temperature

3. Fuel-cladding heat transfer coefficient (gap conductance)

4. Fuel temperature profile

5. Fuel restructuring radii

6. Fuel and cladding displacements due to swelling and thermal expansion

7. Fission gas generated and released

\section{Mode1s}

SIEX models consist of a combination of mathematical and physically-based correlated models. The mathematical models are for heat transfer, gas plenum pressure and, to a certain extent, dimensional changes of the fuel and clad. The correlated models are for gas release, restructuring, and fuel-clad gap dimensions and conductance.

\section{Geometry}

The fuel pin is axisymmetric, with the fuel divided axially into segments of equal height. Each segment (node) may contain a central void, columnar grain fuel, equiaxed grain fuel, unrestructured fuel, a fuel-clad gap and clad. The axial segments are coupled only through their boundary conditions. There is one axial segment for the gas plenum.

\section{Mathematical Models}

\section{a. Heat transfer}

1-D radial heat transfer is assumed at the axial center of each axial segment. The fuel steady-state radial temperature distribution is calculated using the integral of the thermal conductivity, which allows for temperature-dependent therma 1 conductivity and fuel geometry changes. The increase in coolant temperature is found by adding the heat deposited in the coolant at each axial segment. 
b. Fuel and clad dimension changes

The fuel and clad change dimensions by thermal expansion and swelling.

c. Gas plenum pressure

Gas pressure is calculated using the "perfect gas law" with the gas volumes from fill gas, water vapor in fuel, absorbed gases in fuel and released fission gases.

\section{Correlated Models}

a. Fuel-clad residual gap and gap conductance

b. Fuel microstructure (restructuring)

c. Fission gas release

\section{Limitations}

1. Axisymmetric geometry with $1-\mathrm{D}$ radial heat transfer only.

2. Coolant inlet temperature and flow rate for a specific fuel pin are input, with no coolant cross-channel laixing calculater.

3. Fuel-clad mechanical interaction and the "gas bottle" effect are ignored.

\section{Future Efforts}

Continue correlation with data and improve fuel displacement models.

Typical Problem Running Time

One second per case on the CYBER-74.

\section{Ccde Validation}

The code has been calibrated to post-irradiation data from 76 EBR-II irradiated fuel pins (186 fuel metallographic sections) and the data from the HEDL $\mathrm{P}-19$ and $\mathrm{P}-20$ power-to-incipient fuel melting experiments. Documentation of the quality of correlation is scheduled to be completed in 1977. 
Interface/Overlap

MELT/LIFE

References

$\underline{\text { SIEX II }}$

1. D. S. Dutt and R. B. Baker, "SIEX, A Correlated Code for the Prediction of Liquid Metal Fast Breeder Reactor Fuel Therma 1 Performance," HEDL-TME 74-55, December 13, 1974. 
SIEXB

\section{$\underline{\text { Purpose }}$}

SIEXB predicts in-reactor performance of LMFBR absorber pins. Calculations are performed for absorber burnup, temperatures, swelling, gas release and cladding stress as a function of irradiation exposure. Both fixed and moving absorber pins can be analyzed. Predicted behavior is based on realistic operating conditions, with no conservatisms incorporated.

\section{$\underline{\text { Status }}$}

A. Development: The SIEXB Program was developed at HEDL and is A Performance Analysis Code for LMFBR Absorber Pins.

B. Ava1lability: The program is documented in HEDL-TME-76-68.

C. Utilization: The program is used for absorber pin analyses.

Problems Solved

SIEXB is a performance analysis code used to predict in-reactor behavior of irradiation test pins.

\section{Models}

SIEXB performs one-dimensional steady-state thermal calculations for as many as 50 axial nodes in an absorber pin. Frequency of calculation and positional operating history are prescribed by the user. Options exist to calculate gas release, absorber and cladding swelling, and cladding stresses during each time step. The code is presently programmed to analyze boron carbide as the absorber material. The code is constructed in modular form to facilitate updating of calculational models or correlations.

\section{Limitations}

Limitations are described in the user's manual, HEDL-TME-76-68.

Future Efforts

None planned. 


\section{Computer Operation}

1. The program is operational on $C D C-6600$.

2. No special requirements apply.

3. A typical absorber problem is completed on one minute of computer time.

4. The code is used for HEDL absorber pin test predictions and is revised after the experimental results are available.

\section{References}

1. A. L. Pitner, "User's Manual for SIEXB -- A Performance Analysis Code for LMFBR Absorber Pins," HEDL-TME-76-68, July 1976. 
SIMMER

\section{$\underline{\text { Purpose }}$}

Analysis of large scale motion of core material following initiation phase of unprotected core disruptive accidents. Characterization of source term for vessel loading calculations. Characterization of postdisruption material disposition of PAHR calculations.

\section{Status}

A. Development: Al1 versions were developed at LASL in the Fast Reactor Safety group. Current development version is SIMMER-II.

B. Availability: The versions of SIMMER that have been or are in the process of being made operational are:

SIMMER-I: Operational at LASL $^{1}$

SIMMER-II: Developmental at LASL

Documentation and release to NRC

scheduled for October 1977

C. Utilization: The SIMMER codes provide a rigorous treatment for the evaluation of the detailed reactor behavior following the accident phase, as treated by the SAS code system, and prior to system damage, as treated by the REXCO code system.

\section{Problems Solved}

The SIMMER code is being applied to the analysis of two-dimensional sodium boiling, core disruption within a single subassembly, transition phase behavior in whole core geometry, and to the analysis of the source term for primary system damage estimation.

The code is currently limited to two dimensions, and two fields (velocity distributions). The complex behavior of core materials during disruption may require the treatment of several flow regimes, many material components and more than two fields. Development of these capabilities will be considered in future versions of the code. Utilization of the code is now appropriate as a research tool. The confidence level in its validity will increase as relevant experimental information becomes available. 


\section{Mode1s}

A11 versions of SIMMER will contain four groups of physical models. These are models for (1) geometry, (2) neutronics and cross sections, (3) fluid dynamics and structure, and (4) field coupling phenomena. Numerical methods can be lumped into three categories: (1) neutronics methods, (2) fluid dynamics and structure methods, and (3) equation of state methods.

\section{SIMMER-I}

\section{Geometry}

Problems in one and two dimensional cylindrical geometry can be treated by SIMMER-I, on an Eulerian grid with constant radial and constant axial mesh spacing. Microscopic cross section sets and initial conditions are assumed to be regionwise constant.

\section{Neutronics and Cross Sections}

Several neutronics options are possible in SIMMER-I. The user may select between time dependent transport $\left(S_{n}\right)$ theory, time dependent diffusion theory, and point kinetics. The transport option is restricted to isotropic downscattering only. Two options are available for selection of the numerical method used to solve the transport equation. These are the extrapolation and quasistatic methods as described in Ref. 1. The time dependent diffusion theory option is a degenerate version of the transport option. The point kinetics option involves a solution technique employed in the above mentioned quasistatic approach.

Cross sections are modeled using the Bondarenko formalism, where microscopic cross sections can be entered in the LASL format or in standard interface file format (ISOTXS and BRKOXS).

\section{Fluid Dynamics and Structure}

A three field approach is used in SIMMER-I to model the dynamic behavior of materials. A "field" is the same as a velocity distribution. In SIMMER-I, fields are distinguished according to material phase; solid, liquid, and vapor. Each field contains three components. The vapor and liquid field components are fuel, steel, and sodium. The structure field components are solid fuel, cladding and wire wraps, and subassembly can walls.

The Navier Stokes equations are written for the vapor and liquid fields and are coupled through heat, mass, and momentum exchange 
terms between components and fields. The structure field is assumed stationary and is modeled by continuity and energy equations only.

The fluid dynamics methods are based on the Implicit Continuous Eulerian (ICE) and Implicit Multifield (IMF) methods developed at LASL $^{2}$, as modified for the case of core disruption in LMFBR's. The structure field methods primarily utilize an explicit approach. Time step selection is based upon choosing the most constraining event in solution of the mass, momentum and energy equations.

\section{Equation of State}

The pressure is either that of the vapor phase (vapor and liquid assumed to be in local pressure equilibrium) or that of an incompressible fluid (solution of Bernoulli's equation). For the two phase case, a modified polytropic gas law is used the most frequently in SIMMER-I. The solution for vapor field energy and density in the fluid dynamics equations leads directly to the prediction of pressure in this formalism.

\section{Field Coupling Phenomena}

The three fields are coupled through the exchange of mass, momentum, and energy.

Mass exchange involves vapor-liquid phase transitions, condensation on structure, liquid freezing and adhesion to structure, and structure melting. Since there are three components in each field, this leads to fifteen separate modes of mass exchange.

These mass exchange processes are treated explicitly in the overall formalism, although vapor-liquid phase change is treated quasiimplicitly within the calculational framework.

Momentum exchange includes drag between each field. Hence, vaporliquid drag, vapor-structure drag, and liquid-structure drag are modeled. Vapor-liquid drag is assumed to occur in either dispersed or bubbly flow topology. The vapor-liquid drag is treated implicitly in the evaluation of the pressure distribution. Structure related drag terms are treated explicitly and are outside the pressure iteration.

Energy exchange, as in mass exchange, involves many potential modes of exchauge and is treated explicitly. Modeling provides, for example, for fuel-coolant interactions, heating of sodium by cladding, liquid fuel to liquid steel heat transfer, etc. 


\section{SIMMER-II}

\section{Geometry}

Same as in SIMMER-I.

\section{Neutronics and Cross Sections}

Same as in SIMMER-I except extrapolation transport method not available. Space dependent neutronics modified to allow arbitrary initial reactivity state.

\section{Fluid Dynamics and Structure}

The fluid dynamics models in SIMMER-II are being extended to allow for additional materials, components and flow regimes. Five materials are available; fissile fuel, fertile fuel, steel, sodium and control material. Therefore, the liquid field has nine components, the vapor field has six components and the structure field has eight components. Three flow regimes will be modeled and internal checks made for the appropriate transitions. These will include bubbly, film annular and dispersed flow topologies.

The numerical methods employed in the fluid dynamics portion of the calculation are similar to those in SIMMER-I, but have been optimized with regard to code structure, data management, and acceleration schemes.

\section{Equation of State}

Two options are available in SIMMER-II for selection of the EOS treatment. The modified polytropic gas law is retained and a new tabular EOS option is available. The tabular treatment is designed so that the most up-to-date experimental information can be readily incorporated without major changes to the code structure. The mixture rule employed in the tabular treatment assumes ideal behavior.

\section{Field Coupling Phenomena}

The types of field coupling models are simflar to those in SIMMER-I except that many of the rate coefficients are computed as functions of the instantaneous environment within a numerical cell. The rate coefficients will also reflect the local instantaneous flow topology that has been determined. 
The coding in SIMMER-II has been rearranged so that all of the models for rate processes are centralized in one subroutine. In this way, the exchange models can be readily modified without impacting the fundamental methods used for the fluid dynamics.

\section{$\underline{\text { Limitations }}$}

Current limitations of SIMMER-II are:

1. Restricted to two dimensions.

2. Restricted to a few thousand constant-sized mesh cells.

3. Many of the complex physical models remain to be validated by relevant in-pile and out-of-pile data.

4. Currently lacks detailed fuel pin model and is therefore of limited utility for TOP analysis.

5. Practical constraints along with time step limits, restrict its use to problems no longer than 10 seconds or so of real time.

6. Lacks primary loop model and therefore limited to user input boundary conditions.

\section{Future Efforts}

The impact of above limitations will be evaluated and attempts will be made to alleviate the more significant limitations in SIMMER-III.

\section{Computer Operation}

1. SIMMER-I has been made operational on CDC-7600's and the CRAY-I. It is currently being converted to the IBM 360.

2. Logistics: The storage requirements for SIMMER-I depend on the problem type. For the CDC-7600 65,000 words of small core memory are required, while large core memory can range from zero to 300,000 words. Up to 12 files may be required during execution: four files for input data, cross section data, and restart data; six files for printed output, film output, postprocessing data, and restart data; and two files for data manipulation.

SIMMER-I has been written in FORTRAN-IV using CDC UPDATE ${ }^{3}$. For those machines not having CDC UPDATE features, a primitive proprocessor accompanies the code to provide a compiler source. 
SIMMER-I has been compiled with several compilers including FTN (version 4.2). SIMMER-I requires a number of system dependent routines and plotting routines which are described in the SIMMER-I manual.

3. Typical Problem Running Times: CDC-7600 Running Times.

Problem 1

Geometry

Node Structure

Real Time

Running Time

Problem 2

Geometry

Node Structure

Real Time

Running Time

Problem 3
Whole Core Transition Phase Calculation

$1.43 \mathrm{~m}$ radius $\times 2.1 \mathrm{~m}$ high

26 radial $\times 42$ axial

$1.0 \mathrm{~s}$

$8 \mathrm{hr}$.

Whole Vessel Work Energy Partition Calculation

$3.1 \mathrm{~m}$ radius $\times 12.5 \mathrm{~m}$ high

20 radial $\times 41$ axia 1

$1.0 \mathrm{~s}$

3.5 hrs.

1-D Single Subassembly Sodium Boiling

Calculation

$0.0594 \mathrm{~m}$ radius $\times 2.7432 \mathrm{~m}$ high

1 radial $\times 27$ axial

$4.0 \mathrm{~s}$

1.46 hrs.

Problem 4

2-D Single Subassembly Sodium Boiling Calculation

Geometry

$0.0594 \mathrm{~m}$ radius $\mathrm{x} 2.7432 \mathrm{~m}$ high

Node Structure

6 radial $\times 27$ axial

Real Time

$1.178 \mathrm{~s}$

Running Time

9.71 hrs.

4. Code Validation: SIMMER-I has been compared to SAS and to VENUS-II as reported in Ref. 4. Other validation activities related to experiments are ongoing at LASL and are also discussed in LASL quarterly reports. Other NRC/ARSR contractors are involved in supplying data related to SIMMER validation. These contractors include Sandia, Brookhaven National Laboratory, and Oak Ridge National Laboratory. Ultimately SIMMER will be used to plan and 
perform pre- and post-test analyses for the SAREF in-pile experimental program. Efforts are underway for the analysis of the ANL P-2 experiment.

\section{Interface/Overlap}

SIMMER-I receives initial conditions from the SAS code system. A code locally under development at LASL, called PRESIM is designed as a simplified version of SAS for direct interfacing with SIMMER. A code with similar objectives to those of SIMMER is the VENUS-II code, developed at ANL.

\section{$\underline{\text { References }}$}

1. C. R. Be11, P. B. Bleiweis, J. E. Boudreau, F. R. Parker, and L. L. Smith, "SIMMER-I: An $\underline{S}_{\text {}}$, Implicit, Multifield, Multicomponent, Eulerian, Recriticality Code for LMFBR Dis rupted Core Analysis," Los Alamos Scientific Laboratory report LA-NUREG-6467-MS (January 1977).

2. Francis H. Harlow and Anthony A. Amsden, "Numerical Calculation of Multiphase Fluid Flow," Journal of Computational Physics, 17, 19 (1975) •

3. "Update Reference Manual," Control Data Corporation Publication, No. 60342500 (undated).

4. J. F. Jackson, Ed., "Reactor Safety and Technology, Quarterly Progress Report, January 1 - March 31, 1977," Los Alamos Scientific Laboratory report, to be published. 
SOMIX

\section{Purpose}

Analysis of the transient convection and pressure rise in a heat-transfer equipment cell atmosphere heated by a hot sodium droplet spray from a pipe rupture accident in the cell.

\section{$\underline{\text { Status }}$}

A. Development: Under development at AI.

B. Availability: A developmental version is operational at LBL on the CDC- 7600 and AI on the IBM 370. Documentation is in the form of a status report (Reference 1 ). The code and a users manual is expected to be ready for delivery to the ANL Code Center by June 30, 1977 .

C. Utilization: When fully developed, will be used for SAR supporting analysis.

Problems Solved

SOMIX analyzes transient-f ree convection motion in the low and highoxygen gas environment of a cylindrical enclosure, representing an LMFBR heat transfer cell, following a large sodium pipe rupture in the cell which releases a spray of hot sodium droplets. Calculated are the combustion and transfer of heat from the falling spray to the cell gas atmosphere (which may contain any initial concentration of oxygen) oxygen depletion and transport, the temperature rise of the gas, the internal gas circulation resulting from thermal gradients and entrainment of the falling droplets, and the effects on the cell gas pressure of the resulting heat and mass transfer, droplet motion and droplet combustion.

\section{$\underline{\text { Models }}$}

All equations are finite-differenced and solved numerically with an explicit time-differencing scheme. Solution is facilitated by adopting stream function and vorticity concepts. Fast Fourier Transforms avoid the solution delays caused by iterative implicit methods.

\section{Limitations}

1. Maximum cell gas temperature gradients are limited by the Boussinesq approximation made in the numerical solution technique of the 
finite-difference equations. This limits the current version of the code to low oxygen environments (less than $4 \%$ oxygen).

2. The current version of the code has a limited application to cell venting studies.

\section{Future Efforts}

1. Extend maximum allowable cell gas temperature gradient by removing the Boussinesq approximation.

2. Allow venting of the gas in the burning cell to an adjacent cell.

3. Incorporate pool burning model to describe oxygen transport to sodium pools formed due to agglomeration of sodium droplets.

\section{Computer Operation}

1. The code will be operational on the following computers: AI-IBM $370 / 168$ os/vs and LBL CDC-7600.

2. Logistics:

\section{$\underline{\text { IBM }}$}

Core Memory

Mode of Operation

Programming Language

Compiler

Plotting Sof tware
$410 \mathrm{~K}$ bytes

Batch

Fortran

Fortran IV Extended

SC 4020

$\underline{\mathrm{CDC}}$

3. Typical Problem Running Time:

a. Preliminary estimate of the central processor running time: IBM s370 - six minutes and CDC-7600 - two minutes.

b. Problem Description: A sodium spray fire results from a partial pipe break in a heat transfer equipment vault of dimensions 50-ft. high $x$ 66-ft. diameter. The gas environment was initially $2 \%$ oxygen at 1 atm. and $300^{\circ} \mathrm{K}$. The spray injection follows a pump coastdown curve for six seconds. Sodium spray droplet size is $1 / 3-\mathrm{cm}$. diameter at $811^{\circ} \mathrm{K}$.

c. The sodium spray droplet falling and combustion section are the major time consumers. 
4. Code Validation: See Progress report, LMFBR Safety Task 10 , "Characterization of Sodium Fires and Fission Products." AI-ERDA13196 (1977).

Interface/Overlap

SOFIRE/SPRAY

\section{References}

1. M. P. Heisler, "Status Report on SOMIX Development," TI-707-130-028, 1973.

2. N. Frossling, Gerlands Beitr. Geophysics, 52, 170 (1938).

3. M. P. Heisler, K. Mori, "SOMIX-1 Users Manua1," N707TI130045, dated June 30,1977 . 
SPOOL-FIRE

\section{Purpose}

The computation of the pressure and temperature within a containment building as a result of a sodium fire which has both pool and spray characteristics. Further details are given in Reference 1 .

\section{$\underline{\text { Status }}$}
A. Development:
Al1 versions were developed at ANL/RAS. Current development version is SPOOL-FIRE II.
B. Availability: The versions of SPOOL-FIRE which has been or are in the process of being made optional are: SPOOL-FIRE: Released in 1976 and was available through Argonne code center 1977. SPOOL-FIRE II: Developmental at ANL on IBM 370 and no release date set.
C. Utilization: The SPOOL-FIRE code [2,3] has provided design criteria for the containment building of an advanced reactor to be used for the transient testing of LMFBR subassemblies in sealed experi- ment loop configurations, and it could be adapted and used for fusion a reactor safety study of Lithium and air reaction.

\section{Problems Solved}

The SPOOL-FIRE code is a treatment of a combined spray-pool fire. The spray fire is assumed to occur instantaneously and the pool fire is assumed to occur subsequently. The pool fire calculation is a modified version of SOFIRE-II [4]. The user specifies the amount of sodium available for spray or pool fire, the geometry of containment vessel, the sodium combustion rate, the radiative, conductive, and convective heat transfer properties between containment atmosphere, sodium pan, concrete wall and floor, and the environment conditions. The history of pressure and temperature of containment structure as well as leakage of the containment atmosphere can be evaluated. 
Mode1s

A. Spray Fire

1. The quantity of sodium ejected as a spray is assumed to react instantaneously and stoichiometrically with the oxygen in the surrounding atmosphere.

2. The heat of reaction is apportioned among the reaction products, the nitrogen in the atmosphere, and the remaining oxygen, in accordance with their heat capacities; a uniform equilibrium temperature for the mixture is assumed.

3. The pressure in the enclosure increases according to the ideal gas law, with a correction for the oxygen-depletion effect.

\section{B. Pool Fire}

SPOOL-FIRE uses the pool-burning model developed by Atomics International and incorporated in the code SOFIRE-II [4]. Conventional equations of heat transfer by conduction, convection, and radiation are used to perform heat balances and compute temperatures. The SOFIRE-II model assumes that the sodium burning rate is proportional to the rate of diffusion of oxygen to the pool surface. The reader is referred to the AI report for a discussion of the pertinent equations and models [4]. The major departure from the SOFIRE-II models in this work is in the computation of containment temperatures as a function of time. The models of these calculations are discussed below.

\section{Containment Model}

Since SPOOL-FIRE was constructed specifically for utilization in the design of a new reactor facility, no attempt was made to generalize all the possible containment options, e.g., sealed vs. vented. The mechanics involved in problem solution are greatly simplified through the use of the IBM CSMP simulation methodology [5]. As a result, the user can make code modifications relatively simply by adding or modifying differential equations at will to describe a particular physical situation not considered in the present model.

D. Containment Leakage Mode1

One of the goals of this analysis is to calculate the leakage of radioactivity from the containment building under a driving 
pressure created by the energy from a sodium fire. The basic assumptions are:

1. The leak rate characteristic of the containment does not change over time; that is the flow-pressure drop relationship is applicable over the entire pressure range.

2. The gas density is independent of the pressure.

\section{$\underline{\text { Limitations }}$}

Current limitations of SPOOL-FIRE are:

1. No treatment of nitrogen injection for fire suppression or extinguishment.

2. No treatment of sodium-concrete reactions.

3. Sodium mass diffusion limited to free convection.

4. Thermophysical properties are temperature-independent.

\section{Future Efforts}

1. To replace the KAPL ROPE program by a faster running program called ROOT [3]. These programs give the solutions for high order polynomials.

2. Link with PROSA computer code $[6,7]$ in statistical parametric analyses of sodium fire so that the practicing engineers can make best estimate from available data.

\section{Computer Operation}

1. IBM $370 / 195$

2. Logistics: $178 \mathrm{~K}$ Bytes of Memory. FORTRAN IV and CSMP are the programming languages used.

3. Typical Problem Running Time: In a typical problem of a fire involving a spray $907 \mathrm{~kg}$ for sodium spray and $3629 \mathrm{~kg}$ for a sodium pool in a containment building with a volume of $34,547 \mathrm{~m}^{3}$ was calculated. The calculation required 146,500 steps to obtain pressure-time histories through 8.5 days of real time. The computer time required for this calculation was 5.5 minutes of CPU time. 
4. Code Validation: Theoretical calculations have been compared to experiment $[2,3]$.

Interface/Overlap

PROSA [7] /SPRAY [9]

\section{$\underline{\text { References }}$}

1. I. Charak and L. W. Person, "SPOOL-FIRE - An IBM 370/195 Code for the Analysis of Combined Spray and Pool Burning of Sodium" Argonne National Laboratory, presented at the Int. Mtg. on Fast Reactor Safety and Related Physics, Chicago, Illinois, Octtober 5-8, 1976.

2. L. W. Person, "Using SPOOL-FIRE for Sodium Fire Study" Trans. Am. Nuc1. Soc. 24, p. 254, November 1976.

3. L. W. Person "The Application of SPOOL-FIRE in Theoretical Analysis and Experimental Comparison" Nuclear Technology $\underline{32}$, p. 320 (1977).

4. P. Beiriger et. al. "SOFIRE-II User Report AI-AEC-13055 (March 30, 1973).

5. International Business Machines Corporation, "Continuous System Modeling Program III (CSMP III) -- Program Reference Manual, Program Number 5734-XS9, Publication No. SH19-TOO1-2. Third Edition (September 1972).

6. L. W. Person and J. K. Vaurio, "Statistical Parametric Analysis of Sodium Fire" to be submitted to the 1977 ANS Winter Meeting, San Francisco.

7. J. K. Vaurio and C. Mueller, "A Probabilistic/Deterministic Procedure for Analyzing LMFBR Core Disruptive Accidents" presented at the Int. Meeting on Fast Reactor Safety and Related Physics. Chicago, Illinois, October 5-8, 1976.

8. B. U. B. Sarma, et. al., "Review of Sodium Fire Analytical Models GEAP-14053, General Electric Company (June 1975).

9. P. R. Shire, "Reactor Sodium Coolant Hypothetical Spray Release for Containment Accident Analysis: Comparison of Theory with Experiment," Proc. Fast Reactor Safety Mtg., Beverly Hills, California, April 2-4, 1974, p. 474 (1974). 
SPQR

\section{Purpose}

The purpose is to study the neutronics behavior of a fast reactor core during a HCDA using Monte Carlo to simulate the time dependent core disassembly in three dimensions.

\section{Status}

A. Development: The first version of $S P Q R$ is being developed at ORNL.

B. Availability: An adiabatic version of the code with no feedback is operational on the $360 / 95$ at ORNL. Quasistatic and feedback models are being developed.

C. Utilization: The operational code is currently being used to calculate sample problems for comparison with TDA ( $t$ ime dependent ANISN).

Problems Solved

The code is being developed to give three-dimensional neutronics capability to HCDA analysis. It is intended to replace one- and two-dimensional diffusion/transport neutronic modules in existing safety analysis code packages.

\section{Models}

SPQR is a quasistatic code which uses the Monte Carlo method to calculate the shape functions. This Monte Carlo portion is a modification of the MORSE multigroup code. A conventional delayed neutron module has been coupled with the Monte Carlo to form a quasistatic treatment.

\section{Limitations}

The current operational version is an adiabatic approximation of the quasistatic method and is limited to super-prompt critical excursions; no feedback, except delayed neutrons, is available.

\section{Future Efforts}

Future efforts will involve the inclusion of the complete quasistatic treatment. $S P Q R$ will be coupled to existing thermodynamic and 
hydraulic codes to facilitate geometry changes as well as the inclusion of neutronic feedback.

\section{Computer Operation}

1. The current version is operational on the $360 / 95$ at ORNL.

2. The core memory can vary from 300 to $1500 \mathrm{~K}$ bytes depending primarily on the cross section information to be stored. All computer requirements are essentially those of the MORSE code.

3. The running time of the code is proportional to the number of energy groups, the extent of the system in neutron mean free paths, the number of shape functions to be calculated, and the desired statistical uncertainty in the shape function distributions. Typical running time on a 1-D sample problem is on the order of one hour. However, this time would not increase for these problems if they were calculated in three dimensions as would be the case for either transport or diffusion codes.

4. The SPQR sample problem solutions are being compared with those from TDA.

Interface/Overlap

FX2/MORSE

\section{References}

1. M. B. Emmett, "The MORSE Monte Carlo Radiation Transport Code System," ORNL-4972 (1975).

2. ORNL LMFBR Safety and Core Systems Monthly Progress Reports. 
SPRAY

\section{Purpose}

Analysis of sodium spray fire accidents in low-oxygen or air atmosphere equipment and pipeway cells as the consequence of postulated piping leaks in LMFBR's.

\section{$\underline{\text { Status }}$}

A. Development: Developed at HEDL, current version is SPRAY-III (June 1, 1977).

B. Availability: Obtainable from ANL Code Center. The code is operational at GE - BRD, at HEDL on the CYBER-74 and at BNL (CDC-7600).

C. Utilization: Used in FFTF FSAR and CRBR PSAR sodium spray fire analysis. Reference document is "SPRAY Code Users Report," HEDL-TME 76-94.

\section{Problems Solved}

Calculates, for cells containing initial gas atmosphere up to $21 \%$ oxygen and $100 \% \mathrm{R} \cdot \mathrm{H}$. the temperature and pressure history of the cell gas and the cell structure transient thermal response resulting from a sodium spray fire accident.

\section{$\underline{\text { Models }}$}

\section{Geometry}

Cell is modeled as a cylindrical enclosure. An option allows venting of the gas in the spray containing cell to an adjacent cell. The most severe spray release modes are modeled with the code technique.

\section{Sodium Burning Dynamics}

The code performs the thermodynamic, heat transfer, mass transfer and sodium droplet combustion calculations for droplets falling through a conical volume in a gravitational field.

\section{Gas Circulation}

Gas entrainment by sodium droplets results in one-dimensional gas convection with turbulent cross-flow correlation. 
4. Additional features provided by SPRAY-III version.

- Input of SIGMA provides for lognormal droplet size distribution.

o Unburned sodium droplets form a pool on floor with heat transfer to gas and walls.

- Continuous oxygen concentration range from $0-21 \%$ treated with one theory of sodiumn combustion.

- Sodium-water vapor reaction explicitly included in combustion mode1.

\section{Limitations}

1. Cell liner perfectly insulated on outside.

2. Spray filled volume must be $<100 \%$ of cel1 volume.

3. Cylindrical cell geometry; imperfect mixing caused by corners and interior components is neglected.

Future Efforts

Additional verification and model improvnent as applicable experimental results become available.

Interface/Overlap

SOFIRE/SOMIX, CACECO

\section{References}

1. P. R. Shire, "SPRAY Code Users Report," HEDL-TME 76-94, March 1977.

2. P. R. Shire, "A Combustion Model for Hypothetical Sodium Spray Fire Within Containment of a LMFBR," M. S. Thesis, 1972. 


\section{Purpose}

Analysis of transient neutronic-thermal-hydraulic behavior due to plantwide events with operability of the reactor scram system.

\section{$\underline{\text { Status }}$}

A. Development: Under development at BNL.

B. Availability: Is developmental on $\mathrm{CDC}-7600$; various modules of the code are operational at BNL. The pre-accident modeling and programming for the entire plant are reported in Ref. 1. Progress in code development has been reported in various progress reports (Refs. 2 through 9). A first version for calculating transient response for the loop-type LMFBRs is expected to be available on or before April 1, 1978.

C. Utilization: When completed, various versions of the SSC will provide an advanced computational tool for analysis of plant-wide events. It will be utilized by NRC for an independent confirmatory assessment of applicants' position.

\section{$\underline{\text { Problems Solved }}$}

SSC (Super System Code) is being designed to simulate thermal-hydraulic response of the entire plant when subjected to various off-normal and accident conditions. Examples of events include (1) pipe break up to and including a double-ended rupture in the primary heat transport system of a loop-type LMFBR, (2) after-heat removal in absence of any forced pumping power at short to intermediate to long-term durations, and (3) a variety of thermohydraulic transients that may be encountered in operation of a power plant. In all of these events, the plant protection system (PPS) is assumed to be functioning per its design.

The SSC series of codes have a built-in self-starting capability. In other words, pre-accident or steady-state calculations for the entire plant are performed by the code on the basis of the users' specifications of the plant design and operational data. The transient calculations for power, pressure, flow rate and temperatures are performed by inputting a forcing function (for example, loss of power to pumps). These calculations are continued up to the point of reaching melting temperature of the 
cladding material. Explicit calculations for the release of fission gas from the plenum of a fuel pin into the coolant channel and sodium boiling are performed.

\section{Models}

The SSC series of codes are structured in a modular fashion. Models for components/processes are interfaced with other modules to provide for an integrated, advanced thermohydraulic transient code. Specific series of codes, under various stages of development, include SSC-L for loop-type LMFBRS, SSC-P for pool-type LMFBRs and SSC-S for an eventual heat sink version. The SSC-S differs from the SSC-L in two major ways: (1) it is designed for simulating transients that can range over a period of hours and days and (2) auxiliary heat removal paths and circuits are added. All of these series of codes employ the following basic modules: neutronics, fuel heat transfer, coolant dynamics, flow in pipings, intermediate heat exchanger, pump, steam generator.

\section{Neutronics}

Explicit calculations for time-dependent power generation in fuel and blanket rods are performed. The power generation is expressed as a sum of fission and decay heating rates. A point kinetics model (one-energy group, space-independent) is used to describe fission heating rates. In addition to the input reactivity (due to control rods), the reactivity feedback from (a) Doppler, (b) coolant density/ voiding, and (c) axial and radial expansion of fuel and structural material is considered. The decay heating rates are dependent upon the type of rod. Gamma heating and heating by neutron absorption $(n-\gamma)$ in cladding, coolant, structural material and bypass flow are also explicitly included.

\section{Core Modeling}

The entire reactor core is represented by a user-specified number of parallel, one-dimensional channels. These channels can either be heat producing or nonheat producing. With this flexibility, both homogeneous and inhomogeneous cores can be modeled. This representation also permits inclusion of blanket assemblies with different burnups. Explicit representation of "hot," "peak," "average" and "cold" channels, thus, is possible. The bypass flow between the thermal liner and the reactor vessel is also included. Shield and control assemblies can also be included.

In the SSC-L code, all of these channels are coupled with each other through (a) inlet and outlet plena and (b) neutronically. In 
the SSC-S code, interchannel heat transfer may be required. In that case, this process will be an added coupling mode.

\section{Fuel Heat Transfer}

The heat conduction equation for a generalized fuel rod is solved in an axisymmetric, cylindrical geometry. The axial heat conduction is neglected. The fuel rod consists of five different axial regions: lower fission gas plenum, lower blanket, active fuel, upper blanket and upper fission gas plenum. Any one or more of these regions may be ontted simply by controlling input numbers. The heat-producing reglon is divided radially and axially into meshes. Prior to inftiating transients, an option for calculating restructuring in both fuel and blanket materials is provided for. The thermal expansion of fuel and cladding is calculated at steady-state as well as during transients. Thus, the gap between the fuel and cladding is computed as a function of tine. The heat transfer across the gap between the fuel and cladding is computed by including (a) conduction through a mixture of fill gas and fission gases, (b) thermal radiation and (c) the free convection of gases. When the gap is closed, a direct input of the contact conductance is required. The effect of spacer wire and other structural material (hexagonal can wall of the assembly) on heat transfer is included. The temperature dependence of all properties is considered.

\section{Coolant Dynamics}

This module provides for thermal and hydraulic calculations in the entire vessel. The reactor vessel is represented by (a) a lower inlet plenum, (b) "extended" core, (c) bypass channel and (d) upper outlet plenum. The "extended" core consists of a number of parallel channels, as noted above. The continuity, momentum and energy conservation equations are solved in all of these regions. The single-phase models are used everywhere except for a single-bubble slug model for boiling in the extended core. The interchannel flow redistribution before and after boiling initiation is computed. In these calculations, flow-regime-dependent friction factor and heat transfer correlations are used. This module also includes an explicit calculation of consequences due to the release of fission gases from a fuel pin in its associated coolant channel.

\section{Coolant Mixing in Outlet Plenum}

The mixing of coolant from different assemblies with that in the outlet plenum is represented by up to a two-zone mixing model. This model computes the jet penetration zone, which can then be used to 
divide the coolant in the outlet plenum into two zones. In each of these two zones, a complete mixing model is used. Alternately, a single, complete mixing model can be used. The presence of structural material and bypass $f$ low is accounted for.

6. Flow in Piping

The coolant flow in pipings of the primary and intermediate heat transport systems (PHTS, IHTS) is calculated by solving conservation equations for incompressible fluid in one space dimension. The heat capacity of pipings is considered in transients. The momentum conservation equations include pressure changes due to acceleration/ deceleration, gravity, frictional and area changes. The friction factor is considered to be flow-regime dependent. In the case of the eventual heat sink version (SSC-S), the heat conduction through pipings, insulation and ambient is included.

7. $\quad$ Pump

A homologous model for the pump in the PHTS and IHTS is incorporated. The sodium pump is a centrifugal free surface pump. The pump is divided into impeller and pump tank portions. The cover gas of the pump tank is connected with a reservoir that can also be connected with the cover gas in the reactor vessel. The angular momentum balance for the impeller relates the rate of change of impeller speed to net acting torque. The energy equation gives rise in coolant temperature.

8. Intermediate Heat Exchanger

The heat exchanger is divided into inlet and outlet plena and the heat transfer region. A perfect mixing model for the plena is used. The energy conservation equation in the heat transfer region $f$ or the primary and secondary coolant is coupled with the tube wall. In the momentum equation, pressure changes due to acceleration/deceleration, friction, gravity, inlet/outlet and others are accounted for.

9. Check Valve

A model for the check valve is also included.

\section{Pipe Break}

The discharge of a subcooled fluid (sodium) from a pipe into the outer pipe or guard vessel is modeled. Two types of models are available: a free-jet flow and a confined flow mode1. The models can be used for pipe breaks of any size. 


\section{Steam Generating System}

A momentum integral model for calculating hydraulics in the steam generating system is adapted. Both once-through and a recirculation type of steam generator can be used. Detailed models for piping, heat exchanger, pump and volume nodes are provided for. The turbine condenser and the feedwater systems are modeled in a simple way.

\section{Limitations}

A11 of the models developed for the SSC series of codes assume that the plant protection system is available and operative per design. Currently, modeling and computations are carried up to the time of reaching melting point of the cladding. Only intact steam generators are considered. In other words, break or leakage of water/steam tube and the resulting interaction with sodium are not considered.

\section{Future Efforts}

These include development of a first version of the SSC-S and SSC-P codes. The plant protection and control systems in a generalized format will be incorporated.

Interface/Overlap

/DEMO

\section{$\underline{\text { References }}$}

1. A. K. Agrawa1, et. a1., "Preaccident Modeling of an LMFBR Plant for SSC-L," Brookhaven National Laboratory, BNL-NUREG-50602, December 1976.

2. A. K. Agrawal, et. a1., "SSC: An Advanced Thermohydraulic Transient Code for LMFBRs," Quarterly Progress Report, July-September 1975, Brookhaven National Laboratory, BNL-50467, October 1975.

3. A. K. Agrawa1, et. a1., "SSC: An Advanced Thermohydraulic Transient Code for LMFBRs," Quarterly Progress Report, October 1-December 31 , 1975, Brookhaven National Laboratory, BNL-50502, April 1976.

4. A. K. Agrawal, et. al., "SSC: An Advanced Thermohydraulic Transient Code for LMFBRs," Quarterly Progress Report, January 1-March 31, 1976, Brookhaven National Laboratory, BNL-NUREG-50527, July 1976. 
5. A. K. Agrawa1, et. al., "SSC: An Advanced Thermohydraulic Transient Code for LMFBRs," Quarterly Progress Report, April 1-June 30, 1976, Brookhaven National Laboratory, BNL-NUREG-50543, September 1976.

6. A. K. Agrawal, et. al., "SSC: An Advanced Thermohydraulic Transient Code for LMFBRs," Quarterly Progress Report, July 1-September 30 , 1976, Brookhaven Nationa1 Laboratory, BNL-NUREG-50607, December 1976.

7. A. K. Agrawal, et. al., "SSC: Code Development" in Reactor Safety Research Programs Quarterly Progress Report, October 1-December 31, 1976, Brookhaven National Laboratory, BNL-NUREG-50624, pp. 169-199, February 1977.

8. A. K. Agrawal, et. al., "SSC: Code Development" in Reactor Safety Research Programs Quarterly Progress Report, January 1-March 31, 1977, Brookhaven Nationa1 Laboratory, BNL-NUREG-50661, pp. 101-124, May 1977.

9. A. K. Agrawa1, et. al., "SSC: Code Development" in Reactor Safety Research Programs Quarterly Progress Report, Apri1 1-June 30, 1977, Brookhaven National Laboratory, BNL-NUREG-50683, pp. 127-138, August 1977 . 
STRAW

\section{Purpose}

Analysis of a single core subassembly hydrodynamic-structural response to local pressurization and/or thermal loading accidents and the interaction of the accident subassembly with its surroundings.

\section{Status}

A. Development: Developed and under improvement by ANL/RAS.

B. Avallability: Operational at ANL on IBM 370. Documentation is available (Ref. 1-3).

C. Utilization: Has been used for FFTF and CRBR safety analysis. Comparison with experiments has been performed for EBR-II and FFTF ducts.

\section{Problems Solved}

2-D analysis of subassembly transient response to rapid pressurization and the transmittal of the pressure loading to adjacent subassemblies. Thermal or thermal-mechanical response of accident and/or adjacent subassemblies are also analyzed. The structural damage to the accident subassembly duct is determined as well as the potential for subassemblyto-subassembly damage propagation. It employs a finite-element method which is valid for large-displacement, small-strain problems with material nonlinearities.

Some capabilities of STRAW are:

1. Interaction of accident subassembly with surrounding: STRAW analyzes the interaction of the accident duct with the surrounding subassembly structures and with the between-subassembly fluid. Plane (i.e., within the duct cross section) and axial (i.e., perpendicular to the duct cross section) compressible fluid motion are calculated within and between ducts.

2. Pressure source: the driving internal pressure may be input or internally calculated with an FCI model.

3. Treatment of long-duration accidents with an implicit temporal integration formulation. 
4. Thermal effects: can analyze a structure subjected to variable inside and outside temperature distributions (as a duct wall subjected to a high heat flux from molten fuel) and determine thermal stresses. Young's modulus and yield surface may be temperature dependent.

Models

1. Geometry

The standard LMFBR geometry is a unit height cross-section of a hexagonal subassembly and its surroundings with no axial dependence.

2. Governing Equation

Analysis is based on the finite-element method which uses a convected coordinate technique (each element being associated with a coordinate system which rotates with that element) and a direct nodal force computation scheme for the internal nodal forces. Three types of elements are included: the flexural-beam element (for modeling of duct walls), the continuum element (for modeling of internals) and the hydrodynamic element (for modeling of fluids). All elements can handle arbitrarily large rotations and translations, although the continuum element is restructed to small deformations. The beam element includes a correction for the change in cross-sectional area based on complete incompressibility of the material. The beam element material is considered elastic-plastic with linear, isotropic, strain-hardening properties. The continuum element material is linear, isotropic and elastic. The hydrodynamic element is presently linear and hydrostatic.

The governing finite-element equations for the beam element are based on the derivations of Belytschko and Hsieh (Ref. 4) and those for the continuum element are based on the formulation of oden (Ref. 5). The hydrodynamic equations are based on derivations by Kennedy and Belytschko (Ref. 1).

\section{Method of Solution}

The governing equations may be solved using an implicit or an explicit temporal integration scheme. The implicit scheme allows the calculation of long-duration transients, static analysis and thermal stress analysis since a strict stability limitation is not imposed on the time-step size, as is required for the explicit case. In the explicit case, lumped masses are used to represent the inertial properties of the structure, continuum and fluid, while the implicit scheme uses a consistent mass mode of calculation. 


\section{Axial Fluid Flow}

A superimposed model of axial flow (i.e., perpendicular to the duct cross section) calculates the axial compliance of the duct internals. The axial flow of fluid above the pressurization zone is resisted only by the viscous shear stresses exerted by the fuel pin walls and the inertia of the fluid. This axial flow is modeled by super elements which are coupled to the 2-D plane hydrodynamic model of the subassembly cross section.

\section{Heat Transfer}

An FCI model, identical to REXCO-HT (See REXCO summary) is available as an option.

\section{Limitations}

1. Geometry is restricted to $2-D$.

2. Subassembly internal structure is assumed to behave like a homogenized material.

3. The implicit integration mode cannot be used with the sliding interface or rotated coordinate option that is available in the explicit mode.

\section{Future Efforts.}

1. Eliminate limitation number 3 .

2. Develop mathematical model for fuel $p$ in bundle response to treat distinct regions of fuel and sodium.

3. Develop models for subassembly impact, fracture effects and fuel pin stress analysis.

4. Develop more interactive models to simulate $3-D$ effects.

\section{Interface/Overlap}

- /SADCAT

\section{$\underline{\text { References }}$}

1. J. M. Kennedy and T. Belytschko, Energy Source and Fluid Representation in a Structural Response Code--STRAW, ANL-8140

(November 1974). 
2. D. F. Schoeberle, et. al., Implicit Temporal Integration for LongDuration Accidents in a Structural Response Code--STRAW, ANL-8136 (October 1974).

3. J. M. Kennedy, Non1inear Dynamic Response of Reactor-Core Subassemblies, ANL-8065 (January 1974).

Beam Element

4. T. Belytschko and B. J. Hsieh, "Nonlinear Transient Finite-Element Analysis with Convected Coordinates," Rep. 72-7, Dept. of Materials Engr., U. of I11. at Chicago Circle (1972).

\section{Continuum Element}

5. J. J. Oden, "Finite Elements of Nonlinear Continua," McGraw-Hill, Inc., New York (1972).

Hydrodynamic Element

6. Same as 1 . 
SLBBDOSA

\section{Purpose}

Estimation of external doses resulting from accidental releases of radionuclides to the atmosphere.

\section{Status}

A. Development: Developed at Battelle Northwest Laboratories.

B. Availability: Documented in 1975 as BNWL-B-351 (Ref. 1). It is operational at BNWL and runs on a CYBER 74 machine.

C. Utilization: SUBDOSA has been use: in calculating the external dose to indivi luals potentially residing in the vicinity of various fuel-cycle facilities at the time of a postulated accident.

\section{Problems Solved}

SUBDOSA calculates the dose from airborne radionuclides external to the body as the result of an accidental release.

1. Doses are calculated as a function of: quantity released, duration of release, atmospheric conditions during release, and horizontal distance from the release point.

2. Doses are computed for skin, eye, total body, and male gonads for beta Irradiations and for total body, surface tissue and subsurface tissues for gamma irradiation.

3. Radionuclide decay is calculated for each radionuclide based on travel time to the exposure point. This concentration is used for all downwind integration points which exceed $800 \mathrm{~m}$ from the point of exposure.

4. The plume concentration at a vertical position $z$ and lateral position $\mathrm{y}$ is calculated via a standard Gaussian dispersion model for which various values may be chosen to represent $\sigma_{y}$ and $\sigma_{z}$.

5. Doses are calculated for releases within each of several release time intervals. Up to six time intervals can be allowed and 
separate nuclide inventories and atmospheric dispersion conditions are considered for each time interval.

Models

1. The total body tissue dose from gamma radiation is calculated using a model which considers the photon energy, the dose buildup factor for air, the total linear attenuation coefficient in air, and the mass absorption coefficient for various gamma energy groups.

2. The incremental dose is calculated separately as a function of photon energy and integrated over the cloud volume to obtain dose rate factors for each energy group. The cloud is considered to be finite.

3. The only time-dependent parameter is the release rate.

4. The nuclide decay scheme accounts for chain decay including transitions to and from isomeric states.

5. The attenuation of gamma dose with tissue penetration is also considered.

6. For beta particles in air, the radionuclide cloud is assumen to be semi-infinite. A factor 0.5 is applied to account for selfshielding from half of the cloud.

7. Data libraries include data on 331 fission products plus 144 activation products, including transuranic elements. Effective beta energies have been calculated for each of these nuclides for tissue depths of $0,7,20$, and $100 \mathrm{mg} / \mathrm{cm}^{2}$.

8. The skin dose is the sum of the surface gamma dose and the beta depth dose at $7 \mathrm{mg} / \mathrm{cm}^{2}$. A tissue depth of $1 \mathrm{~cm}$ is assumed to be representative for estimating the dose to the male gonads. The total body dose is calculated as the gamma dose at a tissue depth of $5 \mathrm{~cm}$ with no beta contributions included.

\section{Limitations}

1. Shielding of buildings are not taken into account.

2. Building wake effects are not considered. 
3. Atmospheric dispersion models do not include an upper boundary or lid for long-range dose calculations.

4. The code is primarily useful for calculating doses from about one to six miles from the source of release.

5. Spatial and temporal changes in meteorological conditions cannot be readily considered by the models which handle atmospheric dispersion.

\section{Future Efforts}

No future efforts planned at present.

Interface/Overlap

DACRIN/EXREM.

\section{References}

1. D. L. Strenge, E. C. Watson, and J. R. Houston, "SUBDOSA - A Computer Program for Calculating External Doses from Accidental Atmospheric Releases of Radionuclides," BNWL-B-351, UC-11, June 1975. 


\section{SUPERENERGY-II}

\section{Purpose}

Analysis of bundle or multibundle single phase thermal hydraulic behavior (Forced Convection) under transient conditions.

\section{$\underline{\text { Status }}$}

A. Development: All versions currently under development by MIT Departments of Nuclear and Mechanical Engineering.

B. Avallability: The versions of the code which are in the process of being made operational are as follows:

SUPERENERGY-IIa: Multibundle code. Developmental at MIT. Scheduled release date - September 1977.

SUPERENERGY-IIb: Single bundle code. Development at MIT. Scheduled release date - September 1977.

C. Utilization: All versions in development phase - see next section.

\section{Problems Solved}

The two versions of the code currently under development will predict the single phase thermal hydraulic behavior of the subassembly coolant under power or flow transient conditions. The multiassembly version will handle up to a twelfth core sector, modeling each of the 39 coupled subassemblies in a coarse seven pin assembly nodal arrangement. The single assembly version will be ordered in a fine subchannel mesh so that the fine coolant temperature profile can be seen. Both versions will include user options to specify additional heat flux or temperature bounding conditions and the inclusion of an interassembly flow path.

Models

Both versions of the transient code use similar models. The energy mixing model is based on the steady state ENERGY model (see reference section) developed at MIT. This model uses correlated enhanced eddy diffusivity of heat and swirl flow velocity empirical input parameters to move the energy between bundle subchannels. For the transient codes, this model is connected to a $1-D$ (radial) finite differenced fuel model. Since the fuel model is not of primary interest but only used as a means 
to approximate the fuel transient characteristics to the coolant, the fuel axial nodal capacity is limited to improve running time and storage requirements.

\section{Limitations}

The computer code limitations:

1. Axial step size is limited by stability criteria resulting from the explicit differencing method used.

2. The time step size is limited by the Courant condition and therefore by axial stability.

3. No two phase models are included.

4. Flow conditions are limited to forced convection flows by a modified Grash of criteria which predicts when buoyancy effects become important.

\section{Future Efforts}

Evaluation planned when codes reach operational stage.

\section{Computer Operation}

1. Computer: The codes are in the developmental stages on an IBM $370 /$ computer.

2. Logistics: The codes are programmed in FORTRAN for the use in batch processing. No special peripherals are necessary. The anticipated core storage required for the most complex possible case is less than $1500 \mathrm{~K}$ bytes.

3. Running Times: Running times have not been established, but based on steady state code experience with SUPERENERGY (1), they should by very fast.

4. Code Validation: Validation is in two stages.

a. the physical model of the ENERGY method is compared to isolated assembly test data $(5,6)$;

b. comparison of transient code behavior with COBRA, which has been adjusted to provide matched steady state results. 


\section{Interface/Overlap}

None

\section{$\underline{\text { References }}$}

\section{Steady State}

1. B. C. Chen, N. E. Todreas, "Prediction of Coolant Temperature Fields in a Breeder Reactor including Interassembly Heat Transfer," MIT Department of Nuclear Engineering, CO0-2245-20TR Revision 1, May 1975.

2. E. U. Khan, W. M. Rohsenow, A. A. Sonin, N. E. Todreas, "A Porous Body Model for Predicting Temperature Distributions in Wire Wrapped Fuel and Blanket Assemblies of a LMFBR," MIT Departments of Mechanical and Nuclear Engineering, COO-2245-16TR, June 1975.

3. E. U. Khan, W. M. Rohsenow, A. A. Sonin, N. E. Todreas, "Input Parameters to the ENERGY Code (to be used with ENERGY Codes Manual)," MIT Departments of Mechanical and Nuclear Engineering, CO0-2245-17TR, May 1975.

4. E. U. Khan, W. M. Rohsenow, a. A. Sonin, N. E. Todreas, "Manual for ENERGY I, II, III Computer Programs," Departments of Mechanical and Nuclear Engineering, CO0-2245-18TR Revision 1, May 1975, July 1976.

5. E. U. Khan, N. E. Todreas, W. M. Rohsenow, A. A. Sonin, "Analysis of Mixing Data Relevant to Wire Wrapped Fuel Assembly Thermal-Hydraulic Design," MIT Departments of Mechanical and Nuclear Engineering, COO-2245-12TR, September 1974.

6. F. Carre and N. Todreas, "Development of Input Data to ENERGY Code for Analysis of Reactor Fuel Bundles," Co0-2245-2 ITR, May 1975.

\section{Transient}

7. N. E. Todreas, M. Golay and L. Wolf, "Coolant Mixing in LMFBR Rod Bundles and Outlet Mixing Transients," Progress Report, CO0-2245-34, December 1976.

8. N. E. Todreas, M. Golay and L. Wolf, "Coolant Mixing in LMFBR Rod Bundles and Outlet Mixing Transients," Progress Report, C00-2245-38, March 1977.

9. R. Masterson, N. Todreas, "Analysis of the Feasibility of Implementing and Implicit Temporal Differencing Scheme in the SUPERENERGY Code," CO0-2245-35TR, February 1977. 
SUPORAN

\section{$\underline{\text { Purpose }}$}

The effort was initiated to provide a structural analysis for an EBR-II type core support structure consisting of two concentric circular plates, one above the other, and interconnected by tubes which serve as recepticles for the fuel subassemblies. The program was subsequently made more generic treating single plates, without interconnecting tubes, with thermal effects, and a variety of end constraints.

\section{Status}

A. Development: Developed at ANL

B. Availability: SUPORAN was first written for the CDC computer system and since has been converted to the IBM 370. The original version of SUPORAN is available from the Argonne Code Center. An improved version is also available at ANL.

C. Utilization: The code was used to analyze the EBR-II structure under the applied load, and also yield the deformation of the support structure under assumed aging conditions. It also has been used in the design of conceptual commercial pool-type reactor design.

Problems Solved

Analysis of a structure composed of two concentric circular plates, one on top of the other, spaced at a finite distance apart, and interconnected by tubes and/or circular cylindrical shells. The two plates may have varied penetrations, thicknesses, and other properties. Semi-infinite cylindrical shells can be used with the two-plate structure at the edges, where they could be part of the containment vessel, or a intermediate locations, simulating internal vessels.

Arbitrary static pressure loading can be imparted to the structure between the two plates or on the outside of the core support structure. Temperature differences can also be prescribed across the surfaces of the structure to establish the resultant deformation and the state of stress. 


\section{Mode1s}

1. Geometry

Axisymmetric structure.

2. Method of Solution

The solution is accomplished by the individual structural components: (a) annular plates, (b) tubes (beams with circular cross-section) and (c) thin semi-infinite circular shells. When the structure is prescribed in the input as a composite of individual components, the unknown internal forces between the components are internally solved for by matrix inversion.

\section{Boundary Conditions}

The edges of the two plates may have different boundary conditions: (a) the bending constraint extending from fixed to free, may be prescribed, or (b) the plate edges may be imbedded into an infinite she11 - simulating the joint between the two plates with walls of the primary vessel.

\section{$\underline{\text { Limitations }}$}

Loading is static; the material deforms elastically; the overall structure undergoes small deformations.

The limitations are primarily controlled by the assumptions within the individual components - pure bending of plates and the beam theory.

\section{Future Efforts}

None planned - although the addition of a connical shell was suggested by the users. The shell would serve as a skirt connecting the core support structure to a large primary pressure vessel.

Interface/Overlap

\section{$\underline{\text { References }}$}

1. A. H. Marchertas, Stress Analysis of a Reactor Core Support Structure Consisting of Two Interconnected Multiregion Plates, ANL-7162, (June 1967). 
2. A. H. Marchertas, Stress Analysis of a Reactor Core Support Structure Consisting of Two Interconnected Multiregion Plates, ANL-7162 Supplement (March 1968). 
SUPWAN

\section{Purpose}

SUPWAN is being developed to perform a 1-D analysis of pressure pulse propagation in a piping network wherein the pipe walls may experience plastic strain and wherein cavitation may occur.

\section{$\underline{\text { Status }}$}

A. Development: Developed at HEDL. SUPWAN is current version.

B. Availability: Developmental.

C. Utilization: Will be used to determine response to FFTF piping network to HCDA loadings.

Problems Solved

Calculates the fluid pressure history and the pipe wall plastic stra:n in a piping network which is experiencing a pressure transieat. The pressure pulse in the system may be attentuated by plastic yielding of the pipe wall.

\section{Models}

The piping network is modeled as a series of tubes interconnecte 1 by various kinds of junctions. The network is established by the user defining the pipe diameters, wall thicknesses, lengths and junction connections. The 1-D conservation equations of mass, energy and momentum for fluid flow (for either sodium or water) are solved by the method of characteristics. The capabilities of the code include the following models:

\section{External Boundary Conditions}

Two forcing functions are supplied by the user, one to be used at the inlet of pipe one and the other to be used at the exit of any number of the other pipes as specified by the user. Other external boundary conditions include dead ends (zero velocity), free surface, or a semi-infinite pipe. 


\section{Internal Boundary Conditions}

Internal boundary conditions such as tees, pumps and valves are modeled using zero volume junctions. The user may specify such aspects as pump characteristics for these junctions.

\section{Plastic Pipe Wall Strain}

Based on the calculated pressure the plastic pipe wall strain is determined using true stress strain information supplied by the user. A new wave speed is calculated which reflects the possible attenuation effects of the plastic deformation. Based on this wave speed the pressures are then recalculated and an iteration procedure established to match the pressure, wave speed, and plastic strain.

4. Cavitation

Based on the calculated enthalpy and pressure (calculated from the conservation equations) the state of the fluid is determined. Any time the quality drops below 1.0 cavitation has occurred and the fluid becomes highly compresstble. The possible attenuation of the pressure pulse due to this cavitation is calculated.

5. $\quad$ Fiction

The head loss due to friction is included if the user specifies the friction factors to be used.

\section{Heat Transfer}

The user may also specify heat flux from each pipe into the fluid.

\section{Elevation Changes}

Elevation changes are accounted for in the code. The user specifies the slope of all the pipes.

\section{Limitations}

1. Limited to 17 pipes with 41 nodes each.

2. Limited to seven types of plastic pipes. Each type of plastic pipe has either a different dimension or is made of a different material.

3. Neglects radial inertial effects of pipe wall and radial fluid motion. 


\section{Future Efforts}

The code is currently being developed. Current plans are to make the code operational, debug it and verify it to make sure that the above models work.

\section{Computer Operation}

Development is being done on the CDC-6600 machine. The code requires 110,000 binary words of core and $100 \mathrm{cp}$ seconds to run a problem of 19 pipes and about 250 nodes for 4.0 milliseconds of real time. Current plotting is performed with standard Calcomp plot calls.

SUPWAN will be verified by comparing its results against results obtained in experiments performed by Stanford Research Institute (see reference below). Additional verification runs will be identified and performed as the code is debugged.

Interface/Overlap

TRAPP /NATRANSIENT, HAMOC, NAHAMMER

\section{$\underline{\text { References }}$}

1. A. L. Florence and G. R. Abrahamson, Simulation of a Hypothetical Core Disruptive Accident in a Fast Test Flux Facility, HEDL-SRI-1, (May 1973). 
TEMP

\section{Purpose}

The purpose of TEMP is to calculate FFTF fuel pin temperatures during both steady-state and transient reactor behavior.

\section{Status}

A. Development: TEMP was developed at HEDL.

B. Availability: TEMP is operational at HEDL. It has been documented (Ref. 1).

C. Utilization: TEMP is used for:

1. Fuel pin static capsule TREAT transier.t tests.

2. Fue1 pin loop TREAT transient tests.

3. Fue1/cladding gap conductance modeling.

4. Subroutine in code PECTPIN.

\section{Problems Solved}

The computer code TEMP calculates fuel pin temperatures during a transient However, it was developed to accommodate the calculation of temperatures in any system of axisymmetric concentric cylinders. When used to calculate fuel pin temperatures, the code will handle a fuel pin as simple as a solid cylinder or as complex as a central void surrounded by fuel which is broken into three regions by two circumferential cracks. Any fuel situation between these two extremes can be analyzed along with additiona] cladding, heat sink, coolant or capsule regions surrounding the fuel.

$\underline{\text { Models }}$

The continuum physics based modeling of the thermal/mechanical behavior of mixed oxide fuel pins has been previously reported (Ref. 2). The theory shows that the transient heat conduction equation is derived from the internal energy equation, which shows that the temperature rate is a function of temperature gradient, specific heat absorption, and strain rate. The assumptions of axial symmetry and generalized plan strain are used to simplify the motion to a function of material radius and time. The resultant one-dimensional heat conduction equation is the basis of TEMP. 
Significant subdivisions of the TEMP code are: the heat transfer module, the deformation module, the gap conductance module and the material properties module.

User-oriented features of TEIP include the user's option to select a solution method in the range between and including pure explicit and implicit solutions. The user may select any number of iteration to be performed at each time step. Any number of printouts can be requested. It is not necessary to supply a pseudo-gap with high gap conductance between two joining regions. The spatial radii used in TEMP are dependent on the material thermal expansion. The gap conductance and material property subroutines can be altered by the user to match the material in the analysis.

\section{Limitations}

The material properties for FFTF fuel and cladding are programmed into TEMP. Therefore, a different type of fuel pin requires reprogramming. Only radial heat flow is considered in TEMP.

\section{Future Efforts}

TEMP needs to be coupled with a code like TOPLE so that axial coolant temperature can be considered. Gap conductance modeling must be reviewed and tested.

\section{Computer Operation}

1. Computer: Control Data Corporation (CDC) CYBER 74-18

2. Logistics:

a. Machine requirement: 50,000 octal (20480 decimal) of 60 bit CYBER words

b. Peripheral Storage: None

c. Programming language: FORTRAN-IV

d. Operating system: SCOPE

3. Running time: Typical running times are approximately five (5) seconds for a static capsule TREAT test analysis that has 60 radia1 nodes. 
4. Code Validation: TEMP was first used in a simple one-region form to calculate the solution to two problems which can be solved in a closed-for manner. The first problem was a hollow cylinder with an insulated inner surface and with the temperature of the outer surface increasing linearly in time. The second problem was a solid cylinder with a constant outside surface temperature which is subjected to a constant heat generation rate. These problems were solved with TEMP and the agreement was excellent.

The code was also compared with experimental results obtained from a steel pipe initially at $1100^{\circ} \mathrm{F}(867 \mathrm{~K})$ with the outer surface insulated and flowing sodium cooled from $1100^{\circ} \mathrm{F}$ to approximately $800^{\circ} \mathrm{F}(700 \mathrm{~K})$ in 32 seconds. (Ref. 3).

TEMP results were also checked against the ARGUS code (Ref. 4).

Interface/Overlap

PECTPIN, PECTCLAD

\section{$\underline{\text { References }}$}

1. F. E. Bard, B. Y. Christensen and B. C. Gneiting, TEMP - A Computer Code to Calculate Fuel Pin Temperatures During a Transient, HEDL-TME 75-85, Hanford Engineering Development Laboratory, Richland, Washington, (Draft).

2. F. E. Bard, Some Aspects of Continuum Physics Used In Fuel Pin Modeling, HEDL-TME 74-30, Hanford Engineering Development Laboratory, Richland, Washington, June 1975.

3. J. M. Corum, H. C. Young and A. G. Grinde11, "Thermal Ratchetting in Pipes Subjected to Intermittent Thermal Downshocks at Elevated Temperatures," Pressure Vessels and Piping; Verification and Qualification of Inelastic Analysis Computer Programs (J. M. Corum and W. B. Wright, ed.), ASME, pp 47-58, June 23-27, 1975.

4. D. F. Schoeberle, J. Heest and and L. B. Miller, A Method of Calculating Transient Temperatures in a Multiregion, Axisymmetric, Cylindrical Configuration. The ARGUS Program 1089/RE248, written in FORTRAN II, ANL-6654, Argonne National Laboratory, Argonne, Illinois, November 1963. 
TERMOD

\section{Purpose}

Analysis of environmental transport of radionuclides, through terrestrial food chains of primary radiological importance to man.

\section{Status}

A. Development: Developed by the Environmental Sciences Division at ORNL. Current version is TERMOD.

B. Avallability: TERMOD was documented in 1971 (Refs. 1, 2). The code is operational at ORNL and runs on a PDP-10 computer system.

C. Utilization: TERMOD has been used for numerous environmental impact statements prepared at ORNL to assess the transfer of radioactive materials through terrestrial food chains as the result of routine releases. It has not yet been applied in the formal assessment of accidental releases.

\section{Problems Solved}

Given a rate of radionuclide deposition, the amount or concentration of the radionuclide in above soil food crops, soil, pasture grass, subsurface soil, beef, and milk and daily input to man are calculated as a function of time as the difference between inputs to and losses from specified compartments. Because of this approach, the code has potential capability for use in accidental release assessment.

\section{Models}

TERMOD is a coupled compartment code used to predict radionuclide intake by man from consumption of vegetation, meat, and milk contaminated by radionuclides in soil and from air. The code incorporates 75 radionuclides and requires estimates of time invariant transfer coefficients, some of which are radionuclide dependent. TERMOD is a linear compartment donor controlled model written in BASIC language in a conversational mode. 


\section{Limitations}

1. Some of the values in the data base are representative of equilibrium concentration conditions, whereas in reality they are time-dependent.

2. Feedback from subsurface soil pool to above surface food crop is not considered; the only feedback is from pasture soil to pasture grass.

3. Uptake of radioactivity from air by inhalation or consumption of water is not considered in the model.

\section{Future Efforts}

A revision of TERMOD is planned for the near future.

\section{Interface/Overlap}

INREM, EXREM/AIRDOS.

\section{References}

1. R. S. Booth and S. V. Kaye, "A Preliminary Systems Analysis Model of Radioactivity Transfer to Man from Deposition in a Terrestrial Environment," ORNL-TM-3135, Oak Ridge Nationa1 Laboratory, 1971.

2. R. S. Booth, S. V. Kaye, and P. S. Rohwer, "A Systems Analysis Methodology for Predicting Dose to Man from a Radioactivity Contaminated Terrestrial Environment," Proc. Third Symp. on Radioecology, AEC-CONF-710501, 1971 . 
THT

\section{Purpose}

A general 3-D heat transfer program for computation of steady-state and transient temperature distributions for problems including conduction, convection, and thermal radiation.

\section{$\underline{\text { Status }}$}

A. Development: The THT-series was developed at GE. The fifth, most advanced and current developmental version is THT-E.

B. Availability: THT-D was released in 1968 for use on the GE-625 (Ref. 1) and was subsequently made operational on the UNIVAC-1108 and CDC-6400. THT-E is developmental at GE on the GE-635 (Ref. 2).

C. Utilization: THT-D and $-E$ have been used in analysis of TREAT experiments. Both versions have been used for TREAT TOP experiment analysis, but on $1 \mathrm{y}$ THT-E has been applied to LOF experiments because it provides the necessary flow and pressure drop computations. Coupled with the BEHAVE-SST code, the THT code provides a complete thermal-mechanical analysis of TREAT experiments.

\section{Problems Solved}

The THT codes provide a completely general solution capability for large, complex, 3-D transient and steady-state heat transfer problems which can include conduction, convection, and radiation models of heat transfer, with the option to compute fluid flow rates on a 1-D basis. Material thermal properties are temperature dependent. THT-E specifically intended for use in thermal-hydraulics problems where flor and pressure drop relationships are required, calculating coolant (single phase gases and liquids) flow and pressire drop in dependent flow channels containing compressible or incompressible fluid. THT-E is faster and potentially more accurate than THT-D. The user specifies geometry and all material properties for both codes; neither code contains phenomenological models or any fuel-rod-related correlations. 


\section{Models}

1. Geometry

Completely general geometry specified by the user in three dimensions. THT $-D$ and THT-E use the lumped parameter approach for describing thermal systems, the problem geometry being divided into nodal volumes (i.e., nodes). These are preferably small volumes to minimize spatial truncation errors in the solution. A single temperature, assumed to be at the centroid of the node, characterizes the entire node. The nodes can have up to six faces each. This, a node can have a maximum of six neighbors with respect to heat transfer by conduction and convection, while no such limitation exists with respect to thermal radiation. The number of nodes which can be specified depends on the available computer memory and amount of non-geometrical data, with 6000 nodes being the invariant maximum for THT-E. Nodes may uniformly contain solid, flowing gas or liquid, or stationary gas or liquid. Nodes may be of any shape. Nodes may change phase irreversibly. In THT-E, fluid mixing is allowed at flow channel junctions. Flow channels are independent otherwise and connected to common pressure sources (as an option, flow may be specified and pressure calculated assuming no common pressure source). Flow is treated in one dimension. Cylindrical geometry is generated by a subroutine using abrreviated input. THT-D allows nodes to contain a binary gas mixture which varies with time.

2. Radiative Heat Transfer

Grey-surface radiation is modeled by definition of a radiation heat transfer coefficient. Receiving and emitting nodes are defined by the user. Emmisivities may be specified as functions of temperature.

3. Convective Heat Transfer

Convection heat transfer coefficients are determined from empirical correlations or may be tabulated. In THT-D, flow rates for use in the correlations (and in heat transfer calculations) are provided by the user as tables of flow rate vs. time. The THT-E code calculates flow rate vs. time if the user selects that option. Fluid temperature mixing at flow channel junctions is modeled by an eddy diffusivity method.

4. Phase Changes

Solid-to-liquid and liquid-to-vapor phase changes are allowed, but transition from stationary to moving fluid is not allowed. 


\section{Heat Generation}

Heat generation rates are specified in tabular form as functions of time, location, and temperature. Temperature-dependent heat generation is operational but user experience is insufficient to verify stability of the solution. Surface heat flux may also be specified in tabular form as a function of time and position.

6. Thermal Material Properties

Properties of each material are specified by the user in tabular form as functions of temperature. Latent heats may also be specified.

7. Fluid Flow (THT-E only)

One-dimensional, single-phase compressible or incompressible flow without chemical reactions in independent flow channels. One option calculates flow rate and flow distribution for parallel channels connected to common plenums with the pressure conditions specified. The other option calculates the pressure drop for individual channels with the channel flow rate specified. Fluid flow is calculated on a pseudo-transient basis (steady-state flow in response to time-varying conditions). Compressible and/or incompressible flow may be present in a single problem. Arbitrarily connected flow channels cannot be analyzed at present.

\section{Limitations}

1. Cannot analyze two-phase compressible flow with boiling phenomena.

2. Phase changes are irreversible.

3. Cannot analyze flow distribution in arbitrarily connected flow channels.

4. Coolant mixing model cannot analyze forced diversion or flow sweeping.

5. Too large and costly to perform iterative analysis of redistribution of material after melting.

6. THT-D limited to 2000 nodes; THT-E linited to 6000 nodes.

7. Pressure-drop calculation not validated by experiment. 
8. Temperature-dependent heat generation option may not be numerically stable.

9. Operational only on GE-600 series ( $-D$ and $-E$ ) and UNIVAC-1108 (-D on $1 \mathrm{y})$.

10. THT-E does not allow variable binary gas mixture nodes.

\section{Future Efforts}

No major activities planned. The following code improvements are under consideration.

1. Add reversible phase change and model boiling phenomena.

2. Model forced diversion flow and flow field near a blockage.

3. Consider fuel motion (by inexpensive approximate methods) in thermal solution.

4. Validate pressure drop calculation.

5. Convert THT-E to other computers.

6. Add variable binary gas mixture to THT-E.

\section{Computer Operation}

1. The THTD program is operational on the Honeywe11-6000, UNIVAC-1108, and CDC -6400 computers. The THTE program is developmental on the Honeywe11-6000 computer.

2. Logistics: Core memory required depends on size of problem. For a typical TREAT static capsule analysis using 200 nodes, both programs require approximately $23 \mathrm{~K}$ memory on the Honeywell-6000 system.

3. Typical Problem Running Time: A typical TREAT single-rod, staticcapsule problem involving 200 nodes and a 15-second transient required $42 \mathrm{CP}$ minutes using THTD. The THTE program required approximately $60 \%$ of this time.

4. Code Validation: Not applicable.

\section{Interface/Overlap}

Interface: Both codes supply temperatures via tape to the BEHAVE-SST fuel rod mechanics program. 
Overlap: Any general-purpose, 3-D transient heat transfer program.

\section{$\underline{\text { References }}$}

1. S. C. Skirvin, "User's Manual for the Standard THT-D Computer Program on GE-600 Series Computers," General Electric Research and Development Center, May 1969, 69-C-205.

2. S. C. Skirvin, "A Brief Guide to the Use of Version $E$ of the Transient Heat Transfer Computer Programs (NMP-857)," General Electric Missile and Space Division, June 1968 (GEMP-614). 
THYME

\section{Purpose}

Simulation of the Sodium Loop Safety Facility (SLSF) thermal-hydraulic behavior during experimental transients and hypothetical accidents.

\section{$\underline{\text { Status }}$}

A. Development: All versions were developed by the SLSF project at ANL.

B. Availability: THYME: Not operational. This version is no longer in use, since it was developed for the original discarded SLSF design. (Ref. 1).

THYME-B: Not operational. This version is no longer in use and is superceded by THYME-C .

THYME-C: Operational at ANL, HEDL and GE.

$\underline{\text { Problems Solved }}$

\section{THYME-C}

The THYME computer programs have been written specifically to predict the steady-state and transient thermal-hydraulic response of the SLSF in the Engineering Test Reactor (ETR). Prior to the transient computations, detailed steady-state loop temperature and pressure distributions are determined from the user specified sodium flow rates, gas plenum pressure, reactor water flow rate and power, and helium system flow rate. Transients which can be simulated include: variations pump power, reactor power, helium flow rate and reactor water flow rate, and the formation of loop or test section blockages. Experiment and accident simulations including different combinations of these transients can be made. The code's capabilities also include provisions for simulating the loss-of-test section geometry after fuel pin failure and melting of various test section materials. The THYME-B version was used in the SLSF safety assessment and the PI experiment and THYME-C was used in both the P2 pre- and post-test analyses and the P3A pretest analysis. 


\section{Models}

\section{THYME-C}

The analytical model is divided into three separate parts, treating the steady-state hydraulics, the steady-state temperature distribution and the transient simulation. The first two parts are written in standard FORTRAN, while IBM's Continuous Simulation Modeling Program (CSMP) is used for the transient portion.

\section{Steady-State}

The steady-state hydraulic program is identical to FEFPSTY, with the exception of additional output transferred to the next program step. The test section and loop sodium flow rates, gas plenum pressure and loop geometry are specified and the pressure distribution and required pump power are computed. In the steady-state thermal code, the loop is divided into 149 nodes and the temperature distribution is determined from the input geometry, sodium flow rates, helium flow and reactor power and water flow rates. An option is also included allowing specification of the test section inlet temperature; in this case the helium flow is computed. In addition to the steady temperature distribution, various heat transfer coefficients, material properties, fuel pin heat generation rate, structural $\gamma$-heating rates, and an overall heat balance are output. The fuel bundle is modeled as a single average fuel pin, with 6 axial nodes in the active fuel region and 4 axial nodes in the gas plenum region. The same nodal structure is carried radially outward, including the hex-can, test section insulation, outer test section duct, bypass sodium, flow divider, downcommer sodium and the primary vessel. For the primary vessel, additional detail is provided at the midplane, providing accurate predictions for the surface temperature. The loop heat exchanger is treated as a single average tube, with 7 axial nodes and the electromagnetic pump is represented by 5 axial nodes. Adequate detail is provided for the remaining loop components, accurately accounting for sodium transport times and heat capacity effects.

\section{Transient}

Prediction of the loop transient response is determined by integrating the transient therma1-hydraulic differential equations with a fourthorder-variable-time-step Runge-Kutta integration method. The transient hydraulic model is divided into larger regions than the in steady-state program, allowing for rapid computations, and contains additional features necessary in certain experiment and accident simulations. Blockage formation in the test section, bypass or the loop riser is 
simulated by transient increases in the frictional resistance. In the case of complete test section blockage, this flow path can be dropped completely from the hydraulic equations. Two-phase sodium flow is accounted for in the bypass, using the Lockhart-Martinelli correlation for annular slip flow. The steady-state and transient thermal nodal structures are identical, with minor exceptions. A large degree of flexibility is also included int he transient thermal model. Phase changes due to fuel, cladding, hex-can and test section insulation melting are allowed. Cladding relocation and blockage formation are simulated by an appropriate reduction in the test section heat capacity. Fuel and steel boil up and the radial attack on the hex-can and the insulating material is simulated by specification of the radial heat transfer rates as a function of time. Specification of various events in the transient sequence is provided by more detailed codes, such as SAS.

\section{Limitations}

The primary limitation of the program is the minimal detail provided in the test section, which is reasonable for a code oriented toward predicting the overall SLSF response. In cases when the test section geometry is lost through fuel fallure and melting; a thorough understanding of the transient sequence is needed to prepare the input.

The original objective of the code was to predict the loop behavior for relatively high flow and power conditions. Uncertainty may exist when attempting to analyze isothermal and natural circulation conditions. There is also some uncertainty in the predicted heat exchanger heat transfer coefficient.

\section{Future Efforts}

As the SLSF program progresses and experimental data becomes available, the code will be continually improved.

\section{Computer Operation}

1. Computer: IBM 370.

2. Core Memory Required: $250 \mathrm{~K}$, Batch Operation.

3. Running Time:

Steady-state: less than 1 minute. Transient: 2-15 minutes for most cases.

4. Code Validation: References (3) and (5). 


\section{$\underline{\text { References }}$}

1. "Therma1-Hydraulic Dynamic Simulation Model for the FEFPL," ANL/RAS 72-21, May 1971 .

2. "Pretest Analysis - SLSF In-Reactor Experiment P1," ANL/RAS 75-46, December 1976.

3. "Interim Report on SLSF In-Pile Experiment P1," February 1976.

4. "Pretest Analysis - SLSF In-Reactor Experiment P2," ANL/RAS 76-31, October 1976.

5. "Interim Report on SLSF In-Pile Experiment P2: Part 1 Experimenta1 Results and Analysis," ANL/RAS 77-8, March 1977. 
TOPLE

\section{$\underline{\text { Purpose }}$}

The purpose of TOPLE is to predict thermal-hydraulic behavior of a test loop with multiple FFTF fuel pins during both steady-state and transient conditions.

\section{$\underline{\text { Status }}$}

A. Development: TOPLE was developed at HEDL.

B. Availability: TOPLE is operational at HEDL. It has been documented (Ref. 1).

C. Utilization: TOPLE is used to predict the behavior of the MARK II-C sodium cooled fuel pin test loop (Ref. 2) used in conducting transient irradiation tests on FFTF fuel pins in the TREAT reactor.

\section{$\underline{\text { Problems Solved }}$}

TOPLE was written to predict the thermal-hydraulic response of FFTF fuel pins in the MARK II-C sodium-cooled test loop. However, it is general enough to perform thermal-hydraulic analyses on any test loop with multiple fuel pins where there is no coolant mixing between coolant subchannels. The code calculates fluid and duct wall temperatures throughout the loop and fuel pin temperatures in the fuel and cladding at specified axial locations as a function of time.

\section{Mode1s}

Solution of the classical one-dimensional heat conduction equation is the basis for steady-state and transient temperature calculations for solid components (fuel, cladding and loop walls). The fluid temperatures are determined by solving the governing equations determined from an energy balance on a finite element of fluid with incompressible flow. It is also assumed that any kinetic energy to thermal energy changes are negligible. The numerical solutions use either explicit, implicit, or semi-implicit methods. The fuel-to-cladding gap conductance can be either a variable or a constant. The code can be separated into three main computational sections. The first section performs sodium temperature calculations, the second section performs fuel pin temperature calculations using a gap conductance model specified in the third section. 


\section{Limitations}

There is no coolant mixing between coolant subchannels.

\section{Future Efforts}

None currently planned.

Computer Operation

1. Computer: Control Data Corporation (CDC) CYBER 74-18.

2. Logistics:
a. Machine requirements
102,000 octal (33792 decimal) of 60 bit CYBER words
b. Peripheral Storage
None
c. Programming Language
FORTRAN-IV
d. Operating System
SCOPE

3. Running Time: Typical running times are approximately 120 seconds.

4. Code Validation: TOPLE has not been validated.

Interface/Overlap

PECTPIN, TEMP

\section{$\underline{\text { References }}$}

1. M. B. Parker, TOPLE A Transient Thermal-Hydraulic Computer Program For Sodium Cooled Test Loops, HEDL-TME 77-28, Hanford Engineering Development Laboratory, Richland, Washington, May 1977.

2. B. C. Gneiting and F. E. Bard, Pretest Analysis of the HUT L2 Transient Test, HEDL-TME 76-71, Hanford Engineering Development Laboratory, Richland, Washington, November 1976. 


\section{TRANS IT}

\section{Purpose}

Analysis of thermal and hydrodynamic behavior of an FBR core during the transition phase of a whole core accident and the identification of possible recriticality events that might occur until a permanent subcritical configuration is reached.

\section{$\underline{\text { Status }}$}

A. Development: Developed and under development at ANL/RAS.

B. Availability: The versions of TRANSIT which exist or are being developed are:

TRANSIT-I: $\quad$ Operational at ANL on IBM/370 in September, 1976 (Ref. 1).

TRANSIT-II: Developmental at ANL on IBM/370. Will be made operational in September, 1977. An informal (ANL/RAS report) documenting its models will be available in August, 1977.

TRANSIT-HYDRO: Developmental at ANL on IBM/370. Will be operational in December, 1977 and released by June, 1978 .

C. Utilization: TRANSIT-HYDRO could be used in the analyses of events during the transition phase of a TUC-CDA for existing or planned LMFBR's. It can serve as an analytical tool for planned in-pile transition phase related experiments. TRANSIT-II can be a useful tool for parametric and probabilistic studies.

\section{Problems Solved}

TRANSIT is an independent code system which provides a mechanistic description of the temporal evolution of the post-initiating phase of a TUC accident. When coupled with SAS, one would achieve a complete description of the accident from its early stages until permanent escape paths of molten material out of the core are available. 
Models

TRANSIT has a modular structure. This enables one to accommodate improvements in specific models without affecting overall code structure. The main modules in TRANSIT are: fluid-structure heat transfer, coolant dynamics, dynamics of the molten region, blockage formation and melting, structure melting and treatment of intact subassemblies.

TRANSIT-1:

\section{Geometry}

TRANSIT has a hex $-\mathrm{z}$ geometry. Radially, every subassembly in the core is modeled. The analysis could include radial blanket subassemblies. Axially, TRANSIT has five major regions: shield orifice, lower blanket, core, upper blanket and fission gas plenum. TRANSIT-1 assumes that there is no axial dependence in events within any one of these regions.

\section{Fluid-Structure Heat Transfer}

Heat transfer from molten core material to existing structure is based on experimental correlations obtained from experiments with simulant materials.

\section{Coolant Dynamics}

Coolant exists between can walls, in non-voided subassemblies with intact internal structure and in control and safety rod subassemblies. TRANSIT-1 follows the temperature of the coolant in these locations in the core region only. When the coolant reaches the saturation temperature, it is assumed that voiding occurs instantly throughout the channel.

\section{Dynamics of the Molten Region}

The molten region is assumed to be made up of a one component fluid. Vapor pressure is due to steel vapor pressure. Since there is no axial dependence in the core, material motion can only occur radially from one subassembly to its neighbor, whenever the can wall boundaries have melted away. Material motion and energy are assumed to obey a relaxation model towards the mean. 


\section{Blockage for Motion Mode1}

The blockage formation model implemented in TRANSIT-1 is based on the assumption that heat transfer to the upper cladding structure is limited by it melting temperature. No melting is allowed.

\section{Structure Melting}

Structure in TRANSIT could be either the can walls or blockages. Can wall melting is followed at every wall. The temperature in two adjacent can walls with coolant flowing between them is solved. The temperature profile in the can walls is assumed to be linear. Blockages have one temperature (in lieu of the code's geometry). Melt rates are proportional to the applied heat flux.

7. Treatment of Intact Subassemblies

No coolant is allowed in subassemblies with intact pin structure. Fuel pins heat up adiabatically, while thermally uncoupled to the rest of the core until they reach a certain energy at which disruption is defined to occur.

\section{TRANSIT-II:}

This is a more advanced version of TRANSIT which utilizes more advanced models and a better treatment of the axial dependency of the accident.

1. TRANSIT-II, in addition to the existing geometry in TRANSIT - I allows for a fixed Eulerian grid in the core in each of the blankets. Blockages, if they form, are superimposed on this grid. If blockages melting proceeds, rezoning of the existing nodal structure allows for the expansion of the pool boundaries beyond the original core axial boundaries.

\section{Fluid-Structure Heat Transfer}

Additional heat transfer coefficients based on experimental work has been implemented. A user makes the choice between them.

\section{Coolant Dynamics}

The same model that was utilized in TRANSIT-I has been extended to a multiaxial node geometry. 


\section{Dynamics of the Molten Region}

No changes have been introduced over TRANSIT-I. The relaxation model was extended to account for axial mass and energy transfer.

5. Blockage Formation Mode1

A new model has been implemented based on the results reached by Ref. 2 that ablation may be the dominant mechanism behind freezing.

6. Treatment of Intact Subassemblies

Coolant is now allowed to flow in these subassemblies if conditions for its flow are there. Radiation heat transfer between the intact pins and subassembly walls is turned on after voiding occurs. Otherwise the pins are allowed to heat up adiabatically till they reach an energy at which disruption is defined to occur.

\section{TRANSIT-HYDRO}

This advanced version of TRANSIT currently being developed will utilize a new multi-phase, mulit-field model for the molten region.

The model visualizes the core hexagonal structure as a natural grid in which radial cell boundaries, initially and prior to any melting, are made up of steel walls. These walls correspond to adjacert can walls of neighboring subassemblies. Such a boundary will be referred to as a physical boundary. Horizontal planes drawn across the core define axial boundaries for any node in the core. Physical boundaries do not exist axially unless at the upper and lower most nodes and unless blockages have formed. As the accident progresses, adjacent subassembly walls at some axial location might melt away thus changing the boundary of these adjacent cells from a physical to a mathematical boundary. Material can flow across mathematical cell boundaries. As cell wall melting proceeds in the core, the cell structure is maintained as the mathematical cell structure within which framework our numerical solution is based. If a whole core pool is reached for example, we will still have the hex-cell structure that was in the core when it was intact, however now our hexboundaries are just mathematical cell boundaries. Physical boundaries which experience melting may also experience crust growth and decay. The crust material will be assumed to be entirely fuel. As hexcan walls melt, molten material will be added to the steel inventory at that axial position even if there are crusts on the walls. Our belief is that, in reality, crusts will not be complete, thus allowing the steel that melted from the walls underneath the crusts to enter the pool.

Thus, within a hex-Z cell with mathematical and physical boundaries, steel melted from physical boundaries and fuel deposited on the walls 
will be computed. At every mathematical boundary, an average flow velocity, net mass and energy transported across that boundary will be calculated.

Inside a hex $-Z$ cell molten steel and fuel will be tracked, each having its own velocity and temperature. Fuel and steel vapors will be followed also. However, we will assume that they move axially at the same velocity and that each is at thermal equilibrium with the liquid of its species. A new equation of state has been developed that utilizes a parametric heat transfer mechanism between the fuel and steel. Pressure is the sum of fuel and steel vapor pressures.

Otherwise, the remaining models in TRANSIT-HYDRO will be the same as in TRANS IT-II.

\section{Limitations}

One of the limitations is the transition from SAS to TRANSIT. In particular, where TRANSIT recognizes can wall temperatures, coolant temperature between can walls, control and safety rod subassemblies, SAS lumps the can wall temperatures with the spacer wire, ignores the coolant between subassembly cans and in control and safety rod subassemblies. In TRANSIT-II relaxation coefficients for the molten region need to be supplied. A user is limited to the heat transfer options that are available in the code. In TRANSIT-HYDRO, user input parameters related to liquid-liquid friction, liquid-vapor friction and fuel to steel heat transfer need to be supplied.

Fission gas is not yet included. The major limitation in TRANSIT is the transition of a subassembly from an intact mode to a disrupted pool mode.

Future Efforts (FY'78 and beyond)

1. Develop and implement criteria for flow regime identification in the molten region.

2. Incorporation of fission-gas in the molten region.

3. Implementation of neutronic feedback in TRANSIT-HYDRO.

\section{Computer Operation}

1. TRANSIT has been running on ANL IBM/370. 
2. TRANSIT-II core requirement varies with the number of subassemblies in the core and the number of nodes in the core and blankets. For a seven subassembly problem with five nodes in the core and two in each of the blankets, $700 \mathrm{~K}$-bytes is required. The code is written in the FORTRAN IV language. The compiler requirement is $400 \mathrm{~K}$-bytes. A plotting routine that produces a cross sectional map of the core at different times identifying existing core structure is also available.

3. Typical Problem Running Time: Complete information is currently being assembled and not fully available yet. However, TRANSIT-I calculation for the FTR case uses, 300 seconds in cpu time.

4. Code Validation: Efforts for code validation are currently underway or being planned along the following main lines.

1. Efforts for the experimental validation of the molten-region model in TRANSIT-HYDRO is currently in the design stage at ANL/RAS. Comparison of the model results with available analytical models is planned.

2. Freezing model in TRANSIT exhibits reasonable agreement with the detailed work on freezing (Ref. 2). Comparison with experimental work is an ongoing effort.

3. Comparison of TRANSIT's coolant voiding model especially in control and safety rod subassemblies with experiments is presently being considered at ANL/RAS.

\section{Interface/Overlap}

SAS /SIMMER-I and SIMMER-II

\section{References}

1. S. J. Hakim and R. J. Henninger, "TRANSIT: A Computer Code for a Mechanistic Analysis of the Transition Phase of an FBR Accident," Trans. Am. Nucl. Soc., 24, 261 (1976).

2. S. J. Hakim and R. J. Henninger, "A Hydrodynamic Model for Treating Transient Freezing In Pin Bundles," International Meeting on Fast Reactor Safety and Related Physics, Chicago (1976), and

S. J. Hakim and R. J. Henninger, "USEFUL: A Hydrodynamic Code for Treating Flow and Freezing in Annular, Pipe and Plate Geometries," limited distribution report ANL/RAS to be released in July 1977. 
TRANSWRAP

\section{Purpose}

Analysis of $1-D$ flow transients in a sodium piping network subjected to a sodium-water reaction from a large-leak accident in a steam generator.

\section{$\underline{\text { Status }}$}

A. Development: Developed and under improvement at AI. TRANSWRAP II is latest version.

B. Avallability: TRANSWRAP I is operational at AI and has been documented (References 1-3). TRANSWRAP II is operational at AI and has been documented (References 4-6).

C. Utilization: Has been used for LLTR design and analysis, and for CRBR PSAR safety analysis.

\section{Problems Solved}

Calculates time-dependent fluid velocities and pressures within the piping and various components comprising a secondary sodium loop following a large leak sodium-water interaction in a steam generator module. Calculated results include maximum pressures and velocities at all system locations, temporal locations of rupture disk failures, and a time history of the pressure, temperature, and volume of the expanding hydrogen gas bubble.

\section{Models}

\section{TRANSWRAP I:}

\section{Sodium-water reaction dynamics}

A 1-D reaction zone model located at the junction of two or three pipes. Instantaneous reaction is assumed and wave motion in the reaction zone is neglected. The initial conditions require the specification of a bubble volume and reaction temperature. For single phase 1lquid water, the water in-flow and system transients are obtained by the method of characteristics and are coupled to the reaction zone response. Steam or two-phase flow is limited to a specified ramp-rate in-flow, with fictitlous values of 
velocities, sonic speed, pipe length and friction factors predetermined to match the water system to the specifled mass flow. No compressible flow phenomena, as choking and subsonic or supersonic transient flows are taken into account.

2. Fluid flow and numerical method

Used the method of characteristics to solve the $1-D$, nonlinear fluld-hammer (slightly compressible) equations in a fixed timespace grid for each pipe of the flow network.

3. Pipe dilation

The elastic response of the pipe is handled by modifying the wave speed to account for pipe expansion due to fluid pressure.

\section{Piping system}

Forms pipe networks from numbered branches and junctions. Pipe junctions accommodate the joining of two or three pipes. Components and pipe end junctions include constant velocity boundaries, accumulators, rupture disks, and pressure boundaries. Pressure drops at two and three pipe junctions can be calculated by specifying constant loss coefficients. Pumps can be approximated by an equaivalent pipe representation. The relief system piping downstream of a rupture disk can be included in the calculation.

\section{TRANSWRAP II:}

This version represents an improvement over TRANSWRAP I in the areas of bubble kinetic behavior and monitoring of the venting process in the relief system. Treatment of the sodium piping system is essentially the same as TRANSWRAP I, although an elastic-plastic wall treatment within the failed module has been added.

\section{Sodium-water reaction dynamics}

The water rejection treatment includes both single and two-phase water injection rate calculations. The sodium-water reaction allows for two-phase water, noninstantaneous reaction time, partial water reaction, treatment of unreacted water, and various reaction equations with different proportions of solid reaction products resulting. The expansion of the bubble is tracked throughout the secondary system, leading to greater accuracy in the calculation of the change in bubble volume. A spherical 
bubble model calculates bubble behavior during the early part of the transient.

\section{Relief system}

Computation of filling and venting of the relief system includes noninstantaneous rupture disk failure and blowdown of bubble mixture out of the relief system.

\section{Limitations}

TRANSWRAP I has the following 1imitations, which are eliminated by TRANSWRAP II:

1. Sodium voiding of components and piping due to hydrogen gas displacement is not accounted for.

2. Transient (constantly changing properties) two-phase water flow cannot be treated within the framework of the constant property pipe assumption.

3. The calculation of the initial expansion phase $(<1 \mathrm{msec})$ of the bubble growth is bypassed to accommodate the one-dimensional plane wave calculational model.

4. The calculation of the gas bubble behavior assumes instantaneous reaction, assumes only one chemical reaction $\left(\mathrm{Na}_{2} \mathrm{O}\right)$, and neglects any heat loss mechanisms.

5. Rupture relief disks are assumed to react instantaneously.

6. Plastic wall deformation is not accounted for.

TRANSWRAP I and II both have the following limitations:

7. The 1-D nature of the code does not allow multidimensional treatments, such as for components.

8. Piping system limitations are as follows:

a. Number of pipes and junctions: 169

b. Maximum nodes per pipe: 40

c. Pipe junction: Up to three pipes 


\section{Future Efforts}

Experimental verification in the U.S. Large Leak Test Program.

\section{Computer Operation}

TRANSWRAP is operational at AI and GE on the IBM S/370. The code is programmed in FORTRAN IV with no special compiler requirements. Core memory requirements, including minimum CRT capability for plotting pressure and velocity profiles at 20 locations are:

$$
\begin{array}{ll}
\text { TRANSWRAP I } & \sim 300 \mathrm{~K} \\
\text { TRANSWRAP II } & \sim 460 \mathrm{~K}
\end{array}
$$

The corresponding problem running times on the IBM system for a typical case consisting of approximately 100 pipes, 100 joints, and 1,400 calculational nodes for a real time simulation of approximately 200 milliseconds are:

$\begin{array}{ll}\text { TRANSWRAP I } & \sim 1 \text { minute } \\ \text { TRANSWRAP II } & \sim 3 \text { minutes } \\ \text { (with single phase } & \\ \text { water injection) } & \\ \text { TRANSWRAP II } & \sim 12 \text { minutes } \\ \text { (with transient two- } & \\ \text { phase water injection) } & \end{array}$

Interface/Overlap

/NAHAMMER, NATRANSIENT, SWAAM

References

TRANSWRAP I

1. C. Bell and M. Heisler, "TRANSWRAP - A Compressible Hydrodynamic Code for Large Leak Sodium/Water Reaction Analysis," AI Report TI-001-130-025, February 5, 1973. 
2. C. Bell and M. Heisler, "Capabilities and Limitations of TRANSWRAP," AI Report TI-001-130-027, March 21, 1973.

3. C. Bell, "TRANSWRAP - A Code for Analyzing the System Effects of Large-Leak, Sodium/Water Reactions in LMFBR Steam Generators," Beverly Hills Safety Meeting, CONF-740401-P2, Apri1 1974.

\section{TRANSWRAP II}

4. C. Bell, "TRANSWRAP II, Final Summary Report," AI Report TI-033-120-003, April 25, 1974 .

5. TRANSWRAP II User's Manual, AI Report TI-033-120-002, March 7, 1974.

6. C. Bell, et al, "LMFBR Steam Generator Large Leak Analysis Methods Including Description of Tests Being Prepared for the Large Leak Test Rig," Proceedings of the U.S./U.S.S.R. Seminar on Steam Generators, Los Angeles, California, December 1974. 


\section{Purpose}

Analysis of 1-D pressure pulse propagation in fluid-filled pipes.

\section{$\underline{\text { Status }}$}

A. Development: Developed at W-ARD from the BLOWDOWN-2 code.

B. Availability: Operational at W-ARD on CDC-7600; a description of BLOWDOWN-2 has been documented (Ref. 1).

C. Utilization: Used by HEDL to perform analysis of primary loop piping response to HCDA pressure pulses in support of the FFTF FSAR.

\section{Problems Solved}

TRAPP is a modified sodium version of the two-phase water code BLOWDOWN-2. TRAPP performs an analysis of the transient pressure field in the primary piping loops when HCDA pressure pulses are simultaneously imposed at the inlet and outlet nozzles of the reactor vessel. Elastic behavior of the pipe walls and the effect on pulse propagation is accounted for. Sodium cavitation is calculated by a two-phase voiding model.

\section{Mode1s}

\section{Geometry}

The pipe system is modeled as a 1-D network of flow channels connected at junctions.

\section{Fluid dynamics}

The $1-D$, non-linear, transient partial differential equations for conservation of mass, momentum and energy of a compressible fluid flow and the EOS for the fluid are transformed by the method of characteristics into a set of ordinary differential equations which describe the fluid motion and properties along three characteristic paths: one representing the wave travelling in the positive direction with speed equal to the local speed of sound plus the local flow speed, the second representing a wave travelling in the negative direction with speed equal to the local speed of sound 
minus the local flow speed and the third representing the path of the fluid particle with local flow speed. The equations of characteristics are solved for a fixed spatial grid and a variable time step determined by the minimum time required for the fastest moving wave to traverse the smallest mesh spacing. The local values of flow rate, pressure, enthalpy, temperature, density, quality and speed of sound are determined for the fixed spatial grid as a function of time, accounting for the effects of compressibility in two-phase flow such as flow choking. The code may be used with either one or two input pulses.

\section{Pipe dilation}

The effect of elastic deformation of the pipe wall is taken into account by modifying the local speed of sound.

\section{Limitations}

1. The 1-D nature of the code does not allow for radial fluid motion effects.

2. No pipe wall plastic deformation is considered.

\section{Future Efforts}

HEDL will coup] e TRAPP with TUBE (see TUBE summary) to form SUPWAN for a complete elastic-plastic piping analysis.

\section{Interface/Overlap}

TUBE / -

\section{References}

1. S. Fabic, "Description of the BLOWDOWN-2 Computer Code," WCAP-7593, Rev. 1, October 1970. 
TRITON

\section{$\underline{\text { Purpose }}$}

Steady state core assemblies subchannel coolant and duct temperatures calculations accounting for inter-assembly heat transfer.

\section{$\underline{\text { Status }}$}

A. Development: Under development at ARD.

B. Availability: The code is in the final stage of development and is not generally available. It is, however, operational at the development site and also (in a binary deck form) at HEDL.

C. Utilization: Used as ARD for calculation of duct temperatures in CRBR and PLBR core assemblies and at HEDL for same calculations in FFTF.

\section{$\underline{\text { Problems Solved }}$}

The TRITON code essentially calculates the following temperatures accounting for the effect of inter-assembly heat transfer:

1. Subchannel coolant temperature distribution;

2. Duct temperature;

3. Assembly exist mixed mean temperature.

The above is done for all types of core assemblies: fuel, blanket, control and radial shield.

\section{Models}

Solution of the fuel and blanket assemblies hydraulics is the same as in COTEC, which represents the building block of TRITON. For the control assemblies case, the hydraulic flow split between absorber bundle and bypass is input; the flow distribution in the bundle is calculated as for fuel and blanket assemblies,, while the flow distribution in the bypass and in the flow regions above and below the absorber bundle is estimated by considering parallel, hydraulicallyindependent channels. The latter is also adopted for the radial shield 
assemblies where, with the rod touching, all flow channels are physically separated. In the solution of the coolant temperature field, TRITON considers a cluster of seven assemblies; the outermost boundaries of the six peripheral assemblies are assumed adiabatic, while inter-assembly heat transfer is considered at the interfaces between the central and the six peripheral assemblies and among the six peripheral assemblies themselves. The energy conservation equation is solved simultaneously for the seven assemblies belonging to the cluster and the temperature fleld determined with an axial marching technique.

Cnce the side channel temperatures are calculated, the duct temperatures follow straightforwardly from solution of the Fourier heat transfer equation.

Gamma-heating in the control assembly ducts is presently accounted for by smearing it over the bundle and the bypass. Sodium in the interstitial gap between assemblies is considered as stagnant.

Assembly exit mixed mean temperature is calculated similarly to the subchannels coolant temperature, except that a much coarser mesh is selected. The common plenum in the assembly above the rod bundle is divided into six $60^{\circ}$ sectors. The temperature in each sector is calculated accounting for inter-assembly heat transfer and the mixed mean corresponds to the average of the six sectors' individual temperature.

Automated input/output interface are implemented between TRITON and the core restraint mechanical design codes since a large amount of data calculated by TRITON are needed as input to these codes. Typically, needed data are duct temperatures for all core assemblies faces at a large number of axial ( $f e w$ inches interval) and radial (inner surface, midwall, outer surface) positions and for different times in life. To generate required data for all assemblies, seven assemblies cluster calculations are performed in succession, changing each time the central assembly (for which calculated temperatures are dumped to output).

\section{Limitations}

1. Solution of hydraulic rield relies on input of experimentally calibrated constants (same as COTEC);

2. Does not consider flowing sodium in assemblies interstitial gap;

3. Accounting for ducts gamma-heating is simplified;

4. Does not account for effects of uncertainties; 
5. Maximum number of rods per assembly: 271 .

\section{Future Efforts}

Since development of TRITON is still continuing, effort is currently in progress on most of the areas outlined below:

1. Develop model of interstitial gap capable of accounting for flowing sodium conditions;

2. Improve method of handling ducts gamma-heating;

3. Develop version of code capable of evaluating effects of uncertainties on duct temperatures and cross-duct gradients;

4. Develop capability to analyze bowed ducts configuration;

5. Extend TRITON from the present seven-assemblies cluster version to a version capable of analyzing an entire core or at least a symmetry sector of the core.

\section{Computer Operation}

1. ARD and Berkeley CDC-7600; HEDL CDC-6600.

2. Logistics:

a. Core memory requirements: program is dynamically stored; core storage is extended during execution of program from base storage of $70 \mathrm{~K}$ octal locations (small core); small and large core limitations depend on individual computer. Memory requirements are a function of number of pins and channels and number of axial steps;

b. Special peripherals: one sequential file, three random access files;

c. Mode of operation: batch;

d. Programming language: FORTRAN-IV except matrix routines written in COMPASS:

e. Special system routines: $\operatorname{CDC}$ routines for manipulating random access files; 
f. Special plotting: a special plotting program which displays hexagonal mapping of core assemblies duct temperatures is part of TRITON.

3. Typical Problem Running Time: for a cluster of seven 217 pin ( 438 channels) fuel assemblies, assembly length 112.32 inches with axial increment of 0.5 inches ( 225 axial steps), running time required by TRITON was 157 seconds (and $0.501 \mathrm{CRU}^{\circ} \mathrm{s}$ ) on ARD CDC-7600. Core storage required was $103{ }_{8} \mathrm{~K}$ smal1 core and $25_{8} \mathrm{~K}$ large core.

4. Code Validation: TRITON results for typical CRBR conditions have been preliminarily compared against corresponding calculations by MIT code SUPERENERGY (N. A. Todreas, MIT, personal communications with M. D. Care11i, ARD) and ANL code CORE-3D (E. U. Khan, ANL, personnel communication with M. D. Carelli, ARD). More detailed comparisons will be performed as development of TRITON and wther codes progress. Comparison against EBR-II in-pile and ARD radial blanket heat transfer test out-of-pile experimental data are planned.

Interface/overlap

COTEC, NICER, FURFAN, LIFE-III, SUPERENERGY, CORE-3D. 
UNCLE

\section{Purpose}

Analysis of in-pile thermal, microstructural, mechanical, and nuclear performance of cylindrical, mixed-carbide and mixed-nitride fast-reactor fuel elements as a function of reactor operating history.

\section{$\underline{\text { Status }}$}

A. Development: The UNCLE codes were developed at ANL/MSD. The models and properties in the codes have been reviewed periodically by an ERDA/RDD sponsored task group composed of AI, ANL, BCL, C-E, LASL, UCLA, and WARD .

B. Availability: UNCLE-l was released to advanced fuels LMFBR contractors in August 1976 (Ref.1). It is operational on the IBM 370/195 at ANL, AI, and HEDL and the CDC-7600 at BCL, C-E, LASL, and W-ARD. UNCLE-S a refined version of UNCLE-1, was released in May 1977 (Ref. 2). It is operational on the IBM $370 / 195$ at ANL, AI, and UCLA, UNCLE-T, a transient version of UNCLE-S, was released in preliminary form in July 1977 (Ref. 2). It is operational on the IBM $370 / 195$ at ANL and the CDC-7600 at HEDL.

C. Utilization: The UNCLE codes have a similar status within the LMFBR community as the LIFE codes on which they are based. They have been used to characterize the normal and off-normal behavior of advanced mixed-carbide and mixed-nitride fueled LMFBR fuel elements and to provide initial conditions for accident analyses. While the primary applications of the UNCLE codes have been to help plan and analyze fuel-element irradiation experiments, they have also been used for design sensitivity and materials sensitivity studies.

\section{Problems Solved}

UNCLE- 1 and UNCLE-S have been developed to compute the detailed thermal, microstructural, mechanical, and nuclear behavior of an advanced LMFBR fuel element over the long times during any specified history of $\mathrm{fast-}$ flux irradiation in a normal reactor power cycle. UNCLE-T has the 
capability of analyzing fuel-element performance for mild overpower and loss-of-coolant incidents, as well as for normal reactor events. Options are provided in the codes for specifying mixed-carbide or mixed-nitride fuel, helium or sodium thermal bond, and stainless steel or PE-16 cladding. The solution procedure in UNCLE-1 is based on an intermediate version of LIFE-3 while the solution procedure in UNCLE-S is based on the final version of LIFE-3. Because UNCLE-S makes UNCLE-1 obsolete, only UNCLE-S will be described in the following sections.

Mode1s

UNCLE-S

1. Geometry

See LIFE-3.

2. Heat transfer

The radial, quasi-static temperature distribution is calculated by the integral-KdT method (same as LIFE-3) with options for mixedcarbide and mixed-nitride thermal conductivity and thermal expansion. The gap conductance model includes options for helium or liquid sodium thermal bond between fuel and cladding.

3. Fuel restructuring

Advanced fuels generally operate at temperatures below $1900^{\circ} \mathrm{C}$ at which little grain growth and porosity migration have been observed. The LIFE- 3 restructuring model ahs been included in UNCLE-S but the rate constants have been reduced to force predictions of no restructuring.

\section{Plutonium migration}

Same as LIFE-1 but not invoked for advanced fuels.

5. Fission product production and gas release

The fission-gas-release model is essentially the same as that in LIFE-3. However, the gas-release rate has been made a function of interconnected porosity as well as local temperature in order to correlate with the post-irradiation data. 
6. Plenum pressure

Same as LIFE-3.

7. Stress-strain analysis

Same as LIFE-3 with fuel elastic, creep, and hot pressing constants based on mixed-carbide and mixed-nitride correlations.

8. Fuel-swelling due to fission products

The fuel-swelling model for carbide/nitride fuels is qualitatively and quantitatively different from that for oxide fuels. Based on in-reactor data, the advanced fuels appear to be more gas-retentive and they appear to exhibit "breakaway swelling" above a critical temperature $\left(\sim 1200^{\circ} \mathrm{C}\right.$ for mixed-carbide fuels and $\sim 1400^{\circ} \mathrm{C}$ for mixednitride fuels). The UNCLE-S swelling model assumes that the number of bubbles per unit volume is dependent on local temperature but independent of burnup. The higher the temperature, the smaller the number of bubbles and the larger the size of the bubbles. Below the critical swelling temperature, the model predicts uniform swelling across the fuel radius. Above the critical temperature, the model predicts a high swelling inner fuel region and a low swelling outer fuel region.

10. Fuel cracking and healing

Same as LIFE-3.

11. Cladding failure criteria

Same as LIFE-3.

UNCLE-T

UNCLE-T contains a transient heat transfer analysis in addition to all of the UNCLE-S characteristics. The user can invoke the transient analysis by specifying the appropriate option number on the reactor history cards. In this way, normal and off-normal events can be analyzed by the same code in a "continuous" manner. The transient heat transfer analysis employs an implicit Crank-Nicholson solution procedure similar to the one used in BEHAVE-3. 


\section{Limitations}

1. The finite length of fuel pellets is ignored and compatibility between axial sections is not required.

2. No cladding or fuel melting is allowed.

3. Cladding carburization or nitriding is not modeled.

4. The fuel swelling and gas release models do not explicitly include nucleation, migration and coalescence of bubbles and their interaction with structural defects.

5. The fuel cracking and healing model is based on mixed-oxide data (qualitative and quantitative).

\section{Future Efforts}

1. Overall material property correlation and mechanistic model upgrading and improvement.

2. Improved failure criteria including nonaxisymmetric loading of cladding.

3. Generalization of the fission gas release and fuel swelling model to treat at least two populations of bubbles (e.g., intragranular and intergranular) and to treat transient effects.

4. Time-independent plastic flow of cladding and primary creep of fuel.

5. Improved cracking and crack healing models.

6. Volume expansion upon fuel melting.

Interface/Overlap

SAS /FP IN

\section{References}

1. M. C. Billone, L. S. H. Chow, and A. I. Michaels, "Analys is of Carbide and Nitride Fuel-Element Performance Using UNCLE-I," Trans. Am. Nucl. Soc., 24, 135 (1976). 
2. M. C. Billone, V. Z. Jankus, J. M. Kramer, and C. I. Yang, "Progress in Modeling Carbide and Nitride Fuel Performance in Advanced LMFBRs," to be presented at the ANS International Meeting on Advanced LMFBR Fuels, October 10-13, 1977. 
VENUS

\section{Purpose}

Neutronic-hydrodyanmic analysis of core disassembly resulting from a hypothesized prompt-critical excursion and/or transition phase scenario.

\section{Status}

A. Development: Developed and under improvement at ANL/RAS.

B. Avallability: VENUS-I (Ref. 1) was released in 1971 for use on IBM 360. VENUS-II is operational at ANL and has been documented (Ref. 2). VENUS-III under development at ANL, to be released Winter, 1977.

C. Utilization: Has been the primary analytical tool used for disassembly analysis in support of the FFTF FASR and the CRBR PSAR.

\section{Problems Solved}

Computes in 2-D cylindrical, axisymmetric geometry the power, energy release and space-time history of the temperature, pressure, density and material motion of an LMFBR core during an energetic disassembly excursion resulting from a prompt-critical reactivity insertion. Reactivity feedbacks due to Doppler broadening and material motion are explicitly taken into account. A point-wise description of core material contents enables the assignment of the appropriate EOS corresponding to sodium-in and sodium-out conditions. A rigorous treatment is provided for implosion effects at any arbitrary boundary surface, such as a void region surrounded by a non-void region or at an interface of two regions of a zoned core.

A direct data transfer from SAS 3A to VENUS-II can be performed.

\section{Models}

The following features are common to both VENUS-I and II:

\section{Geometry}

2-D cylindrical, axisymmetric. 


\section{Neutronics}

A one-energy group, space-independent model is used to describe the neutron kinetics. The formulation of Kaganove (Ref. 3), with up to six delayed neutron groups, is used for solution of the point kinetics equations. The time-dependent reactivity is the sum of the input driving reactivity and feedback effects from Doppler broadening and material motion. The reactivity change due to material motion is calculated by first-order perturbation theory, with the material-reactivity-worth distribution assumed independent of time.

\section{Material Motion}

The reactor materials are assumed to behave like a homogeneous mixture, with the properties of an isotropic, nonviscous, compressible fluid. The motion of the reactor materials thus satisfies the equations of motion for a compressible, nonviscous fluid. The governing time-space dependent hydrodynamics equations of mass, momentum and energy conservation are formulated in Lagrangian coordinates. Shock discontinuities are eliminated by inclusion of an artificial pseudovisocosity expression as formulated in the numerical shock-smearing technique of von Neumann and Richtmyer. The equations are finite-differenced in an explicit time-difference scheme and solved with an automatic time-step-size selection scheme to provide numerical stability.

4. $\underline{\operatorname{EOS}}$

VENUS codes are structured such that the user can readily add as input any desired energy or energy-density dependent EOS's for reactor materials if the optional EOS's existing within the code are not suitable for the user requirements. The EOS's available as options within the codes are classified without heat sources (i.e., non-fueled regions, as in the blankets or reflectors):

a. Optional EOS's for media with heat sources

(1) Energy-dependent EOS's for mixed oxide fuel, which give an equilibrium vapor pressure as a function of temperature. These EOS's assume that the fuel density remains constant throughout the excursion.

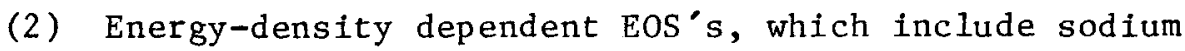
compressibility. 
b. Optional EOS's for media with no heat sources: uses a simplified functional form for pressure-density dependence.

\section{Heat Transfer}

The basic codes consider heating of reactor materials to be restricted to the fuel (i.e., heat transfer from fuel to other core materials is neglected).

\section{Structural Effects}

For low-energy excursions where the structural strength of core internals (i.e., subassembly hexcans and non-disrupted fuel pin clad) cannot be ignored, two standard options are available to account for the effect of these structures on restraining radial motion of core materials:

a. Suppression of any pressures below a threshold value, which will prevent any unrealistic material motion due to low pressures.

b. Radial motion of each Lagrangian mesh position is restrained until the pressure gradient across the position exceeds a threshold value, which is an estimate of the yield strength of the structure being simulated. Once the threshold is exceeded, the mesh position is free to move for the remainder of the calculation.

VENUS-II has the following optional model capabilities:

\section{Heat Transfer}

An FCI model is available which includes heat transfer from fuel to sodium. An expression for heat transfer to sodium includes quasi-static and transient contributions. The parameters affecting the speed of the FCI are the fuel fragmentation and heat transfer delay time and the average fuel particle radius. The inclusion of the FCI model modifies the basic VENUS-II as follows:

a. The vapor pressure of the sodium is added to the fuel vapor pressure.

b. Thermal expansion of sodium is calculated.

c. Cooling of the fuel caused by energy transfer to sodium (fuel chilling) is accounted for. 
d. The temperature dependence of the sodium compressibility is more accurately accounted for, with the actual sodium temperatures used instead of the estimated average values.

\section{Fission Gas Pressure}

A simple fission gas model can account for the effect of fission gas pressure on the disassembly. The fission gas pressure in each Lagrangian mesh cell is calculated by treating the accumulated xenon and krypton as an ideal gas. A delay time accounts for the lag in fission-gas bubble formation.

\section{Axial Expulsion of Sodium}

A simple 1-D model calculates the axial expulsion of sodium following an FCI in intact coolant channels.

\section{Treatment of Small Initial Void Spaces}

A model introduces small amounts of initial void space in an attempt to simulate various physical situations, such as sodium voiding or fuel porosity.

\section{Limitations}

\section{Material Motions}

There are several limitations associated with the hydrodynamics modeling for material motion. Reactor materials are assumed to behave like isotropic, homogeneous, nonviscous, compressible hydrodynamic fluids. This is a reasonable description of solid materials subjected to high pressure (kilobars) compression, but is not valid as the solid material recovers from the compressive loading or is under tension. Thus, the hydrodynamics model may be appropriate for a very energetic excursion (i.e., a large reactivity insertion at prompt critical) but is less accurate for mild excursions where much of the core structure may still be intact and pressures are sufficiently low such that consideration of the mechanical resistance of these structures is important. Also, the Lagrangian formulation of the hydrodynamics has the inherent numerical limitation allowing only small material displacements. Thus, VENUS is applicable primarily to very energetic disassembly accidents where the applicable primarily to very energetic disassembly accidents where the neutronics burst ends before large material displacements have occurred. 


\section{Neutronics and Reactivity Feedbacks}

VENUS uses point-kinetics neutronics (i.e., constant spatial power distribution), first-order perturbation theory for reactivity effects due to material motion, and a constant reactivity-worth distribution which distorts with the Lagrangian grid. These simplifying assumptions for the neutronics and reactivity feedbacks are valid for small material displacements. Reactor material distortion is usually sufficiently small at the termination of the neutronics burst so as not to violate the assumptions. Attempts to follow excursions much beyond termination of the burst will violate the validity of the assumptions.

\section{Structural Effects}

VENUS does not treat mechanistically the interaction of fluids with deformable structures. The restraint of the core structures (i.e., subassembly ducts and fuel pin clad) becomes important for low energy excursions where the structures may absorb an appreciable portion of the avallable excursion energy.

\section{Future Efforts}

1. Imp rove the mixed-oxide EOS and add EOS's for advanced fuels.

\section{Interface/Overlap}

$\mathrm{SAS} / \mathrm{Pad}$

VENUS-III

VENUS-III is designed to be an extension of VENUS-II which allows extended motion of materials to be examined in both the disassembly and transition phase of hypothetical core disruptive accidents. The initial attempt was a conversion of the hydrodynamics into an Eulerian frame of reference, retaining all models used in VENUS-II (Ref. 4). This code uses an implicit finite-difference technique similar to that of Ref. 5, but with modifications to implicitly include energy conservation relations. To eliminate the point kinetics restriction, this code was then coupled to FX2, (Ref. 7) a two-dimensional space-time neutronics code. Specific attention is drawn to the use of point-wise temperatures in Doppler feedback calculations, as well as material tracking of different generic fuel materials as they cross enrichment boundaries (Ref. 6). These codes, VENUS-III and FX2/VENUS-III, are available at ANL for use on the IBM $370 / 195$ and will be available as CDC-7600 versions by Fall, 1977 . 
Documentation will be available by Winter, 1977, but VENUS-III will not be exported. Major model modifications are required to analyze extended motion-extended time scale problems and FX2/VENUS-III RM (Ref. 6) is under development to remove phenomenological restrictions presently in VENUS-III. These are described below. Program completion and release for user testing are scheduled for Winter, 1977.

\section{Geometry}

2-D cylindrical, axisymmetric, Eulerian, rather than Lagrangian grid, thus not requiring grid mapping routines in space-time neutronics calculations. Also allows inter-penetration of materials and eliminates Lagrangian grid mesh distortion problems.

\section{Neutronics}

Space-time neutronics calculations are performed with FX2, a multigroup, 2-D, diffusion theory code, which uses the quasi-static method. Pointwise volume fractions and temperatures are used to generate displacement and Doppler feedback. User options to impose a hypothetical step jump and/or a reactivity ramp rate are included.

\section{Material motion}

Reactor materials are grouped into two generic types which are allowed to move relative to one another. Each type may have more than one component. Specific examples are a fuel-cladding/structurecoolant system with coolant moving relative to the remaining materials under the action of pressures taken as the sum of component partial pressures; or a liquid (fuel and steel)/vapor (fuel and steel) system with vapor moving relative to liquid with pressures determined from vapor as a composite "gas" pressure. Component mass conservation and energy conservation equations are coupled to generic type momentum conservation equations. Momentum exchange is allowed through a user supplied "drag" coefficient. Component temperatures provide energy exchange with user supplied heat transfer coefficients. Equations are solved using implicit finite-difference scheme. These non-linear spatially coupled equations are solved from mesh cell to mesh cell using Gauss-Seidel iteration and the non-linear algebraic set within the cell solved by a multivariate Newton-Raphson technique. (Ref. 8).

4. $\quad \underline{E O S}$

The non-linear Newton-Raphson technique above required analytical fits of EOS data as does the modified ICE technique used in 
VENUS-III. A general analytical form for use in accident analyses is given in Ref. 9 which models the $\mathrm{UO}_{2} \mathrm{P}-\mathrm{V}-\mathrm{T}$ surface through liquid-two-phase-gas-super critical regions while insuring continuity of thermodynamic varlables, especially across phase boundaries. The energy-density dependent EOS used in VENUS-II for $\mathrm{UO}_{2}$ has been converted and extended to this general form. Steel and sodium two-phase and single-phase gas EOS information for partial pressure calculations are also included.

\section{Heat Transfer}

Heat deposited in the fuel neutronically is allowed to transfer to cladding/structure or coolant through user-specified heat transfer coefficients. For liquid-liquid relative motion such as sodium relative motion, component vapor and liquid phases are assumed in thermodynamic equilibrium, thus allowing heat transfer between fuel, cladding/structure, and/or coolant. For vapor-1iquid systems, vapor is isothermal, but liquid components, such as fuel and steel, may have different temperatures.

\section{Structural Effects}

Internal or external structures are accounted for causing appropriate flow division. Heat transfer to them is also accounted for with user-supplied heat transfer coefficients.

\section{Limitations}

The primary limitation is the assumption that reactor materials behave like a fluid and limitations similar to VENUS-II are applicable. Under low ramp rate excursions, the response of the core structure both mechanically and thermally is inaccurate. As in VENUS-II, application is best to highly energetic excursions. Assuming subsequent full core involvement, hydrodynamic fluid arguments become more reasonable and examination of subsequent motion is much better than VENUS-II in both thermal-hydraulics and neutronics. Thermal considerations involved in plugging and freezing are not treated. A description of how core disruption proceeds from the end of an initiating phase analysis to a full core involvement under low ramp rates is not modeled.

\section{$\underline{\text { References }}$}

1. W. T. Sha and T. H. Hughes, VENUS: A Two-Dimensional Coupled Neutronics-Hydrodynamics Computer Program for Fast-Reactor Power Excursions, ANL-7701, October 1970 . 
2. J. F. Jackson and R. B. Nicholson, VENUS II: An LMFBR Disassembly Program ANL-7951, September 1972.

3. J. J. Kaganove, Numerical Solution of the One-Group, SpaceIndependent Reactor Kinetics Equations for Neutron Density Given the Excess Reactivity ANL-6132, February 1960.

4. D. P. Weber, et al., "VENUS-III: An Eulerian Disassembly Code," ANS 1975 Annual Meeting, New Orleans, Louisiana, 1975.

5. F. H. Harlow and A. A. Amsden, "A Numerical Fluid Dynamics Calculation Method for All Flow Speeds," J. Comp. Phy., $\underline{8}, 1971$.

6. D. P. Weber and B. D. Ganapol, "Multi-Field Hydrodynamic Disassembly Calculations with Space-Time Kinetics: FX2/VENUS-III," International Meeting on Fast Reactor Safety and Related Physics, Chicago, Illinois, 1976.

7. D. R. Ferguson, T. A. Daly, and R. W. Schaffer, FX2, A Quasistatic Multidimensional Multigroup Diffusion Theory Code with Feedback, FRA Technical Memorandum No. 87, Argonne National Laboratory, 1976.

8. J. M. Ortega and W. C. Rheinboldt, Iterative Solution of Nonlinear Equations in Several Variables, Academic Press, 1970.

9. D. Roberts, "A Variable Equation of State for Use in Fast Reactor Safety Problems," UKAEA, SRD-R-20, 1973. 
WATRE

\section{Purpose}

The WATRE Code computes the rate of water release from heated concrete. This information is needed for LMFBR accident analyses because water released from heated concrete can add to containment pressure and also react with sodium to form hydrogen gas.

\section{$\underline{\text { Status }}$}

A. Development: Being developed in the Safety Systems Development group at HEDL.

B. Availability: Developmental status.

C. Utilization: Useful in safety analyses to predict the rate of water released from concrete subjected to specified heating conditions. Two safety-related problems considered are: 1) sizing of lines to vent steam from concrete protected by a steel liner plate, 2) prediction of the amount of water vapor released to containment atmosphere of an LMFBR for postulated sodium spill accidents.

\section{Problems Solved}

WATRE solves the heat transport equation for concrete exposed to a heating cycle. The concrete is assumed to be protected by a steel plate and a gas gap, both of specifiable thickness. Water loss from both plane surfaces of the concrete slab is assumed to enter the gas gap, and then vent through an orifice to a gas volume maintained at a specified pressure.

\section{Models}

In WATRE, heat transport into a one-dimensional concrete slab is computed allowing for conduction, transpiration, and heat of phase change. At the faces of the slab, heat transfer due to convection, conduction in the gas gap, and radiation is accounted for.

Within the concrete, vapor pressures are computed from equilibrium data relating relative humidity to total water content and temperature. Water migration (gaseous and liquid) then occurs as a pressure-driven flow through permeable concrete. Water vapor transport due to diffusion is also accounted for. 
Both the heat and mass transport equations are solved in finite difference form using a time-explicit calculational procedure.

\section{Limitations}

As written, the Code is one-dimensional, and allows up to 20 nodes in the concrete. Temperature of a fluid outside the steel liner plate must be specifled as a function of time.

\section{Future Efforts}

Future work will be devoted principally to comparing the code predictions with experiments to determine how well WATRE models the water release phenomenon.

\section{Computer Operation}

1. The WATRE Code is operational on the CDC Cyber 6600 computer at Hanford.

2. WATRE is a Fortran language program, has minimal core memory requirements, and can be restarted. At present, only tape and printed outputs are available.

3. Running time is modest for WATRE. For example, one 52-hour real time problem required about 100 seconds of machine time.

4. Comparison of model predictions with experiments is presently underway, and will be documented in a report now in preparation.

\section{Interface/Over1ap}

This code operates without interface with other codes, but could be used in conjunction with a containment transient code used to compute the temperature of the heat transfer fluid outside the steel plate as a function of time, such as CACECO.

\section{$\underline{\text { References }}$}

A report is presently being prepared to document the WATRE Code. 
XPAND

\section{Purpose}

Large-strain analysis of the swelling of unclad fuel during a loss-offlow accident.

\section{$\underline{\text { Status }}$}

A. Development: Being developed by ANL/RAS and ANL/MSD.

B. Availability: Developmental status.

C. Utilization: Coding incomplete.

\section{Problems Solved}

XPAND is being developed to analyze the behavior of an unclad pellet stack during a loss-of-flow accident. Emphasis is placed on the analysis of fuel disruption through gross swelling. The large-strain behavior of the fuel is modeled by a one-dimensional mechanical analysis of multiple axial segments. The interaction between the mechanical behavior and the thermal and fission gas behavior is being addressed.

\section{Models}

The large-strain mechanical analysis is performed by a subroutine from the LIFE code [1]. Fission gas release and swelling are currently being determined by using the PFRAS code [2] as a subroutine. A modified version of the transient heat transfer analysis from the FPIN code [3] will be used to determine temperatures in the deformed fuel.

\section{Limitations}

1. Coding is incomplete.

2. The mesh geometry is limited to 15 radial nodes and 10 axial segments .

\section{Future Efforts}

Complete coding.

Computer Operation

Being developed for operation on the IBM 370 . 


\section{Interface/0verlap}

PFRAS [2]

\section{References}

1. Documentation: Argonne National Laboratory Report ANL-RDP-60, p. 6.47, April (1977).

2. Other References

[1] V. Z. Jankus and W. J. Shack, "Development of a Finite-Strain Fue1-Element Model," to be published in the Proceedings of the 4 th International Conference on Structural Mechanics in Reactor Technology, (1977).

[2] E. E. Gruber, "A Generalized Parametric Model for Transient Gas Release and Swelling in Oxide Fuels," Argonne National Laboratory Report ANL-77-2, January (1977).

[3] T. H. Hughes, Argonne National Laboratory Report ANL-RDP-59, P. 6.40, March (1977). 